
of Engineers $S_{\circledast}$

Engineer Research and

Development Center

Coastal Inlets Research Program

\title{
Long-Term Morphology Modeling for Barrier Island Tidal Inlets
}

Richard Styles, Mitchell E. Brown, Katherine E. Brutsché, July 2018 Honghai Li, Tanya M. Beck, and Alejandro Sánchez

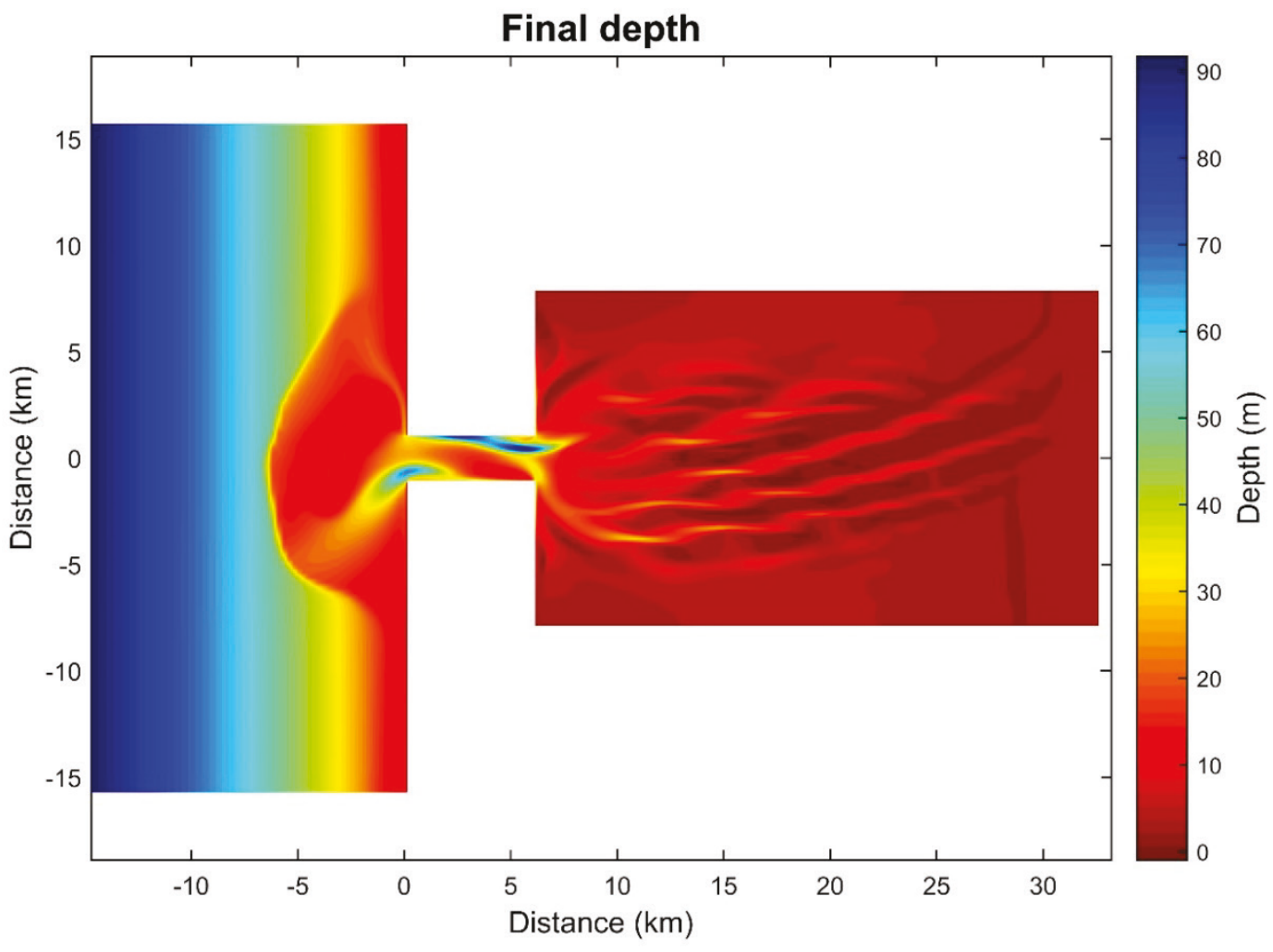


The U.S. Army Engineer Research and Development Center (ERDC) solves the nation's toughest engineering and environmental challenges. ERDC develops innovative solutions in civil and military engineering, geospatial sciences, water resources, and environmental sciences for the Army, the Department of Defense, civilian agencies, and our nation's public good. Find out more at www.erdc.usace.army.mil.

To search for other technical reports published by ERDC, visit the ERDC online library at http://acwc.sdp.sirsi.net/client/default. 


\section{Long-Term Morphology Modeling for Barrier Island Tidal Inlets}

Richard Styles, Mitchell E. Brown, Katherine E. Brutsché, Honghai Li, and Tanya M. Beck Coastal and Hydraulics Laboratory

U.S. Army Engineer Research and Development Center 3909 Halls Ferry Road

Vicksburg, MS 39180-6199

Alejandro Sánchez

Institute for Water Resources

Hydrologic Engineering Center

609 Second Street

Davis, CA 95616-4687

Final report

Approved for public release; distribution is unlimited.

Prepared for U.S. Army Corps of Engineers

Washington, DC 20314-1000

Under Work Unit CG66LB, “Coastal Modeling System” 


\section{Abstract}

The U.S. Army Corps of Engineers, Coastal Inlets Research Program, conducted at the U.S. Army Engineer Research and Development Center, Coastal and Hydraulics Laboratory, has developed the Coastal Modeling System (CMS) as a coupled wave, hydrodynamic, and sediment transport numerical modeling system. The primary focus of this study is to validate CMS for long-term applications through simulations of tidal inlet evolution and verify the results against established theoretical and empirical formulations that describe the stability and equilibrium conditions of tidal inlets. A wide range of conditions are chosen to test the breadth of model applicability including varying waves, tide and inlet geomorphic characteristics. The model is run for 100 years and the resulting morphological state is gauged in terms of inlet stability theory. Overall, CMS compares well to theoretically and empirically predicted inlet cross-sectional areas with some noted deviations due in part to the artificial nature of the idealized inlet geometry. The sharp spatial transition at either end of the inlet throat leads to artificially large gradients that may increase erosion and associated cross-sectional area. The results suggest that CMS can efficiently and accurately, to the degree of available empirical information, quantify long-term evolution of barrier island tidal inlet systems.

DISCLAIMER: The contents of this report are not to be used for advertising, publication, or promotional purposes. Citation of trade names does not constitute an official endorsement or approval of the use of such commercial products. All product names and trademarks cited are the property of their respective owners. The findings of this report are not to be construed as an official Department of the Army position unless so designated by other authorized documents. 


\section{Contents}

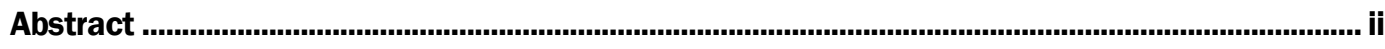

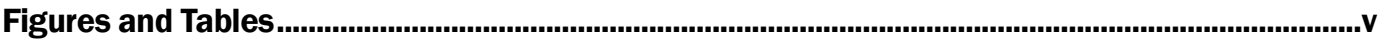

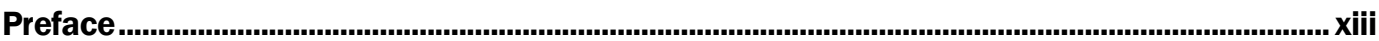

Unit Conversion Factors ..............................................................................................................xiv

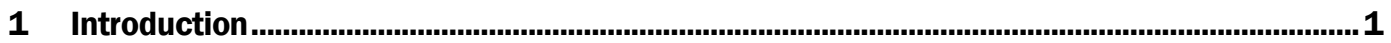

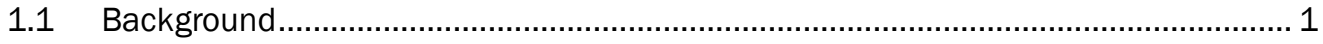

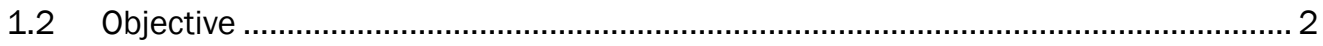

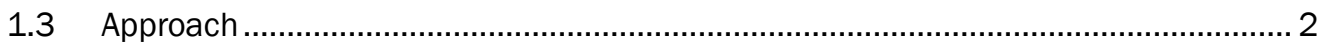

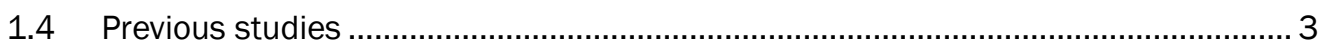

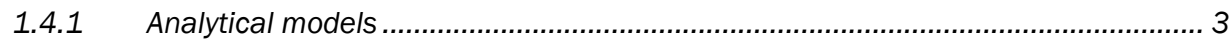

1.4.2 Escoffier analysis of inlet stability ................................................................... 5

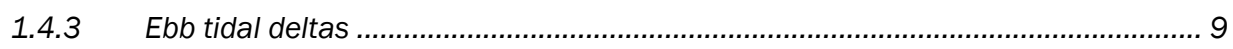

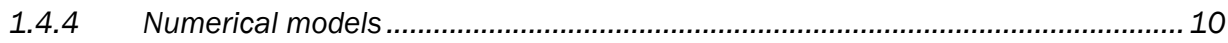

2 Methods ...........................................................................................................................................14

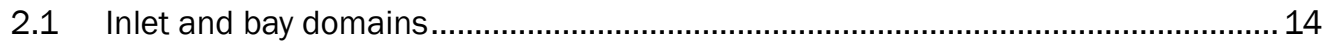

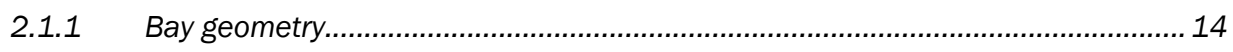

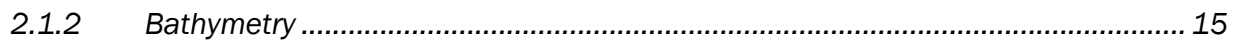

2.2 Coastal Modeling System (CMS) …................................................................ 16

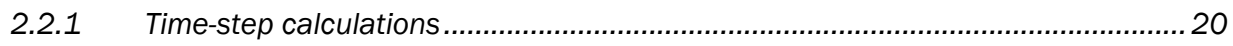

2.2.2 Morphological acceleration factor ................................................................. 20

2.3 Model input and boundary conditions ................................................................ 22

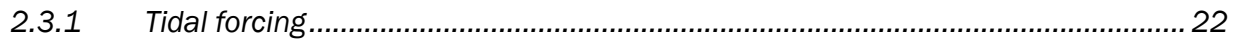

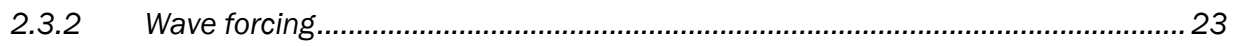

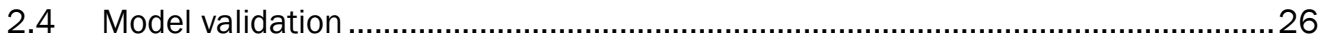

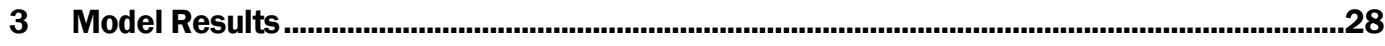

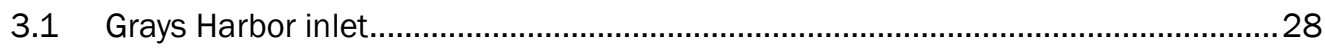

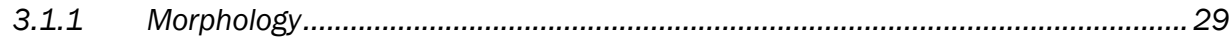

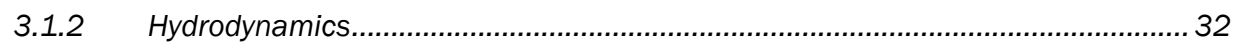

3.1.3 Comparisons with empirical formulas ................................................................ 36

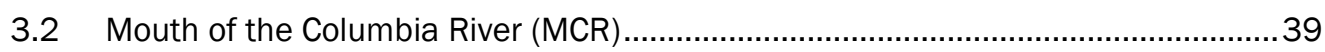

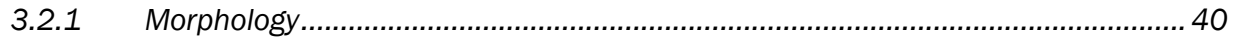

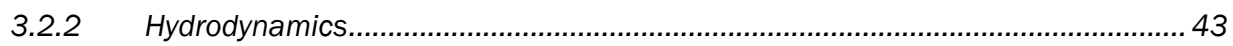

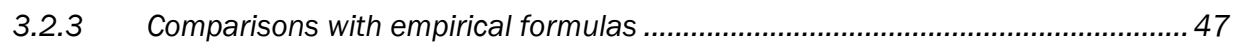

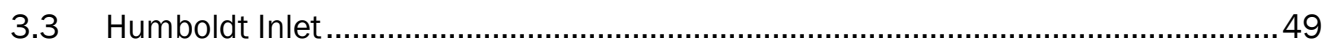

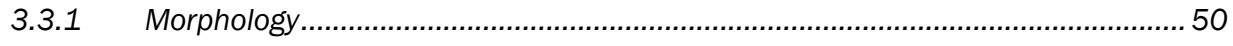

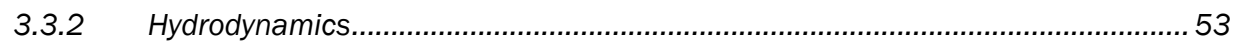

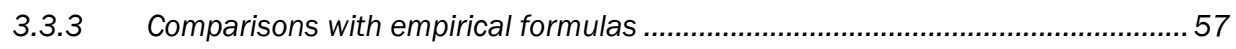

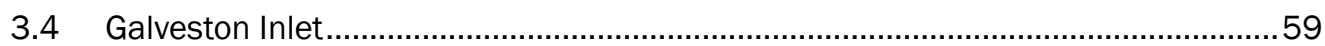

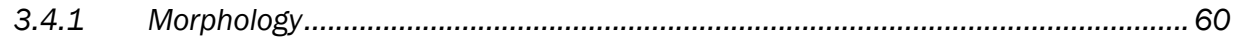




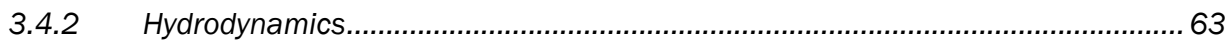

3.4.3 Comparisons with empirical formulas ............................................................ 66

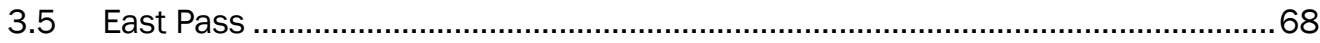

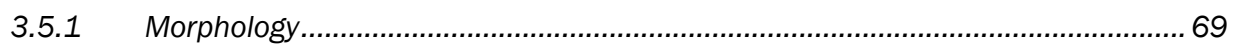

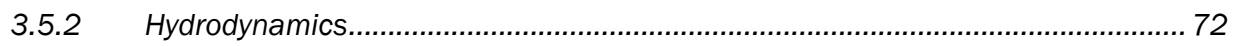

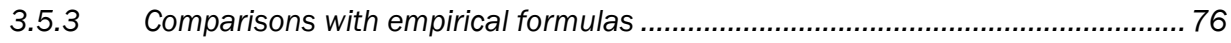

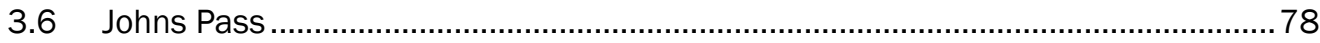

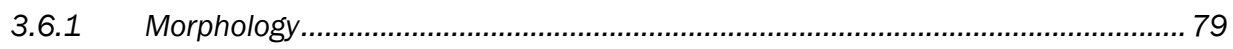

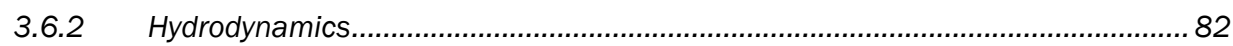

3.6.3 Comparisons with empirical formulas .............................................................. 85

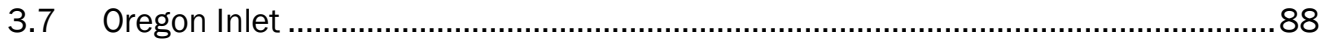

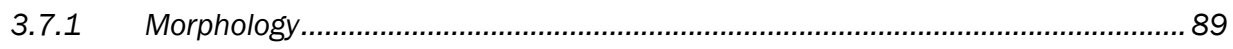

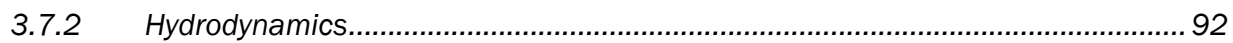

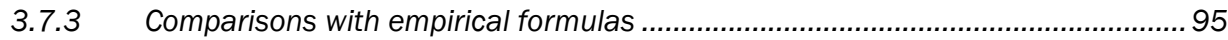

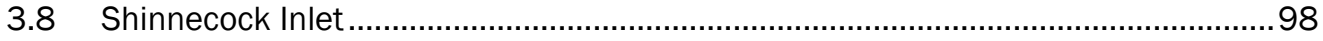

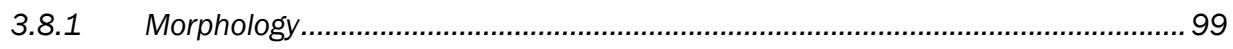

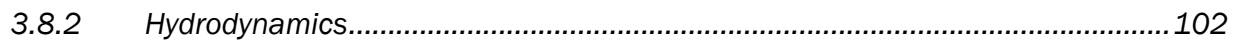

3.8.3 Comparisons with empirical formulas ......................................................... 105

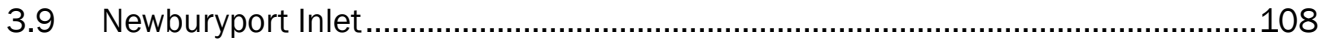

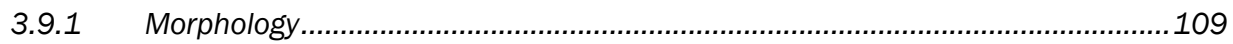

3.9.2 Hydrodynamics............................................................................................... 112

3.9.3 Comparisons with empirical formulas ........................................................115

4 Discussion .................................................................................................................................118

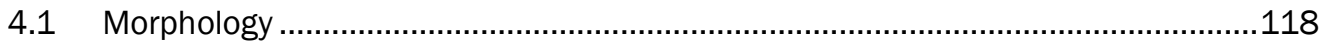

4.1.1 Inlet morphological evolution ......................................................................... 118

4.1.2 Bay morphological evolution ...........................................................................119

4.1.3 Ebb shoal morphological evolution .................................................................119

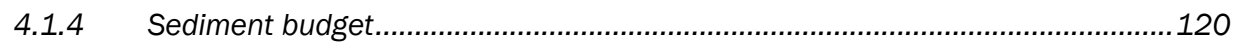

4.2 Hydrodynamics .................................................................................... 121

4.3 Long-term model predictions ...........................................................................123

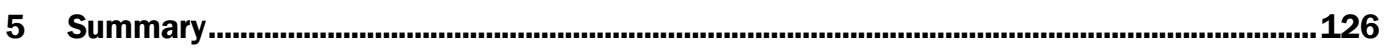

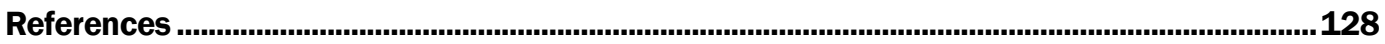

Appendix A: Wave Climatology............................................................................................132

Appendix B: Representative Wave Parameter Time Series ....................................................134

\section{Report Documentation Page}




\section{Figures and Tables}

\section{Figures}

Figure 1.1. Tidal current at spring tide as a function of inlet cross-section area derived by Escoffier (Equation (10)). The dashed line denotes a hypothetical equilibrium current for a stable inlet.

Figure 1.2. Comparison between Escoffier solution and the quadratic solution

Figure 2.1. Map of the nine selected inlets utilized to develop representative grids modeled in this study.

Figure 2.2. Comparison of MAF values of 1,10 , and 20. Red ovals indicate areas of observed qualitative change.

Figure 2.1. Tidal prism relationship for the nine U.S. inlets used to define the input and boundary conditions for the idealized inlets. Inlet cross section and prisms vary by two orders of magnitude providing a broad representation of typical U.S. inlets. The parameter values for the best fit are $n=0.93$ and $C=2.0 \times 10^{-4}$

Figure 3.1. CMS grid and bathymetry for idealized Grays Harbor simulation.

Figure 3.2. Final depth for Grays Harbor after 100-year simulation. White areas shown inside the bays denote computational areas that were dry (above the water level) at the end of the simulation.

Figure 3.3. CMS-predicted temporal evolution of cross-sectional area at the ocean (top), midpoint (middle), and bay (bottom) sides of the inlet. Distances are alongshore from channel centerline with positive towards the right looking oceanward (updrift for Grays Harbor) and negative towards the left (downdrift).

Figure 3.4. Calculated 100 years of bed volume change $(M=$ Million) in cubic meters for Grays Harbor.

Figure 3.5. Current magnitude during maximum flood at the end of the 100-year simulation for Grays Harbor. White areas shown inside the bays denote computational areas that were dry (above the water level) at the end of the simulation.

Figure 3.6. Current magnitude during maximum ebb at the end of the 100-year simulation for Grays Harbor. White areas shown inside the bays denote computational areas that were dry (above the water level) at the end of the simulation.

Figure 3.7. Average and peak average tidal currents at the midpoint of the inlet (top left and top right inset, respectively). The two smaller panels (right inset) illustrate current patterns for the last year of the simulation

Figure 3.8. Volume flux and tidal prism (left inset) at the inlet midpoint. The two smaller panels denote the last year of the simulation to illustrate tidal variability.

Figure 3.9. Water surface elevation difference between the ocean and bay. Positive values denote sea surface slope from the ocean to the bay.

Figure 3.10. Inlet cross-sectional area calculated by the CMS (lines) at three inlet channel locations and the computed cross-sectional area from the tidal prism relationship (points).

Figure 3.11. Time series of ebb shoal volume calculated by the CMS (yellow line) and the computed empirical formulas that relate tidal prism to ebb shoal volume (points). .38

Figure 3.12. An Escoffier analysis comparing the theoretically predicted (green and yellow lines) and CMS-computed (blue points) current. Plus signs denote the minimal crosssectional area and the theoretical maximum velocity required for this inlet to remain 
stable. A 30-day low-pass filter delineates the overall trend of CMS-computed peak velocities for modeled cross-sectional areas (orange line).

Figure 3.13. CMS grid and bathymetry for idealized MCR simulation.

Figure 3.14. Final depth for MCR after 100-year simulation. White areas shown inside the bays denote computational areas that were dry (above the water level) at the end of the simulation.

Figure 3.15. CMS-predicted temporal evolution of inlet cross-sectional area for MCR. Distances are alongshore from channel centerline with positive towards the right looking oceanward and negative towards the left.

Figure 3.16. Calculated bed volume change for the MCR.

Figure 3.17. Current magnitude during maximum flood at the end of the 100-year simulation for the MCR. White areas shown inside the bays denote computational areas that were dry (above the water level) at the end of the simulation.

Figure 3.18. Current magnitude during maximum ebb at the end of the 100-year simulation for the MCR. White areas shown inside the bays denote computational areas that were dry (above the water level) at the end of the simulation.

Figure 3.19. Average and peak average tidal currents at the midpoint of the inlet (top left and top right inset, respectively). The two smaller panels (right inset) illustrate current patterns for the last year of the simulation

Figure 3.20. Volume flux and tidal prism (top left and top right inset, respectively) at the inlet midpoint. The two smaller panels (right inset) denote the last year of the simulation to illustrate tidal variability.

Figure 3.21. Water surface elevation difference between the ocean and bay. Positive values denote sea surface slope from the ocean to the bay.

Figure 3.22. Inlet cross-sectional area calculated by the CMS (lines) at three inlet channel locations and the computed cross-sectional area from the tidal prism relationship (points).

Figure 3.23. Time series of ebb shoal volume calculated by the CMS (yellow line) and the computed empirical formulas that relate tidal prism to ebb shoal volume (points).

Figure 3.24. An Escoffier analysis comparing the theoretically predicted (green and yellow lines) and CMS-computed (blue points) current. Plus signs denote the minimal crosssectional area and the theoretical maximum velocity required for this inlet to remain stable. A 30-day low-pass filter delineates the overall trend of CMS-computed peak velocities for modeled cross-sectional areas (orange line).

Figure 3.25. CMS grid and bathymetry for idealized Humboldt Inlet simulation.

Figure 3.26. Calculated final depth for Humboldt Inlet after 100-year simulation. White areas shown inside the bays denote computational areas that were dry (above the water level) at the end of the simulation.

Figure 3.27. CMS-predicted temporal evolution of inlet cross-sectional area for Humboldt Inlet. Distances are alongshore from channel centerline with positive towards the right looking oceanward and negative towards the left.

Figure 3.28. Calculated bed volume change for Humboldt Inlet.

Figure 3.29. Current magnitude during maximum flood at the end of the 100-year simulation for Humboldt. White areas shown inside the bays denote computational areas that were dry (above the water level) at the end of the simulation.

Figure 3.30. Current magnitude during maximum ebb at the end of the 100-year simulation for Humboldt. White areas shown inside the bays denote computational areas that were dry (above the water level) at the end of the simulation. 
Figure 3.31. Average and peak average tidal currents at the midpoint of the inlet (top left and top right inset, respectively). The two smaller panels (right inset) illustrate current patterns for the last year of the simulation

Figure 3.32. Volume flux and tidal prism (top left and top right inset, respectively) at the inlet midpoint. The two smaller panels (right inset) denote the last year of the simulation to illustrate tidal variability.

Figure 3.33. Calculated water surface elevation difference between the ocean and bay. Positive values denote sea surface slope from the ocean to the bay...

Figure 3.34. Inlet cross-sectional area calculated by the CMS (lines) at three inlet channel locations and the computed cross-sectional area from the tidal prism relationship (points)

Figure 3.35. Time series of ebb shoal volume calculated by the CMS (yellow line) and the computed empirical formulas that relate tidal prism to ebb shoal volume (points).

Figure 3.36. An Escoffier analysis comparing the theoretically predicted (green and yellow lines) and CMS-computed (blue points) current. Plus signs denote the minimal crosssectional area and the theoretical maximum velocity required for this inlet to remain stable. A 30-day low-pass filter delineates the overall trend of CMS-computed peak velocities for modeled cross-sectional areas (orange line). 59

Figure 3.37. CMS grid and bathymetry for idealized Galveston simulation. 60

Figure 3.38. Calculated final depth for Galveston after 100-year simulation.

Figure 3.39. CMS-predicted temporal evolution of inlet cross-sectional area for Galveston. Distances are alongshore from channel centerline with positive towards the right looking oceanward and negative towards the left. Note the Ocean-side vertical axis is truncated to ensure consistency and clarity with the other plots.

Figure 3.40. Calculated bed volume change for Galveston.

Figure 3.41. Current magnitude during maximum flood at the end of the 100-year simulation for Galveston.

Figure 3.42. Current magnitude during maximum ebb at the end of the 100 -year simulation for Galveston.

Figure 3.43. Average and peak average tidal currents at the midpoint of the inlet (top left and top right inset, respectively). The two smaller panels (right inset) illustrate current patterns for the last year of the simulation

Figure 3.44. Volume flux and tidal prism (top left and top right inset, respectively) at the inlet midpoint. The two smaller panels (right inset) denote the last year of the simulation to illustrate tidal variability.

Figure 3.45. Calculated water surface elevation difference between the ocean and bay. Positive values denote sea surface slope from the ocean to the bay.

Figure 3.46. Inlet cross-sectional area calculated by the CMS (lines) at three inlet channel locations and the computed cross-sectional area from the tidal prism relationship (points).

Figure 3.47. Time series of ebb shoal volume calculated by the CMS (yellow line) and the computed empirical formulas that relate tidal prism to ebb shoal volume (points).

Figure 3.48. An Escoffier analysis comparing the theoretically predicted (green and yellow lines) and CMS-computed (blue points) current. Plus signs denote the minimal crosssectional area and the theoretical maximum velocity required for this inlet to remain stable. A 30-day low-pass filter delineates the overall trend of CMS-computed peak velocities for modeled cross-sectional areas (orange line). 
Figure 3.49. CMS grid and bathymetry for idealized East Pass simulation. Closer view of the inlet in zoomed figure on the right.

Figure 3.50. Calculated final depth for East Pass after 100-year simulation. Closer view of the inlet in zoomed figure on the right.

Figure 3.51. CMS-predicted temporal evolution of inlet cross-sectional area for East Pass. Distances are alongshore from channel centerline with positive towards the right looking oceanward and negative towards the left.

Figure 3.52. Calculated bed volume change for East Pass.

Figure 3.53. Current magnitude during maximum flood at the end of the 100-year simulation for East Pass. Closer view of the inlet in zoomed figure on the right.

Figure 3.54. Current magnitude during maximum ebb at the end of the 100-year simulation for East Pass. Closer view of the inlet in zoomed figure on the right.

Figure 3.55. Average and peak average tidal currents at the midpoint of the inlet (top left and top right inset, respectively). The two smaller panels (right inset) illustrate current patterns for the last year of the simulation

Figure 3.56. Volume flux and tidal prism (top left and top right inset, respectively) at the inlet midpoint. The two smaller panels (right inset) denote the last year of the simulation to illustrate tidal variability.

Figure 3.57. Calculated water surface elevation difference between the ocean and bay. Positive values denote sea surface slope from the ocean to the bay..

Figure 3.58. Inlet cross-sectional area calculated by the CMS (lines) at three inlet channel locations and the computed cross-sectional area from the tidal prism relationship (points).

Figure 3.59. Time series of ebb shoal volume calculated by the CMS (yellow line) and the computed empirical formulas that relate tidal prism to ebb shoal volume (points).

Figure 3.60. An Escoffier analysis comparing the theoretically predicted (green and yellow lines) and CMS-computed (blue points) current. Plus signs denote the minimal crosssectional area and the theoretical maximum velocity required for this inlet to remain stable. A 30-day low-pass filter delineates the overall trend of CMS-computed peak velocities for modeled cross-sectional areas (orange line).

Figure 3.61. CMS grid and bathymetry for idealized Johns Pass simulation.....................................79

Figure 3.62. Calculated final depth for Johns Pass after 100-year simulation.

Figure 3.63. CMS-predicted temporal evolution of inlet cross-sectional area for Johns Pass. Distances are alongshore from channel centerline with positive towards the right looking oceanward and negative towards the left.

Figure 3.64. Calculated bed volume change for Johns Pass.

Figure 3.65. Current magnitude during maximum flood at the end of the 100-year simulation for Johns Pass.

Figure 3.66. Current magnitude during maximum ebb at the end of the 100-year simulation for Johns Pass.

Figure 3.67. Average and peak average tidal currents at the midpoint of the inlet (top left and top right inset, respectively). The two smaller panels (right inset) illustrate current patterns for the last year of the simulation.

Figure 3.68. Volume flux and tidal prism (top left and top right inset, respectively) at the inlet midpoint. The two smaller panels (right inset) denote the last year of the simulation to illustrate tidal variability. 
Figure 3.69. Calculated water surface elevation difference between the ocean and bay. Positive values denote sea surface slope from the ocean to the bay.....

Figure 3.70. Inlet cross-sectional area calculated by the CMS (lines) at three inlet channel locations and the computed cross-sectional area from the tidal prism relationship (points).

Figure 3.71. Time series of ebb shoal volume calculated by the CMS (yellow line) and the computed empirical formulas that relate tidal prism to ebb shoal volume (points).

Figure 3.72. An Escoffier analysis comparing the theoretically predicted (green and yellow lines) and CMS-computed (blue points) current. Plus signs denote the minimal crosssectional area and the theoretical maximum velocity required for this inlet to remain stable. A 30-day low-pass filter delineates the overall trend of CMS-computed peak velocities for modeled cross-sectional areas (orange line).

Figure 3.73. CMS grid and bathymetry for idealized Oregon Inlet simulation. Closer view of the inlet in zoomed figure on the right.

Figure 3.74. Final depth for Oregon Inlet after 100-year simulation. Closer view of the inlet in zoomed figure on the right. White areas shown inside the bays denote computational areas that were dry (above the water level) at the end of the simulation.

Figure 3.75. CMS-predicted temporal evolution of inlet cross-sectional area for Oregon Inlet. Distances are alongshore from channel centerline with positive towards the right looking oceanward and negative towards the left.

Figure 3.76. Calculated bed volume change for Oregon Inlet.

Figure 3.77. Current magnitude during maximum flood at the end of the 100-year simulation for Oregon Inlet. Closer view of the inlet in zoomed figure on the right. White areas shown inside the bays denote computational areas that were dry (above the water level) at the end of the simulation.

Figure 3.78. Current magnitude during maximum ebb at the end of the 100-year simulation for Oregon Inlet. Closer view of the inlet in zoomed figure on the right. White areas shown inside the bays denote computational areas that were dry (above the water level) at the end of the simulation.

Figure 3.79. Average and peak average tidal currents at the midpoint of the inlet (top left and top right inset, respectively). The two smaller panels (right inset) illustrate current patterns for the last year of the simulation

Figure 3.80 Volume flux and tidal prism (top left and top right inset, respectively) at the inlet midpoint. The two smaller panels (right inset) denote the last year of the simulation to illustrate tidal variability. .

Figure 3.81. Calculated water surface elevation difference between the ocean and bay. Positive values denote sea surface slope from the ocean to the bay..

Figure 3.82. Inlet cross-sectional area calculated by the CMS (lines) at three inlet channel locations and the computed cross-sectional area from the tidal prism relationship (points).

Figure 3.83. Time series of ebb shoal volume calculated by the CMS (yellow line) and the computed empirical formulas that relate tidal prism to ebb shoal volume (points).

Figure 3.84. An Escoffier analysis comparing the theoretically predicted (green and yellow lines) and CMS-computed (blue points) current. Plus signs denote the minimal crosssectional area and the theoretical maximum velocity required for this inlet to remain stable. A 30-day low-pass filter delineates the overall trend of CMS-computed peak velocities for modeled cross-sectional areas (orange line).

Figure 3.85. CMS grid and bathymetry for idealized Shinnecock simulation. 
Figure 3.86. Calculated final depth for Shinnecock. White areas shown inside the bays denote computational areas that were dry (above the water level) at the end of the simulation.

Figure 3.87. CMS-predicted temporal evolution of inlet cross-sectional area for Shinnecock. Distances are alongshore from channel centerline with positive towards the right looking oceanward and negative towards the left.

Figure 3.88. Calculated bed volume change for Shinnecock Inlet.

Figure 3.89. Current magnitude during maximum flood at the end of the 100-year simulation for Shinnecock Inlet. White areas shown inside the bays denote computational areas that were dry (above the water level) at the end of the simulation.

Figure 3.90. Current magnitude during maximum ebb at the end of the 100-year simulation for Shinnecock Inlet. White areas shown inside the bays denote computational areas that were dry (above the water level) at the end of the simulation.

Figure 3.91. Average and peak average tidal currents at the midpoint of the inlet (top left and top right inset, respectively). The two smaller panels (right inset) illustrate current patterns for the last year of the simulation

Figure 3.92. Volume flux and tidal prism (top left and top right inset, respectively) at the inlet midpoint. The two smaller panels (right inset) denote the last year of the simulation to illustrate tidal variability.

Figure 3.93. Calculated water surface elevation difference between the ocean and bay. Positive values denote sea surface slope from the ocean to the bay.

Figure 3.94. Inlet cross-sectional area calculated by the CMS (lines) at three inlet channel locations and the computed cross-sectional area from the tidal prism relationship (points).

Figure 3.95. Time series of ebb shoal volume calculated by the CMS (yellow line) and the computed empirical formulas that relate tidal prism to ebb shoal volume (points).

Figure 3.96. An Escoffier analysis comparing the theoretically predicted (green and yellow lines) and CMS-computed (blue points) current. Plus signs denote the minimal crosssectional area and the theoretical maximum velocity required for this inlet to remain stable. A 30-day low-pass filter delineates the overall trend of CMS-computed peak velocities for modeled cross-sectional areas (orange line).

Figure 3.97. CMS grid and bathymetry for idealized Newburyport simulation.

Figure 3.98. Calculated final depth for Newburyport after 100-year simulation. White areas shown inside the bays denote computational areas that were dry (above the water level) at the end of the simulation.

Figure 3.99. CMS-predicted temporal evolution of inlet cross-sectional area for Newburyport. Distances are alongshore from channel centerline with positive towards the right looking oceanward and negative towards the left.

Figure 3.100. Calculated bed volume change for Newburyport.

Figure 3.101. Current magnitude during maximum flood at the end of the 100-year simulation for Newburyport Inlet. White areas shown inside the bays denote computational areas that were dry (above the water level) at the end of the simulation.

Figure 3.102. Current magnitude during maximum ebb at the end of the 100-year simulation for Newburyport Inlet. White areas shown inside the bays denote computational areas that were dry (above the water level) at the end of the simulation.

Figure 3.103. Average and peak average tidal currents at the midpoint of the inlet (top left and top right inset, respectively). The two smaller panels (right inset) illustrate current patterns for the last year of the simulation 
Figure 3.104. Volume flux and tidal prism (top left and top right inset, respectively) at the inlet midpoint. The two smaller panels (right inset) denote the last year of the simulation to illustrate tidal variability.

Figure 3.105. Calculated water surface elevation difference between the ocean and bay. Positive values denote sea surface slope from the ocean to the bay..

Figure 3.106. Inlet cross-sectional area calculated by the CMS (lines) at three inlet channel locations and the computed cross-sectional area from the tidal prism relationship (points)

Figure 3.107. Time series of ebb shoal volume calculated by the CMS (yellow line) and the computed empirical formulas that relate tidal prism to ebb shoal volume (points). Scale is adjusted to illustrate a slight decrease in ebb shoal volume at the beginning of the simulation ( $0-10$ years).

Figure 3.108. An Escoffier analysis comparing the theoretically predicted (green and yellow lines) and CMS-computed (blue points) current. Plus signs denote the minimal cross-sectional area and the theoretical maximum velocity required for this inlet to remain stable. A 30-day low-pass filter delineates the overall trend of CMS-computed peak velocities for modeled cross-sectional areas (orange line).

Figure A1. Wave climatology for all modeled Inlets. The dashed line indicates the shoreline orientation at each of the inlets.

Figure B1. Wave height, period, and direction plot for Grays Harbor, WA (taken from WIS station 83011)...

Figure B2. Wave height, period, and direction plot for MCR, TX (taken from WIS station 83015).

Figure B3. Wave height, period, and direction plot for Humboldt Inlet, CA (taken from WIS station 83047).

Figure B4. Wave height, period, and direction plot for Galveston Entrance, TX (taken from WIS station 73074).

Figure B5. Wave height, period, and direction plot for East Pass, FL (taken from WIS station 73176).

Figure B6. Wave height, period, and direction plot for Johns Pass, FL (taken from WIS station 73293).

Figure B7. Wave height, period, and direction plot for Oregon Inlet, NC (taken from WIS station 63223).

Figure B8. Wave height, period, and direction plot for Shinnecock Inlet, NY (taken from WIS station 63135).

Figure B9. Wave height, period, and direction plot for Newburyport Inlet, MA (taken from WIS station 63045).

\section{Tables}

Table 2.1. Geometric characteristics for each of the nine simulated inlets.

Table 2.2. Tidal constituents used in numerical modeling of the nine idealized inlets.

Table 2.3. WIS hindcast station locations and characteristics for each of the nine simulated inlets.

Table 4.1. Final sediment volume in millions of cubic meters $\left(10^{6} \mathrm{~m}^{3}\right)$.

Table 4.2. Hydrodynamic and wave conditions as large sediment movement occurs at 
Table A1. Sediment transport rates for the 9 inlets. References denote the source of the field estimates. 


\section{Preface}

This study was conducted for Headquarters, U.S. Army Corps of Engineers (HQUSACE), Washington, DC, under the USACE Coastal Inlets Research Program (CIRP). The HQUSACE CIRP Program Manager was Ms. Mary Cialone, U.S. Army Engineer Research and Development Center (ERDC), Coastal and Hydraulics Laboratory (CHL), Flood and Storm Protection Division (HF), Coastal Processes Branch (HF-C). Mr. Jeffrey A. McKee was the HQUSACE Navigation Business Line Manager overseeing the CIRP.

At the time of publication, Dr. Jackie Pettway was Chief, CHL Navigation Division (HN), and Mr. Greg Dreaper was Acting Chief, Coastal Engineering Branch (HN-C). Mr. W. Jeff Lillycrop (CHL) was the ERDC Technical Director for Civil Works and Navigation Research, Development, and Technology Transfer (RD\&T) portfolio. The Acting Director of CHL was Mr. Jeffrey R. Eckstein.

The Commander of ERDC was COL Bryan S. Green, and the Director was Dr. David W. Pittman. 


\section{Unit Conversion Factors}

\begin{tabular}{|l|l|l|}
\hline Multiply & By & To Obtain \\
\hline cubic feet & 0.02831685 & cubic meters \\
\hline degrees (angle) & 0.01745329 & radians \\
\hline feet & 0.3048 & meters \\
\hline square feet & 0.09290304 & square meters \\
\hline
\end{tabular}




\section{Introduction}

\subsection{Background}

Tidal inlets are some of the most dynamically active systems in the coastal zone (Komar 1996). Inlets connect the continents to the sea and are primary pathways for terrestrial sediments to the ocean. Coastline evolution and stability are tied to inlet processes as inlets function as both sources and sinks of sediment and can disrupt longshore transport pathways modulating the growth, migration, and erosion of adjacent shorelines. Inlets are the access points for seafaring commerce, which comprises a vast global transportation industry that relies on a network of sustainable navigation channels. Navigation is the largest program in the U.S. Army Corps of Engineers (USACE) Civil Works portfolio, and dredging accounts for a substantial fraction of the total annual Operation and Maintenance budget. The dynamical processes governing inlet behavior present complex engineering challenges that affect the global economy and quality of life for coastal communities.

Long-term behavior of tidal inlets in barrier island systems is controlled by a number of complex, dynamic, and competing physical processes (Hayes 1980; Komar 1996). Tidal currents concentrated in the inlet throat mobilize sediment and maintain an open connection between the coastal ocean and bay. Longshore transport, primarily driven by waves, introduces sediment into the system that modulates the mass balance by contributing to the development of the ebb shoal delta and bypassing to the down-drift beach. Within this conceptual framework, sediments are continually reworked through complex interactions between local waves, ebb shoal morphology, and reversing tidal currents. The interaction between wave action and flood tidal currents carrying sediment into the system and ebb tidal currents removing sediment modulates the long-term stability of barrier tidal inlets.

The Coastal Inlets Research Program (CIRP), administered by the USACE Engineer Research and Development Center's Coastal and Hydraulics Laboratory (CHL), has developed the Coastal Modeling System (CMS) as a coupled wave, hydrodynamic, and sediment transport numerical modeling system that is capable of predicting long-term morphologic change in barrier-inlet systems (Demirbilek and Rosati 2011). This model was 
designed to run on desktop computers, facilitating USACE coastal engineers in calculating realistic long-term morphology change for navigation and flood and coastal storm damage risk reduction projects. This model has been widely used at project locations across the country, with site-specific calibration and validation in short- to medium-term simulations (Sánchez et al. 2011a,b, 2014; Lin et al. 2011). With the growing need to predict longer-term morphologic evolution spanning 50-year coastal project lifetimes, 100 years of predicted sea level change, and other potential climatic factors, it is necessary to evaluate the capability of the CMS to reproduce essential theoretical and empirical relationships known to drive the long-term morphodynamics in barrierinlet systems.

\subsection{Objective}

The primary focus of this study is to examine the physical processes that are responsible for tidal inlet formation, evolution and maintenance, validate CMS for long-term applications, and verify the results against established theoretical and empirical formulations that describe the stability and equilibrium conditions of tidal inlets. Furthermore, the CIRP is responsible for research and development of new techniques and tools to increase the understanding of wave, tide, current, and sediment transport processes at and around inlets.

\subsection{Approach}

This study will demonstrate a new application of CHL's evolving state-ofthe-art capabilities in computational fluid dynamics by addressing fundamental requirements related to the long-term evolution of tidal inlets: (1) establish the numerical stability of CMS for simulation periods up to 100 years, (2) demonstrate the feasibility of carrying out long-term simulations in the context of engineering applications that require robust modeling systems with quick turnaround times, and (3) verify that CMS's hydrodynamic, wave, and morphological algorithms reproduce the known generic characteristics of inlets on climatological time scales. These capabilities are important to the USACE navigation mission as they provide an engineering tool that can evaluate long-term climatological challenges such as sea level change and storminess. 


\subsection{Previous studies}

Tidal inlets have been extensively studied, and a wealth of information is available to evaluate model performance. O'Brien (1939) noted that larger bays tended to have larger inlets and developed a parametric relationship between inlet cross-sectional area $(A)$ and tidal prism $(P)$ using information from U. S. coastal inlets:

$$
A=C P^{n}
$$

where $C$ and $n$ were empirically derived constants. Equation (1) is known as the tidal prism relationship (Hughes 2002) and states that crosssectional area adjusts as a non-linear function of tidal prism. In O'Brien's original study, $C$ and $n$ were determined to be $4.69 \times 10^{-4}$ and 0.85 , respectively, with cross-sectional area measured in square feet and prism in cubic feet. The scarcity of field data at that time encouraged later studies that included a greater number of inlets with more accurate tide and wave measurements (Kraus 1998). The collective results confirm that the basic tidal prism relationship with $C$ and $n$ shows some sensitivity to wave energy, bay area, tidal regime, and the presence of jetties (Jarrett 1976; Kraus 1998; O'Brien 1969).

The underlying assumption leading to the tidal prism relationship is that equilibrium cross-sectional area is maintained when the maximum inlet flow is near the critical value for the initiation of sediment motion. Maximum currents are strong enough to remove newly deposited sediment but are unable to erode the channel to the point of expanding the inlet cross-sectional area. As wave action supplies sediment to the inlet via longshore and cross-shore transport, the equilibrium condition also depends on the efficiency of currents in overcoming the wave sediment flux to maintain an open channel. These processes are implicit in the empirically derived tidal prism relationship, and its justification as a validation metric is supported by its demonstrated applicability to many different inlet types (Kraus 1998; O'Brien 1939, 1969; Stive and Rakhorst 2008).

\subsubsection{Analytical models}

As more information on tidal inlet hydrodynamics has become available, a number of investigators have sought a theoretical basis for Equation (1) (see Stive and Rakhorst [2008] for a review). Kraus (1998) developed an expression for inlet sediment flux in terms of simple momentum balances 
between bottom friction, tidal energy, and longshore sediment transport rate. Invoking the Manning's roughness coefficient led to a non-linear expression for equilibrium cross-sectional area, which combined with mass conservation, produced an analytical expression for $C$ and a noninteger power law for $n$. The coefficient, $C_{k}$, for Equation (1) derived by Kraus is given by

$$
C_{K}=\left(\frac{\alpha \pi^{3} C_{s}^{3} n^{2} W_{e}^{4 / 3}}{Q_{s} T^{3}}\right)^{0.3}
$$

where $\alpha$ is an empirical coefficient $(=1), C_{s}$ is a shape parameter to account for non-sinusoidal tides ( $=1$ )(dimensionless), $n$ is the Manning's coefficient (second/meters ${ }^{1 / 3}$ ), $W_{e}$ is the equilibrium inlet width (meters), $Q_{s}$ is the longshore sediment transport (meters3/second), and $T$ is the tidal period (seconds). Regression analysis using the data of Jarrett (1976) showed good agreement between this theoretical model and the data for both jettied and non-jettied inlets.

Hughes (2002) revisited the tidal prism relationship and derived an analytical expression for equilibrium inlet cross-sectional area and tidal prism by invoking non-linear friction, which led to a power law formulation for total discharge as a function of inlet geometry. Hughes (2002) illustrated several theoretical examples using different inlet cross-section geometries (trapezoidal, parabolic) to reinforce the reasoning behind the empirically derived tidal prism relationship. For applications, Hughes (2002) suggested the following equation:

$$
C_{H}=\frac{0.65 k_{a} W^{1 / 9}}{[g(s-1)]^{4 / 9} d^{1 / 3} T^{8 / 9}}
$$

where $C_{H}$ denotes the coefficient derived by Hughes, $k_{a}$ is an empirically derived coefficient ( $=1.34$ ), $W$ is the inlet width (meters), $g$ is the acceleration due to gravity (meters/second ${ }^{2}$ ), $s$ is the relative sediment density (= sediment density/fluid density), and $d$ is the median grain size diameter (millimeter). Regression analysis derived from 102 U.S. inlets and 18 laboratory studies demonstrated good agreement with Equation (1) as modified by Hughes (2002). 


\subsubsection{Escoffier analysis of inlet stability}

Long-term inlet stability is determined by tidal and wave forces that redistribute sediment. Escoffier (1940) theorized that stable inlets form when the maximum flow equals an equilibrium value so that there is no net change in the cross-sectional area due to sediment transport processes. If the maximum flow in the inlet $(U)$ exceeds the equilibrium value, then the cross-sectional area $(A)$ increases. If the maximum flow is less than the equilibrium value, the inlet will contract and may eventually close.

Escoffier (1940, 1977) constructed a theoretical framework to quantify the equilibrium approach using simplified momentum and continuity arguments for single inlet systems. Assuming the tidal wavelength is much greater than the length of an inlet or bay, the velocity in the inlet is approximately spatially uniform. The linearized one-dimensional (1D) momentum equation can be written as

$$
\frac{\partial u}{\partial t}=-\frac{g}{L}\left(\eta-\eta_{\text {oce }}\right)-\frac{c_{d} u^{2}}{h}
$$

where $u$ is the depth-averaged velocity in the inlet, $t$ is time, $L$ is the length of the inlet, $h$ is the water depth, $\eta$ is the water surface elevation in the bay, $\eta_{\text {oce }}$ is the water surface elevation in the ocean, and $c_{d}$ is the drag coefficient. In earlier treatments, Escoffier used the hydraulic radius instead of water depth in the friction term (Walton and Escoffier 1981). However, the ratio of channel depth to channel width is very small (1/10 1/100) in natural channels (Yalin 1992). Sidewall effects are negligible compared to bed friction, and water depth is the appropriate scale in the friction term. The continuity equation for a simple bay system is written as

$$
\frac{d}{d t}\left(A_{b} \eta\right)=u A
$$

where $A b$ is the bay area. Equation (5) describes the change in bay volume due to the discharge through the inlet throat. In general, $A_{b}$ and $A$ are functions of water depth, but a simple analytical solution emerges if the explicit dependence is overlooked. The set of equations can be solved to determine the maximum velocity through the inlet as a function of inlet cross-sectional area. Following Escoffier (1977) the tidal current speed, $U$, can be solved as 


$$
U=\sqrt{2 g h_{l}}\left(\frac{2 g L n^{2}}{h^{4 / 3}}+m\right)^{-1 / 2}
$$

where $h_{l}$ is the total head loss across the inlet (meters), $n$ is the Manning's roughness coefficient, and $m$ is the head loss coefficient through the inlet throat (dimensionless). To close the solution, Escoffier (1977) linearized the friction term in the inlet throat, which led to the following expression for the bay $(a b)$ and ocean $\left(a_{o}\right)$ tidal amplitude ratio:

$$
\frac{a_{b}}{a_{0}}=\frac{K^{2}}{\sqrt{2}}\left[\left(1+\frac{4}{K^{4}}\right)^{1 / 2}-1\right]^{1 / 2}
$$

where:

$$
K=\frac{A \xi \sqrt{2 g}}{A_{b} \omega \sqrt{a_{0}}} \quad \xi=\left(\frac{2 g L n^{2}}{h^{4 / 3}}+m\right)^{-1 / 2}
$$

and $\omega=2 \pi / T$ is the radian frequency. Assuming a sinusoidal tidal current in the inlet throat, the continuity equation (5) can be solved to give the maximum bay water surface elevation:

$$
\eta_{b m}=a_{b}=\frac{A}{2 A_{b}} \int_{0}^{T / 2} U \sin (\omega t) d t=\frac{A U}{\omega A_{b}}
$$

Rearranging, the maximum inlet velocity is written as

$$
U=\frac{\omega A_{b} a_{b}}{A}
$$

Substituting Equation (7) into Equation (10) gives the solution for the current.

Escoffier (1940) noted that $A$ increases as a function of water depth. For a rectangular channel, the proportionality coefficient is constant $\left(h \propto A^{1 / 2}\right)$. For small $A$, the inlet velocity increases as the cross section expands to accommodate greater exchange and flow drag decreases. For large $A$, the inlet throat is wide, and the flow is no longer constricted leading to a reduced sea surface slope across the inlet. The current decreases monotonically $(U \propto 1 / A)$. 
Escoffier theorized a constant equilibrium velocity $\left(U_{e}\right)$, which would maintain a stable inlet. Figure 1.1 depicts a hypothetical equilibrium velocity in which $U_{\max }>U_{e}$. The first intersection point between the dashed line, indicating the equilibrium velocity, and the blue curve denotes an unstable inlet as small perturbations lead either to higher speeds and further expansion (erosion) of the throat or lower speeds and contraction (deposition). The second intersection point between the dashed line and the blue curve denotes a stable inlet as small perturbations tend to either decrease the current, causing a return to equilibrium as the larger cross section contracts or an increase in current for a smaller cross section leading to dilation. If $U_{e}>U_{\max }$, then there is no feasible area $A$ that will produce strong enough currents to maintain a stable system, and the inlet will eventually close. Sensitivity to $h$ shows that greater friction or shorter inlet length tend to reduce the velocity envelope, which can influence inlet stability if the equilibrium velocity exceeds $U_{\max }$.

In addition to the Escoffier (1977) solution, the maximum flow can be obtained directly from the momentum equation without having to invoke assumptions regarding inlet head loss or linearization of the friction term. Substituting Equation (9) into Equation (4) and neglecting time dependence gives the following quadratic equation:

$$
U^{2}+\frac{g A h}{c_{d} \omega L A_{b}} U-\frac{g h a_{0}}{c_{d} L}=0
$$

with the solution

$$
U=\sqrt{B^{2} A^{2}+2 B a_{0} A_{b} \omega}-B A
$$

where:

$$
B=\frac{g h}{c_{d} \omega L A_{b}}
$$

The Escoffier solution Equation (10) and the quadratic solution Equation (12) relating the maximum tidal current to cross-sectional area are qualitatively similar (Figure 1.2). Both approaches use the continuity equation to derive an expression for $U$ in terms of bay tidal amplitude but invoke different approaches to define friction within the inlet throat. The Escoffier solution relies on two empirical parameters, $n$ and $m$, whereas the quadratic solution requires only $c_{d}$. 
Figure 1.1. Tidal current at spring tide as a function of inlet cross-section area derived by Escoffier (Equation (10)). The dashed line denotes a hypothetical equilibrium current for a stable inlet.

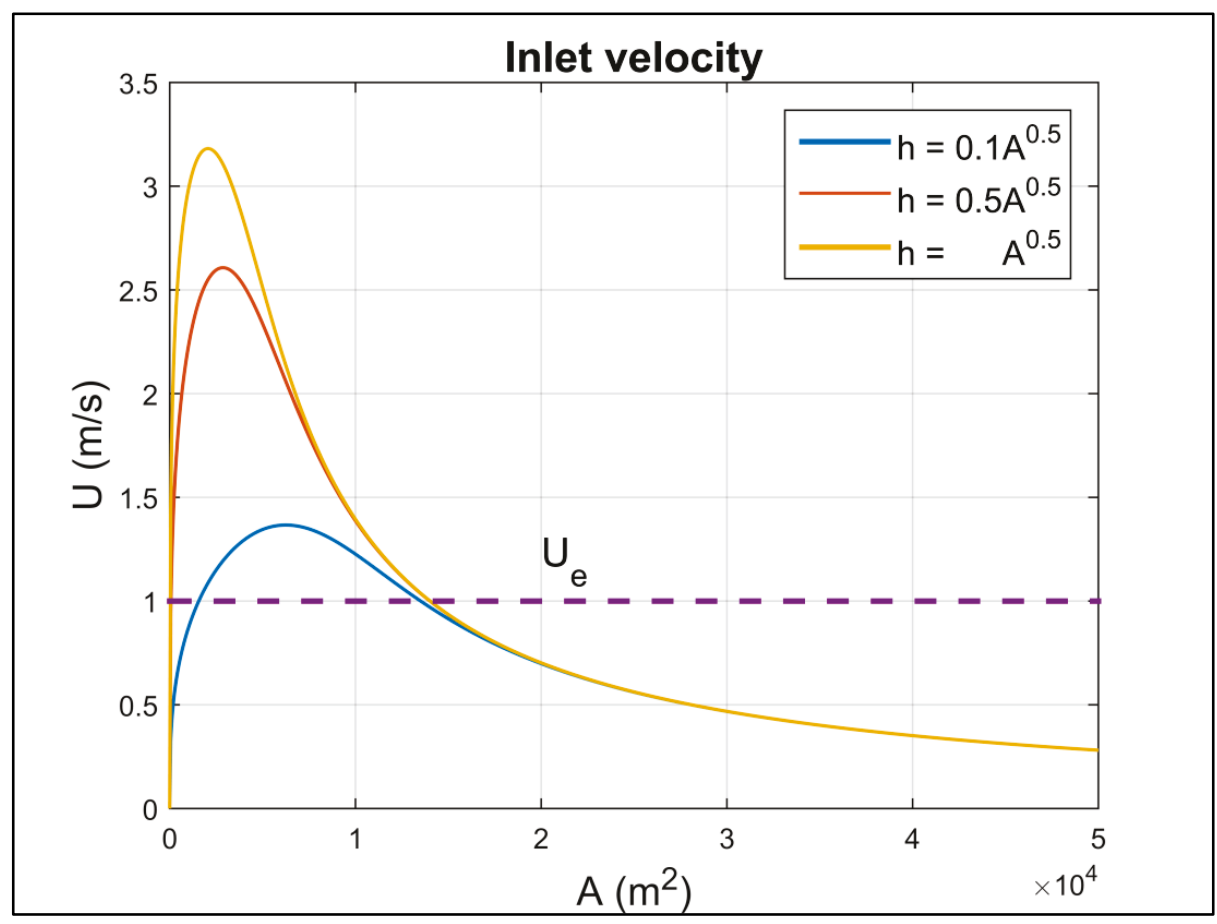

Figure 1.2. Comparison between Escoffier solution and the quadratic solution.

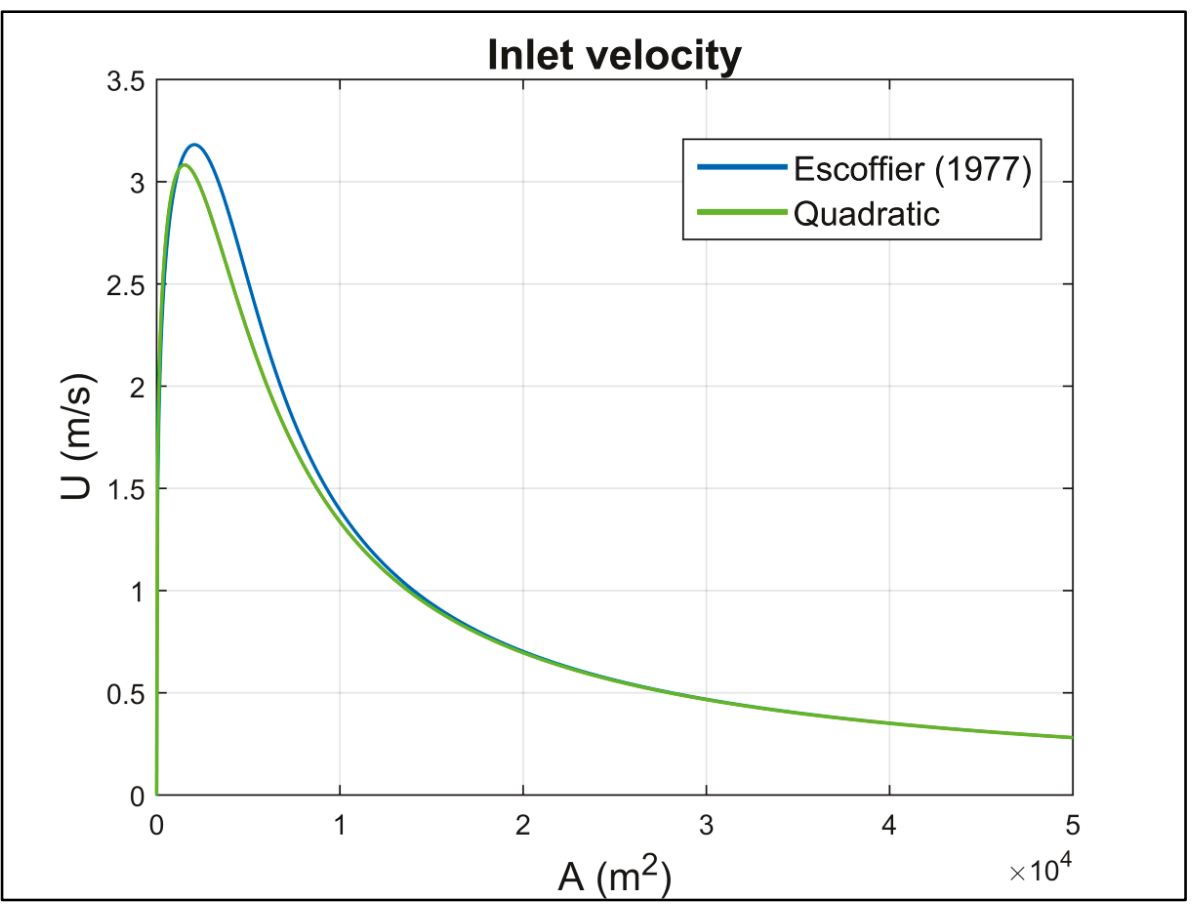




\subsubsection{Ebb tidal deltas}

Ebb tidal deltas, also referred to as ebb shoals, are common features at the seaward entrance of many tidal inlets. Major geomorphological characteristics of ebb deltas arise from differences in current patterns between flood and ebb. To the lowest order, the ebb current behaves as a free turbulent jet that diverges and weakens offshore due to flow expansion. Lateral shear of the exiting jet generates residual circulation patterns in the form of quasi-stationary cells on either side of the inlet. Near the shoreline, the inlet-directed recirculation produces a pair of marginal flood channels oblique to the axis of the inlet (Hayes 1980; Hench and Luettich Jr. 2003). The channels are deeper than the surrounding seabed and flank the terminal lobe positioned directly offshore of the inlet. In contrast, the broadly distributed radial flood currents accelerate into the inlet and exhibit uniform flow characteristics (Hench and Luettich Jr. 2003).

Reversing tidal currents, waves, sediment characteristics, and longshore transport processes can alter the size, position, and orientation of ebb deltas from the rudimentary pattern described above. Wave-driven longshore transport can generate a variety of morphological changes including reorientation of the ebb inlet in the down drift direction and distortion of the terminal lobe (Oertel 1988). Strong longshore tidal currents likewise can modify the shape, size, and orientation of the lobe as well as the inlet axis. Nonlinear tidal distortion produces asymmetries that can lead to strong currents just before the end of the ebb cycle near low tide. The strong currents extend and strengthen the flow in the ebb channel. As the tide turns (beginning the flood cycle), the exiting jet maintains some momentum and forces the early flood currents to divert to either side of the ebb channel. This is a primary mechanism responsible for establishing and maintaining the marginal flood channels (Hayes 1980).

Ebb shoal volumes tend to be larger when the ratio of tidal energy to wave energy is large and smaller when the ratio is small. In their article, "Capacity of Outer Bars to Store Sand", Walton and Adams (1976) produced a comprehensive table of ebb tidal delta volumes (as well as tidal prisms) from various sources (this source can be referenced for a comparison to computed shoal volumes analyzed in this study). Ebb shoal morphology reveals many aspects of the local hydrodynamic and sediment 
transport environment and serves as a reminder of the complex challenges faced when modeling inlet processes.

The tidal prism relationship can be used to evaluate continuity and hydrodynamic scaling, but it does not provide a metric to gauge the sediment transport processes and associated morphological evolution. Using data from 44 U.S. inlets, Walton and Adams (1976) developed an empirical relationship for ebb shoal volume with a similar functional form as the tidal prism relationship:

$$
V_{s}=a P^{b}
$$

where $V_{s}$ is shoal volume and $a$ and $b$ are constants that depend on the local wave and tidal energy regime (e.g., highly exposed, moderately exposed, or mildly exposed). They theorized that the tidal prism is a measure of the energy flux through the inlet and should correlate with the ebb shoal storage capacity.

Hicks and Hume (1996) conducted a similar analysis using 17 inlets from the New Zealand North Island coast and found the same general relationship but included a parameter to account for the angle between the outflow jet and the shoreline $(\theta)$ :

$$
V_{s}=1.37 \times 10^{-3} P^{1.32}(\sin \theta)^{1.33}
$$

where $V_{s}$ represents the average for all inlets and are measured in cubic meters.

\subsubsection{Numerical models}

The analytical treatments discussed above do not provide insight into the process-based dynamics controlling the long-term evolution of inlets. Numerical models produce quantitative predictions and have been widely used to study the morphodynamics of tidal inlet systems over long time scales. Cayocca (2001) used a two-dimensional (2D) coupled wave, current, and sediment transport model to investigate the stability and potential evolution of the Arcachon Lagoon on the French Atlantic coast. Instead of driving the model with long-term wave and current climatology records, he defined representative mean annual conditions that produced sediment transport rates consistent with field measurements. In addition 
to simulating the lagoon with present-day bathymetry, Cayocca (2001) conducted idealized simulations with an initial constant bathymetry to study long-term bay and inlet evolution. The results were consistent with historical observations and provided evidence that the lagoon was likely a stable feature under the present wave and tidal regime.

Van Leeuwen et al. (2003) developed a 2D hydrodynamic model to investigate morphological characteristics of ebb tidal deltas. The model was driven by tidal forcing only and included an idealized simulation of an inlet/bay system with substantial inlet and alongshore tidal flow. Simulations focused on ebb shoal evolution and tidal hydraulics. They noted that residual currents and tidal asymmetry were the two major mechanisms controlling sediment transport. The process of ebb shoal evolution led to two asymmetric channels that were skewed in the downdrift direction, owing to strong longshore tidal currents. In addition to the idealized model runs, they conducted long-term (500 years) simulations of Frisian Inlet in the Dutch Wadden Sea. During the first 100 years, the channel deepened rapidly, producing two asymmetric ebb shoals on the eastern and western side offshore of the wide inlet throat. Ebb shoal growth proceeded more slowly after approximately 200 years but remained asymmetric. Channel deepening continued throughout the simulation yet slowed during the last 100 years, indicating that the system had not yet reached equilibrium. They noted that the general characteristics, including the two ebb shoals, were similar to the present configuration of Frisian Inlet.

Van der Vegt et al. (2006) investigated the mechanisms responsible for creating symmetric ebb tidal deltas. To simplify the analysis, they restricted their model domain to parallel depth contours and drove the model by symmetric forcing. The inlet axis was oriented normal to the coastline, and the system was forced with a shore-normal wave field (no alongshore flow) and without Coriolis accelerations. The flow patterns consisted of a radial inflow during flood and a turbulent jet that produced a pair of symmetric shear generated eddies during ebb. The resulting morphological evolution led to an ebb channel centered in the inlet that branched offshore, producing two symmetric channels. Flow divergence led to shoaling at the end of the ebb channel, producing an ebb shoal. Sensitivity studies under varying tidal prism, inlet width, wave height, and sediment transport formulations did not produce any significant qualitative changes. Model results were used to evaluate existing power 
law formulas relating shoal volume to tidal prism and correctly predicted the slope when scaled against previous measurements. The model underestimated the total sand volume, which may be a function of the sediment transport or wave transformation formulations.

Using a 2D sediment transport model, Dissanayake et al. (2009) set up an idealized inlet system with dimensions similar to Ameland Inlet in the Dutch Wadden Sea and simulated inlet evolution for periods of 50, 100 and 300 years. The model did not include wave forcing or Coriolis force as the primary focus was to investigate inlet cross-sectional growth rates and ebb shoal delta evolution. The results showed rapid ebb shoal growth and inlet channel deepening during the first 20 years followed by a longer period of weaker development, eventually stabilizing to an equilibrium asymptote. The ebb shoal lobe and main channel orientation were rotated from a shore-normal direction in agreement with the long-shore tidal circulation patterns in the area.

Nahon et al. (2012) used a 2D hydrodynamic and morphodynamic model to examine the effects of varying tide and wave regimes on tidal inlet evolution. The model was comprised of a single idealized lagoon/inlet system without Coriolis force and was driven by a single M2 tidal constituent. The simulations included nine wave and current scenarios encompassing the range of energy conditions as classified by Hayes (1980). Model performance was measured in terms of goodness-of-fit between the model results and the tidal prism relationship of Jarrett (1976).

Yu et al. (2014) used a 2D current and morphological model to predict inlet and bay evolution over a 60-year timeframe. Their model domain consisted of nine idealized multiple-inlet barrier island configurations on a rectilinear grid with an initially uniform bathymetry in the bay and inlet. Each configuration had different spatial scales but with similar tidal forcing and non-cohesive sediments with a single grain size. They did not consider winds, waves, or Coriolis force on the assumption that tides were the primary factors contributing to bay area development and inlet crosssectional area growth. They theoretically derived a power law relating inlet cross-sectional area to total bay area, which was confirmed by the numerical simulations. 
These previous studies focused on the morphodynamics of both existing and idealized inlets with and without wave forcing or Coriolis force for varying simulation timeframes (decades to centuries). This study aims to explore the long-term (100 years) evolution of nine idealized inlet/bay systems using combined wave and tidal forcing with a $2 \mathrm{D}$ coupled waveflow-sediment transport model. To place the results in the context of realworld systems and to assess model confidence, the forcing conditions are derived from nine U.S. inlets representing a range of wave and tidal climates. 


\section{Methods}

\subsection{Inlet and bay domains}

Nine idealized inlet geometries were chosen using characteristic basin dimensions derived from coastal inlets along the U.S. East, West, and Gulf coasts (Table 2.1). Three inlet types were chosen from each of the three coastal areas to achieve a broad representation of natural inlet types and to define input parameter values and boundary conditions using realistic tide and wave forcing. The three coasts represent different energy regimes in terms of wave and tidal energy flux, with the West Coast (Grays Harbor Inlet, Washington; Mouth of the Columbia River [MCR], Washington/Oregon; and Humboldt Inlet, California) denoted as "highly exposed," the East Coast (Newburyport Inlet, Massachusetts; Shinnecock Inlet, New York; and Oregon Inlet, North Carolina) as "moderately exposed" and the Gulf Coast (Galveston Inlet, Texas; East Pass, Florida; and Johns Pass, Florida) as "mildly exposed" (Walton and Adams 1976). The realworld locations of each selected inlet are illustrated in Figure 2.1.

Figure 2.1. Map of the nine selected inlets utilized to develop representative grids modeled in this study.

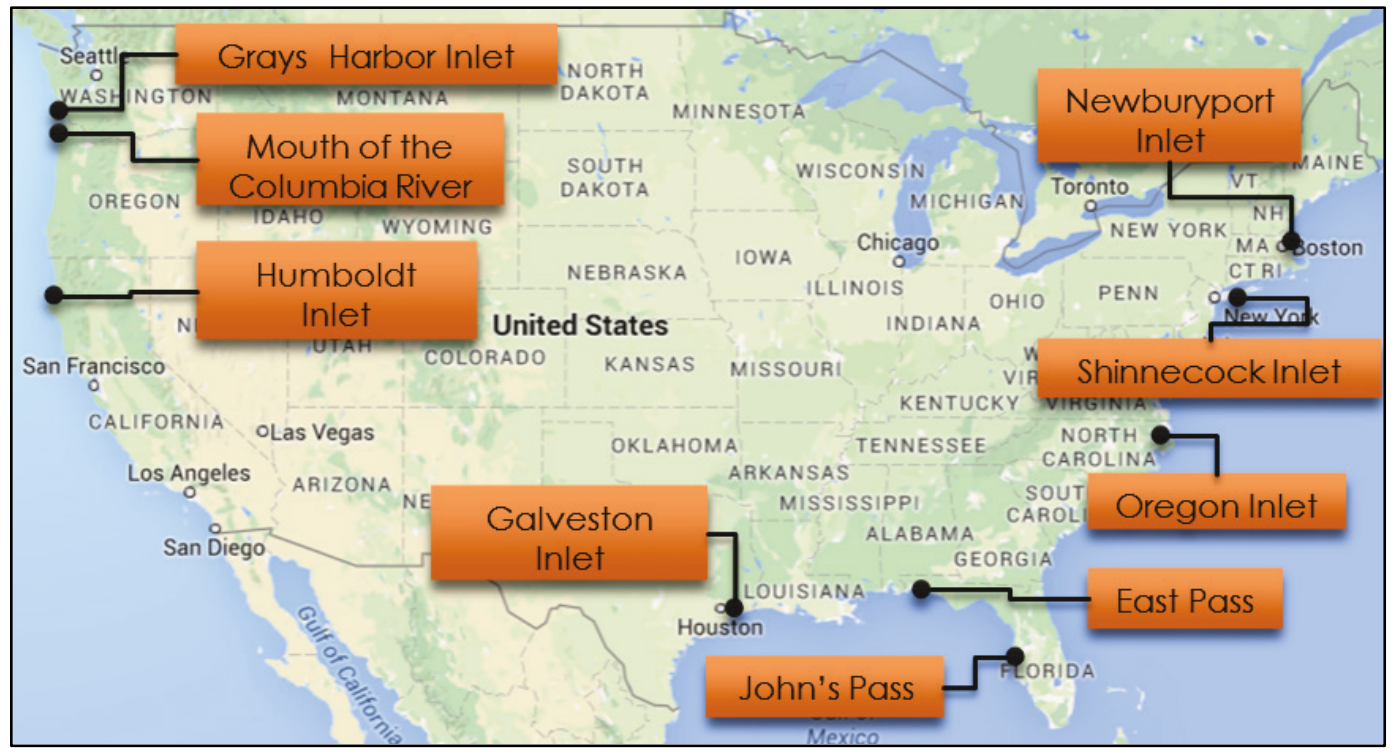

\subsubsection{Bay geometry}

For each of the representative inlet grids, the bay area is represented as a rectangular channel with the width and length chosen to approximate a natural inlet system. For example, Humboldt Inlet is a bar-built coastal 
lagoon that is longer in the alongshore direction. The idealized bay is constructed with an aspect ratio approximating the shape of Humboldt Inlet. Cusps, spits, headlands, and other morphologic features cause natural bays to differ significantly from a simple rectangular polygon. However, the primary purpose of this study is to model the long-term geomorphic evolution of inlets and their associated shoals, so the detailed bay structure is less important for evaluating model performance. Idealized inlets have simplified boundary conditions, making it easier to evaluate model sensitivity to waves, current, sediment transport, and geomorphic parameterizations. However, bay storage is critical to the hydraulics, and the idealized systems are constructed with the same area and thus storage capacity as their natural inlet counterparts. It is noted that the orientation of all of the idealized inlets is the same for ease of comparison but in actuality does not influence the results since a constant Coriolis parameter is used (i.e., $f$-plane approximation). Therefore, each inlet will be oriented symmetrically about the east-west plane, with the ocean on the left side of the grid and the bay on the right side of the grid.

\subsubsection{Bathymetry}

The initial bathymetry is uniform within the bay and inlet throat and deepens offshore following an equilibrium beach profile (Dean 1991). A single sediment grain size is used in each model domain. Initial depths and grain sizes are characteristic of their associated natural inlet, with high-energy systems typically having larger grain sizes. Table 2.1 lists the geometric characteristics of each modeled grid's setup including details about active cells in the domain and computational run time. Details of the inlet dimensions are provided from actual measurements of the real inlet system. Modified bay dimensions used to create the modeled bay are estimated from measured bay area (average bay length and width was multiplied to match bay area). Initial bay depth was determined by evaluating the average bay depths within the bays that are not indicative of shoaling or channel erosion. The distance offshore for each of the grids was determined by examining the physical location of any existing ebb shoal feature for each inlet and extending beyond that point by a certain distance so as to eliminate interaction of the ebb jet with the offshore boundary. Similarly, the alongshore width of the grid was set far enough away to eliminate any lateral boundary affects from influencing the inlet and ebb shoal areas. 
Long-term erosion and deposition patterns are dependent on the availability of sand in a system and therefore are sensitive to the initial depths of the inlet and bay. Initial depth sensitivity tests were conducted in Humboldt Inlet, and the channel depth was increased and decreased by 2 meters (m) from the base case. The simulation results indicate that the shallower inlet case corresponds to a larger shoal because of a larger sediment supply. The deeper channel case erodes to the same channel maximum depth as the other cases, the overall geomorphic patterns remain similar, but the total shoal volume and coverage area tend to be smaller at the end of the simulation due to less initial sediment supply.

Table 2.1. Geometric characteristics for each of the nine simulated inlets.

\begin{tabular}{|c|c|c|c|c|c|c|c|c|c|}
\hline \multicolumn{3}{|c|}{ West Coast } & \multicolumn{3}{|c|}{ Gulf Coast } & \multicolumn{3}{|c|}{ East Coast } & \\
\hline Inlet Length (m) & 2000 & 5700 & 6600 & 700 & 600 & 7500 & 680 & 1500 & 1500 \\
\hline Inlet Width (m) & 550 & 2200 & 3600 & 500 & 190 & 2800 & 310 & 1100 & 500 \\
\hline Inlet Depth (m) & 11.9 & 15.6 & 13.5 & 3.5 & 5.3 & 3.5 & 7.7 & 2.5 & 7.0 \\
\hline Bay Length $(\mathrm{km})$ & 22 & 15 & 10 & 47 & 5 & 30 & 13 & 80 & 6 \\
\hline Bay Width (km) & 3 & 15 & 38 & 7.4 & 3 & 42 & 3.2 & 38 & 3 \\
\hline $\begin{array}{l}\text { Initial Bay Depth } \\
\text { (m) }\end{array}$ & 3.4 & 3.4 & 5.6 & 3.5 & 1.8 & 3.5 & 2.2 & 2.5 & 1.8 \\
\hline $\begin{array}{l}\text { Offshore Length } \\
(\mathbf{k m})\end{array}$ & 12 & 32 & 44 & 15 & 6 & 50 & 13 & 36 & 12 \\
\hline $\begin{array}{c}\text { Offshore Width } \\
(\mathrm{km})\end{array}$ & 6 & 15 & 19 & 7 & 4 & 24 & 5 & 12 & 5 \\
\hline Grain Size $(\mathrm{mm})$ & 0.20 & 0.35 & 0.35 & 0.35 & 0.20 & 0.14 & 0.25 & 0.35 & 0.30 \\
\hline $\begin{array}{l}\text { Grid Cells } \\
\text { (Active) }\end{array}$ & $\begin{array}{c}17876 \\
(16936)\end{array}$ & $\begin{array}{c}17948 \\
(17128)\end{array}$ & $\begin{array}{c}25788 \\
(24842)\end{array}$ & $\begin{array}{c}25246 \\
(24236)\end{array}$ & $\begin{array}{c}19482 \\
(18636)\end{array}$ & $\begin{array}{c}16960 \\
(16108)\end{array}$ & $\begin{array}{c}19714 \\
(18864)\end{array}$ & $\begin{array}{c}29068 \\
(28078)\end{array}$ & $\begin{array}{c}16678 \\
(15878)\end{array}$ \\
\hline $\begin{array}{l}\text { Avg. Latitude } \\
\text { (degrees) }\end{array}$ & 40.7 & 46.9 & 46.2 & 30.4 & 27.7 & 29.5 & 40.8 & 35.8 & 42.8 \\
\hline Run Time & $5 \mathrm{~d}, 5 \mathrm{hr}$ & $4 \mathrm{~d}, 12 \mathrm{hr}$ & $7 \mathrm{~d}, 20 \mathrm{hr}$ & $7 \mathrm{~d}, 12 \mathrm{hr}$ & $6 \mathrm{~d}, 15 \mathrm{hr}$ & $3 \mathrm{~d}, 20 \mathrm{hr}$ & $6 \mathrm{~d}, 10 \mathrm{hr}$ & $11 \mathrm{~d}, 12 \mathrm{hr}$ & $5 \mathrm{~d}, 6 \mathrm{hr}$ \\
\hline
\end{tabular}

\subsection{Coastal Modeling System (CMS)}

The CMS is an integrated suite of numerical models for simulating water surface elevation, current, waves, sediment transport, and morphology change. The system includes representation of relevant nearshore processes, such as wetting/drying of low-lying land features and sediment avalanching and can be used for practical applications of navigation channel performance and sediment management at coastal inlets and adjacent beaches. The CMS consists of a hydrodynamic model, CMS-Flow, and a spectral wave model, CMS-Wave. CMS-Flow and CMS-Wave can be coupled through a steering module developed within the Surface-water 
Modeling System or an internal coupling process (referred to as inline coupling).

CMS-Flow is a 2D finite-volume model that solves the depth-integrated mass conservation and shallow-water momentum equations of water motion on a non-uniform Cartesian grid. Three sediment transport formulations are available in the sediment module: a sediment mass balance, an equilibrium advection-diffusion method, and a nonequilibrium advection-diffusion method. The wave radiation stress and wave field information calculated by CMS-Wave are supplied to CMS-Flow for the flow and sediment transport calculations. Currents, water level, and morphology changes are fed back to CMS-Wave to increase the accuracy of the wave transformation predictions (Sánchez and Wu 2011; Sanchez et al. 2011).

CMS-Wave is a two-dimensional spectral wave transformation model that solves the steady-state wave-action balance and diffraction equation on a non-uniform Cartesian grid (Lin et al. 2011, 2008). The model can simulate important nearshore wave processes including diffraction, refraction, reflection, wave breaking and dissipation mechanisms, wavewave and wave-current interactions, and wave generation and growth. It is a full-plane model with primary waves propagating from all open boundaries directed into the model domain. If the reflection option is selected from one open boundary, CMS-Wave will perform a backward marching scheme for the boundary reflection after the forwardingmarching calculation is completed. The fundamental wave diffraction process is theoretically developed and calculated in the wave-action balance equation. Additional model features include the grid nesting capability, wave runup, wave transmission through structures, wave overtopping, and storm wave generation.

Using a process-based morphodynamic model to conduct long-term simulations requires an intensive amount of computational time. Considering the difference in time scales between hydrodynamic and transport processes and morphological changes, the morphological acceleration factor is a reasonable tool to use for CMS simulations, in which the morphological time-step is a multiplier of a constant morphological factor and a smaller morphodynamic time-step (Lesser et al. 2004). 
The shallow water hydrodynamic equations governing a 2D, rotating, viscous fluid may be written as

$$
\begin{gathered}
\frac{\partial h}{\partial t}+\frac{\partial\left(h U_{j}\right)}{\partial x_{j}}=0 \\
\frac{\partial\left(h U_{i}\right)}{\partial t}+\frac{\partial\left(h U_{i} U_{j}\right)}{\partial x_{j}}-\varepsilon_{i j} f h U_{j}=-g h \frac{\partial \bar{\eta}}{\partial x_{i}} \\
+\frac{\partial}{\partial x_{j}}\left(v_{t} h \frac{\partial U_{i}}{\partial x_{j}}\right)-\frac{1}{\rho} \frac{\partial}{\partial x_{j}}\left(S_{i j}+R_{i j}\right)-m_{b} \frac{\tau_{b i}}{\rho}
\end{gathered}
$$

where $h$ = water depth (meters), $U_{i}=$ current velocity (meters/second), $f=$ Coriolis parameter (radians/s) equal to $2 \Omega \sin \phi$ where $\Omega$ is the angular speed (radians/s) of the earth rotation, $\rho$ is the fluid density (kilograms/meters 3 ), and $\phi=$ latitude (degrees). $\varepsilon_{i j}=1$ for $i=1$ and $j=2$, $\varepsilon_{i j}=-1$ for $i=2$ and $j=1$, and $\varepsilon_{i j}=0$ otherwise, where $i$ and $j$ subscripts denote $U$ and $V$ components, respectively. $v_{t}=$ horizontal turbulent eddy viscosity (meters $2 /$ second), $\tau_{b i}=$ wave-averaged bed shear stress (Pa), $m_{b}$ = bed slope coefficient $S_{i j}=$ wave radiation stress (Pa m), and $R_{i j}=$ surface roller stress ( $\mathrm{Pa} \mathrm{m}$ ). The governing hydrodynamic equations are solved on a Cartesian grid using a fully implicit finite-volume method. (For more details on hydrodynamic calculations, refer to Sánchez et al. [2014].)

Sediment transport is simulated using the 2D depth-averaged total-load sediment transport equation which for the case of a single grain size is given by (Sánchez and Wu, 2011)

$$
\frac{\partial}{\partial t}\left(\frac{h C_{t}}{\beta_{t}}\right)+\frac{\partial\left(h U_{j} C_{t}\right)}{\partial x_{j}}=\frac{\partial}{\partial x_{j}}\left[v_{s} h \frac{\partial\left(r_{s} C_{t}\right)}{\partial x_{j}}\right]+\alpha_{t} \omega_{s}\left(C_{t^{*}}-C_{t}\right)
$$

where $C_{t}=$ concentration of total load (kilograms $/$ meters 3 ), $. C_{t^{*}} .=$ equilibrium concentration of total load (kilograms/meters 3 ), $\alpha_{t}=$ totalload adaptation coefficient, $v_{s}=$ sediment mixing coefficient (meters $2 /$ second), $\omega_{s}=$ sediment fall velocity (meters/second), $r_{s}=$ fraction of suspended sediments, and $\beta_{t}=$ total-load correction factor. 
The total-load adaptation coefficient is calculated as $\alpha_{t}=U h /\left(L_{t} \omega_{s}\right)$, where $L_{t}$ is the total-load adaptation length (meters). The correction factor, $\beta_{t}$, accounts for the vertical distribution of the suspended sediment concentration and velocity profiles, as well as the fact that bed load usually travels in a velocity slower than the depth-averaged current velocity. By definition $\beta_{t}$ is the ratio of the depth-averaged total-load and flow velocity. The bed change is calculated as

$$
\rho_{s}\left(1-p_{m}^{\prime}\right) \frac{\partial z_{b}}{\partial t}=\alpha_{t} \omega_{s}\left(C_{t}-C_{t^{*}}\right)+\frac{\partial}{\partial x_{j}}\left(D_{s} q_{b} \frac{\partial z_{b}}{\partial x_{j}}\right)
$$

where $\rho_{s}=$ sediment density (kilograms/meters 3 ), $p_{m}^{\prime}=$ bed porosity, $z_{b}$ = bed elevation (meters), $D_{s}=$ empirical bed-slope coefficient (constant), $q_{b}=h U C_{t}\left(1-r_{s}\right)=$ bed load mass transport rate (kilograms/meter/second). It is noted that the CMS is capable of simulating multiple grain sizes but for simplicity this feature is not utilized in this study and is left for future work. The sediment transport equations are solved using a fully implicit finite-volume method on the same grid and the same time-step as the hydrodynamic equations. (For more details of the of the sediment transport model, refer to Sánchez et al. [2014].)

CMS-Wave is based on the wave-action balance equation as

$$
\frac{\partial\left(C_{x} N\right)}{\partial x}+\frac{\partial\left(C_{y} N\right)}{\partial y}+\frac{\partial\left(C_{\theta} N\right)}{\partial \theta}=\frac{\kappa}{2 \sigma}\left[\left(C C_{g} \cos ^{2} \theta N_{y}\right)_{y}-\frac{C C_{g}}{2} \cos ^{2} \theta N_{y y}\right]-\varepsilon_{b} N-S
$$

where $C$ and $C_{g}$ represent the wave celerity and the group velocity, respectively, $x$ and $y$ are the horizontal coordinates, $C_{x}, C_{y}$, and $C_{\theta}$ are the characteristic velocity with respect to $x, y$, and, $\theta$, respectively, $N_{y}$ and $N_{y y}$ denote the first and second derivatives of $N$ with respect to $y$, respectively, $\kappa$ is an empirical parameter for the intensity of diffraction effect, $\varepsilon b$ is the parameter for wave breaking energy dissipation, $S$ is the sum of $S_{\text {in }}$ (additional source term), $S_{d s}$ (sink term, wind forcing, bottom friction, etc.), and $S_{n l}$ (nonlinear wave-wave interaction term),

$$
N=\frac{E(\sigma, \theta)}{\sigma}
$$


is the wave-action density and is a function of frequency $\sigma$ and direction $\theta$. $E(\sigma, \theta)$ is spectral wave density representing the wave energy per unit water-surface area per frequency and direction interval (Lin et al. 2008).

\subsubsection{Time-step calculations}

The CMS uses multiple time-steps when calculating a solution. A hydrodynamic time-step is used for all calculations except those pertaining to some aspect of sediment transport. Sediment transport calculations and bed change each have a separate time-step that can be assigned when those processes are active. Hydrodynamic time-step values vary dependent on the chosen solution scheme. The explicit scheme typically uses timestep values of 2 seconds (sec) or less while the implicit scheme values generally range from $60 \mathrm{sec}$ to 1 hour (hr).

The two time-step values associated with sediment transport should be multiples of the selected hydrodynamic time-step or could be assigned the same value. Because the hydrodynamic time-step used in the implicit solution scheme is much larger, the CMS applies that value also to the sediment transport and morphologic update time-step effectively using one common time-step for all processes. The implicit solution scheme was chosen to be applied in all model runs for this project using a time-step value of 450 or $600 \mathrm{sec}$ as needed for run stability.

\subsubsection{Morphological acceleration factor}

The intent of this study is to simulate 100 years of morphologic evolution in various energy environments similar to regimes around the United States. The computational time to simulate 100 years of morphologic evolution for each case using the typical approach would be excessive. The CMS can implement a morphological acceleration factor (MAF), which has the effect of simulating morphology change at an accelerated rate. For example, a simulation with a duration of 5 years and an acceleration factor of 20 would produce 100 years of effective sediment transport with the computational time associated with only 5 years of simulation time.

In these simulations, hydrodynamics, sediment transport, and morphology change were computed every 450 or 600 sec. Calculated morphologic changes at the morphodynamic time-step are then multiplied by the selected MAF, and the bathymetry within both the wave and flow 
grids are updated. This approach is repeated at each morphologic timestep as specified in the parameter file.

Five sensitivity tests were conducted on the Humboldt grid setup to determine the largest MAF value that produced qualitatively comparable results to using no acceleration factor. These test cases were run for an effective 10-year period depending on the assigned MAF values of 1, 2, 5, 10, and 20. For example, for an MAF value of 1 , the test case was run for 10 years, and for an MAF value of 10, the test case was run for 1 year. Figure 2.2 shows a comparison of MAF of 1, 10, and 20. The red ovals identify areas that were relatively consistent until the MAF value of 20 was selected at which time it was determined that, to maintain consistency in this idealized-inlet study, an MAF value of 10 would be used for each of the cases simulated.

Figure 2.2. Comparison of MAF values of 1, 10, and 20. Red ovals indicate areas of observed qualitative change.

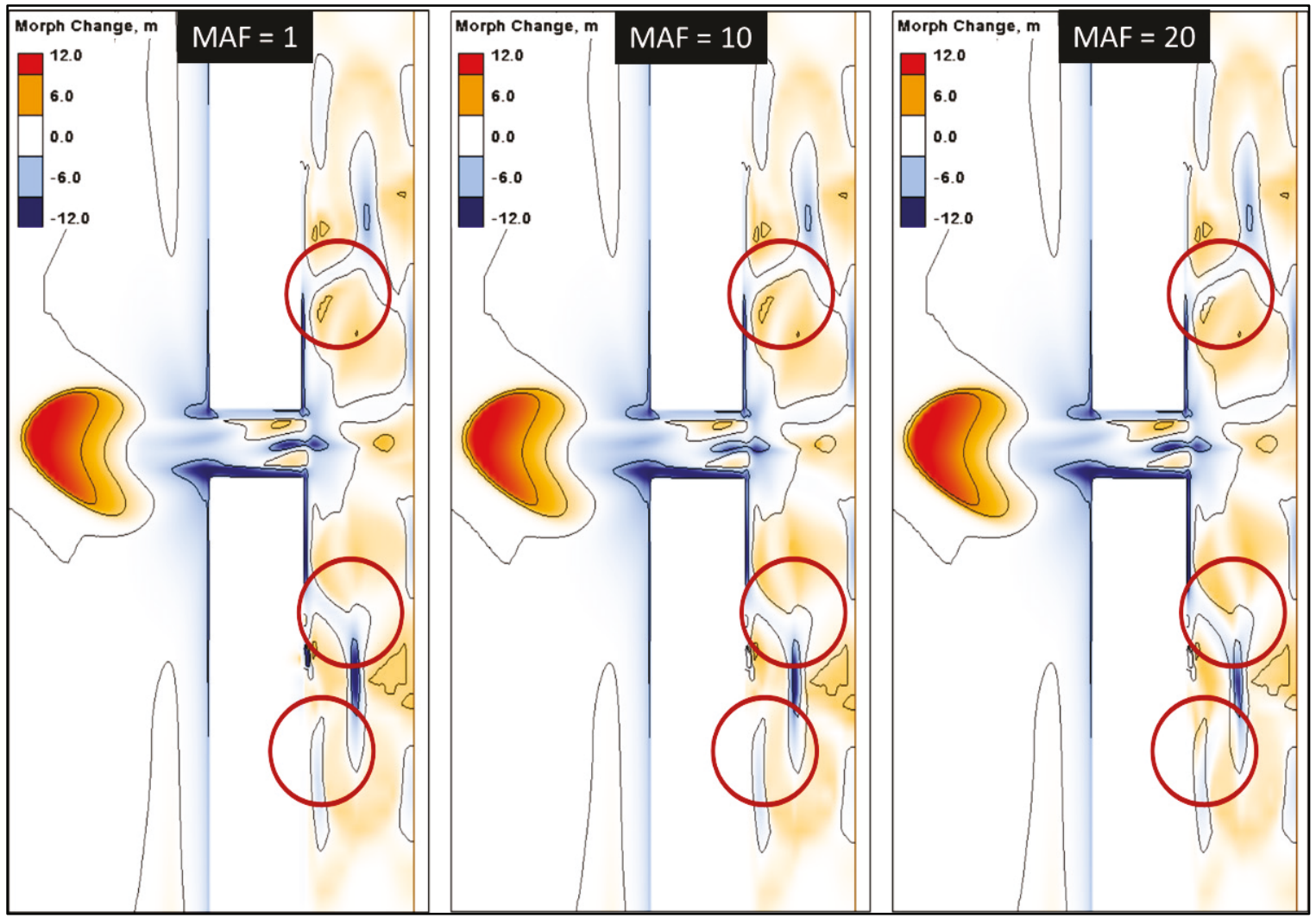




\subsection{Model input and boundary conditions}

\subsubsection{Tidal forcing}

Amplitude and phase of tidal constituents were extracted from the National Oceanic and Atmospheric Administration tide data base for the nine inlet areas. A total of 13 tidal constituents were used to reconstruct the tidal time series for each region (Table 2.2). Tidal characteristics vary widely between study sites in both amplitude, phase, and dominant constituents. The West and East Coast have the largest tidal range and are dominated by the M2 (semi-diurnal) tidal constituent while the Gulf Coast has the lowest tidal range and is dominated by the K1 and O1 (diurnal) tidal constituents. The thirteen constituents used for this study represent some of the largest tidal amplitudes for each given inlet area. The water surface elevation time series generated from these constituents does not include the 18.6-year lunar nodal cycle, which produces an average 4\% change in mean tidal range and can affect velocities in an inlet throat as the larger tidal range increases tidal prism and associated discharge (Wang and Townend 2012). The 100-year simulation timeframe exceeds the nodal frequency, so the latter is regarded as a finite or limited perturbation in duration and is not expected to significantly affect the results. Furthermore, the initial conditions comprise a flat featureless bottom and evolve to a deep channel with associated shoals, so the net morphological change is very large compared to perturbations induced by nodal tide fluctuations. 
Table 2.2. Tidal constituents used in numerical modeling of the nine idealized inlets.

\begin{tabular}{|c|c|c|c|c|c|c|c|c|c|c|}
\hline \multirow{2}{*}{ M2 } & Amp & 0.700 & 0.985 & 0.929 & 0.116 & 0.246 & 0.440 & 1.169 & 0.032 & 0.138 \\
\hline & Phase & 215.1 & 240.7 & 250.6 & 282.1 & 123.1 & 353.6 & 115.7 & 90.3 & 16.2 \\
\hline \multirow{2}{*}{ S2 } & Amp & 0.175 & 0.270 & 0.249 & 0.029 & 0.096 & 0.090 & 0.165 & 0.016 & 0.023 \\
\hline & Phase & 236.6 & 271.3 & 278.5 & 297.5 & 141.0 & 22.7 & 153.0 & 97.3 & 37.1 \\
\hline \multirow{2}{*}{ N2 } & Amp & 0.148 & 0.203 & 0.188 & 0.032 & 0.046 & 0.099 & 0.239 & 0.006 & 0.030 \\
\hline & Phase & 190.5 & 217.9 & 226.8 & 257.7 & 120.3 & 338.9 & 85.6 & 105.6 & 358.5 \\
\hline \multirow{2}{*}{ K1 } & Amp & 0.401 & 0.425 & 0.415 & 0.142 & 0.158 & 0.065 & 0.130 & 0.142 & 0.030 \\
\hline & Phase & 233.4 & 244.0 & 248.4 & 37.3 & 12.4 & 172.0 & 211.2 & 19.1 & 188.7 \\
\hline \multirow{2}{*}{ M4 } & Amp & 0.012 & 0.026 & 0.015 & 0.003 & 0.009 & 0.0 & 0.010 & 0.0 & 0.0 \\
\hline & Phase & 200.6 & 210.0 & 245.9 & 277.0 & 76.0 & 46.0 & 133.0 & 318.1 & 344.8 \\
\hline \multirow{2}{*}{01} & Amp & 0.249 & 0.259 & 0.260 & 0.128 & 0.151 & 0.039 & 0.104 & 0.137 & 0.018 \\
\hline & Phase & 217.2 & 228.4 & 232.5 & 36.9 & 3.600 & 174.7 & 194.2 & 10.7 & 193.3 \\
\hline \multirow{2}{*}{ NU2 } & Amp & 0.029 & 0.041 & 0.032 & 0.006 & 0.010 & 0.019 & 0.046 & 0.001 & 0.006 \\
\hline & Phase & 194.5 & 218.6 & 230.0 & 260.9 & 121.6 & 340.9 & 89.6 & 103.5 & 8.1 \\
\hline \multirow{2}{*}{ SSA } & Amp & 0.038 & 0.000 & 0.052 & 0.086 & 0.037 & 0.028 & 0.018 & 0.050 & 0.026 \\
\hline & Phase & 264.100 & 0.0 & 184.100 & 55.600 & 48.2 & 42.900 & 89.8 & 70.1 & 10.5 \\
\hline \multirow{2}{*}{ SA } & Amp & 0.065 & 0.126 & 0.111 & 0.066 & 0.091 & 0.067 & 0.032 & 0.095 & 0.046 \\
\hline & Phase & 255.0 & 289.6 & 307.200 & 155.700 & 151.9 & 129.1 & 126.3 & 160.1 & 158.9 \\
\hline \multirow{2}{*}{ Q1 } & Amp & 0.044 & 0.045 & 0.044 & 0.025 & 0.032 & 0.007 & 0.020 & 0.030 & 0.007 \\
\hline & Phase & 211.3 & 222.400 & 225.000 & 36.700 & 348.0 & 175.600 & 185.800 & 357.8 & 200.4 \\
\hline \multirow{2}{*}{ P1 } & Amp & 0.126 & 0.131 & 0.124 & 0.047 & 0.053 & 0.021 & 0.043 & 0.045 & 0.013 \\
\hline & Phase & 231.2 & 239.9 & 246.8 & 37.300 & 12.5 & 172.200 & 209.9 & 20 & 216.6 \\
\hline \multirow{2}{*}{ L2 } & Amp & 0.016 & 0.030 & 0.027 & 0.003 & 0.007 & 0.012 & 0.033 & 0.001 & 0.005 \\
\hline & Phase & 225.2 & 243.1 & 267.5 & 306.5 & 143.1 & 8.3 & 145.9 & 75.0 & 35.6 \\
\hline \multirow{2}{*}{ K2 } & Amp & 0.047 & 0.072 & 0.070 & 0.008 & 0.027 & 0.025 & 0.045 & 0.004 & 0.005 \\
\hline & Phase & 228.3 & 264.3 & 271.2 & 298.7 & 134.6 & 25.0 & 156.1 & 97.2 & 33.5 \\
\hline
\end{tabular}

\subsubsection{Wave forcing}

Wave data is derived from the Wave Information Studies (WIS; http://wis.usace.army.mil) database maintained by the CHL. The WIS data comprise a network of virtual buoys located along all U.S. coasts including the Great Lakes and other U.S. island territories. The database maintains long-term ( 35 years) hindcast model predictions of wave conditions that can be used for climate studies and that can drive coupled wave/current circulation models. The WIS data include estimates of directional spectra, significant wave height, peak period, average period, and direction. Table 2.3 lists the WIS stations used to drive the CMS-Wave for each of the nine simulated inlets. 
Table 2.3. WIS hindcast station locations and characteristics for each of the nine simulated inlets.

\begin{tabular}{|c|c|c|c|c|c|c|c|c|c|c|}
\hline \multirow[b]{2}{*}{ Location } & \multirow[b]{2}{*}{$\begin{array}{l}\text { WIS } \\
\text { Station } \\
\text { ID }\end{array}$} & \multirow[b]{2}{*}{ Year } & \multicolumn{4}{|c|}{ Mean of Selected Year } & \multicolumn{4}{|c|}{ Mean of 42-Year Record } \\
\hline & & & $H_{s}(m)$ & $\mathrm{T}_{\mathrm{p}}(\mathbf{s})$ & $\mathrm{T}_{\mathrm{a}}(\mathbf{s})$ & $\begin{array}{c}\Theta \\
(\operatorname{deg})\end{array}$ & $H_{s}(m)$ & $T_{p}(\mathbf{s})$ & $\mathrm{T}_{\mathrm{a}}(\mathbf{s})$ & $\begin{array}{c}\Theta \\
(\mathrm{deg})\end{array}$ \\
\hline Grays Harbor & 83011 & 1996 & 2.2 & 10.8 & 8.3 & 272 & 2.2 & 11.0 & 8.4 & 273 \\
\hline MCR & 83015 & 1996 & 2.3 & 10.8 & 8.3 & 276 & 2.3 & 10.9 & 8.4 & 278 \\
\hline Humboldt & 83047 & 1980 & 2.5 & 11.0 & 8.6 & 298 & 2.4 & 11.0 & 8.5 & 298 \\
\hline Galveston & 73074 & 1985 & 0.5 & 4.8 & 4.3 & 136 & 0.5 & 4.8 & 4.3 & 136 \\
\hline East Pass & 73176 & 2009 & 0.5 & 4.7 & 4.4 & 185 & 0.4 & 4.7 & 4.4 & 177 \\
\hline Johns Pass & 73293 & 1994 & 0.3 & 4.3 & 4.1 & 228 & 0.3 & 4.5 & 4.2 & 234 \\
\hline Oregon Inlet & 63223 & 2009 & 1.3 & 8.4 & 6.9 & 92 & 1.2 & 8.4 & 6.8 & 91 \\
\hline Shinnecock & 63108 & 1989 & 1.0 & 8.2 & 6.8 & 123 & 1.0 & 8.1 & 6.8 & 124 \\
\hline Newburyport & 63045 & 2004 & 0.7 & 7.9 & 6.5 & 105 & 0.7 & 8.1 & 6.8 & 110 \\
\hline
\end{tabular}

Additionally, Table 2.3 lists the determination of degree of wave exposure by Walton and Adams (1976), which will determine how some empirical equations are applied in the analysis of tidal prism as it relates to ebb shoal volume. This referenced characterization reflects the average wave energy listed in Table 2.3.

Without 100 years of wave data for the model, a method was developed to characterize the wave processes controlling inlet evolution and stability without requiring wave data from an arbitrary, or selective, timeframe (i.e., the last 30 years). Using a selective timeframe such as the full 32-year WIS dataset will introduce perturbations in the long term that can affect morphologic processes captured even at the longer time scales induced by the MAF. If the 32-year dataset were duplicated for a full 100 years, then it would include patterns in storminess that were not inclusive of a realistic 100-year suite of return period storms. The climatologic effects observed in the WIS dataset would skew the morphological impact on a mediumterm time scale (one third of the simulation time); thus, utilizing the full 32-year dataset was determined to be too disproportionate of a variable to include in these idealized simulations. In addition to this reasoning for the removal of storms as a variable, it was determined that the development of a storms database for each site was considered to be outside of the scope of this study. Wave climatology for the inlets is presented in Appendix A. 
Wave driven longshore transport is a primary contributing factor to tidal inlet stability (Kraus 1998). Given that the purpose of this study is to investigate the morphological evolution of tidal inlets, it is more important for the model to capture the general sediment transport processes at inlets as opposed to storm and beach processes driven by detailed wave data. As such, the WIS data were used in this study to drive 1 year of simulated waves in CMS-Wave that would produce the average long-term longshore sediment transport rate for each inlet region. The 1-year time series for each inlet is depicted in Appendix B.

Longshore sediment transport rate $(Q)$ is predicted using the Coastal Engineering Research Center (CERC) formula

$$
Q=k\left(\frac{\rho \sqrt{g}}{16 \sqrt{\gamma}\left(\rho_{s}-\rho\right)\left(1-p_{m}^{\prime}\right)}\right) H_{b r}^{2.5} \sin \left(2 \theta_{b r}\right)
$$

where $k$ is a constant ( $=0.39), \gamma$ is the breaker index ( $=0.78), H b r$ is the wave height at breaking, and $\theta_{b r}$ is the wave angle at breaking (Rosati et al. 2002). Transport rate is in cubic meters per second, and the model is run using hourly WIS hindcast wave height and direction predictions between 1 January 1980 and 31 December 2011 (32 years). The average yearly transport rate that is in closest agreement with the transport rate for the full record was used in the CMS Wave simulations (Appendix A). In this way, the CMS Wave model can be run by repeating only a single year wave time series, which ensures that the average longshore transport rate is essentially captured by the shorter 1-year record. The sediment transport rate predicted from the single year wave time series is representative of the much longer 32-year record, providing a longshore sediment transport climatology for the long-term simulations.

CMS Wave reads the directional spectra output files from WIS. The directional spectra are integrated over the shore-normal half plane to remove locally generated wave energy propagating offshore. Otherwise, the total wave energy reaching the shoreline, and associated long-shore sediment transport, would be overestimated. Extracting a single year time series for the 100-year simulations produces a discontinuity in the wave record between hour 24 on December 31 and hour 1 on January 1. During the last $6 \mathrm{hr}$ of December and the first $6 \mathrm{hr}$ of January, the spectra are tapered using a weighting function to eliminate sharp discontinuities that could produce model instabilities. While data tapering artificially modifies 
the spectra, it is applied only a half day per year, so statistically this represents $0.1 \%$ of the record and has negligible effect on the results.

\subsection{Model validation}

Wave, current, and inlet morphological evolution data are not available for the 100-year timeframe this study encompasses, so model calibration is conducted using established empirical formulations that describe the longterm equilibrium characteristics of tidal inlets. The simulations are designed to predict inlet stability including equilibrium inlet crosssectional area, so one of the factors used to assess model performance is the tidal prism relationship. Plotting the inlet cross-sectional area as a function of tidal prism for the nine U.S. inlets shows good agreement with Equation (1) with a coefficient of determination of 0.97 (Figure 2.1). Given that the idealized bays are constructed with the same dimensions as their natural bay counterparts, the benchmark for assessing CMS inlet modeling performance is the tidal prism relationship.

Figure 2.1. Tidal prism relationship for the nine U.S. inlets used to define the input and boundary conditions for the idealized inlets. Inlet cross section and prisms vary by two orders of magnitude providing a broad representation of typical U.S. inlets. The parameter values for the best fit are $n=0.93$ and $C=2.0 \times 10^{-4}$.

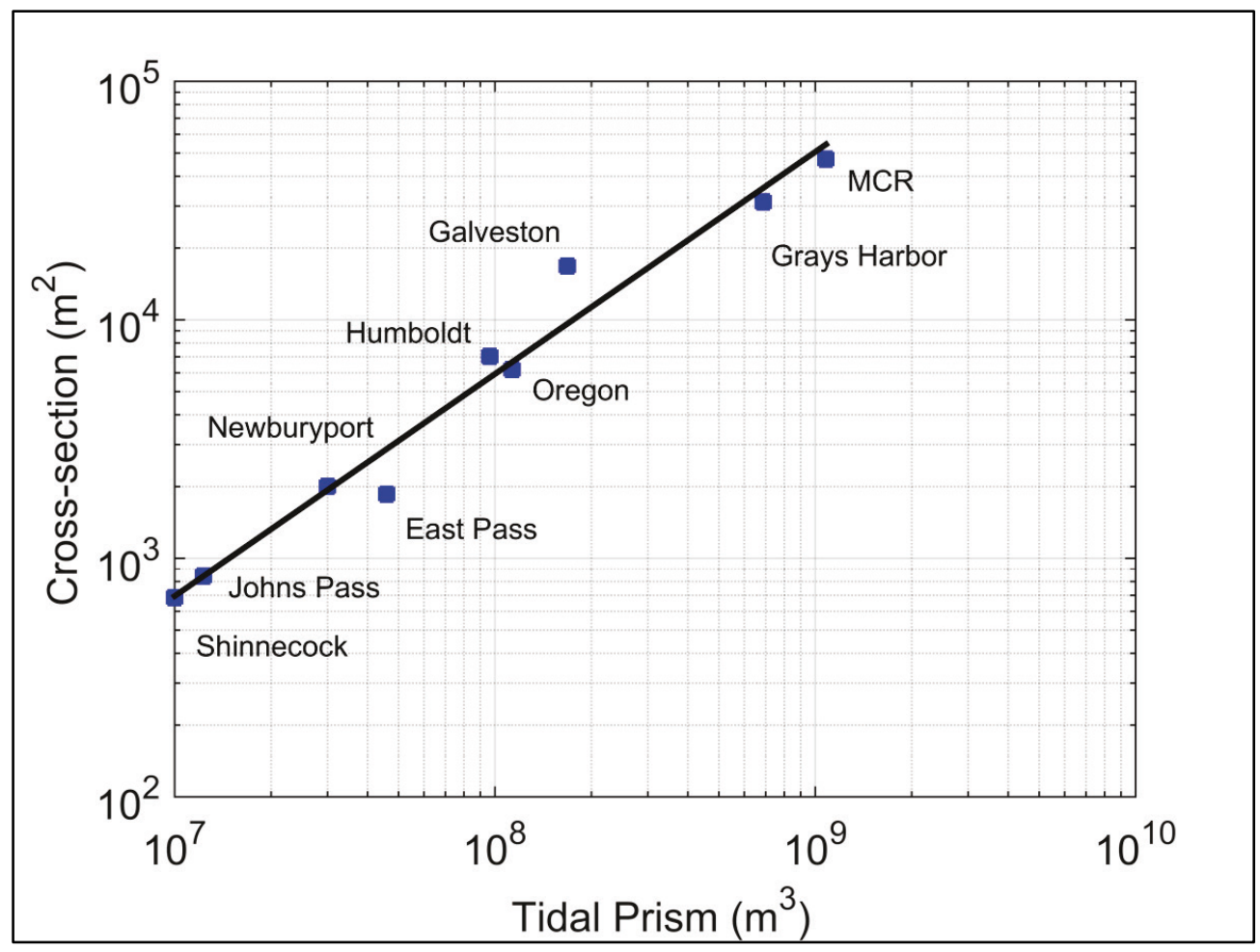


Specifically, each modeled simulation will be analyzed for comparison on the following validation characteristics:

- Morphology: Resultant bed change, inlet cross-section plots, and general geomorphic characteristics are discussed. Cross-sectional plots from the ocean-side, inlet midpoint, and bay-side positions are plotted, and the central cross section is used in cross-sectional area to prism analyses. Bed change for the ebb shoal (ocean side), inlet channel (area between inlet ocean and bay cross-sections), and the entire bay is plotted to evaluate trends in volumetric change.

- Hydrodynamics: Spatial currents for the ebb and flood cycles are detailed focusing on the average and peak average tidal currents at the midpoint of the inlet. Volume flux and tidal prism are computed at the midpoint of the inlet, and water surface elevation differences between the ocean and bay are plotted and discussed.

- Comparison with Empirical Formulas: Equations (1), (14), and (15) provide empirical solutions that are used to gauge the accuracy of longterm inlet morphodynamics computed by the CMS. The Escoffier analysis of inlet stability is also discussed in terms of tidal inlet equilibrium theory. 


\section{Model Results}

The results focus on different aspects of model performance including hydrodynamics, morphology, and validation. Each inlet was considered separately to highlight the effects of varying tide, waves, and bay geometries. Inter-comparisons highlighting commonalities are presented at the end of this section.

Each model is run for 100 years using the input wave and current conditions described above. The MAF was set to 10, meaning the bed change per morphologic time-step is multiplied by 10 . The designed model run time was 10 years, but with the acceleration factor the bed change represents 100 years of simulation.

Variably spaced CMS-Flow and CMS-Wave grids were used to improve model efficiency by reducing the total number of grid cells. The finest resolution was in the inlet and adjacent ocean and bay areas, where the greatest morphological change occurs. Velocity gradients are also greater near the inlet, and the finer resolution is needed to resolve the flow field and sediment transport patterns. Grid and model domain metrics are presented as each model is introduced. Inlet cross sections are presented with the $y$-axis oriented alongshore and the channel centerline as the zero. Looking oceanward, $y$-positive is to the right, and $y$-negative is to the left of the channel centerline. Morphology is described in terms of "northerly right" ( $y$-positive) and "southerly left" ( $y$-negative) as this convention is uniform for all grids. Note that the real-world inlets have various orientations that do not conform to this idealized convention; however, generally speaking, the left-right convention does describe the overall behavior of the morphology found in real-world settings because the model setup does utilize real-world oriented tidal and wave forcing.

\subsection{Grays Harbor inlet}

The model grid for the Grays Harbor idealized inlet/bay system is depicted in Figure 3.1. The bay width and length is 3.0 kilometers $(\mathrm{km})$ and 21.6 $\mathrm{km}$, respectively, and the initial depth of the system is $3.4 \mathrm{~m}$. Bay width and length are chosen to produce a rectangle equal in area to that of Grays Harbor. The depth contours offshore are straight and parallel and follow an equilibrium beach profile near the shoreline. Water depth is constant within the throat and bay and tapered at the ocean side to match the 
offshore depths. The bay depth is based upon average bathymetric conditions for Grays Harbor.

Figure 3.1. CMS grid and bathymetry for idealized Grays Harbor simulation.

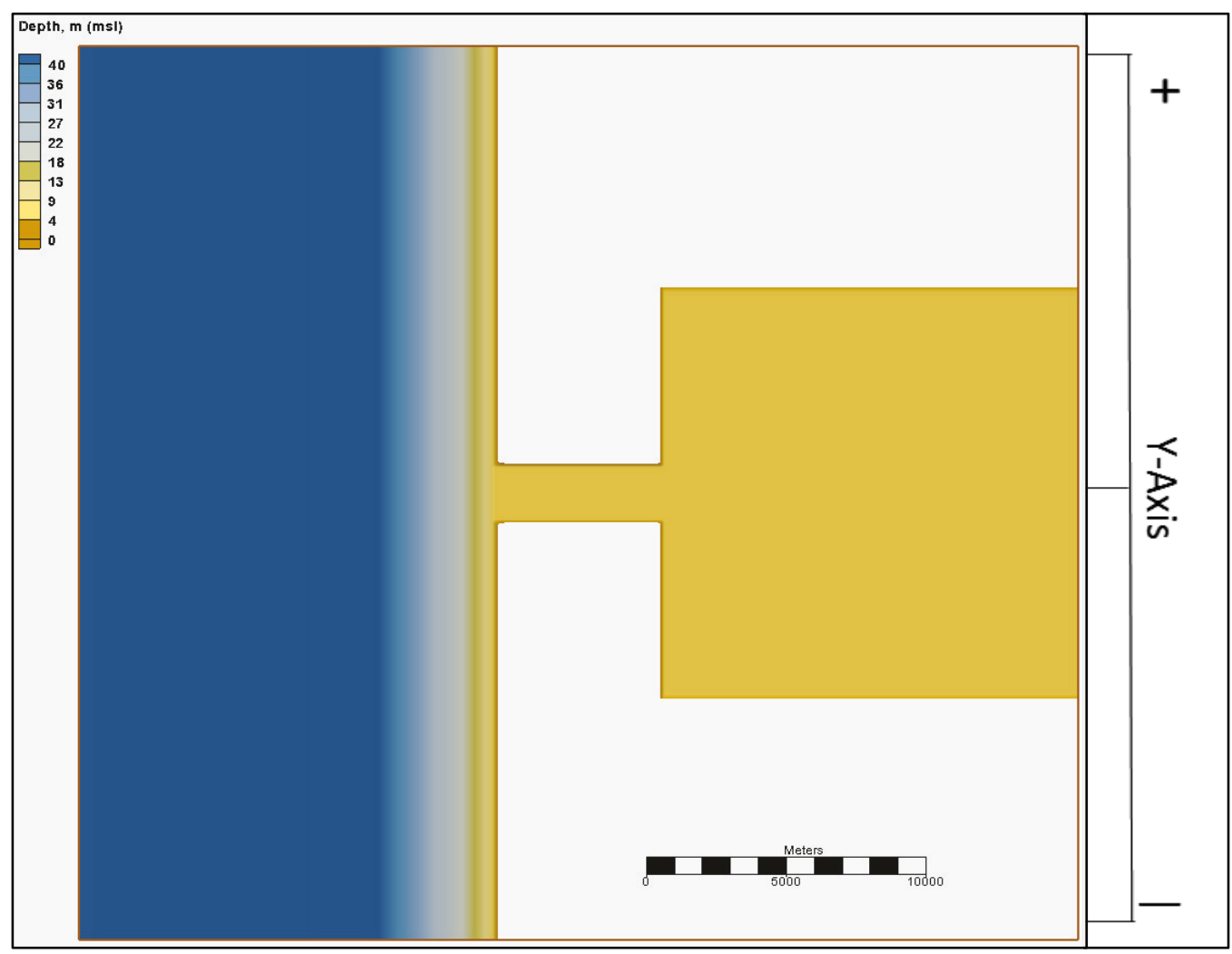

\subsubsection{Morphology}

The final morphological evolution is depicted in Figure 3.2. The ebb shoal extends approximately $5 \mathrm{~km}$ up and $8 \mathrm{~km}$ down the coast and $5 \mathrm{~km}$ offshore. The lobe is skewed and elongated alongshore in the negative $y$ direction (i.e., southward) due to the wave-generated longshore transport. There are two marginal flood channels on either side of the lobe with the southerly channel also serving as the main ebb channel.

The orientation and depth of the channel varies along the inlet throat. The channel forms a pair of alternating scour holes on opposite ends of the inlet separated by a shallower region in the middle. The deepest sections are near the sides of the inlet as opposed to aligning with the centerline. The channel extends seaward of the inlet and turns southward. The bay has evolved into a series of incised tidal channels distributed into random patterns of elongated fingers. Initially, the channels form near the landward end of the inlet as the alternating current digs grooves that 
extend into the bay. Once an initial scour depression has formed, the tidal flow concentrates along the depression parallel to the inlet axis. This in turn widens and lengthens the depression into a series of finger-like channels that extend deep into the bay.

Figure 3.2. Final depth for Grays Harbor after 100-year simulation. White areas shown inside the bays denote computational areas that were dry (above the water level) at the end of the simulation.

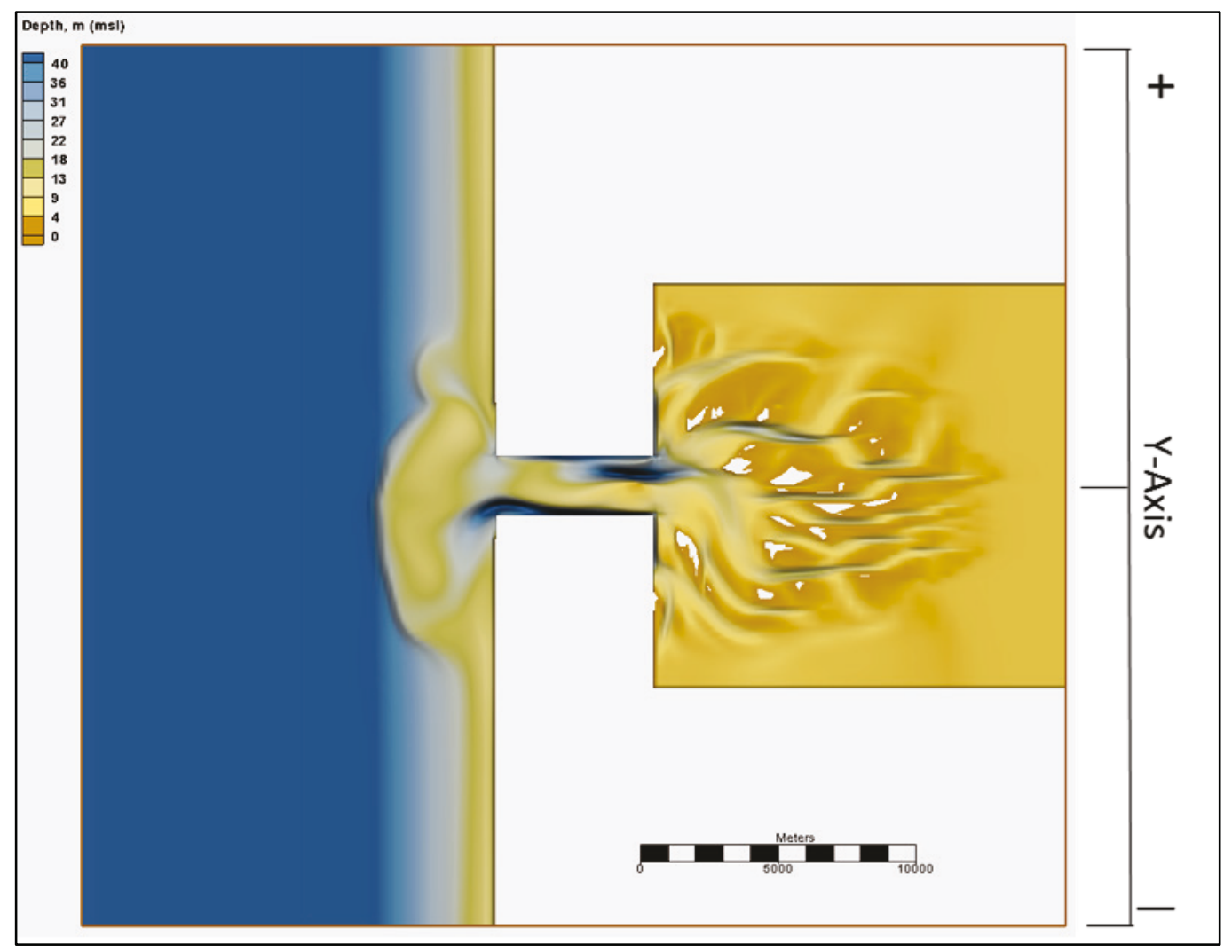

Figure 3.3 depicts the temporal evolution of the cross-sectional area at the ocean, midpoint, and bay side of the inlet. The process of bed deepening on the ocean side is relatively uniform, but the rate is greatest along the southern or left bank of the inlet (negative $y$-axis). The main channel deepening at the ocean side of the inlet occurs more rapidly during the first 40 years, reaching approximately $40 \mathrm{~m}$, and then occurs more slowly reaching only $55 \mathrm{~m}$ by the end of the simulation. Initially, deepening at the inlet midpoint occurs near the centerline, but by 60 years, the channel becomes asymmetric with the deepest portion migrating towards the positive (northern) side of the inlet. The process of bed deepening is dissimilar for the bay side with a deep channel forming on the positive (northern) side of the inlet. The channel continues to deepen throughout the simulation reaching $\sim 50 \mathrm{~m}$ at 100 years. Although the ebb shoal has 
not fully reached equilibrium, the rate of change of inlet channel morphology has slowed substantially by 100 years of simulation. This decrease in change allows for the comparison with the empirical inlet velocity and cross-sectional area equations.

Figure 3.3. CMS-predicted temporal evolution of cross-sectional area at the ocean (top), midpoint (middle), and bay (bottom) sides of the inlet. Distances are alongshore from channel centerline with positive towards the right looking oceanward (updrift for Grays Harbor) and negative towards the left (downdrift).
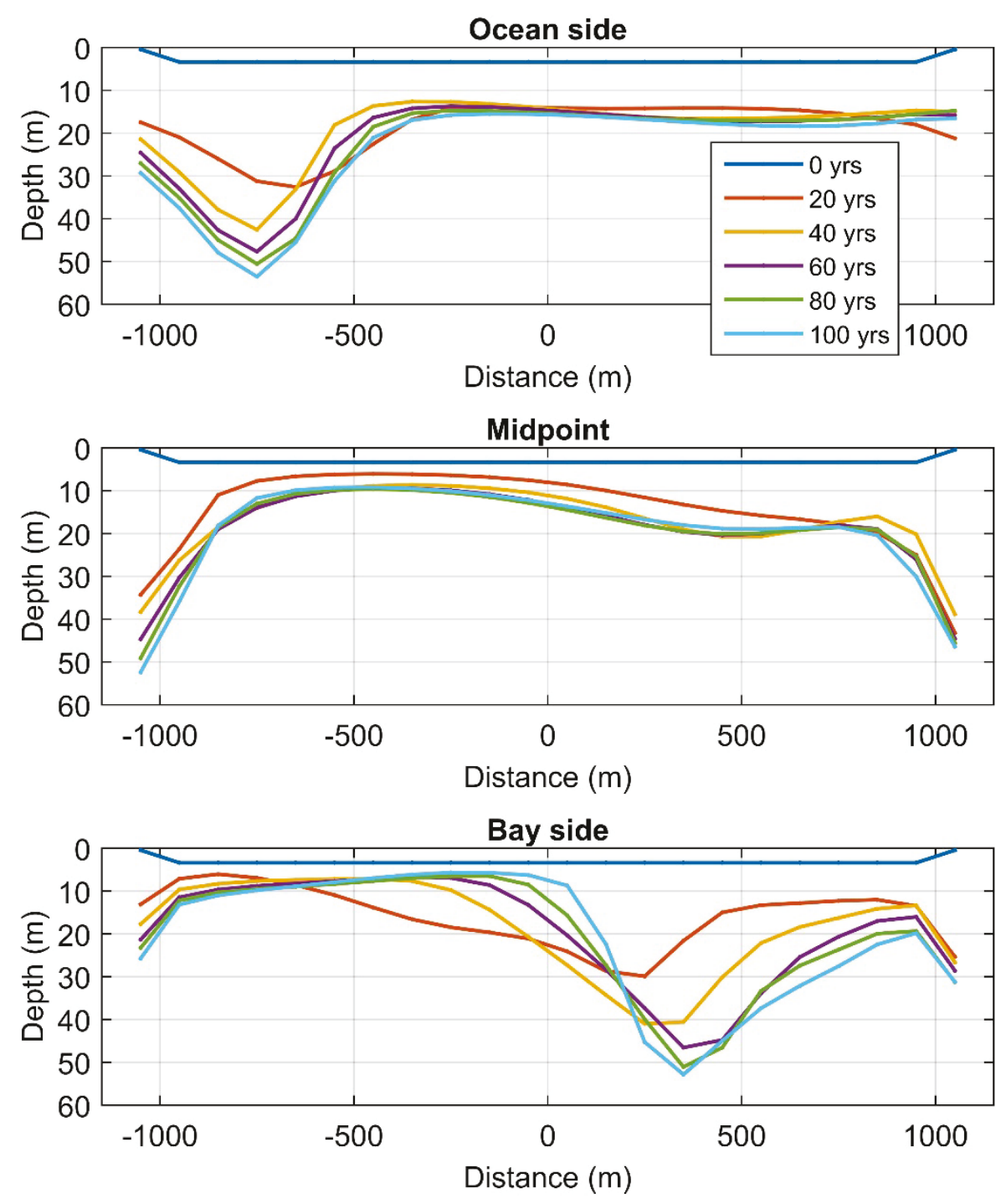

The net bed volume changes in the bay, inlet, and ebb shoal are depicted in millions (M) of cubic meters in Figure 3.4, which shows the sediment material is removed from the bay and inlet and deposited on the ebb shoal. Total increase in ebb shoal volume nearly balances bay and inlet losses. After 100 years, the system is still evolving with bay/inlet sediments 
contributing to the growth of the ebb shoal. The bay is still deepening but at a slower rate than the inlet, indicating that it is ebb dominant. Sediment loss from the inlet is more than four times the loss from the bay.

Figure 3.4. Calculated 100 years of bed volume change $(M=$ Million $)$ in cubic meters for Grays Harbor.

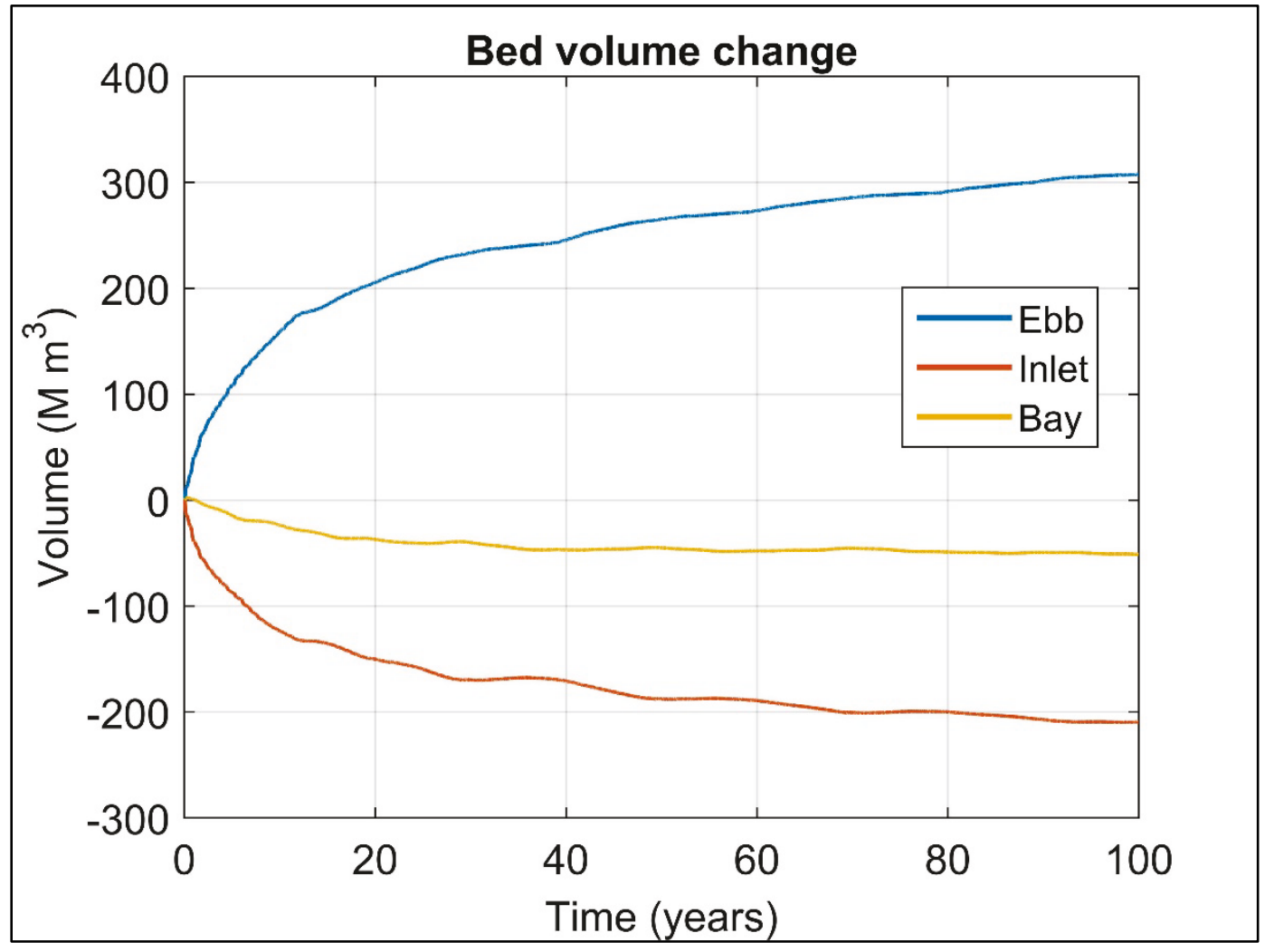

\subsubsection{Hydrodynamics}

Spatial current magnitude distribution near the end of the simulation during maximum flood and maximum ebb is depicted in Figure 3.5 and Figure 3.6, respectively. Flood currents enter the inlet primarily through the marginal flood channels and increase in velocity in the inlet throat. Currents remain strong upon exiting the inlet and then diffuse laterally into the bay. Within the bay, currents become strongly channelized over time as the distributary channels develop. Ebb currents are consistently strong within the bay channels and are strongly convergent at the inlet. Currents disperse laterally upon exiting the inlet but are skewed towards the deeper channel that has developed oriented towards the south. 
Figure 3.5. Current magnitude during maximum flood at the end of the 100-year simulation for Grays Harbor. White areas shown inside the bays denote computational areas that were dry (above the water level) at the end of the simulation.

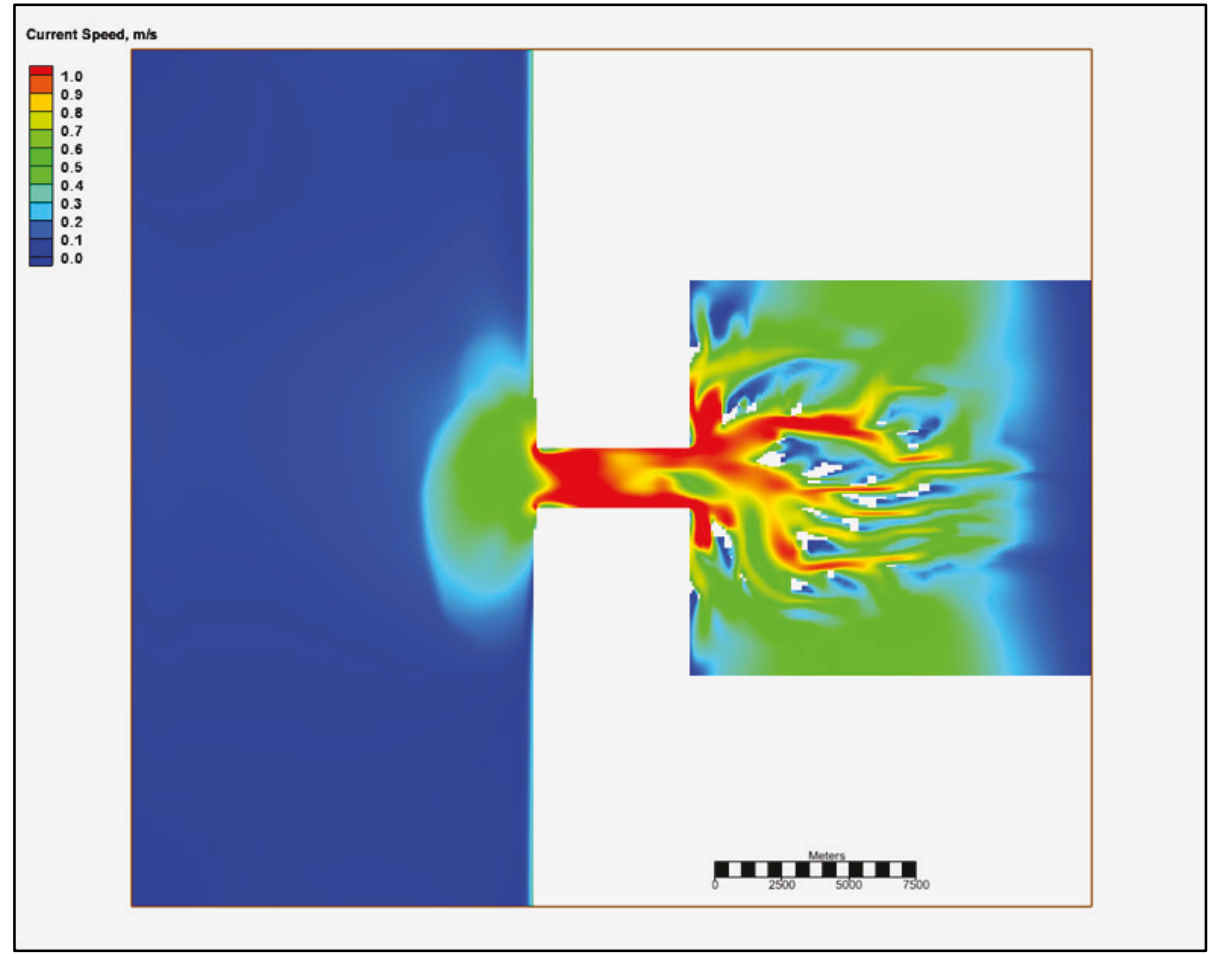

Figure 3.6. Current magnitude during maximum ebb at the end of the 100-year simulation for Grays Harbor. White areas shown inside the bays denote computational areas that were dry (above the water level) at the end of the simulation.

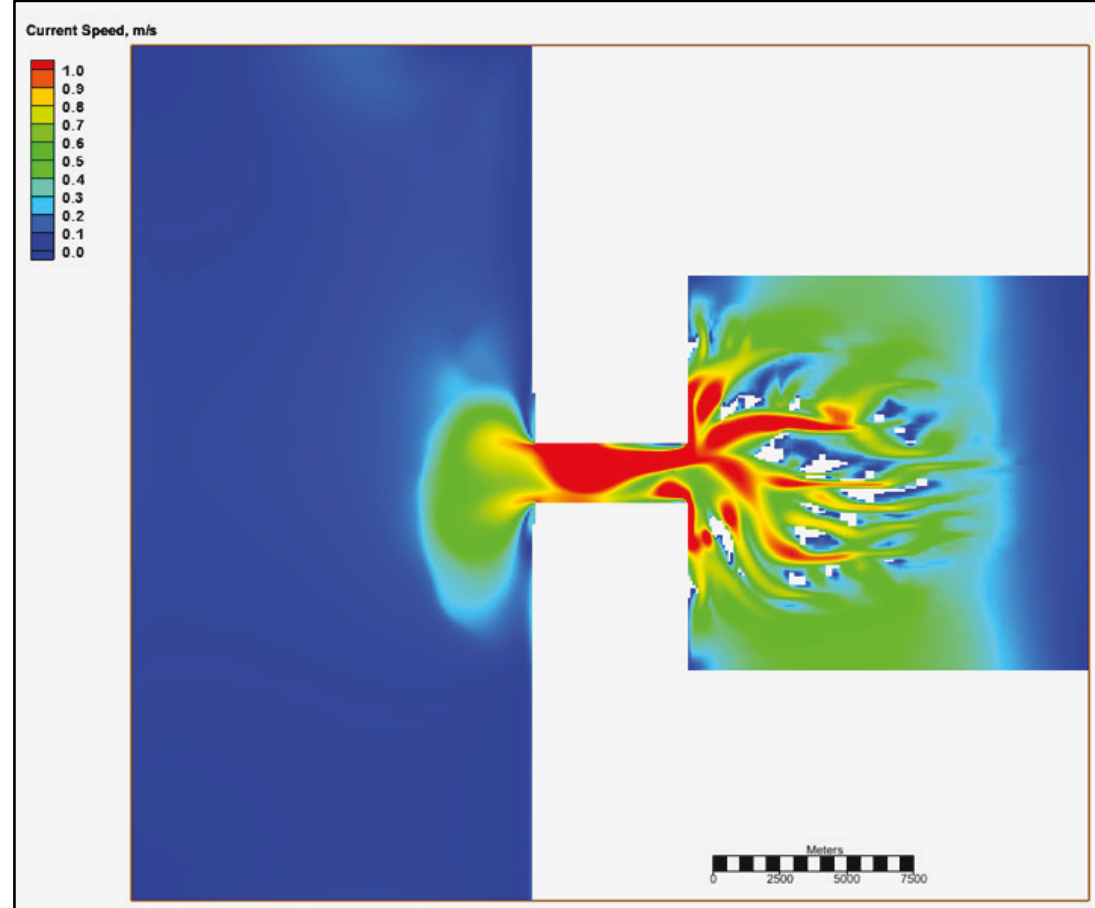


Tidal current time series in the inlet throat show a decrease in the amplitude envelope during the simulation (Figure 3.7). This decrease in peak current amplitude, which drives sediment transport, is due to the deepening of the inlet throat. The mean peak currents are on the order of $1 \mathrm{~m} / \mathrm{sec}$ at 100 years, which is in agreement with spring tide conditions at Grays Harbor (Styles 2006).

Figure 3.7. Average and peak average tidal currents at the midpoint of the inlet (top left and top right inset, respectively). The two smaller panels (right inset) illustrate current patterns for the last year of the simulation.

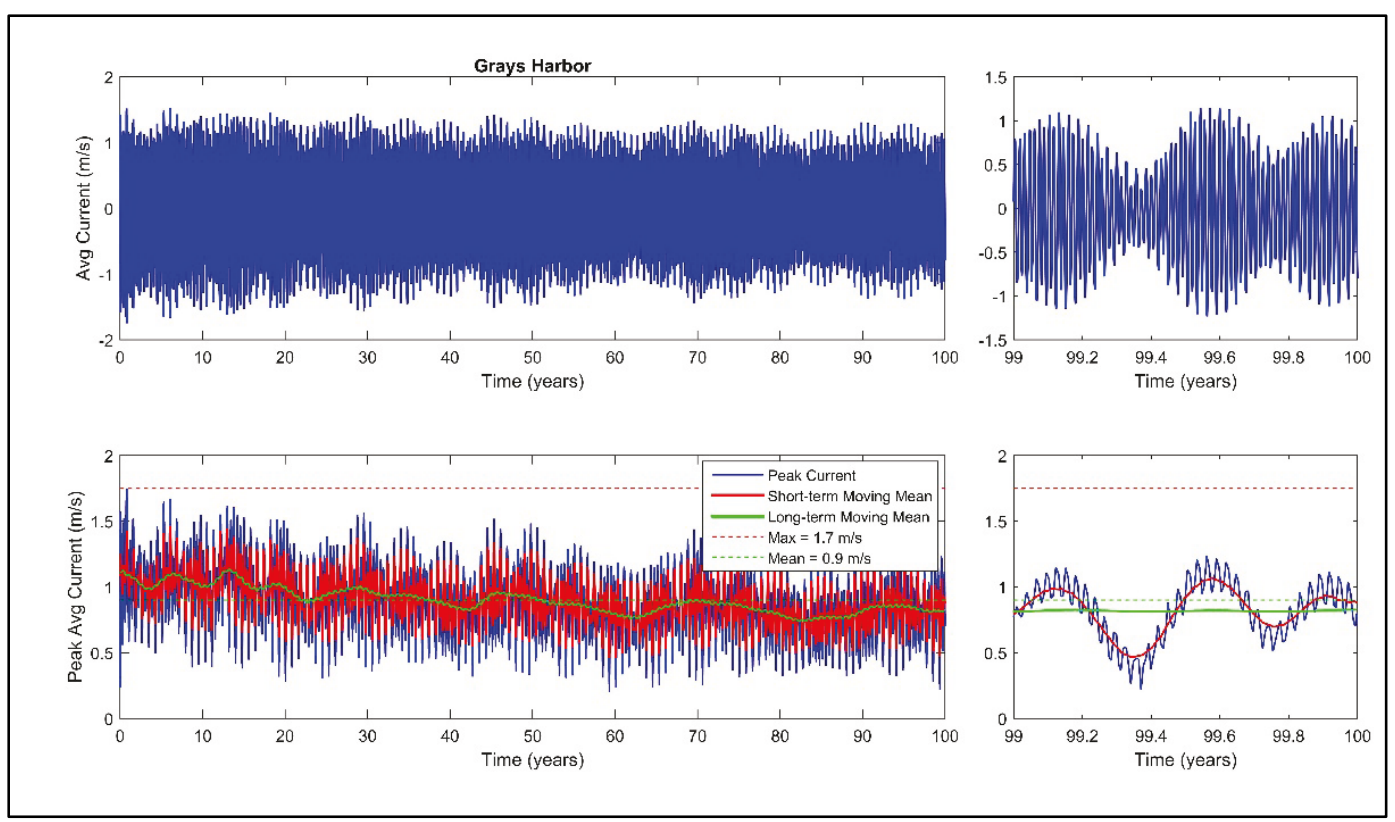

Volume flux is calculated by integrating the instantaneous current over the cross-sectional area. In addition to variations associated with the tide, the volume flux amplitude envelope increases initially as the cross-sectional area increases (Figure 3.8). After approximately 40 years, the envelope and current signal equilibrates and is indicative of a tide driven by a steady neap/spring cycle and seasonal variations. Tidal prism is calculated by integrating the flux over the flood portion of the tidal cycle. The integration limits are determined by the zero-crossing method. Tidal prism increases for the first 35 years and then asymptotically reaches an equilibrium value within the tidal forcing envelope. 
Figure 3.8. Volume flux and tidal prism (left inset) at the inlet midpoint. The two smaller panels denote the last year of the simulation to illustrate tidal variability.

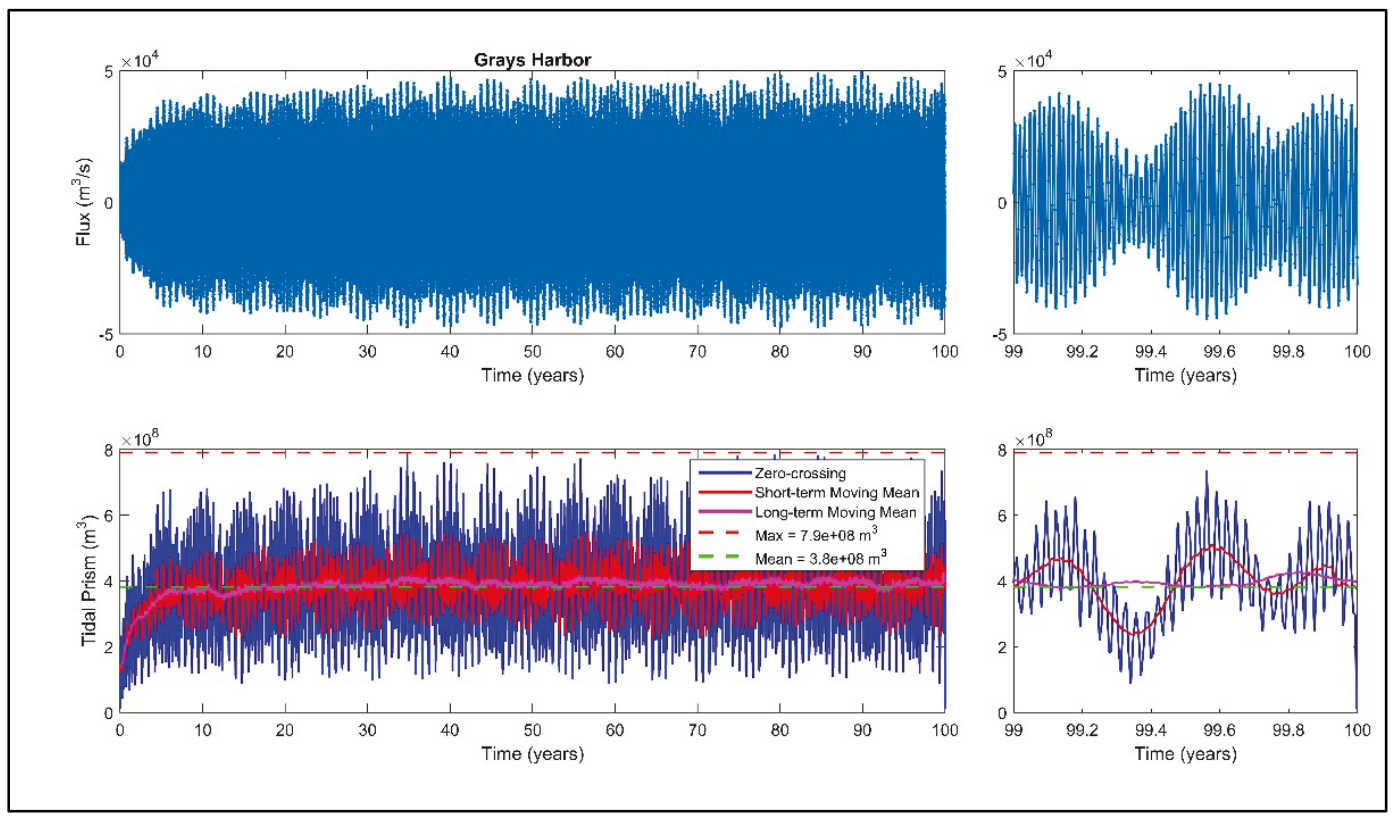

The maximum water surface elevation difference between the ocean and bay decreases during the first 40 to 50 years and then stabilizes within a tide-modulated envelope (Figure 3.9). The difference is a measure of the sea surface slope and hydrostatic pressure gradient. The temporal evolution suggests a net reduction in maximum pressure gradient and associated inlet currents in agreement with the tidal current magnitude and tidal setup caused by bottom friction. The extremes are asymmetric with regard to the zero-crossing as indicated by the larger $\Delta \eta$ during maximum ebb. This tidal distortion produces greater sea surface slope across the inlet during ebb leading to stronger outflow.

Figure 3.9. Water surface elevation difference between the ocean and bay. Positive values denote sea surface slope from the ocean to the bay.

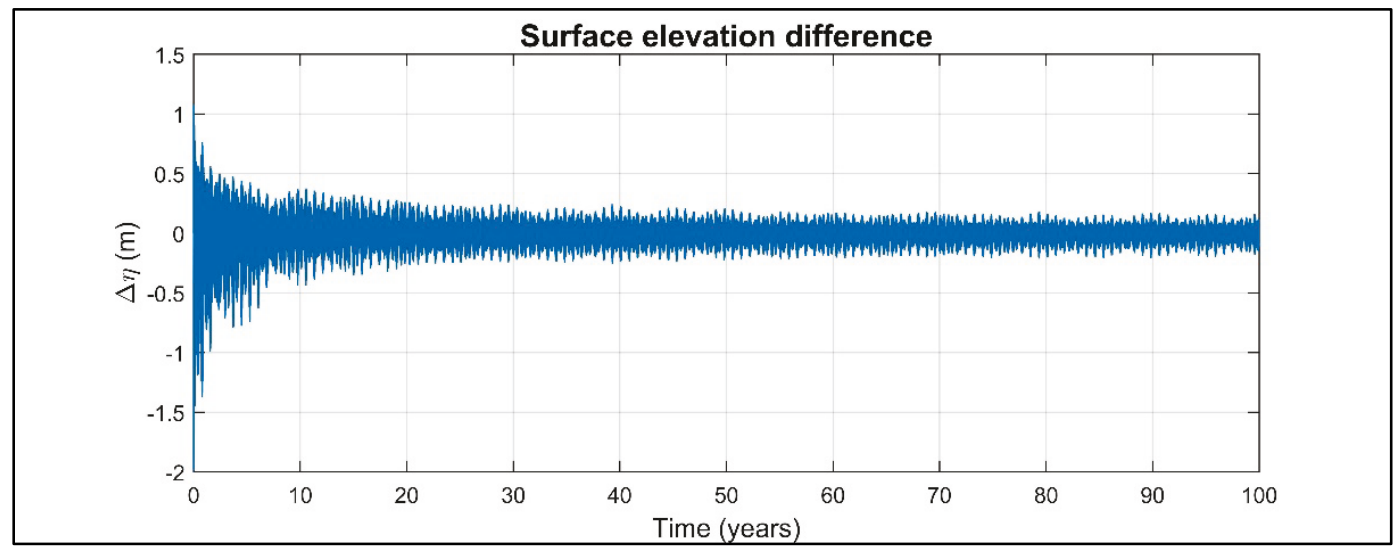




\subsubsection{Comparisons with empirical formulas}

The tidal prism relationship in Equation (1) expresses the cross-sectional area as a function of tidal prism and is an intrinsic morphological characteristic of quasi-stable inlet systems. Tidal prism varies as a function of tidal range and fluctuates between spring and neap tide as well as the average seasonal cycle. In practice, the tidal prism relationship is applied during spring tide when the currents have the potential to mobilize the greatest amount of sediment. This is based on the idea that at equilibrium, sediments will only mobilize under the strongest forcing conditions to maintain a stable cross-sectional area. Applying the tidal prism relationship to a time-series record produces fluctuations in crosssectional area for each tidal cycle.

As the inlet is dynamically in equilibrium, a time-series plot of CMScomputed cross-sectional areas at different inlet throat locations (lines in Figure 3.10) shows the long-term exponential trend of growth and provides insight into the inlet morphological changes that lead to a stable equilibrium approaching a maximum cross-sectional area and prism. The CMS-computed tidal prism time series depicted in Figure 3.8 is input into the tidal prism relationship from Equation (1) to provide calculated crosssectional areas from CMS (points in Figure 3.10). These calculated crosssectional areas from the tidal prism relationship for spring (maximum) and neap (minimum) tides provide the upper and lower bounds for crosssectional equilibrium as the morphology changes through time. At the beginning of the 100-year simulation the cross-sectional area grows significantly as the channel is still deepening. As the tidal currents erode the bed, deepening the inlet, the CMS-computed cross-sectional area (lines) approach the upper half of the envelope (maximum points in Figure 3.10) for predicted equilibrium cross-sectional areas, which represents the highest spring tide conditions. The cross-sectional area at either end of the inlet is in closer agreement with the highest tidal range whereas the midpoint cross section approaches the average spring tide conditions (maximum tidal forcing).

The sharp corners on either end of the inlet lead to artificial flow expansion/contraction that increases lateral shear and focuses kinetic energy flux as compared to an otherwise naturally curved inlet. As such, the inlet cross-sectional area varies along the length of the inlet, with greater sizes identified along the distal cross-sections at either end of the inlet channel throat. 
Figure 3.10. Inlet cross-sectional area calculated by the CMS (lines) at three inlet channel locations and the computed cross-sectional area from the tidal prism relationship (points).

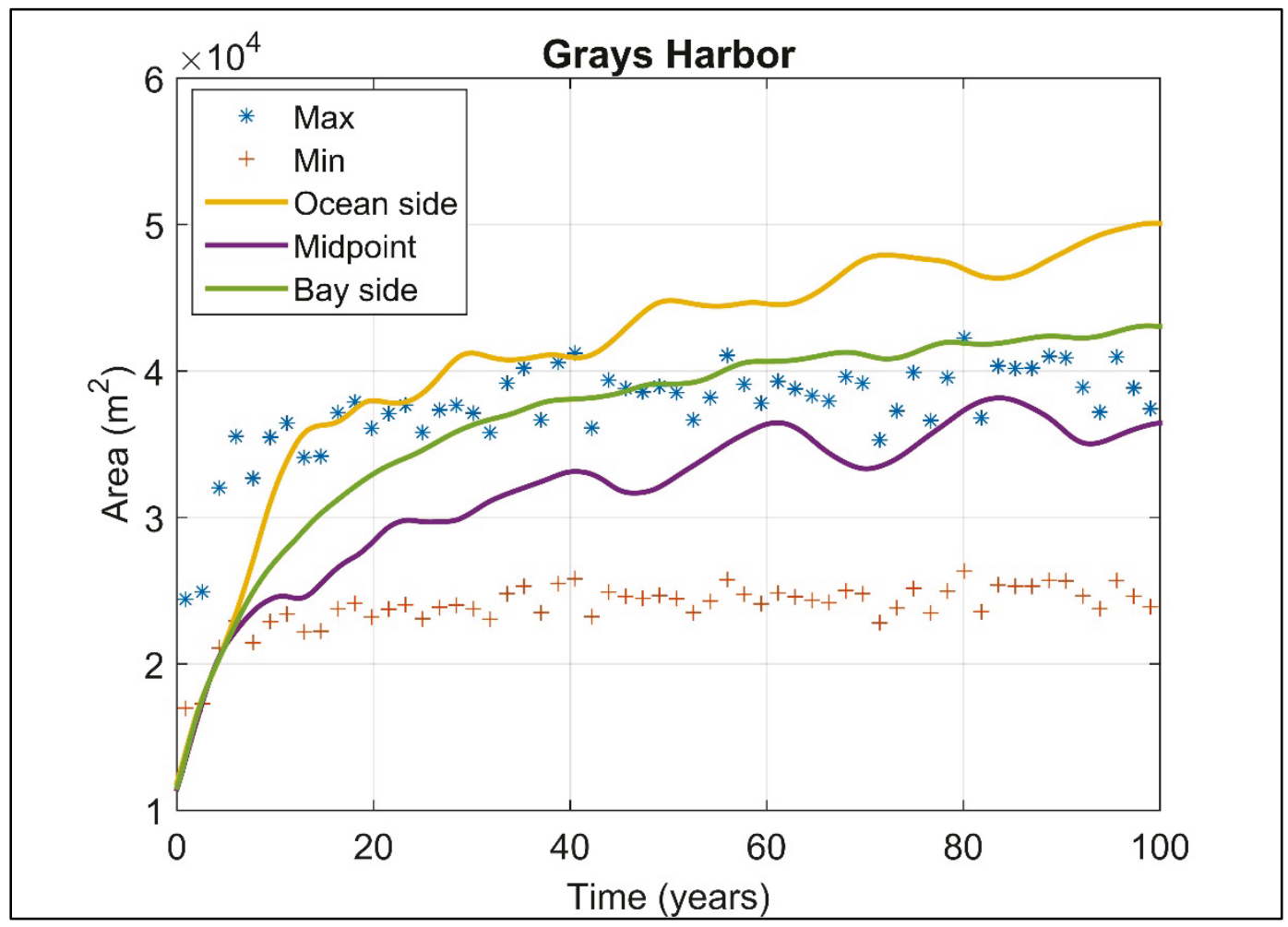

Figure 3.11 plots the time-series ebb shoal volume calculated by the CMS (lines) and the empirical computation of ebb shoal volume (points) from Equations (14) and (15). Like the tidal prism relationship, the empirical method expresses shoal volume as a function of spring (maximum) and neap (minimum) tidal prism. The ebb shoal growth results from deposition of sediment eroded from the inlet and bay as well as sediment deposited from longshore sediment transport. As sediment transport is associated with the strongest currents, the CMS-computed shoal volumes correlate with the empirical computation of shoal volume during spring tides. Initially, the CMS-computed ebb shoal volumes are greatly out of sync with the empirical computed volumes as the inlet is in dynamic equilibrium. The CMS underpredicts the ebb shoal volume computed by empirical formulas, but as the inlet approaches equilibrium towards the end of the simulation, the prediction converges closer to the average volume associated with the Walton and Adams (1976) Equation (14) rather than the Hicks and Hume (1996) Equation (15). 
Figure 3.11. Time series of ebb shoal volume calculated by the CMS (yellow line) and the computed empirical formulas that relate tidal prism to ebb shoal volume (points).

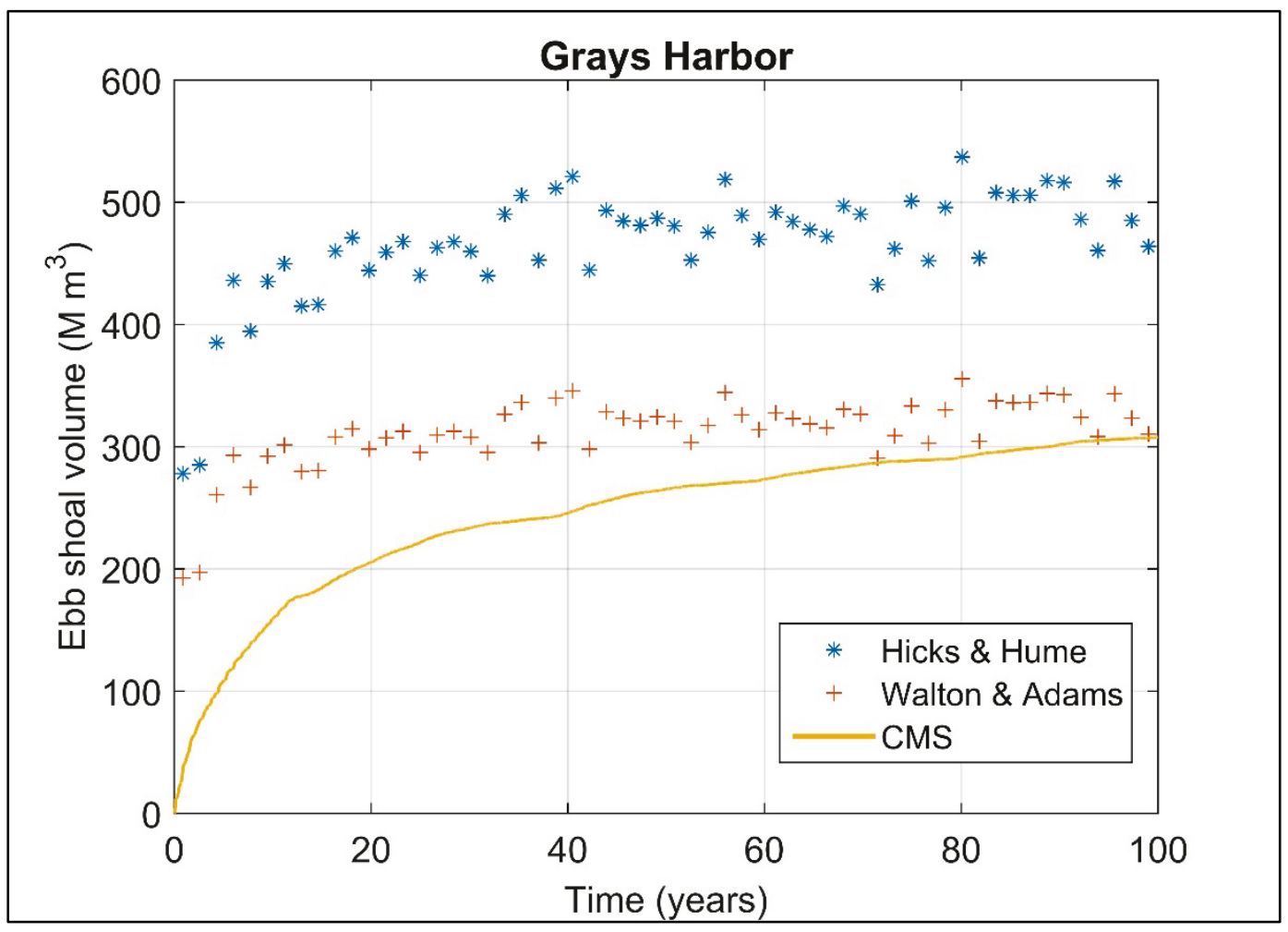

The Escoffier analysis provides criteria to gauge inlet stability. The solid yellow and green curves in Figure 3.12 denote the theoretically predicted maximum tidal current as a function of cross-sectional area (Equation (12)). The input parameters (e.g., bay area, inlet dimensions, water surface elevation) are derived from the CMS idealized Grays Harbor simulation. Points that lie to the right of the peak denote stable inlet conditions as previously discussed. The plus signs denote the minimal cross-sectional area for Grays Harbor and signify the theoretical maximum velocity required to maintain a stable inlet. The calculated CMS results for maximum velocities, or peak currents (blue points in Figure 3.12), are based on the minimal inlet cross-sectional area, which is midway between the ocean and bay. CMS maximum velocities are computed for spring and neap tidal cycles, and therefore the predictions include spring/neap variability in maximum velocities for a given cross-sectional area. The tidal cycle time series is filtered using a 15-day window that excludes neap tidal velocities yet provides a record that characterizes the largest currents over the 100-year timeframe. Even after the neap tidal signal is removed, peak currents show scatter owing to seasonal variations. The tidal record is further filtered using a 30-day lowpass filter window to delineate the overall trend of peak velocities for modeled cross-sectional areas (orange line in Figure 3.12). Although time is 
not plotted in Figure 3.12, the CMS results reveal that as the inlet grows in cross-sectional area (from left to right) there is a net reduction in the maximum current that trends with the theoretical predictions.

Figure 3.12. An Escoffier analysis comparing the theoretically predicted (green and yellow lines) and CMS-computed (blue points) current. Plus signs denote the minimal cross-sectional area and the theoretical maximum velocity required for this inlet to remain stable. A 30-day low-pass filter delineates the overall trend of CMS-computed peak velocities for modeled cross-sectional areas (orange line).

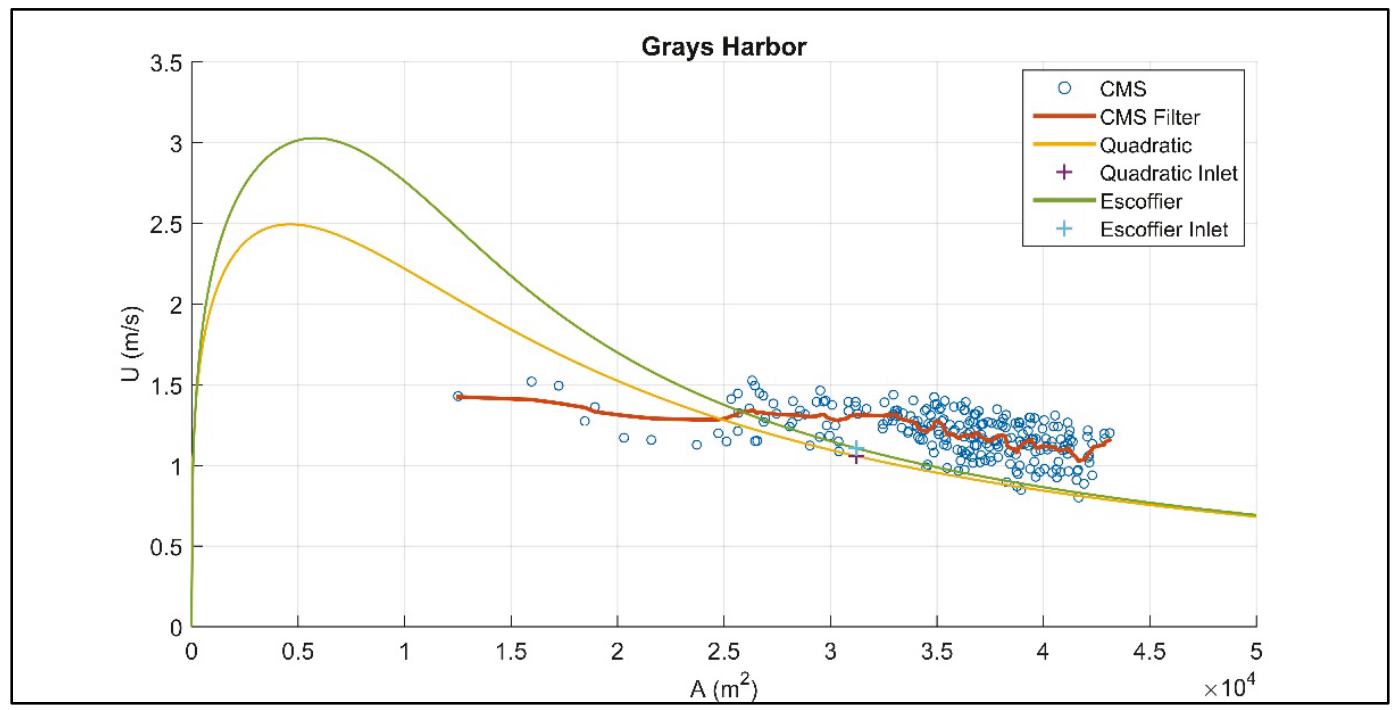

\subsection{Mouth of the Columbia River (MCR)}

The MCR is located along the Washington and Oregon border and is the largest of the West Coast bay and inlets in this study. The model grid for MCR idealized inlet/bay system is depicted in Figure 3.13. The dimensions and initial depth are listed in Table A1. Bay width $(38 \mathrm{~km})$ and length (10 $\mathrm{km}$ ) produce a rectangular area equal to the area of MCR. The depth contours offshore are straight and parallel and follow an equilibrium beach profile near the shoreline. Water depth is constant at $5.6 \mathrm{~m}$ within the throat and bay and tapered at the ocean side to match the offshore depths. The bay depth of $5.6 \mathrm{~m}$ is based upon average conditions for MCR. 
Figure 3.13. CMS grid and bathymetry for idealized MCR simulation.

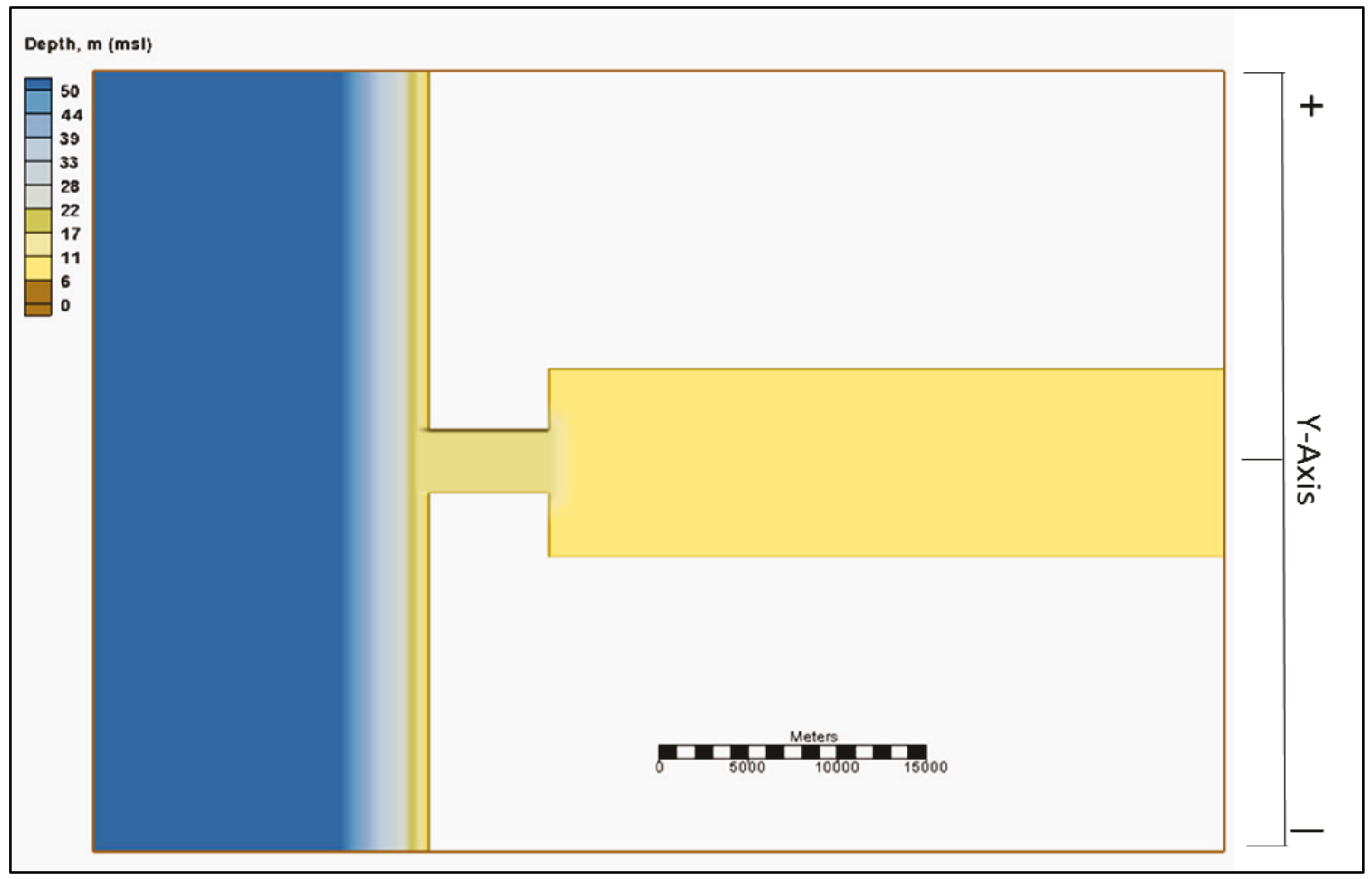

\subsubsection{Morphology}

The final morphological evolution for the MCR simulation is depicted in Figure 3.14. The ebb shoal extends approximately $5 \mathrm{~km}$ up the northern shoreline, $8 \mathrm{~km}$ down the southern shoreline, and $8 \mathrm{~km}$ offshore. The main lobe of the ebb shoal is skewed and elongated in the negative $y$-direction (alongshore left, or to the south) due to the wave-generated longshore transport. There are two marginal flood channels on either side of the lobe with the northerly channel adjacent to the updrift beach and with the wider and shallower southern marginal flood channel co-occupying a secondary ebbing channel. The main ebb channel is deep and is located just north (positive) of the centerline of the inlet.

There are two channels within the inlet throat oriented along the northern and southern side of the inlet. The northern channel is shallowest in the middle and deeper at either ocean side of the inlet extending further offshore than the southern channel. The southern channel has a more uniform depth along the inlet throat. The deepest sections of each channel are near the sides of the inlet as opposed to aligning with the centerline. The bay contains a series of incised linear tidal channels distributed into random, elongated fingers. 
Figure 3.14. Final depth for MCR after 100-year simulation. White areas shown inside the bays denote computational areas that were dry (above the water level) at the end of the simulation.

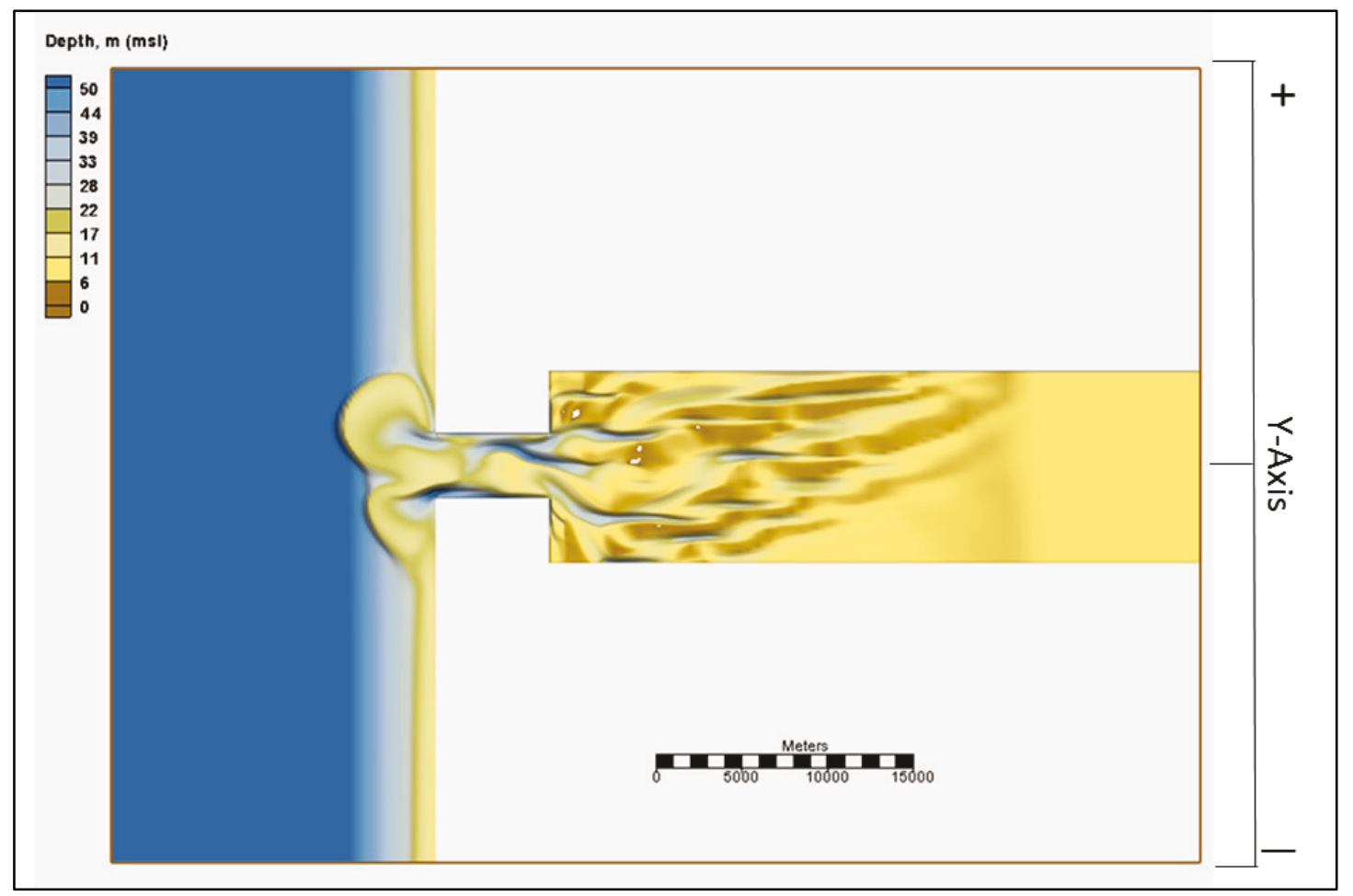

Figure 3.15 depicts the temporal evolution of the cross-sectional area at the ocean, midpoint, and bay side of the inlet. Bed deepening at the ocean side occurs on opposite sides of the channel. Initially the channel develops along the northern ( $y$-positive) side but then begins to deepen on the southern side after the first 20 years. At 100 years, there are two channels separated by a relatively shallow center, the northern channel being incised and approaching $60 \mathrm{~m}$ in depth. Deepening at the midpoint crosssection is asymmetric with the deepest portion initially on the southern ( $y$ negative) side of the inlet. The deepest section shifts throughout the simulation as the southern channel shoals and the northern incised channel deepens to approximately 40 m water depth at 100 years. Bed deepening at the bay side cross section shows multiple channels forming across the inlet and a deeper channel thalweg near the centerline (slightly $y$-negative). In general, the channel continues to evolve throughout the simulation with the channel thalweg migrating from the positive $y$-axis at the ocean side of the inlet to the negative $y$-axis at the midpoint and bay. 
Figure 3.15. CMS-predicted temporal evolution of inlet cross-sectional area for MCR. Distances are alongshore from channel centerline with positive towards the right looking oceanward and negative towards the left.

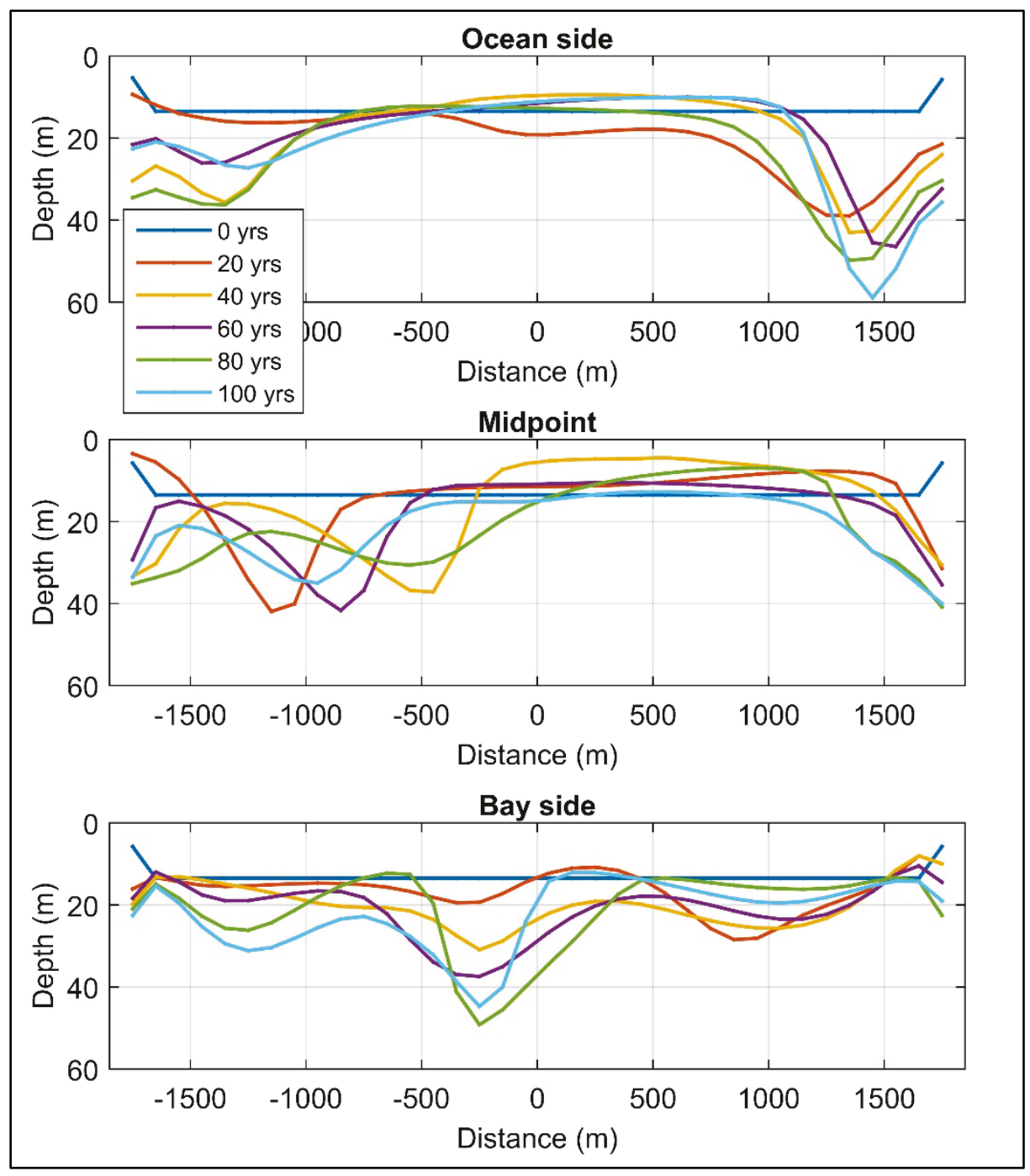

The net bed volume changes in the bay, inlet, and ebb shoal are depicted in Figure 3.16, which shows that a significant portion of the sediment material removed from the bay and inlet is deposited on the ebb shoal, with total increase in ebb shoal volume nearly balancing bay and inlet losses. By the end of the simulation, the ebb shoal continues to grow, and the inlet and bay continue to lose sediment. The results for bed change for MCR indicate that it is ebb dominant. 
Figure 3.16. Calculated bed volume change for the MCR.

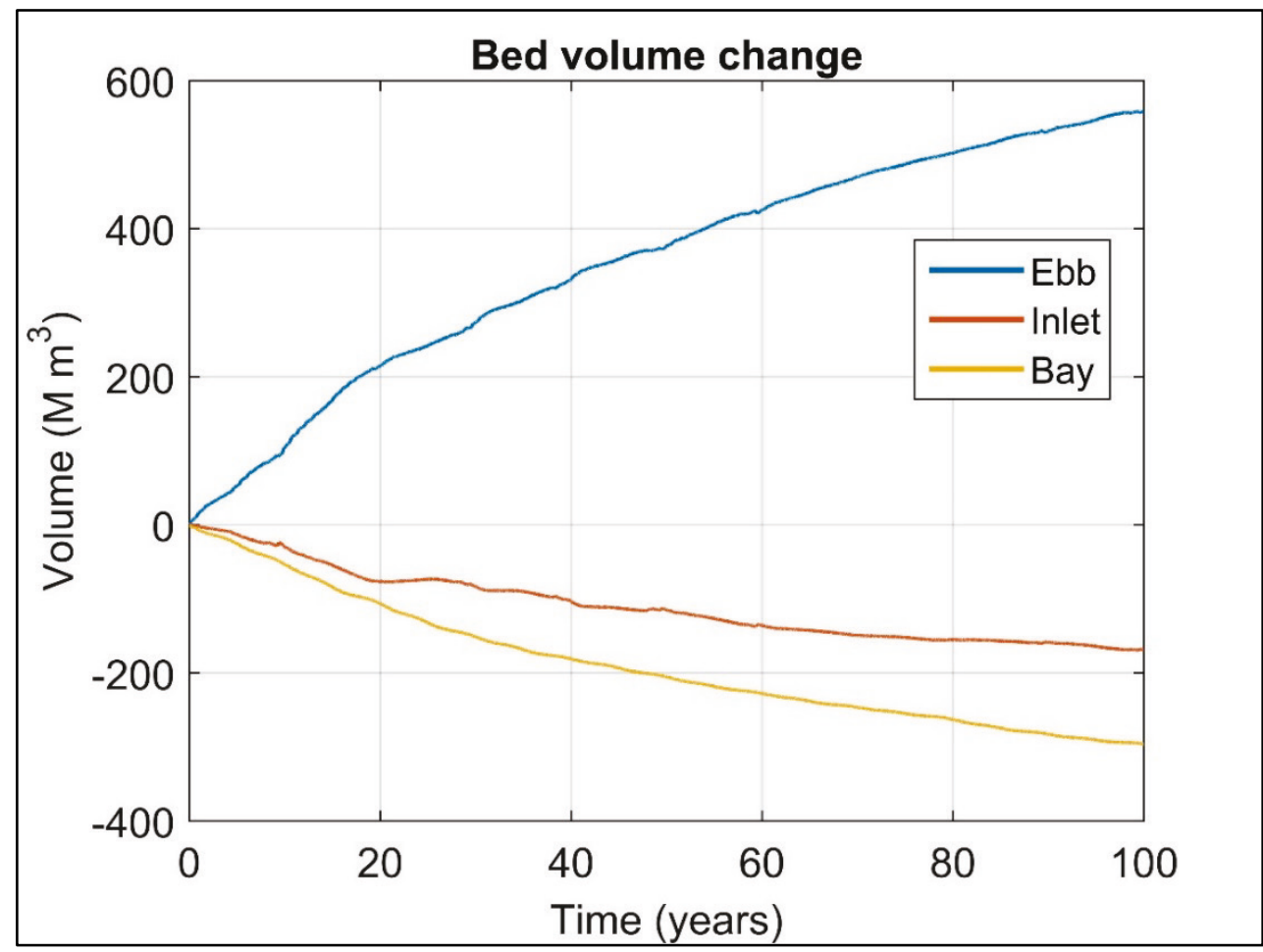

\subsubsection{Hydrodynamics}

Spatial current magnitude distribution near the end of the simulation during maximum flood and maximum ebb is depicted in Figure 3.17 and Figure 3.18, respectively. Flood currents enter primarily through the marginal flood channels and strengthen in the inlet throat. Currents remain strong upon exiting the inlet and follow the deeper bay channels. Tidal flats have developed in the bay forming linear bars between the channels. Ebb currents are consistently strong within the bay channels and converge at the inlet. Upon exiting, ebbing currents disperse somewhat but are concentrated in the north and south channels. The net flow is stronger during the ebbing tide, especially in the bay, which is consistent with the sediment transport pattern described above and the inlet's ebb dominance. 
Figure 3.17. Current magnitude during maximum flood at the end of the 100-year simulation for the MCR. White areas shown inside the bays denote computational areas that were dry (above the water level) at the end of the simulation.

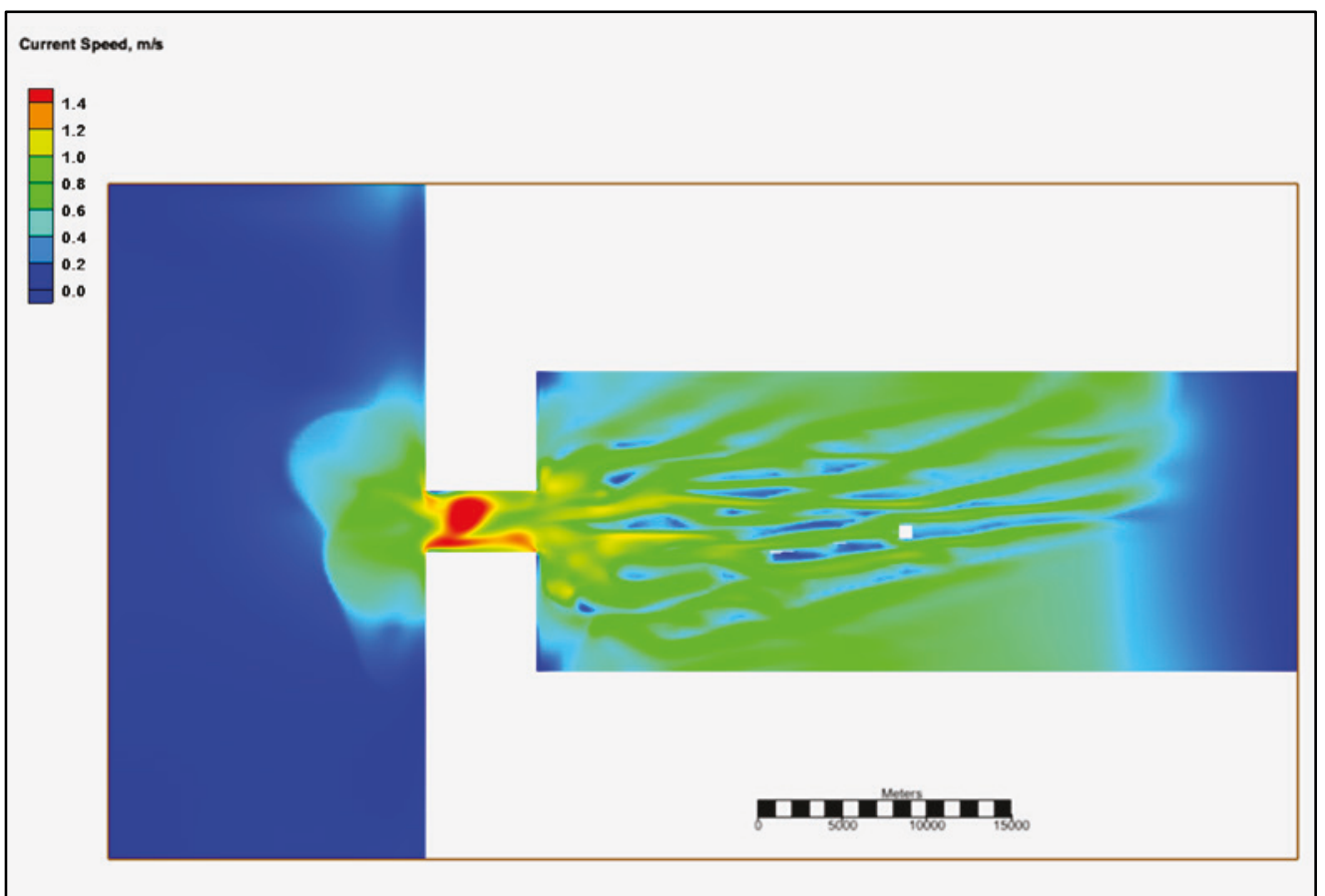

Figure 3.18. Current magnitude during maximum ebb at the end of the 100-year simulation for the MCR. White areas shown inside the bays denote computational areas that were dry (above the water level) at the end of the simulation.

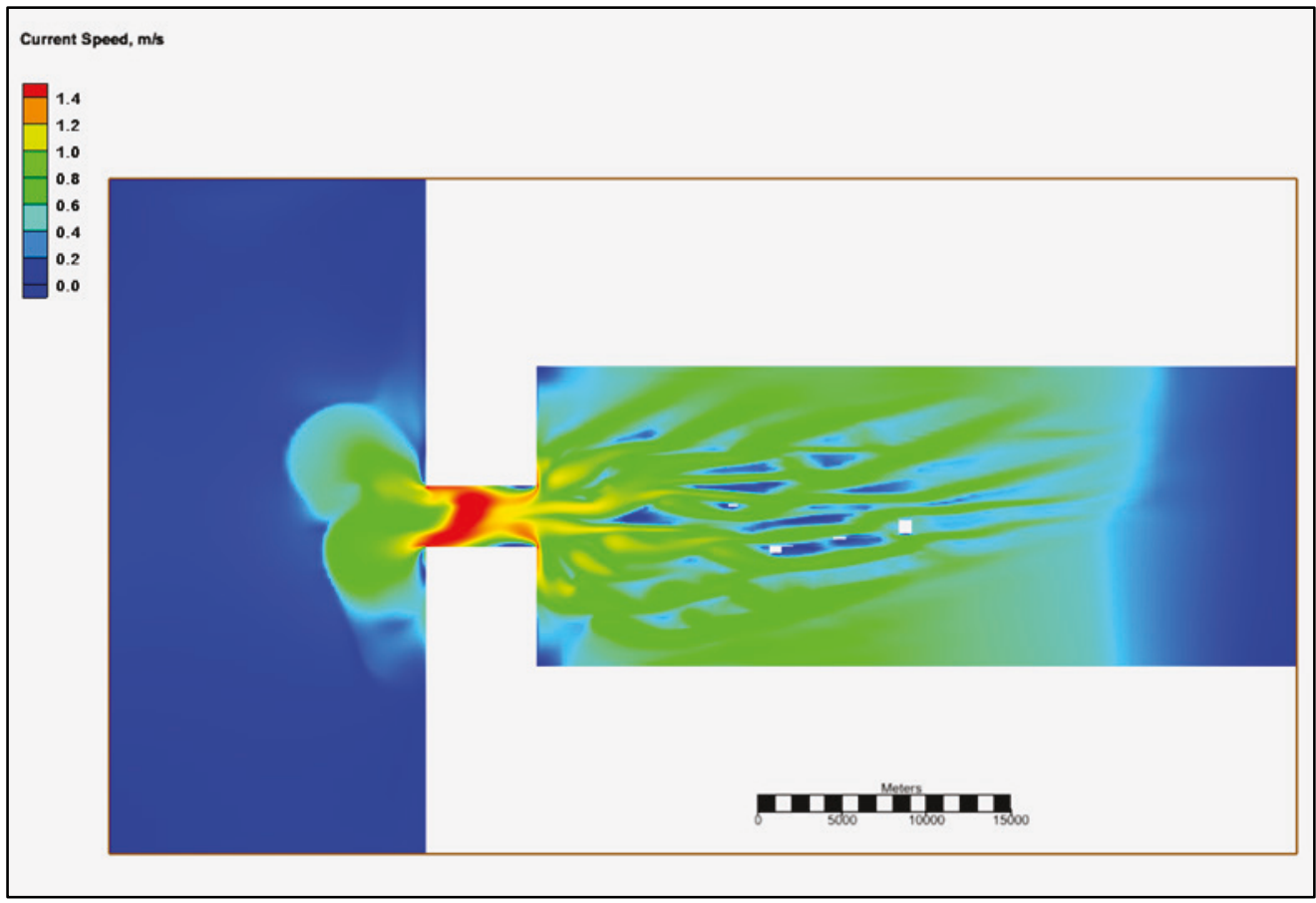


The tidal current envelope in the inlet throat shows a gradual reduction during the simulation (Figure 3.19). Peak current amplitude, which drives sediment transport, shows a similar trend as the average current. In addition to tidal variations, the volume-flux amplitude envelope increases initially as the cross-sectional area increases (Figure 3.20). The envelope continues to widen but at a diminishing rate throughout the simulation. Tidal prism increases for most of the simulation then appears to approach an equilibrium value within the tidal envelope.

Figure 3.19. Average and peak average tidal currents at the midpoint of the inlet (top left and top right inset, respectively). The two smaller panels (right inset) illustrate current patterns for the last year of the simulation.

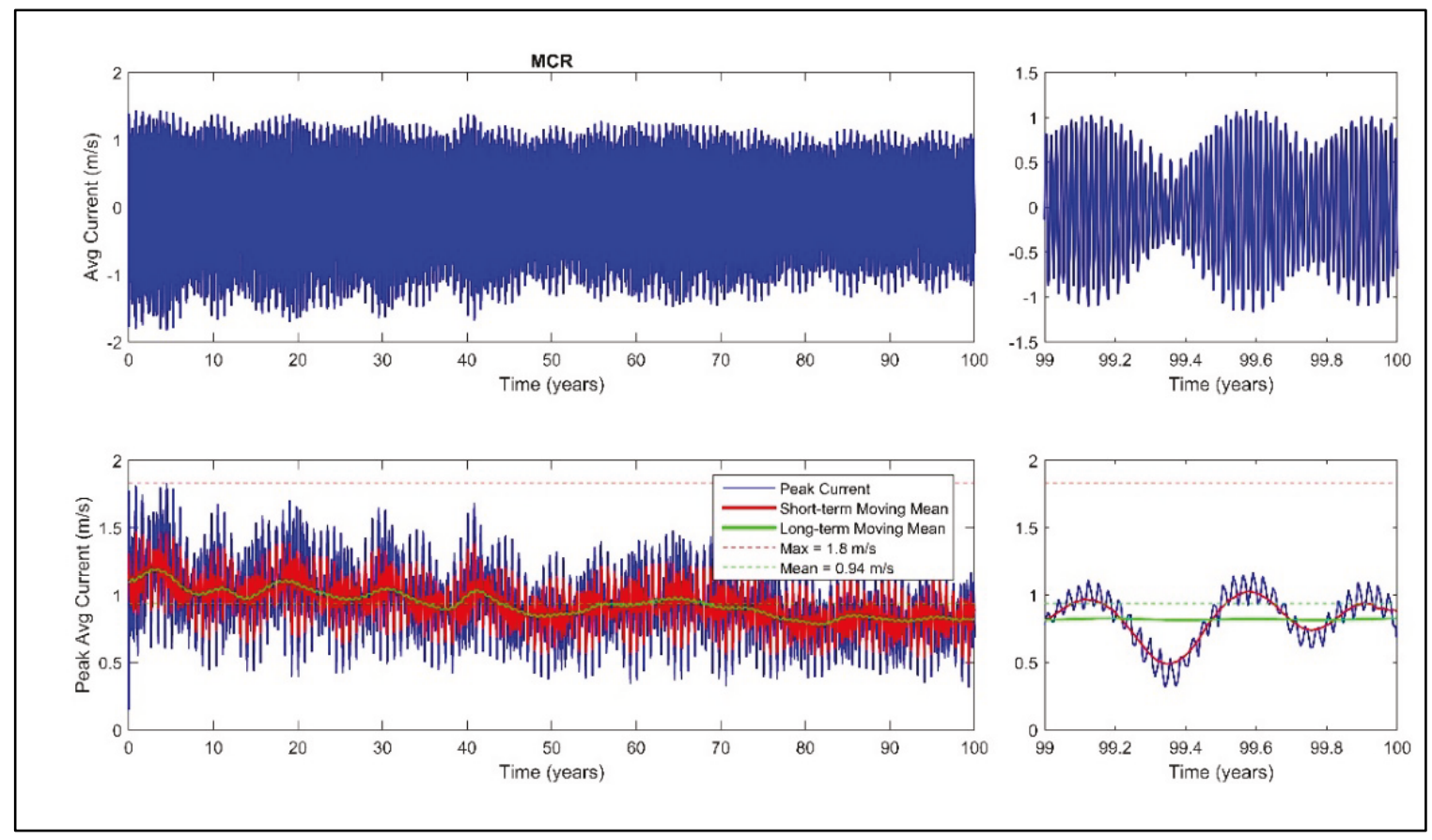


Figure 3.20. Volume flux and tidal prism (top left and top right inset, respectively) at the inlet midpoint. The two smaller panels (right inset) denote the last year of the simulation to illustrate tidal variability.

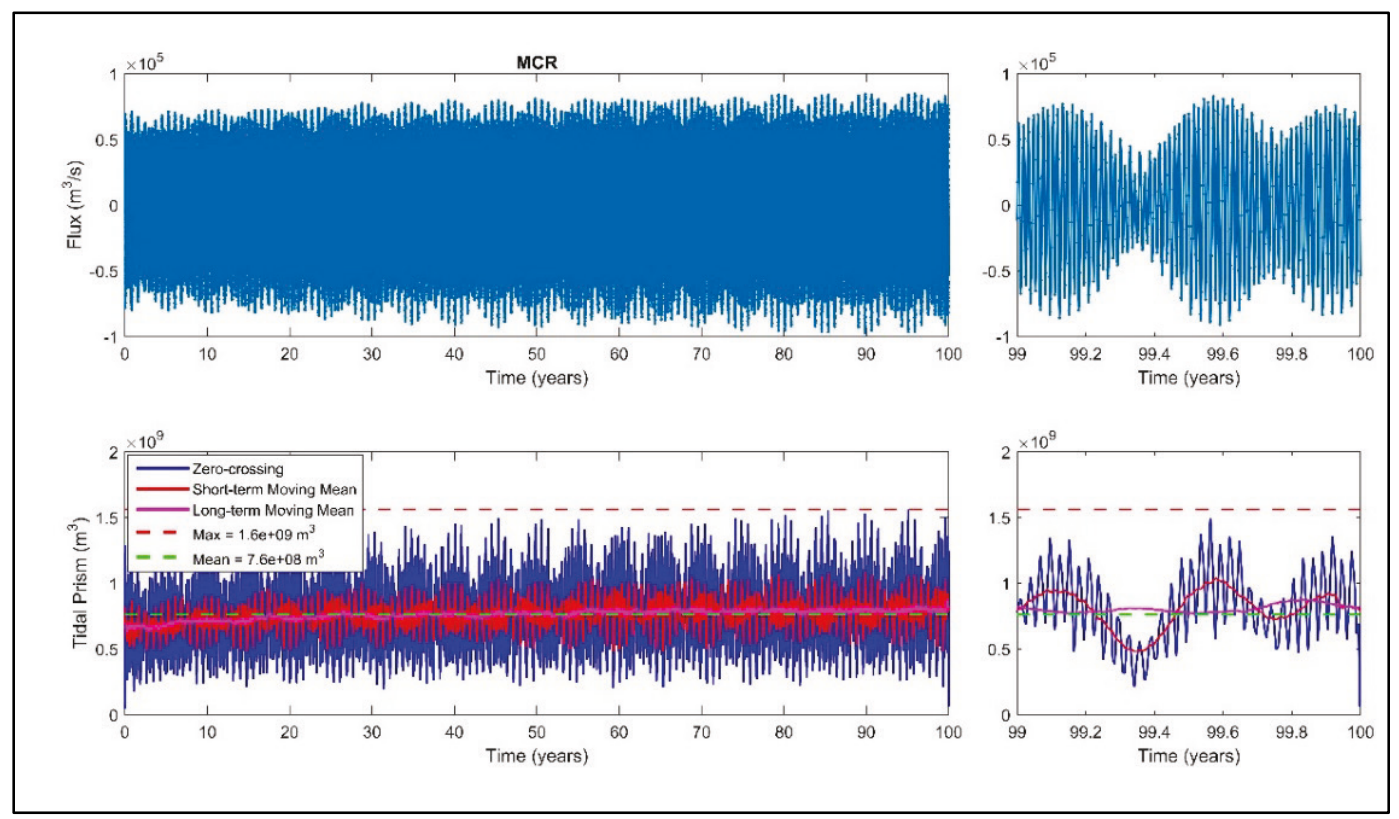

The maximum water surface elevation difference between the ocean and bay decreases gradually during the first 50 years and then decreases more gradually for the remainder of the simulation (Figure 3.21). The extremes are asymmetric with respect to the zero-crossing as indicated by larger $\Delta \eta$ during maximum ebb. This tidal distortion produces greater sea surface slope across the inlet during ebb leading to stronger outflow and ebb dominated conditions.

Figure 3.21. Water surface elevation difference between the ocean and bay. Positive values denote sea surface slope from the ocean to the bay.

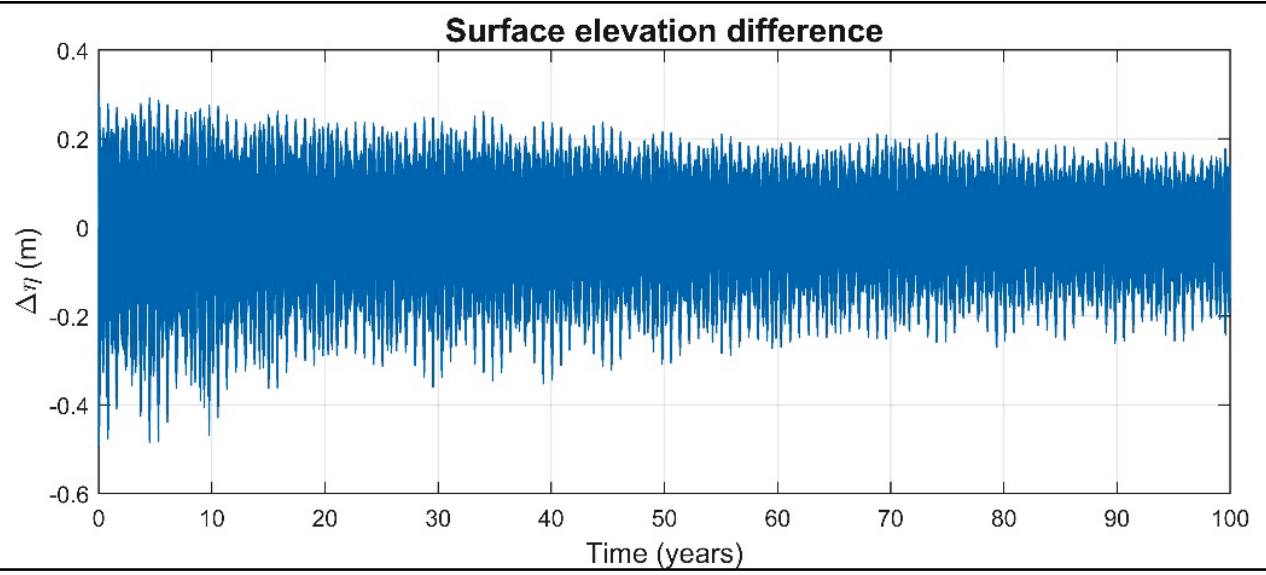




\subsubsection{Comparisons with empirical formulas}

At the beginning of the 100-year simulation, the cross-sectional area grows as the channel deepens (Figure 3.22). The CMS-predicted cross-sectional area at the bay and ocean sides approaches the upper envelope, which encompasses the highest spring tide conditions and the greatest seasonal variability. The cross-sectional area at the midpoint is slightly lower but tends to converge to the values at the bay and ocean sides near the end of the simulation. Short-term variability in cross-sectional area is associated with morphological evolution of the inlet as material is redistributed between the inlet, ebb shoal, and flood shoal. The localized variability is embedded within the long-term evolution of the system towards equilibrium.

Figure 3.22. Inlet cross-sectional area calculated by the CMS (lines) at three inlet channel locations and the computed cross-sectional area from the tidal prism relationship (points).

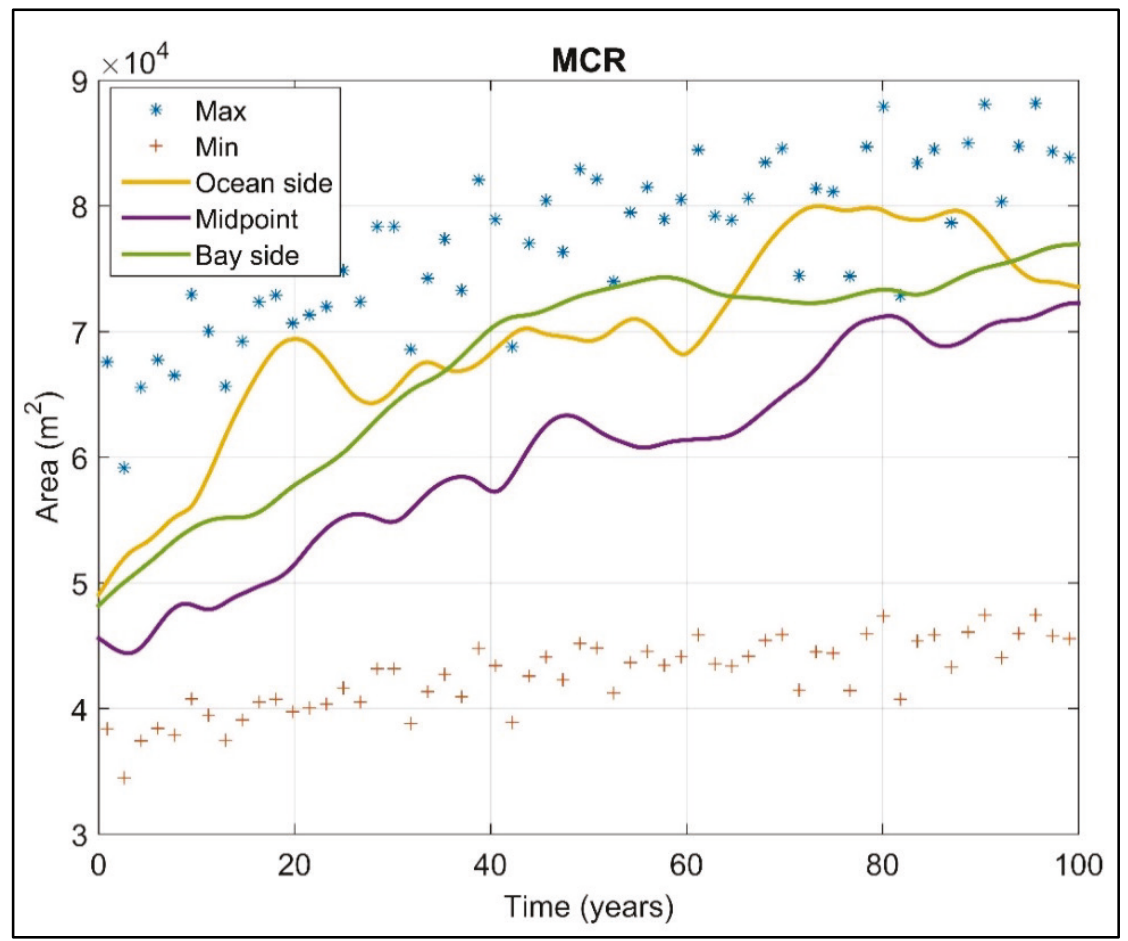

Time series of ebb shoal volume calculated by the CMS (lines) and empirical formulas (points) for the associated tidal prism calculations are depicted in Figure 3.23. As sediment transport is associated with the strongest currents, the empirical predicted shoal volume should correlate best with the spring tide computed volumes at equilibrium. The CMScalculated ebb shoal volume is less than, but approaches, the average 
predicted by Walton and Adams (1976). However, by the end of the simulation, the ebb shoal volume has not reached equilibrium and is still growing. The maximum volume predicted by the empirical formulas are trending more towards equilibrium (flatter slope); therefore, the simulated ebb shoal volume would likely reach the Walton and Adams (1976) predicted value in several more decades.

Figure 3.23. Time series of ebb shoal volume calculated by the CMS (yellow line) and the computed empirical formulas that relate tidal prism to ebb shoal volume (points).

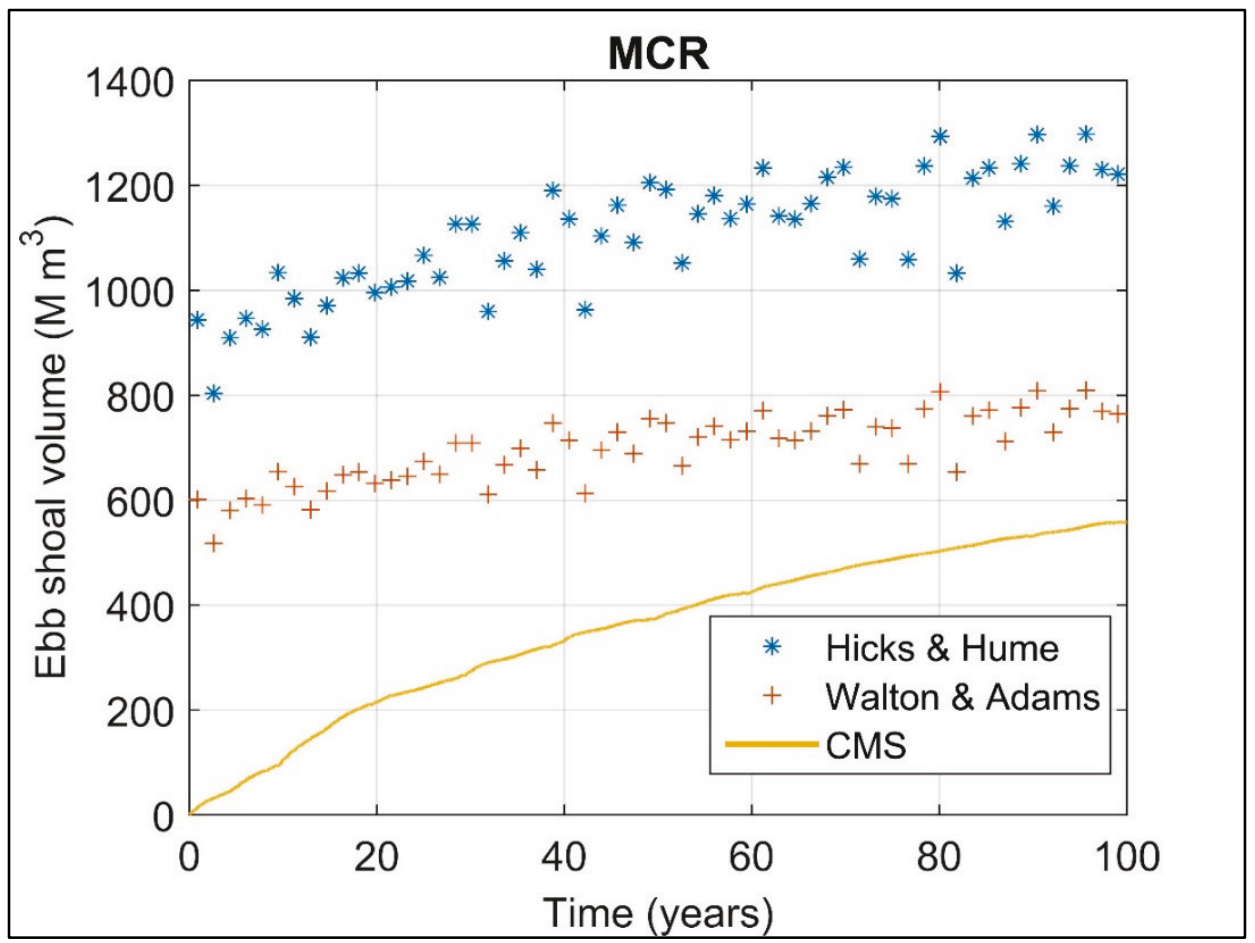

The Escoffier equilibrium theory applied to MCR is depicted in Figure 3.24. The input parameters (e.g., bay area, inlet dimensions, water surface elevation) are derived from the CMS-idealized MCR simulation, and the plus signs denote the measured MCR minimal cross-sectional area. Data filtering and averaging parameters are the same as that applied to Grays Harbor. The CMS results reveal inlet growth and a net reduction in the maximum current that trends with the theoretical predictions. The CMS currents are consistently higher than the theoretical prediction, and the cross-sectional area near the end of the simulation is larger than the realworld inlet cross-sectional area. 
Figure 3.24. An Escoffier analysis comparing the theoretically predicted (green and yellow lines) and CMS-computed (blue points) current. Plus signs denote the minimal cross-sectional area and the theoretical maximum velocity required for this inlet to remain stable. A 30-day low-pass filter delineates the overall trend of CMS-computed peak velocities for modeled cross-sectional areas (orange line).

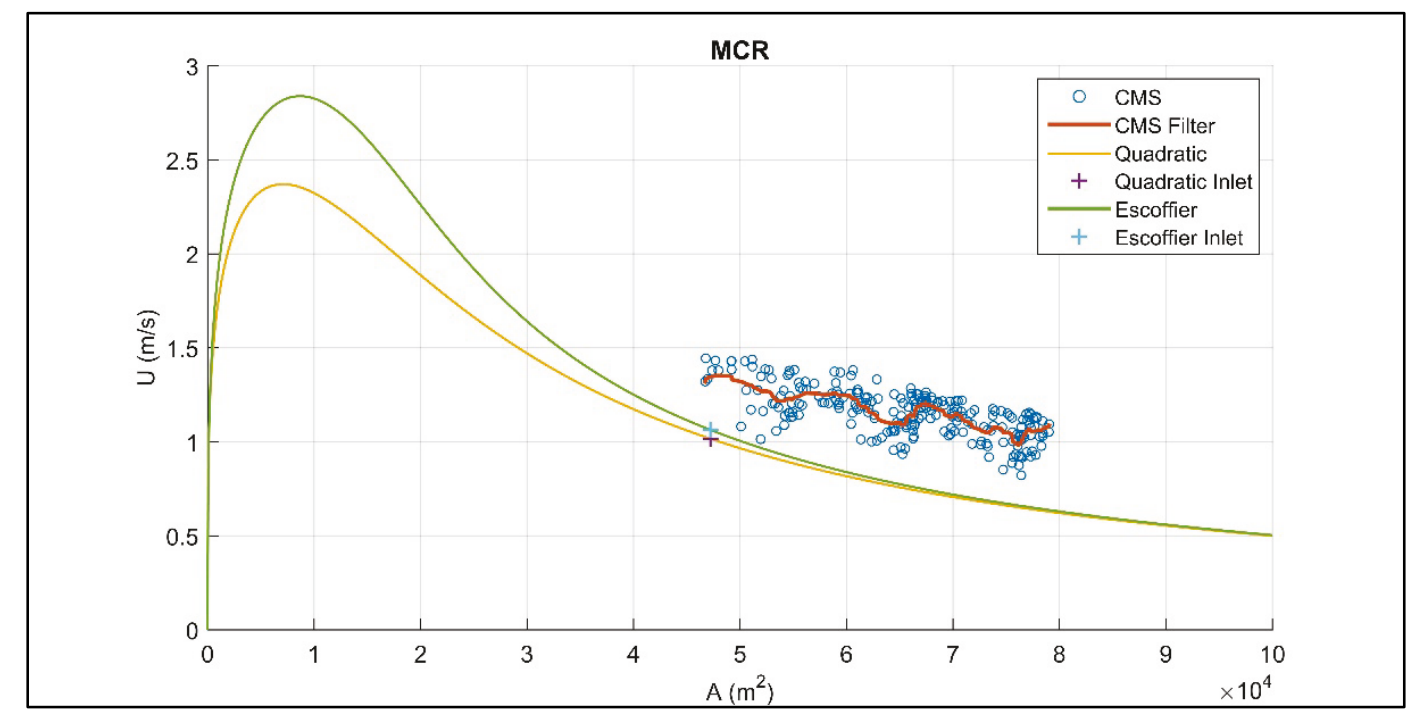

\subsection{Humboldt Inlet}

Humboldt Inlet is a narrow bay elongated in the direction parallel to the shoreline and is located in northern California. The model grid for the Humboldt Inlet idealized inlet/bay system is depicted in Figure 3.25. The dimensions and initial depth are listed in Table A1. The selected bay width and length, 3 and $21.6 \mathrm{~km}$, respectively, produce a rectangular area equal to the area of Humboldt Inlet. Depth contours offshore are straight and parallel and follow an equilibrium beach profile near the shoreline. Water depth is constant at $3.4 \mathrm{~m}$ within the throat and bay and tapered at the ocean side to match the offshore depths. The bay depth is constant and based upon average conditions for Humboldt Inlet. 
Figure 3.25. CMS grid and bathymetry for idealized Humboldt Inlet simulation.

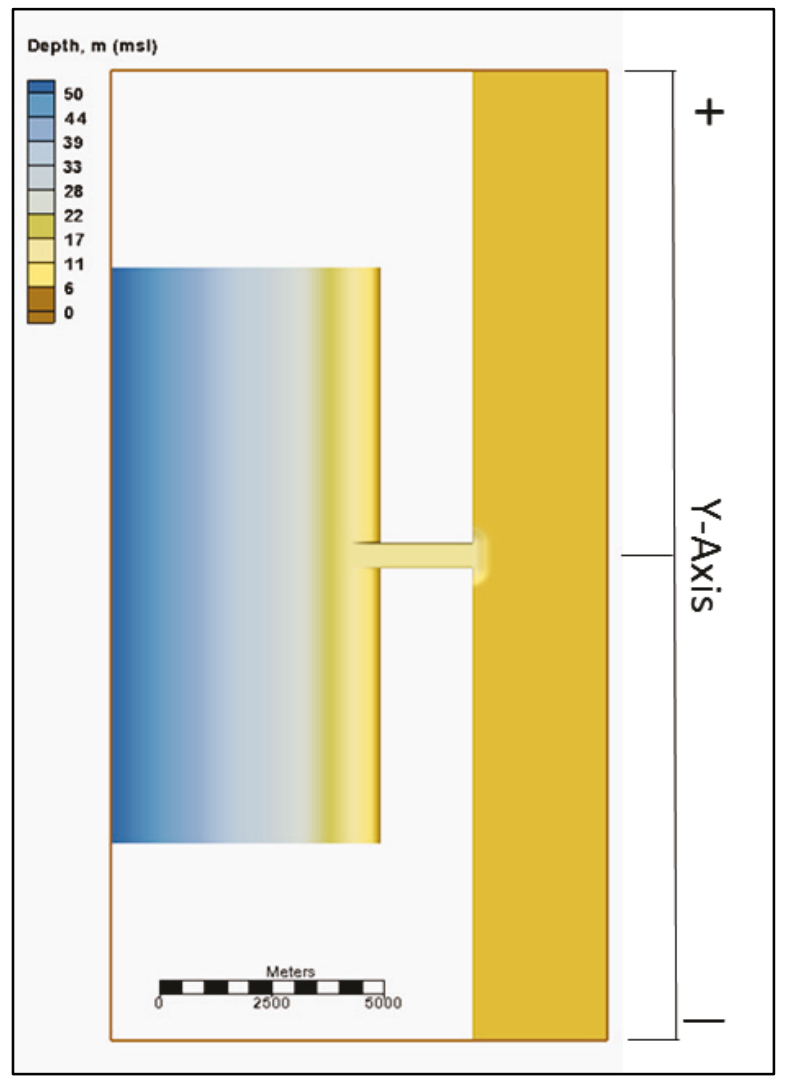

\subsubsection{Morphology}

The final morphological evolution is depicted in Figure 3.26. The ebb shoal extends approximately $2 \mathrm{~km}$ up the coast, $2 \mathrm{~km}$ down the coast, and $4 \mathrm{~km}$ offshore. The main lobe is nearly symmetric with respect to the alongshore direction. There are two marginal flood channels on either side of the lobe with nearly symmetric channel configurations. The ebb channel is deep and extends offshore normal to the shoreline axis.

Mid-way within the inlet throat, the channel shoals slightly and then shifts towards the positive $y$-axis before exiting into the bay. The deepest sections are at either end of the inlet throat. The bay contains a series of incised tidal channels distributed into random, elongated fingers. The narrow bay causes the inlet channel to split into two main channels that turn sharply to align with the $y$-axis. 
Figure 3.26. Calculated final depth for Humboldt Inlet after 100-year simulation. White areas shown inside the bays denote computational areas that were dry (above the water level) at the end of the simulation.

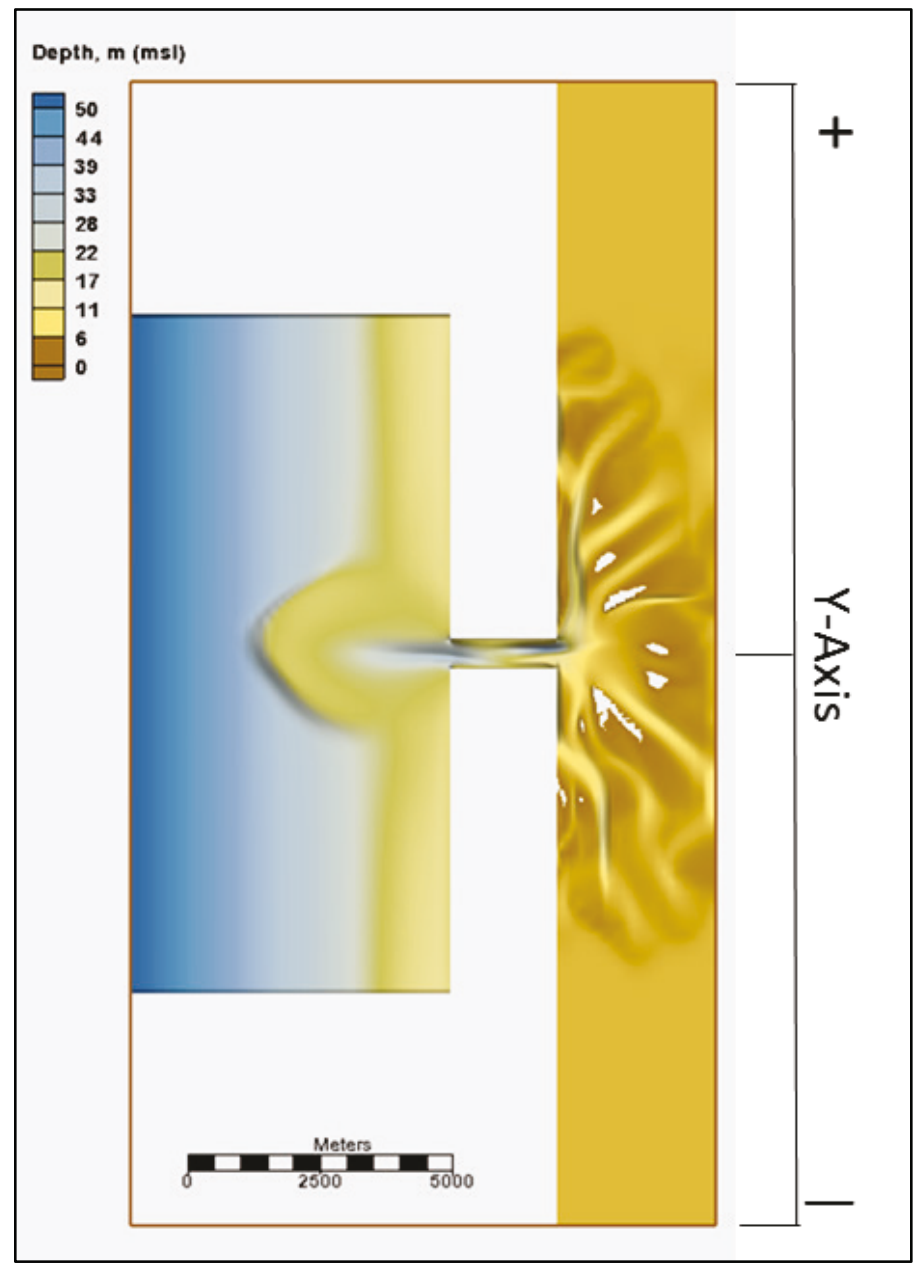

Figure 3.27 depicts the temporal evolution of the cross-sectional area at the ocean, midpoint and bay side of the inlet. Bed deepening at the ocean side is very uniform with the deepest section skewed in the negative $y$-direction. Bed deepening ends after approximately 60 years, and the cross section remains fairly stable. Initially, deepening at the midpoint is fairly uniform across the channel and stabilizes after approximately 60 years. On the bay side, deepening is skewed in the positive $y$-direction with slight migration toward the north ( $y$-positive) bank. Like the other modeled locations, the deepening process is smooth with the majority of the deepening occurring in the first 20 years. 
Figure 3.27. CMS-predicted temporal evolution of inlet cross-sectional area for Humboldt Inlet. Distances are alongshore from channel centerline with positive towards the right looking oceanward and negative towards the left.

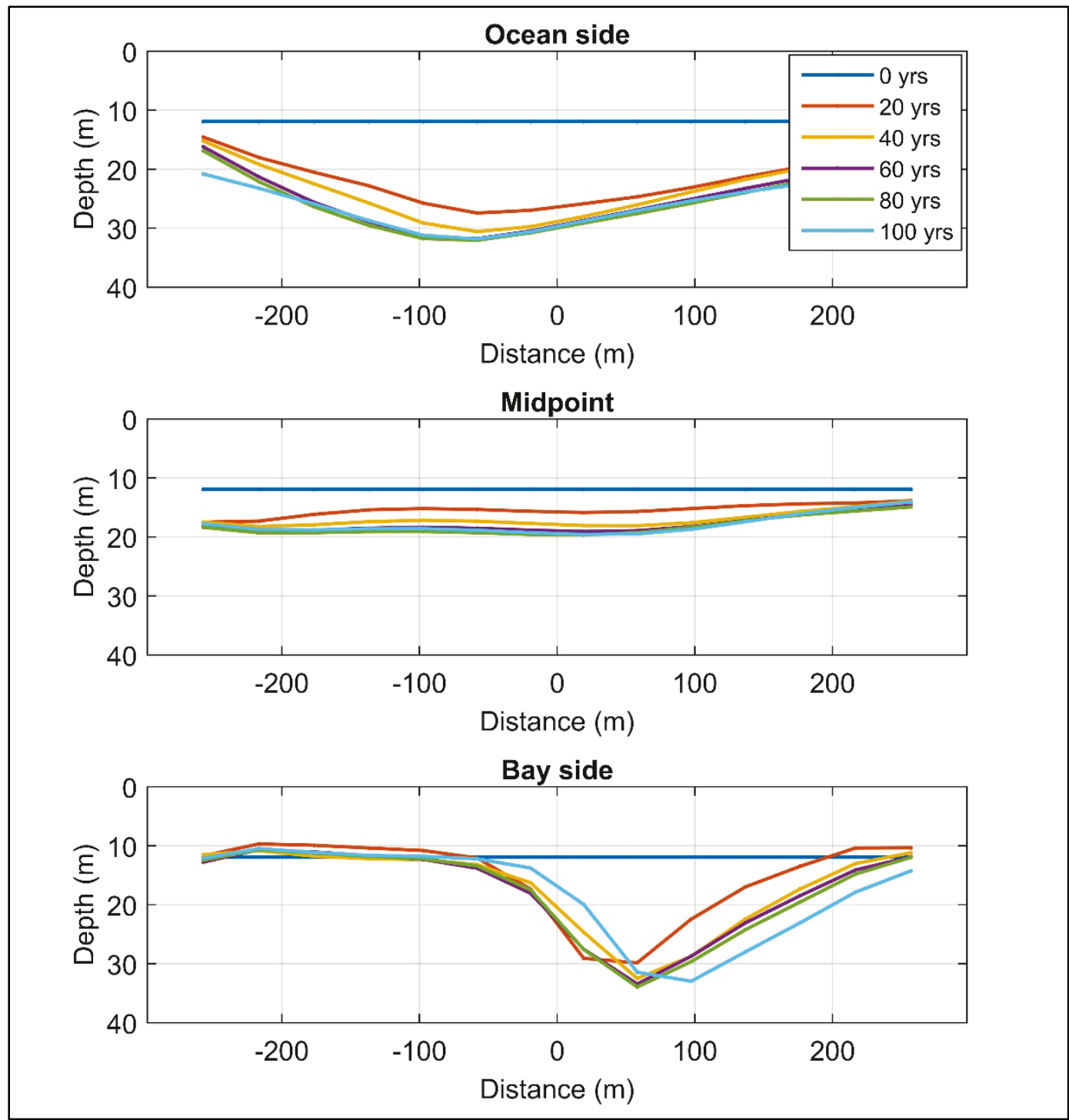

The predicted bed volume change shows net gains in the bay and ebb shoal and loss in the inlet (Figure 3.28). The primary sediment transport pathway removes material from the inlet and deposits it on the ebb shoal and flood shoals within the bay, with total increases exceeding inlet losses. The results for bed change for Humboldt indicate that it is flood dominant during much of the simulation timeframe. The additional sediment is introduced via longshore sediment transport along the adjacent beaches. By the end of the simulation, the ebb shoal continues to grow, and the inlet and bay begin to stabilize and show little net change. The mass balance suggests large sediment inputs from the offshore area and possible longshore sediment drift delivering sediment to the ebb shoal and bay. 
Figure 3.28. Calculated bed volume change for Humboldt Inlet.

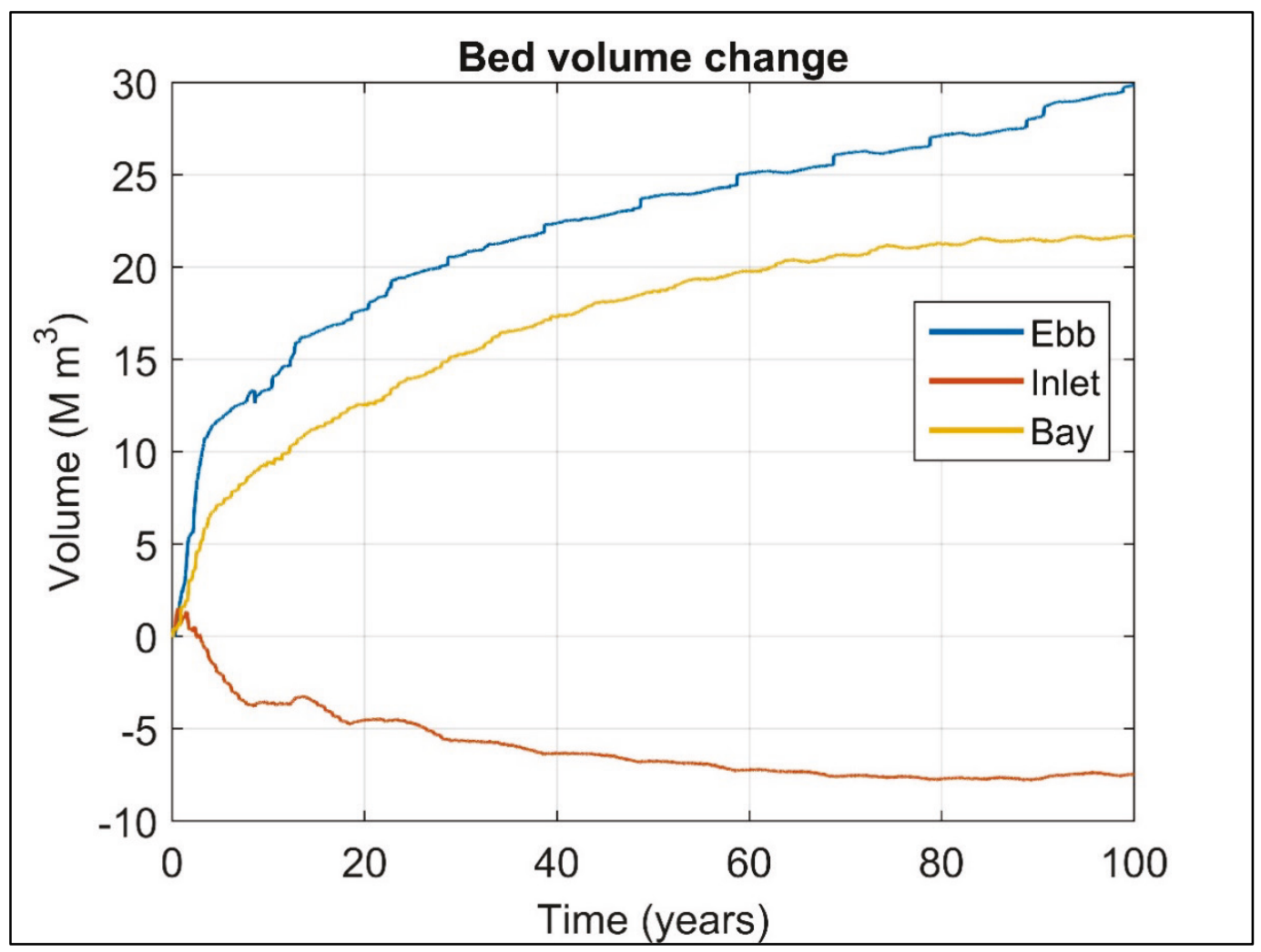

\subsubsection{Hydrodynamics}

Spatial current magnitude distribution near the end of the simulation during maximum flood and maximum ebb is depicted in Figure 3.29 and Figure 3.30, respectively. Flood currents enter primarily through the marginal flood channels and strengthen in the inlet throat. Current strength is broad across the much of the inlet throat and remains strong upon exiting the inlet following the deeper bay channels. Tidal flats have developed in the bay forming linear bars between the channels. Ebb currents are consistently strong within the bay channels and converge at the inlet. The ebb jet is more concentrated with the highest velocities centered in the channel thalweg. Upon exiting, currents disperse somewhat but are concentrated in the north and south channels. The net flow is stronger during flood especially in the bay, which is consistent with the sediment transport pathways described above. 
Figure 3.29. Current magnitude during maximum flood at the end of the 100-year simulation for Humboldt. White areas shown inside the bays denote computational areas that were dry (above the water level) at the end of the simulation.

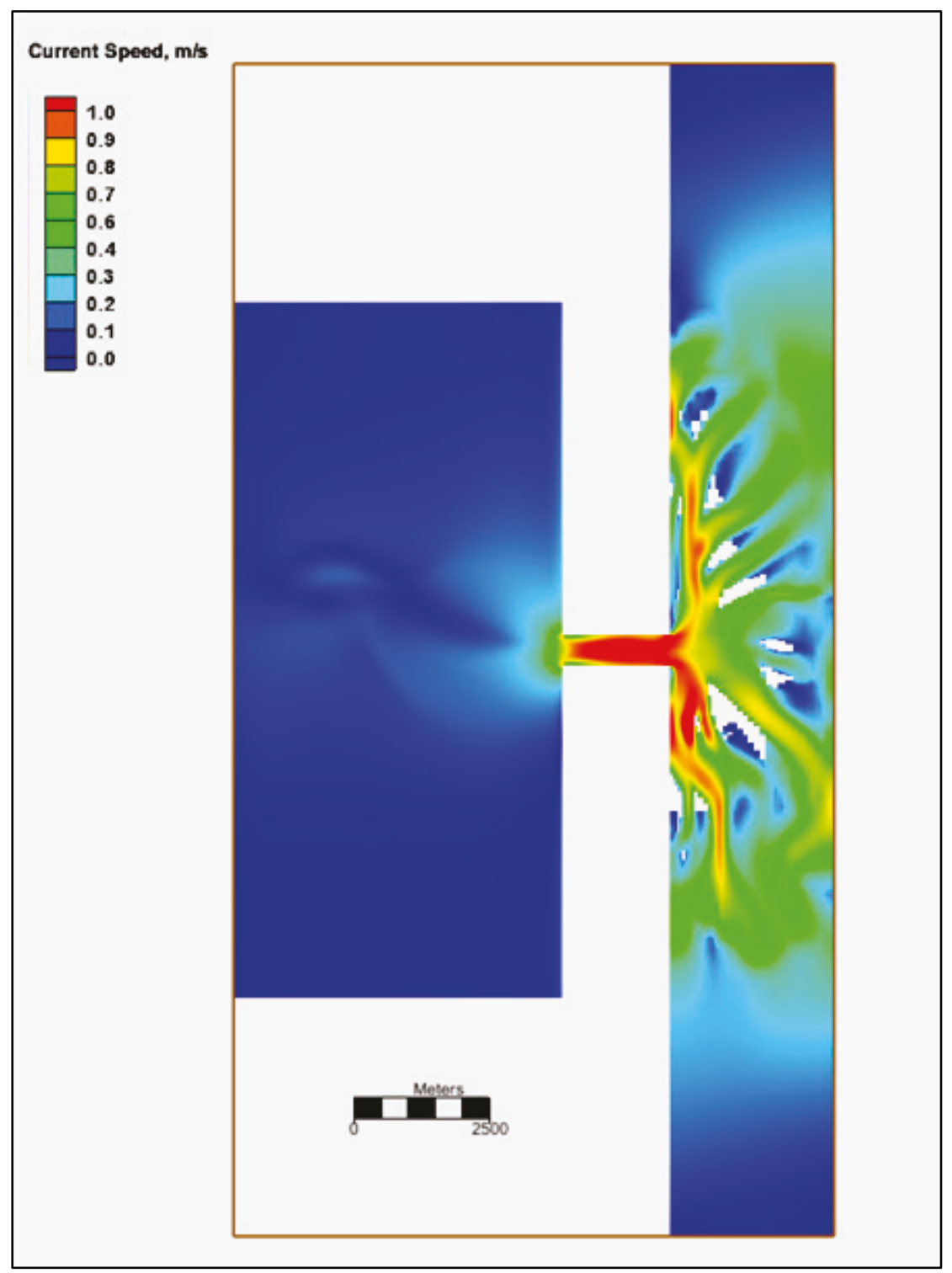


Figure 3.30. Current magnitude during maximum ebb at the end of the 100-year simulation for Humboldt. White areas shown inside the bays denote computational areas that were dry (above the water level) at the end of the simulation.

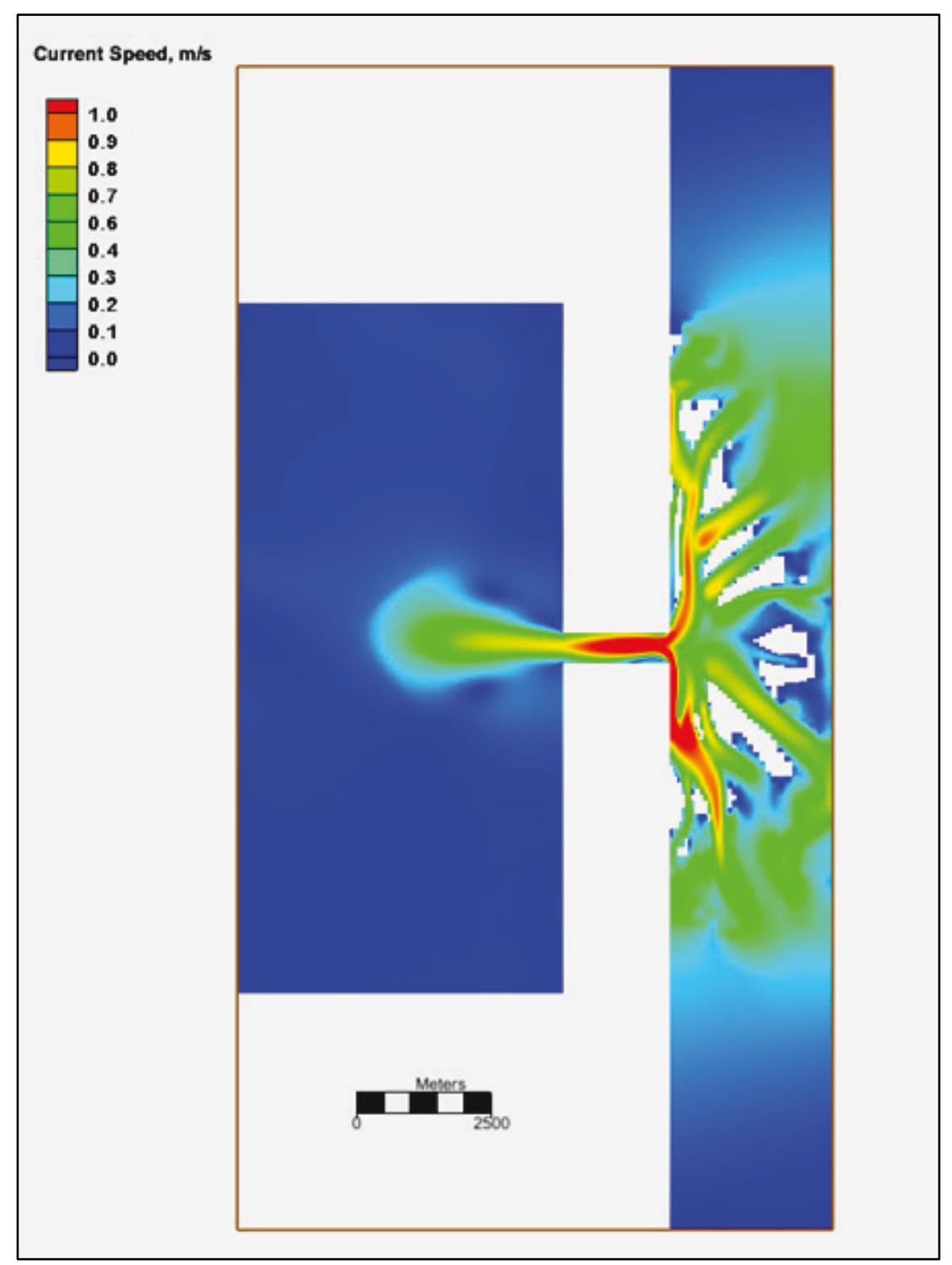

The tidal current envelope in the inlet throat decays over the first $\sim 50$ years and then is fairly uniform with an approximately $1 \mathrm{~m} / \mathrm{sec}$ maximum amplitude (Figure 3.31). Peak current amplitude, which drives sediment transport, is likewise fairly uniform after 50 years. In addition to tidal variations, the volume flux amplitude envelope is fairly uniform with a slight initial increase as the inlet throat cross-sectional area increases (Figure 3.32). The flux and tidal prism envelopes are fairly uniform through the simulation. 
Figure 3.31. Average and peak average tidal currents at the midpoint of the inlet (top left and top right inset, respectively). The two smaller panels (right inset) illustrate current patterns for the last year of the simulation.

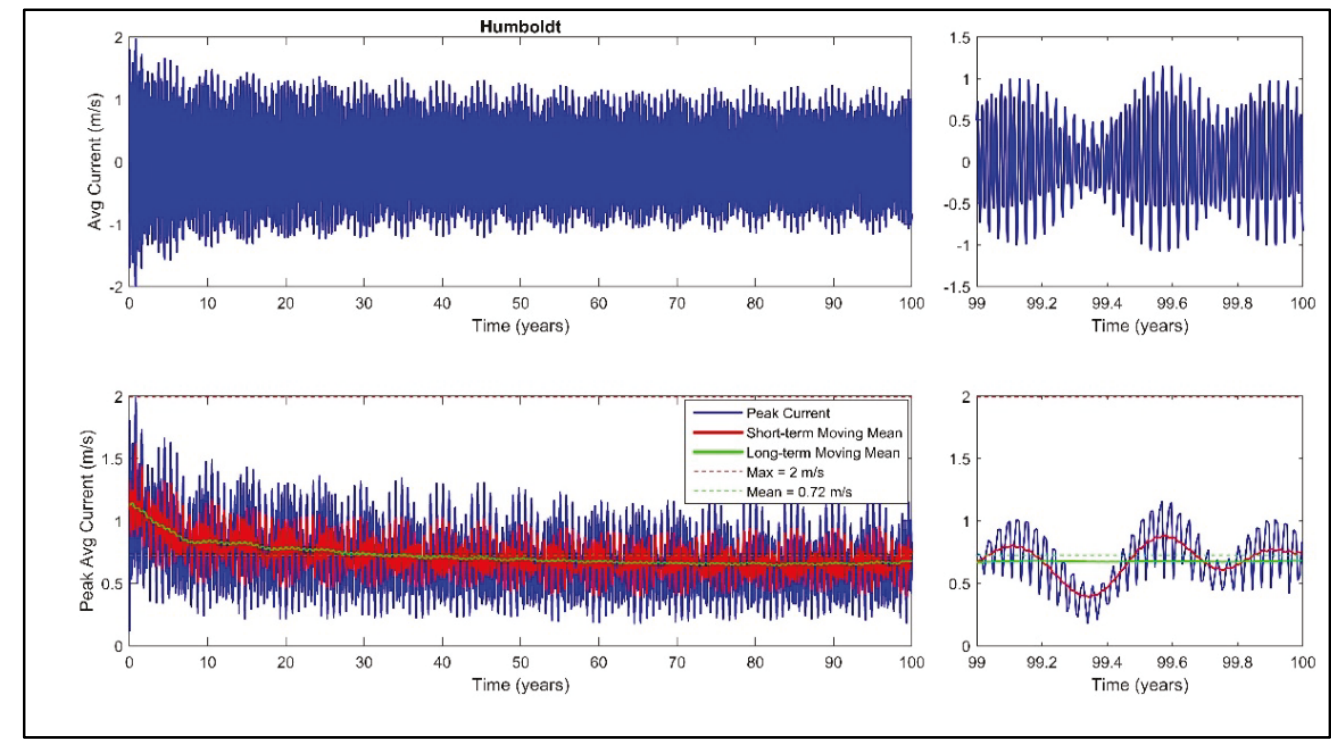

Figure 3.32. Volume flux and tidal prism (top left and top right inset, respectively) at the inlet midpoint. The two smaller panels (right inset) denote the last year of the simulation to illustrate tidal variability.

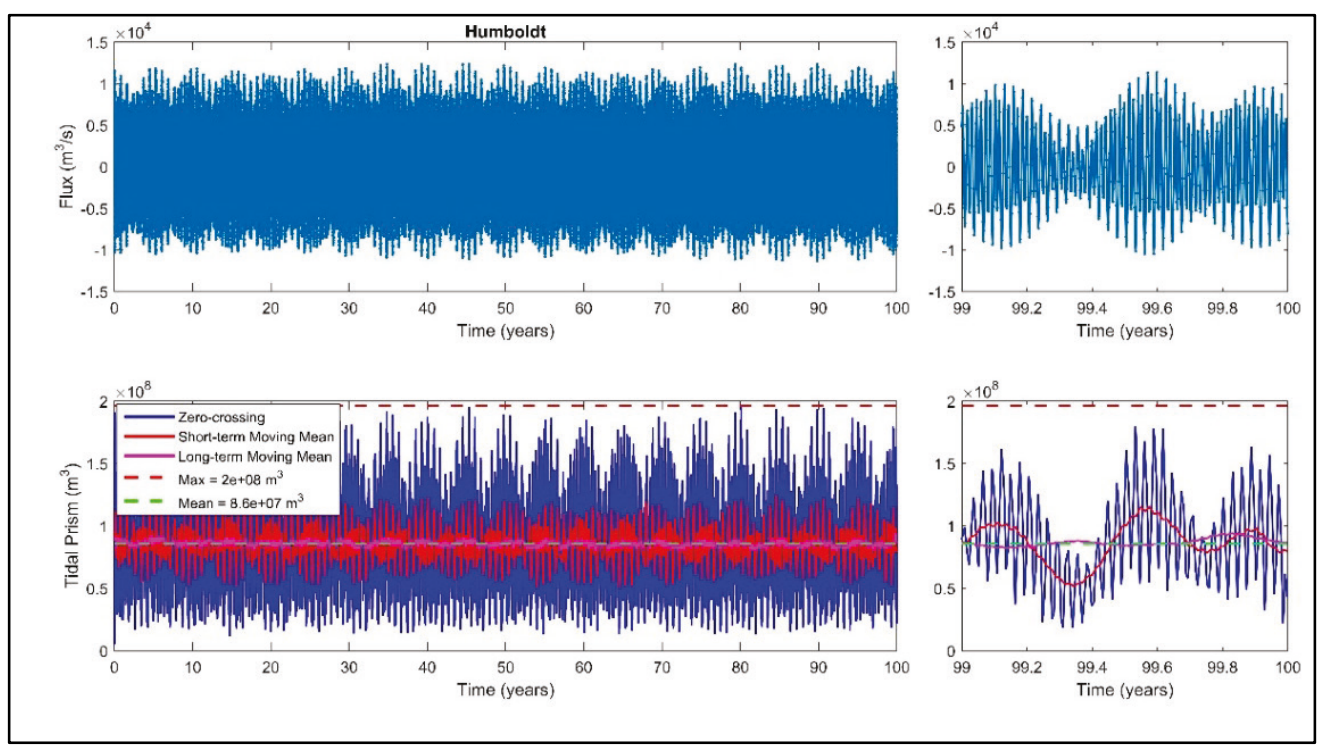

Maximum water surface elevation difference between the ocean and bay decreases rapidly during the first 10 years and then more gradually for the remainder of the simulation (Figure 3.33). The extremes are asymmetric with respect to the zero-crossing as indicated by a larger $\Delta \eta$ during maximum flood. This tidal distortion produces greater sea surface slope across the inlet during flood leading to stronger inflow into the bay. 
Figure 3.33. Calculated water surface elevation difference between the ocean and bay. Positive values denote sea surface slope from the ocean to the bay.

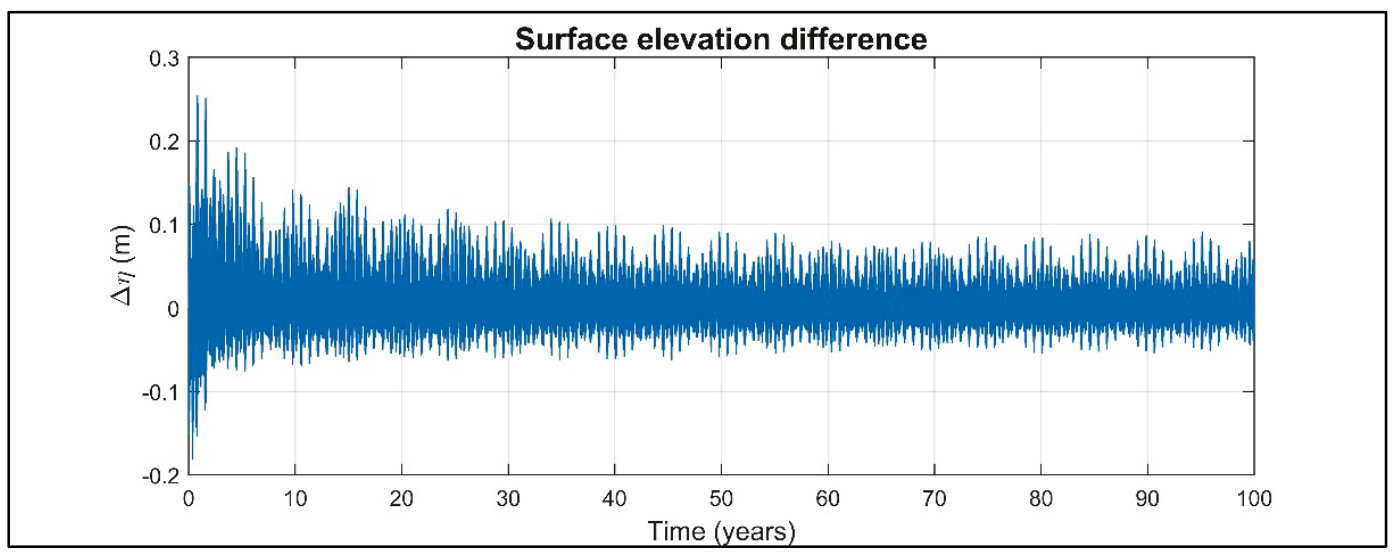

\subsubsection{Comparisons with empirical formulas}

At the beginning of the 100-year simulation, the cross-sectional area grows as the channel deepens (Figure 3.34). The CMS-predicted cross-sectional area at the midpoint and bay approaches the upper edge of the envelope, which encompasses the highest spring tide conditions including the greatest seasonal variability. The cross-sectional area at the ocean side overpredicts the empirical formula-predicted cross-sectional areas. This is reasonable as the ocean side cross section is located just outside of the inlet throat and is therefore not the narrowest cross section in the inlet throat, a criterion to apply the O'Brien formula.

Time series of ebb shoal volume change calculated by the CMS and empirically calculated is depicted in Figure 3.35. As sediment transport is associated with the strongest currents, the empirically predicted shoal volume should correlate with the spring tides at equilibrium. The CMS-calculated ebb shoal volume is significantly lower than the empirical predictions. However, by the end of the simulation, the ebb shoal volume has not reached equilibrium and is still growing and approaching the empirically predicted values. 
Figure 3.34. Inlet cross-sectional area calculated by the CMS (lines) at three inlet channel locations and the computed cross-sectional area from the tidal prism relationship (points).

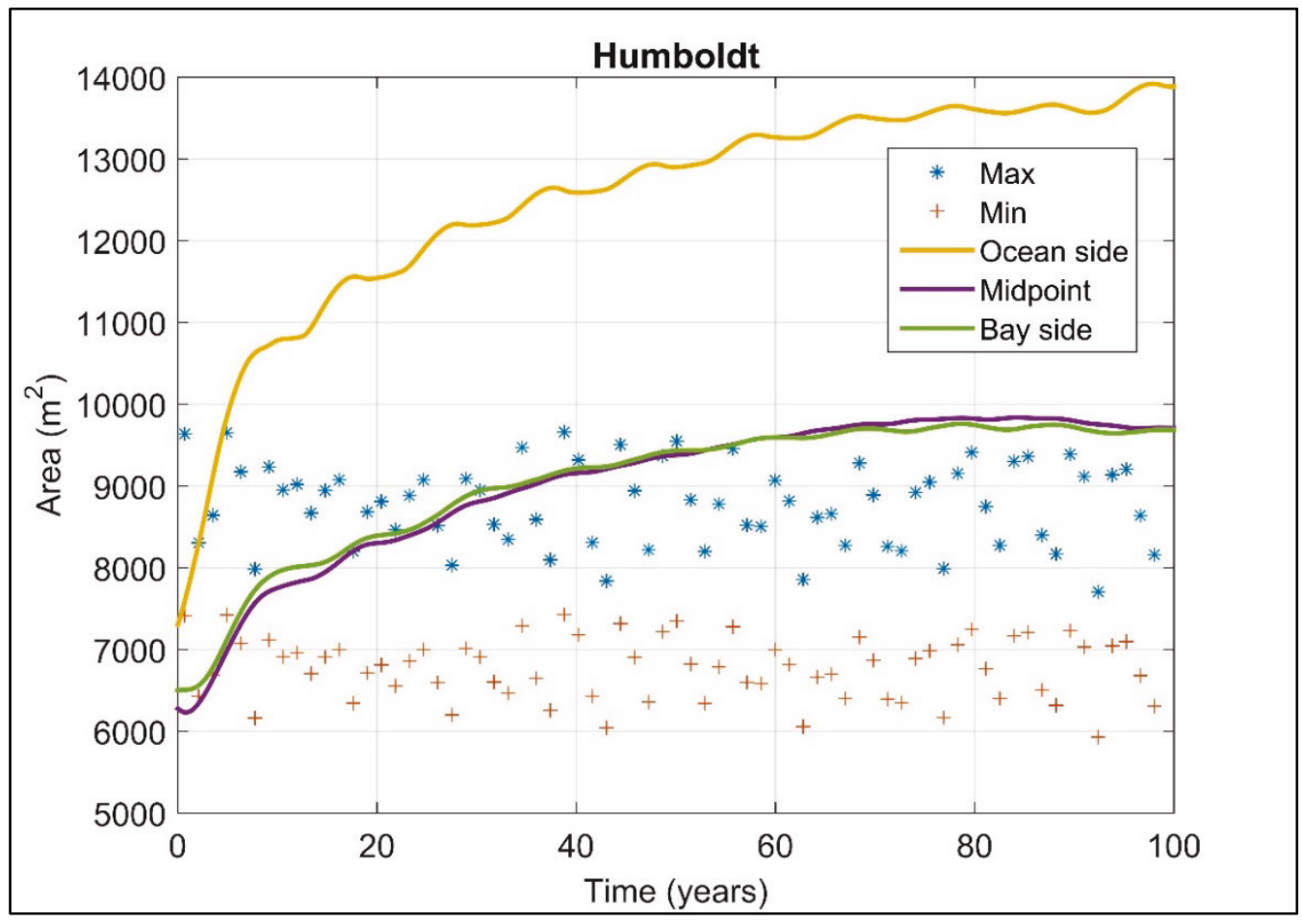

Figure 3.35. Time series of ebb shoal volume calculated by the CMS (yellow line) and the computed empirical formulas that relate tidal prism to ebb shoal volume (points).

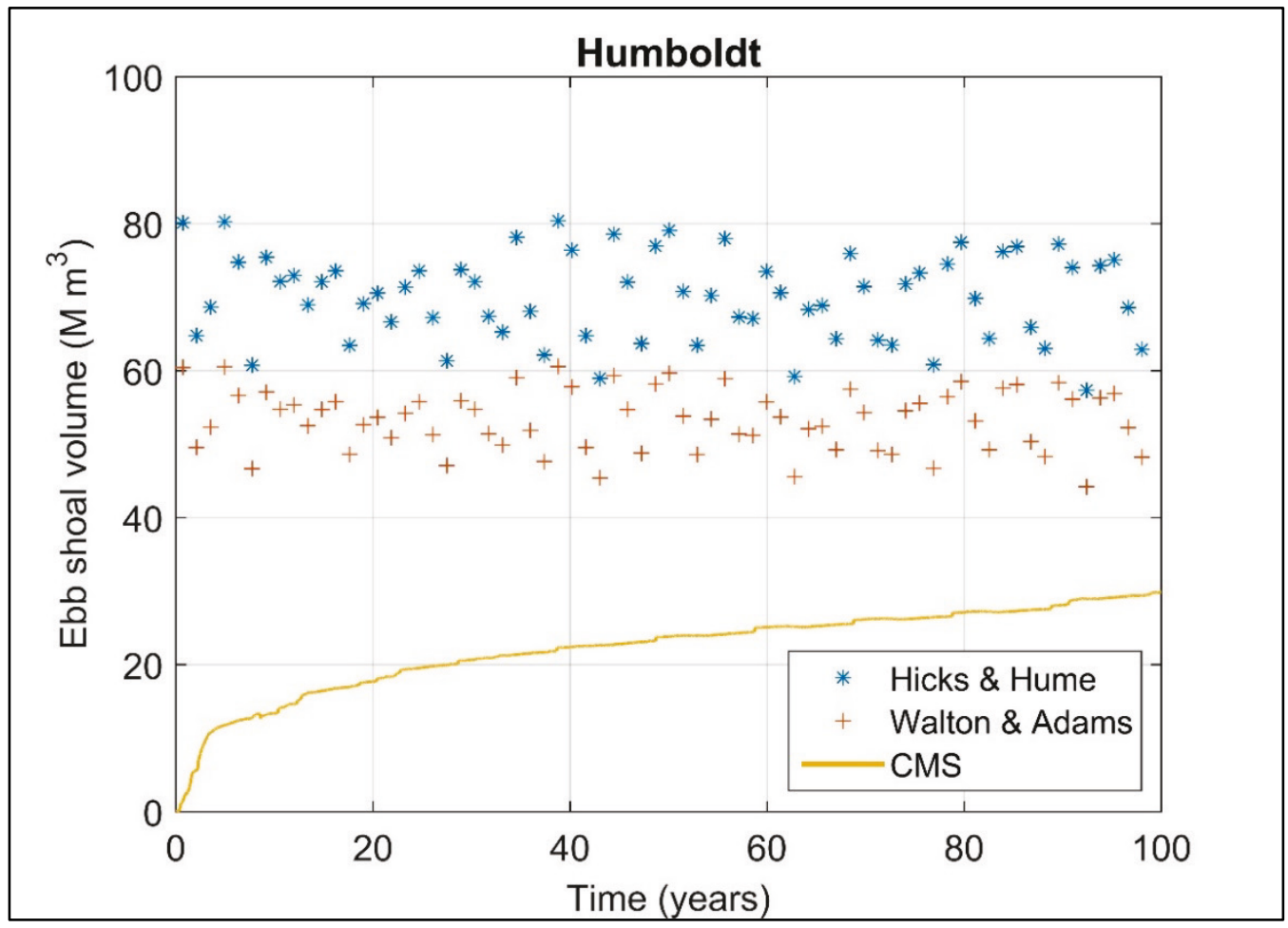


The Escoffier equilibrium theory applied to Humboldt is depicted in Figure 3.36. The input parameters (e.g., bay area, inlet dimensions, and water surface elevation) are derived from the CMS-idealized Humboldt simulation, and the plus signs denote the measured Humboldt Inlet minimal cross-sectional area. Data filtering and averaging parameters are the same as that applied to Grays Harbor. The CMS results reveal inlet growth and a net reduction in the maximum current that trends with the theoretical predictions. The CMS current is greater than the Escoffier solution but continues to decrease throughout the simulation.

Figure 3.36. An Escoffier analysis comparing the theoretically predicted (green and yellow lines) and CMS-computed (blue points) current. Plus signs denote the minimal cross-sectional area and the theoretical maximum velocity required for this inlet to remain stable. A 30-day low-pass filter delineates the overall trend of CMS-computed peak velocities for modeled cross-sectional areas (orange line).

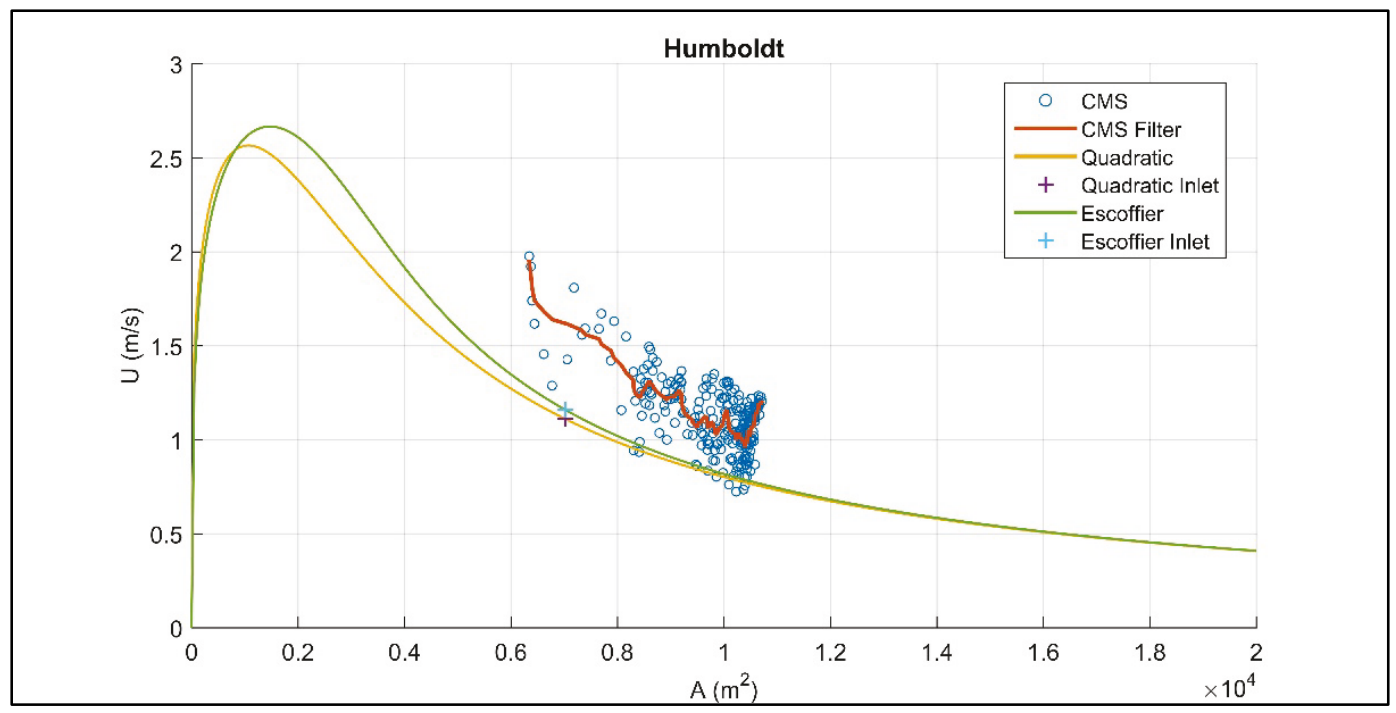

\subsection{Galveston Inlet}

Galveston Inlet, located on the Texas coast, is the largest Gulf Coast bay and inlet system. The Gulf Coast differs in both tidal range and wave conditions compared to the West Coast. The tidal range is approximately one-third of the West Coast tide range, and the tides are mixed to diurnal. Waves are generally weaker on the Gulf Coast than compared to the U.S. East and West Coasts due to limited fetch.

The model grid for the Galveston idealized inlet/bay system is depicted in Figure 3.37. The dimensions and initial depth are listed in Table A1. The selected bay width and length, 42 and $30.4 \mathrm{~km}$, respectively, produce a rectangular area equal to the area of Galveston Bay. The depth contours 
offshore are straight and parallel and follow an equilibrium beach profile near the shoreline. Water depth is constant at $3.5 \mathrm{~m}$ within the throat and bay and tapered at the ocean side to match the offshore depths. The bay depth is based upon average conditions for Galveston.

Figure 3.37. CMS grid and bathymetry for idealized Galveston simulation.

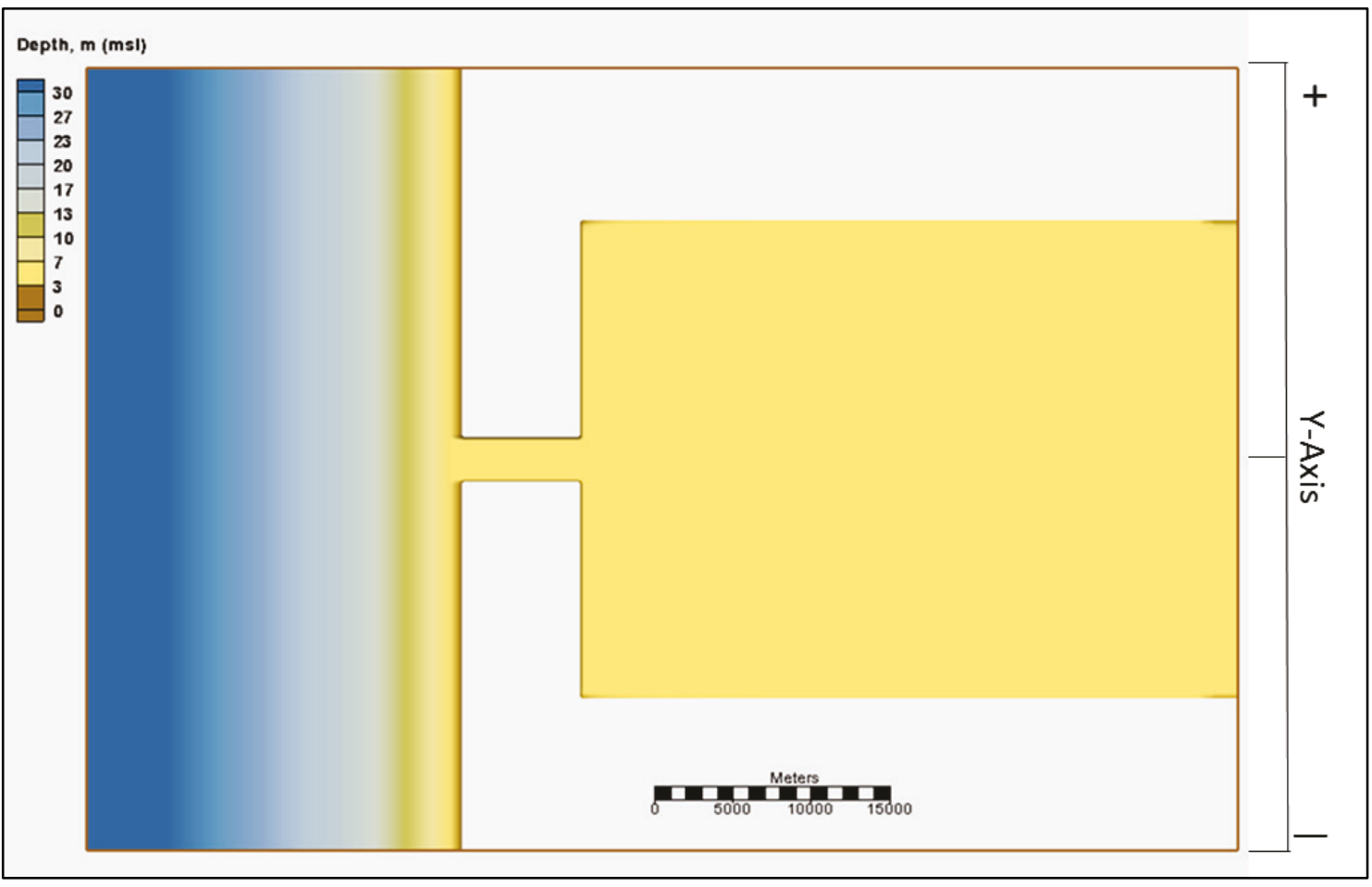

\subsubsection{Morphology}

The final morphological evolution reveals that the ebb shoal extends approximately $5 \mathrm{~km}$ up (north) and down (south) the coast and $4 \mathrm{~km}$ offshore (Figure 3.38). The main lobe is elongated mostly symmetrically perpendicular yet angled slightly in the positive $y$-direction due to the wave generated longshore transport. The ebb channel extends offshore and rotates towards the negative $y$-direction.

The main channel within the inlet throat consists of two deep sections at either end, separated by a shallow region in the middle. The deeper sections are on opposite sides of the inlet and are aligned with the centerline. On the bay side of the inlet the channel bifurcates but then sharply terminates upon entering the bay. Within the bay, there are no discernable channels. 
Figure 3.38. Calculated final depth for Galveston after 100-year simulation.

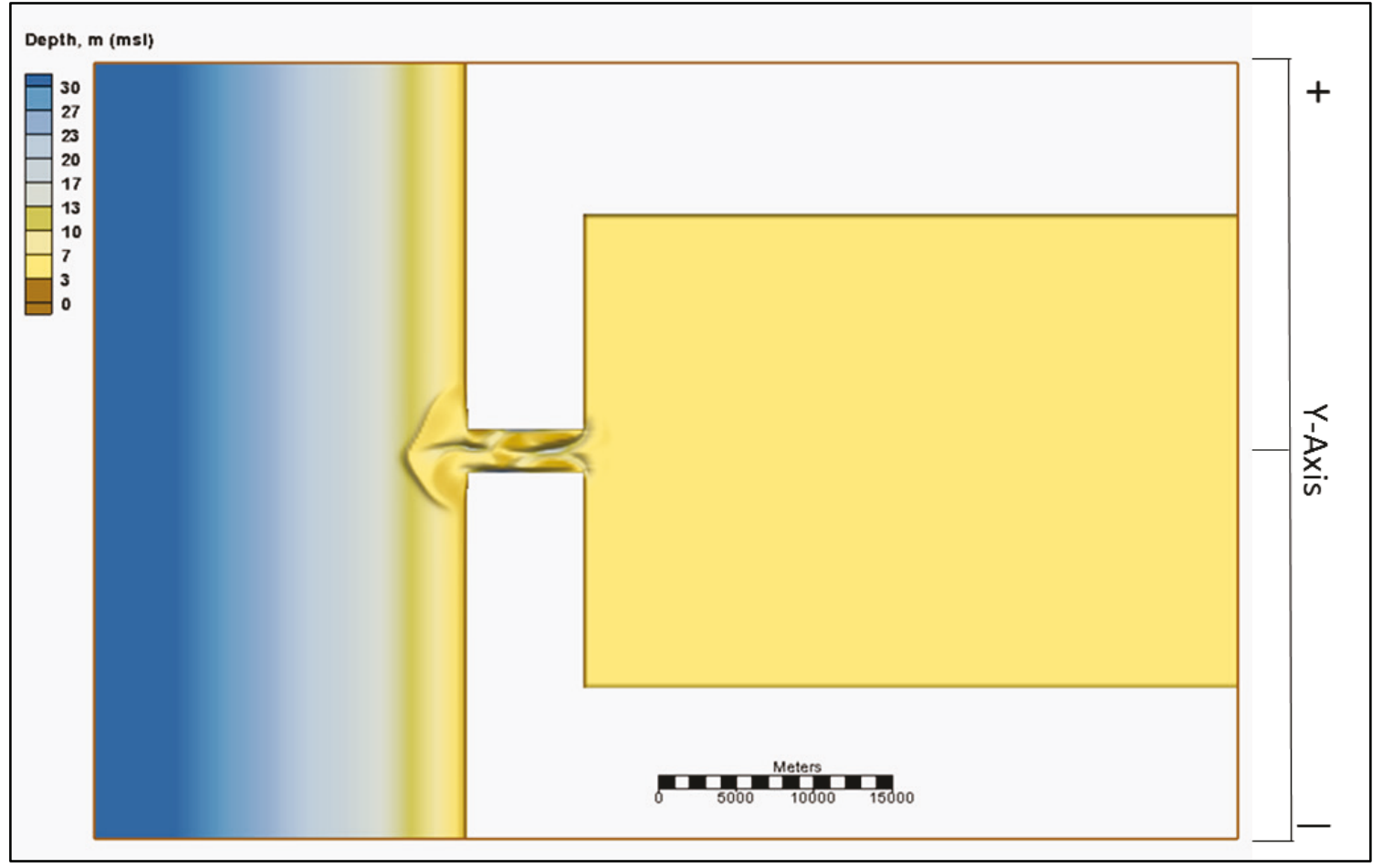

Figure 3.39 depicts the temporal evolution of the cross-sectional area at the ocean, midpoint, and bay side of the inlet. Bed deepening at the ocean side is skewed towards the positive side of the inlet forming a deep incised channel by the end of the simulation. The midpoint evolves into deep channels on the sides of the inlet with a shallow region in the middle. Bed deepening at the bay side shows steady channel formation on either side of the inlet centerline separating a shallower shoal in the middle. In general, the channel continues to evolve throughout the simulation at a significant yet diminishing rate. The thalweg is not well defined through the inlet throat. There is a main channel at either end of the inlet, but it bifurcates and is partially braided in the inlet interior. The pattern is similar to an immature creek network that typifies marshes and other sediment-rich tidal flats. 
Figure 3.39. CMS-predicted temporal evolution of inlet cross-sectional area for Galveston. Distances are alongshore from channel centerline with positive towards the right looking oceanward and negative towards the left. Note the Ocean-side vertical axis is truncated to ensure consistency and clarity with the other plots.
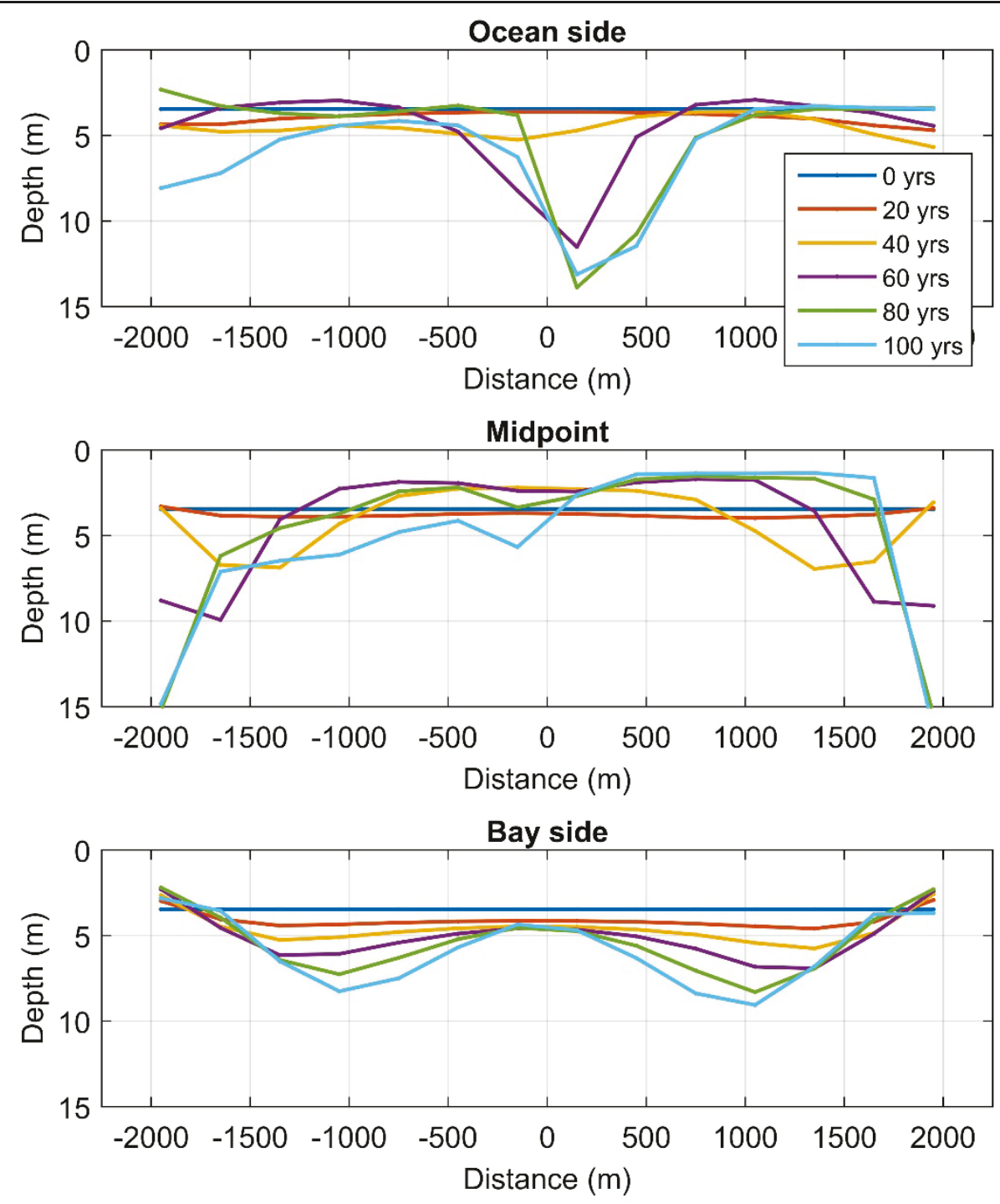

The net bed volume change shows erosion in the bay and inlet and growth in the ebb delta (Figure 3.40). Initially, bed change is slow due to the relatively weak tide compared to the west and east coast inlets. The primary sediment transport pathway removes material from the bay and inlet and deposits it on the ebb shoal. By the end of the simulation, the ebb shoal continues to grow, and the inlet and bay continue to lose sediment, owing to the inlet's ebb dominance. Net loss in the bay and inlet channel is nearly equal to the growth of the ebb shoal signifying that nearly all contributions to the ebb shoal growth are from initial deepening of the inlet channels. 
Figure 3.40. Calculated bed volume change for Galveston.

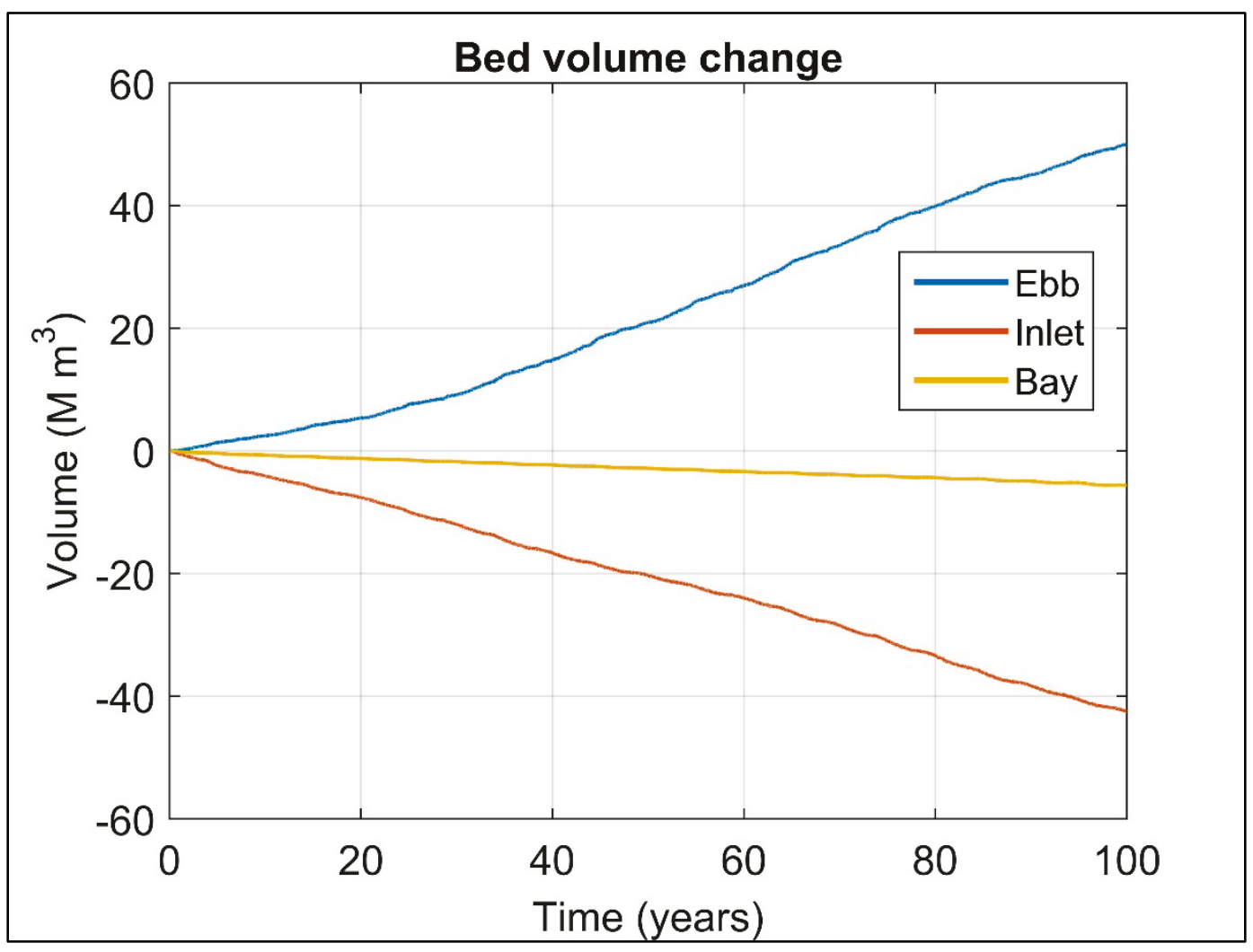

\subsubsection{Hydrodynamics}

Spatial current magnitude distribution near the end of the simulation during maximum flood and maximum ebb is depicted in Figure 3.41 and Figure 3.42, respectively. Radial flood currents enter the inlet then accelerate along the channel pathways. Currents split at the bay side of the inlet forming two flood channels at the bay entrance. Ebb currents exit the bay and enter the inlet in a radial pattern due to the absence of bay channel formation and converge to flow in the channel pathways. Upon exiting, currents disperse somewhat but are concentrated in the central and negative $y$-axis channels. The maximum flow is stronger during ebb especially in the inlet channels, which is consistent with ebb dominance and the sediment transport pathways described above. 
Figure 3.41. Current magnitude during maximum flood at the end of the 100-year simulation for Galveston.

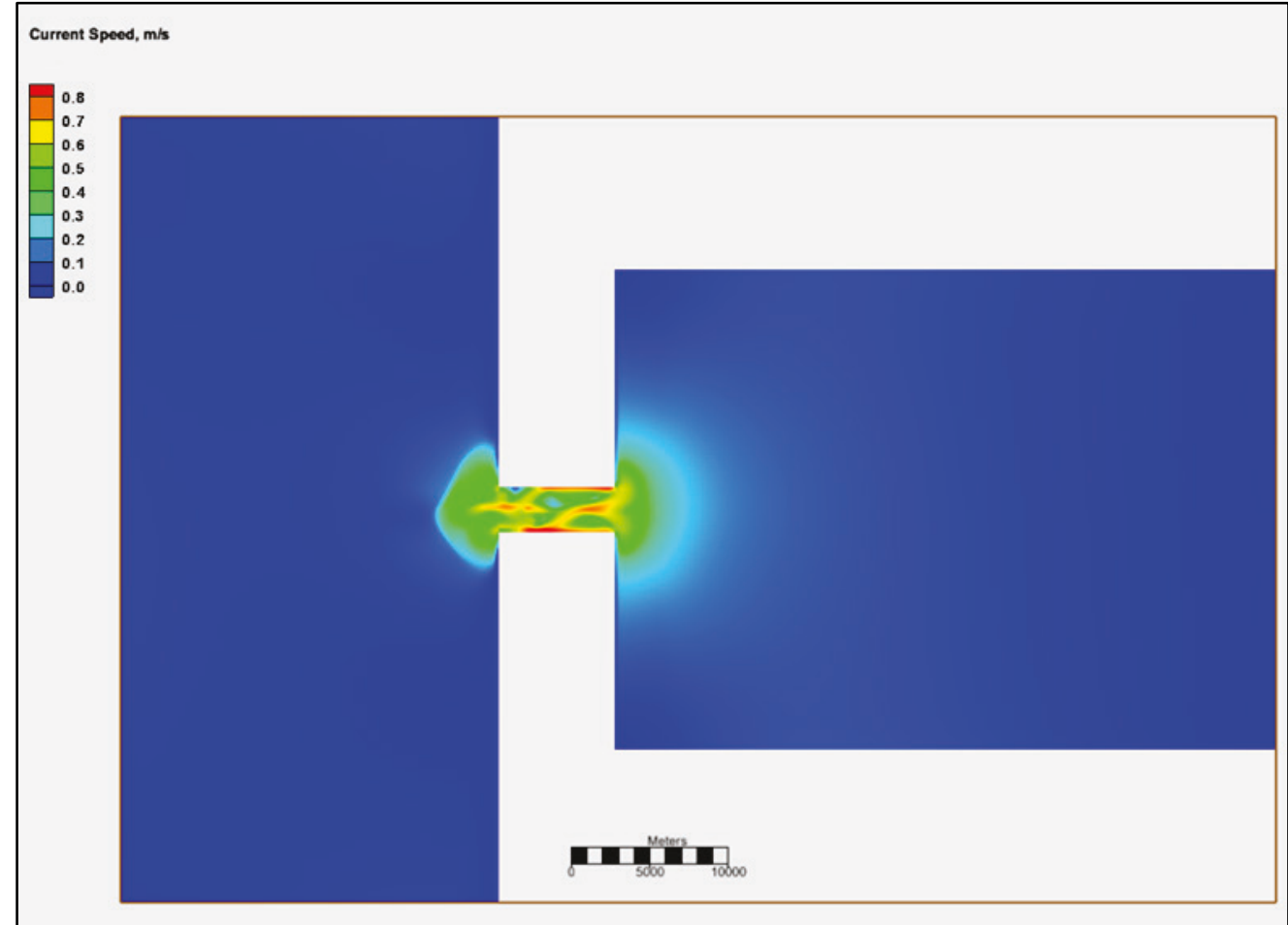

Figure 3.42. Current magnitude during maximum ebb at the end of the 100-year simulation for Galveston.

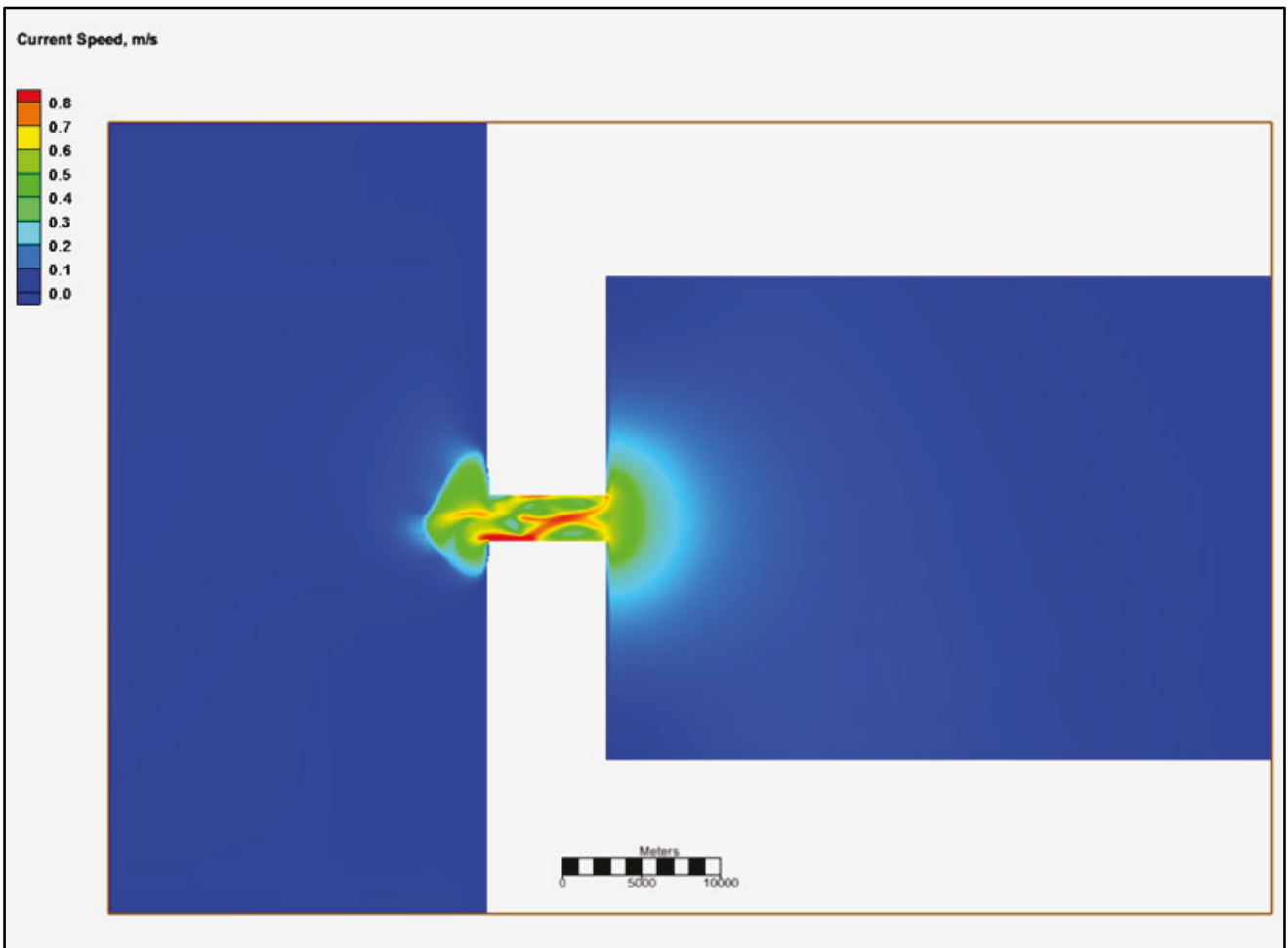


The tidal current envelope in the inlet throat is fairly uniform throughout the simulation with a slight decrease towards the end (Figure 3.43). Peak current amplitude increases slightly towards the middle of the simulation and then decreases. The volume flux (Figure 3.44) increases as the crosssectional area increases. The envelope widens but at a diminishing rate throughout the simulation. A similar pattern is seen in the tidal prism.

Figure 3.43. Average and peak average tidal currents at the midpoint of the inlet (top left and top right inset, respectively). The two smaller panels (right inset) illustrate current patterns for the last year of the simulation.

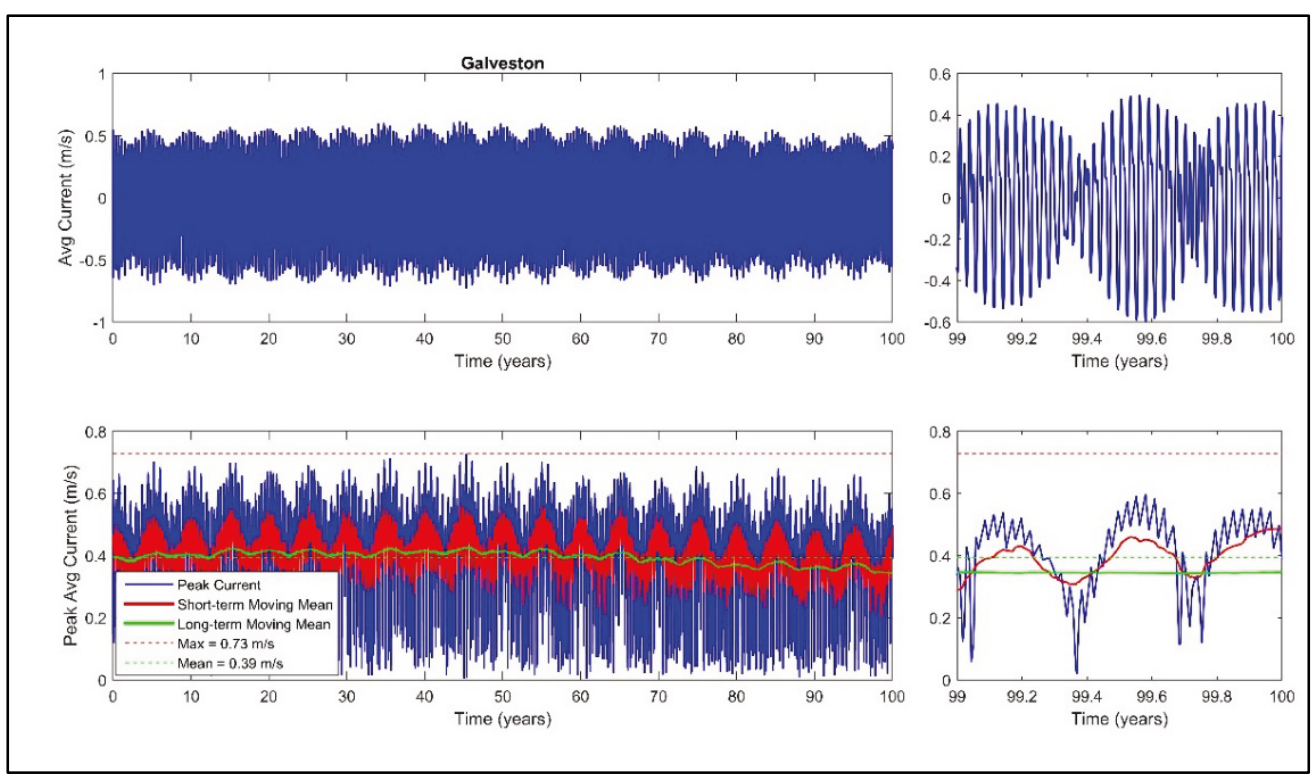

Figure 3.44. Volume flux and tidal prism (top left and top right inset, respectively) at the inlet midpoint. The two smaller panels (right inset) denote the last year of the simulation to illustrate tidal variability.

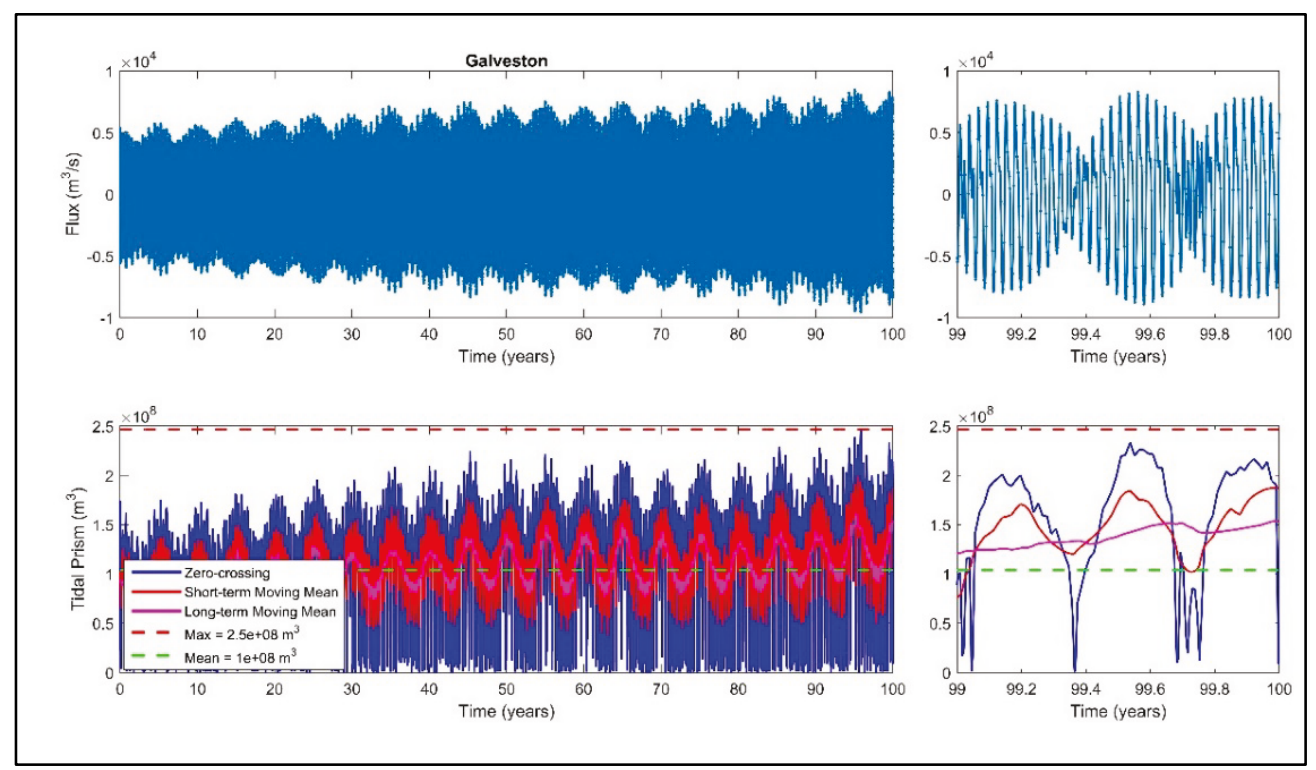


Maximum water surface elevation difference between the ocean and bay decreases throughout the simulation (Figure 3.45). The extremes are asymmetric with regard to the zero crossing, indicating steeper gradients during the ebb phase of the tidal cycle. As the simulation progresses, this difference diminishes primarily for the seaward tilting slope (negative), indicating less asymmetry between flood and ebb.

Figure 3.45. Calculated water surface elevation difference between the ocean and bay. Positive values denote sea surface slope from the ocean to the bay.

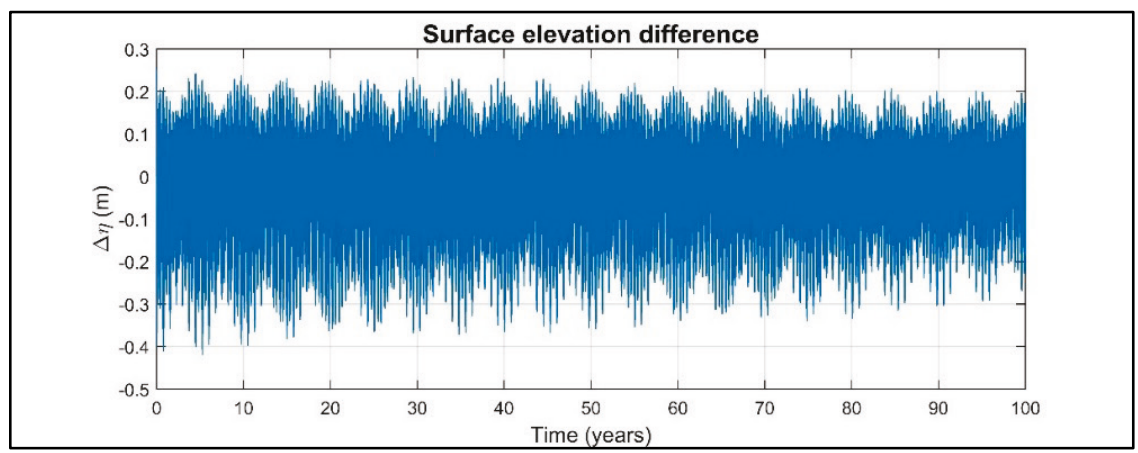

\subsubsection{Comparisons with empirical formulas}

The cross-sectional area calculated by the CMS increases uniformly with the maximum predicted values by the tidal prism relationship (Figure 3.46). The cross-sectional area at all three locations follow the upper edge of the tidal prism relationship envelope indicating that the CMS produces results consistent with the theory.

Figure 3.46. Inlet cross-sectional area calculated by the CMS (lines) at three inlet channel locations and the computed cross-sectional area from the tidal prism relationship (points).

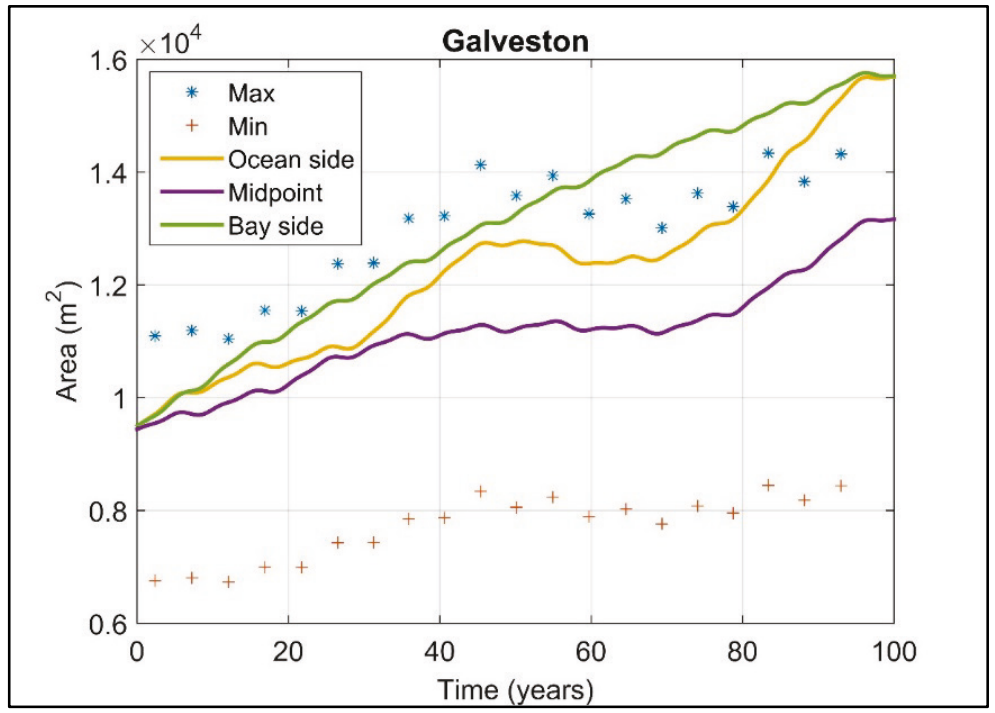


Time series of ebb shoal volume calculated by the CMS, and the computed volume from empirical formulas are depicted in Figure 3.47. The CMS ebb shoal volume is significantly smaller than the maximum predicted by the empirical formulas. However, both the CMS and empirical prediction are still increasing (as the cross-sectional area is also increasing), signifying that the system has not reached equilibrium by the end of the simulation.

Figure 3.47. Time series of ebb shoal volume calculated by the CMS (yellow line) and the computed empirical formulas that relate tidal prism to ebb shoal volume (points).

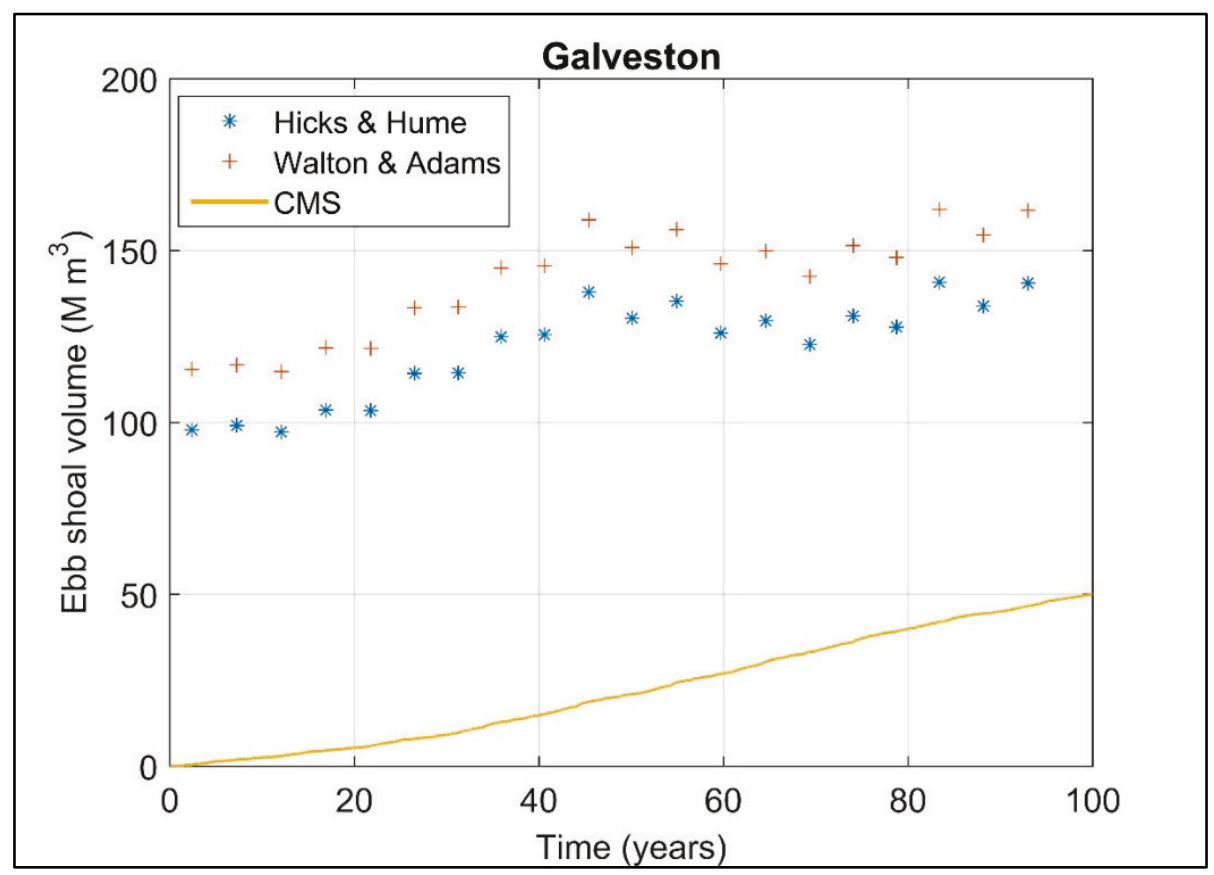

The Escoffier equilibrium theory applied to Galveston is depicted in Figure 3.48. The input parameters (e.g., bay area, inlet dimensions, and watersurface elevation) are derived from the CMS-idealized Galveston simulation, and the plus signs denote the measured Galveston minimal cross-sectional area. Data filtering and averaging parameters are the same as those applied to Grays Harbor. The CMS results reveal inlet deepening and a quasi-steady maximum current that is below the quadratic and Escoffier prediction. The CMS results also predict a smaller cross-sectional area compared to that observed in the present-day Galveston Inlet. Note that based on the CMS-computed hydrodynamics and morphodynamics, the modeled system has not reached equilibrium at 100 years. Further simulation time will likely increase the predicted cross-sectional area and result in an equilibrium state that is in closer agreement to the actual bay/inlet scale. 
Figure 3.48. An Escoffier analysis comparing the theoretically predicted (green and yellow lines) and CMS-computed (blue points) current. Plus signs denote the minimal cross-sectional area and the theoretical maximum velocity required for this inlet to remain stable. A 30-day low-pass filter delineates the overall trend of CMS-computed peak velocities for modeled cross-sectional areas (orange line).

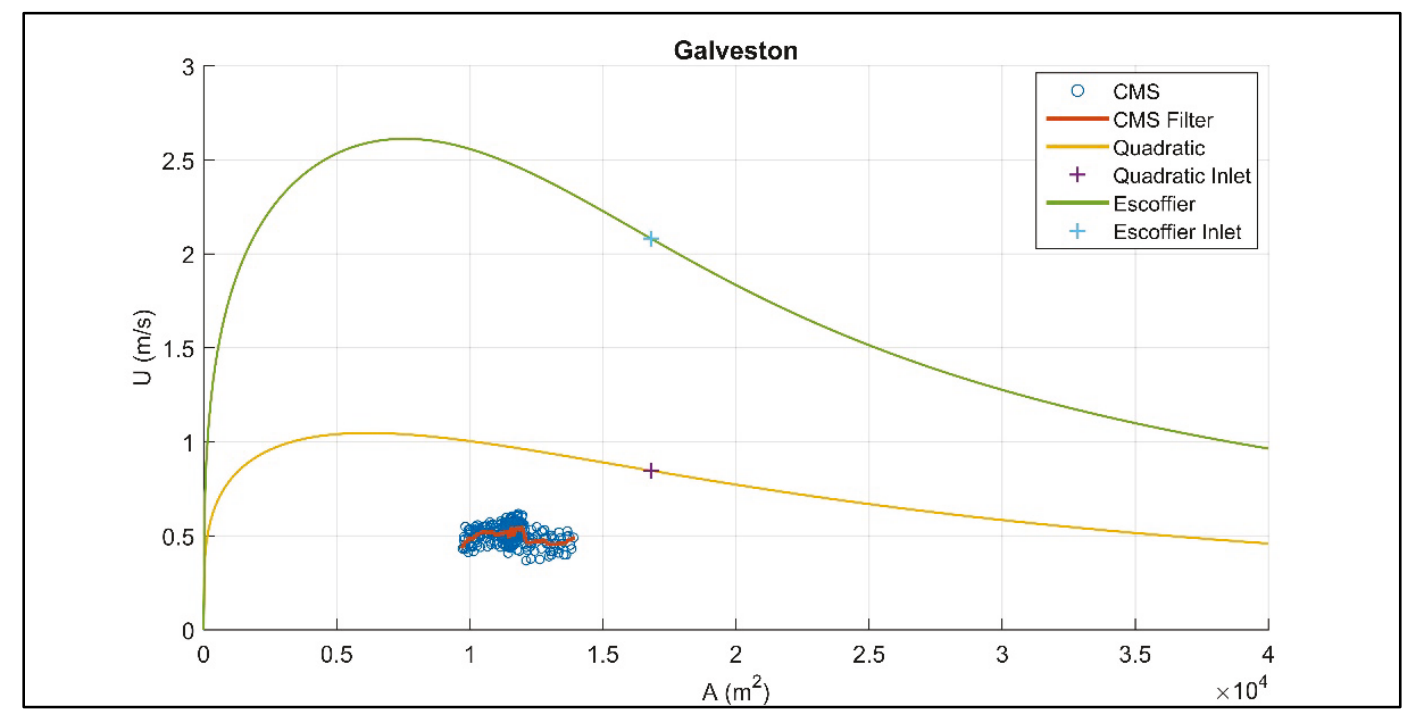

\subsection{East Pass}

East Pass is located in the Florida Panhandle near Pensacola, FL, and is part of a multi-inlet barrier island system. The model grid for the East Pass idealized inlet/bay system is depicted in Figure 3.49. The dimensions and initial depth are listed in Table A1. The modeled bay width and length, 7.4 and $46.7 \mathrm{~km}$, respectively, produce a rectangular area equal to the area of the back barrier lagoon, which is elongated in the alongshore direction as is typical of bar built estuaries. The depth contours offshore are straight and parallel and follow an equilibrium beach profile near the shoreline. Water depth is constant at $3.5 \mathrm{~m}$ within the throat and bay and tapered at the ocean side to match the offshore depths. The bay depth is constant and based upon average conditions for East Pass. 
Figure 3.49. CMS grid and bathymetry for idealized East Pass simulation. Closer view of the inlet in zoomed figure on the right.

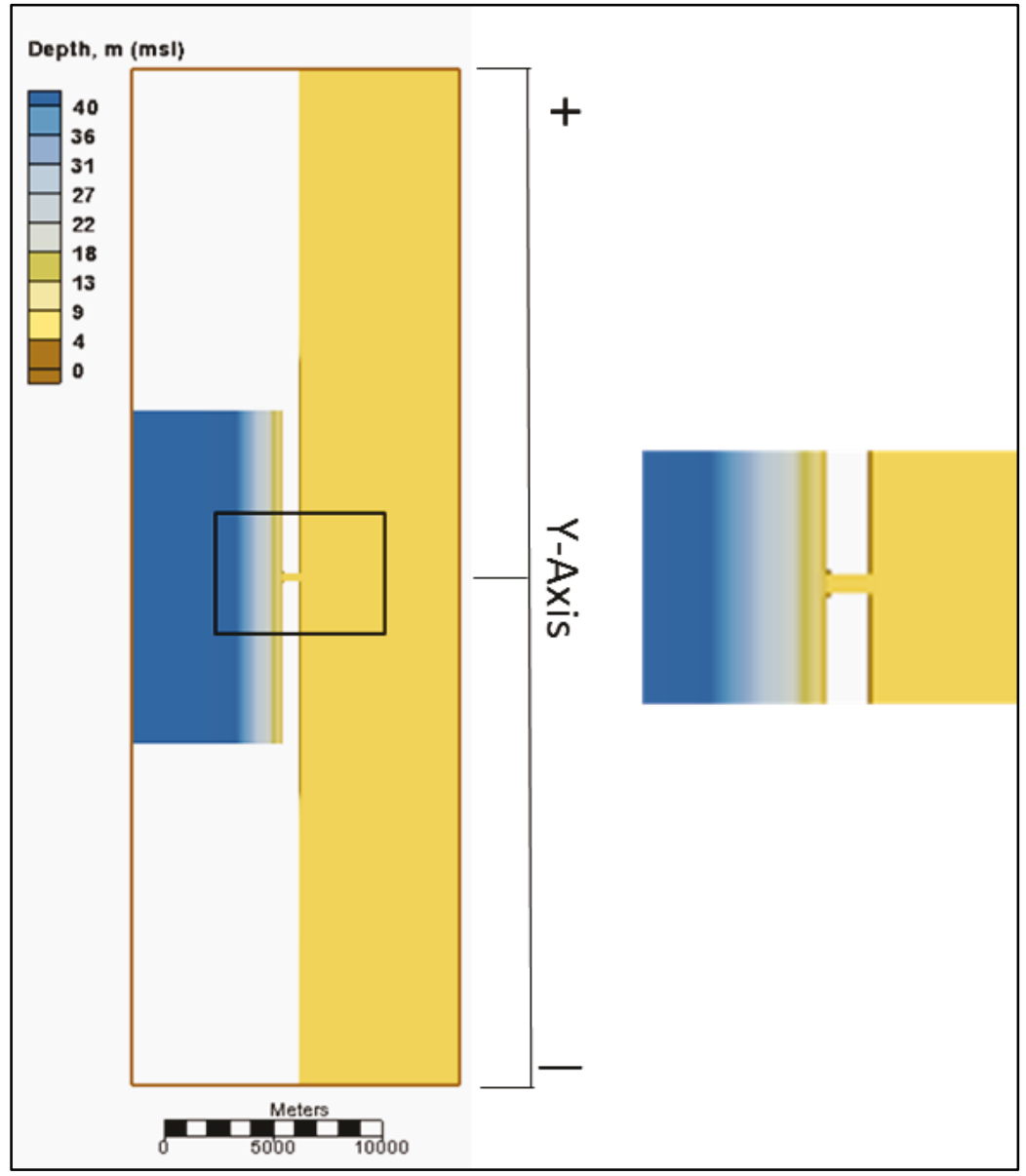

\subsubsection{Morphology}

The final morphological evolution shows that the ebb shoal extends approximately $1 \mathrm{~km}$ up (north) and down (south) the coast and $3 \mathrm{~km}$ offshore (Figure 3.50). The main lobe is symmetric with respect to the inlet axis, and the ebb channel is deep and aligned with the centerline of the shoal.

The main channel within the inlet throat is oriented along the centerline and then shallows before exiting into the bay. Shallow, linear shoals flank the inlet throat resulting from flow separation. The inlet channel bifurcates to align with the shoreline inside the bay, then shoals to shallow depths before extending further from the inlet. The bay is void of welldefined channels but rather forms some low depressions near the inlet. 
Figure 3.50. Calculated final depth for East Pass after 100-year simulation. Closer view of the inlet in zoomed figure on the right.

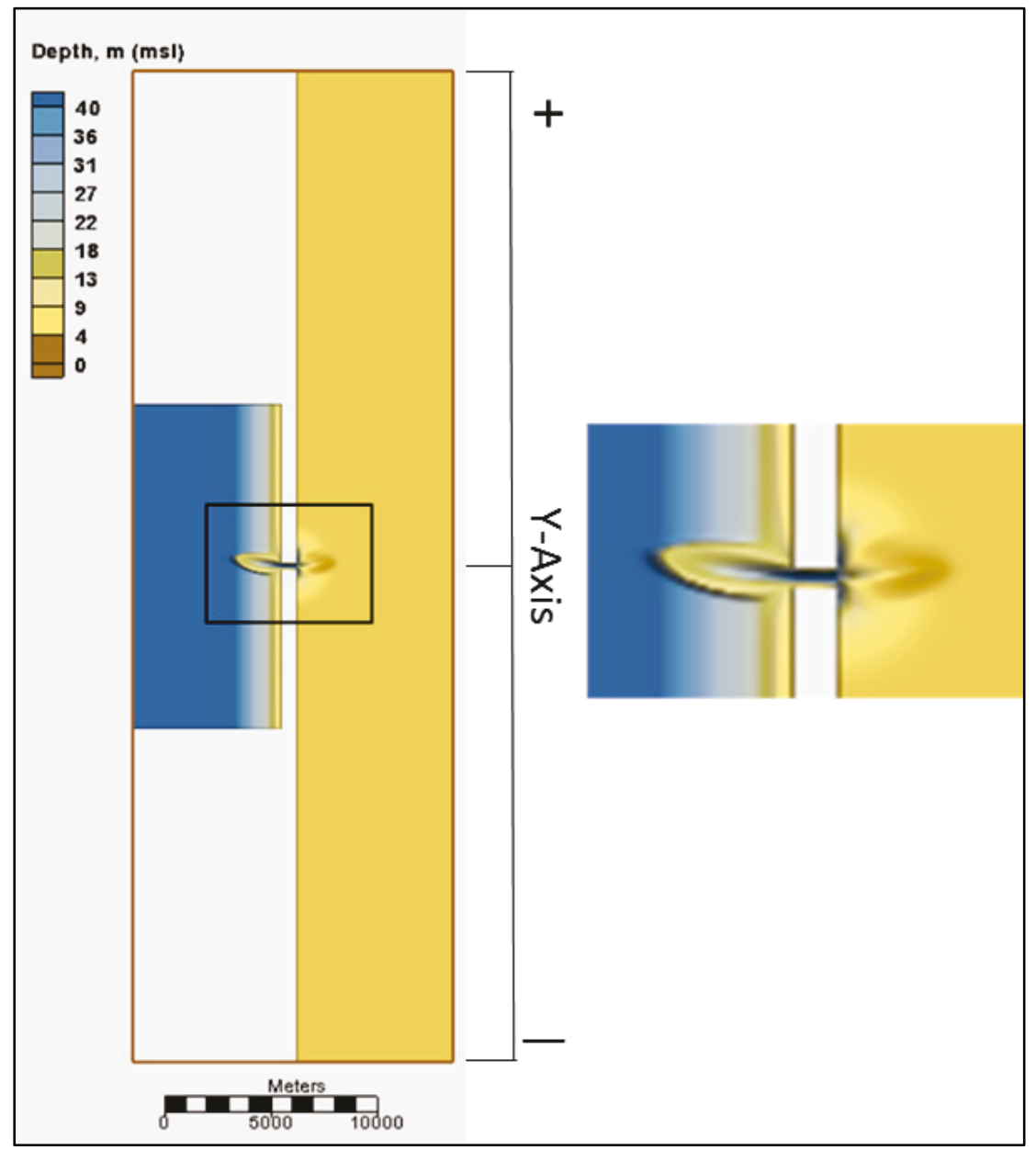

Figure 3.51 depicts the temporal evolution of the cross-sectional area at the ocean, midpoint, and bay side of the inlet. Bed deepening at all three locations is indicative of bed scouring in a confined channel, in which the erosion is greatest in the center forming a more or less symmetric crosssection. The inlet deepens rapidly during the first 20 years and then more gradually over the remainder of the simulation. The thalweg is slightly skewed towards the positive $y$-axis and remains stationary throughout the simulation. 
Figure 3.51. CMS-predicted temporal evolution of inlet cross-sectional area for East Pass. Distances are alongshore from channel centerline with positive towards the right looking oceanward and negative towards the left.

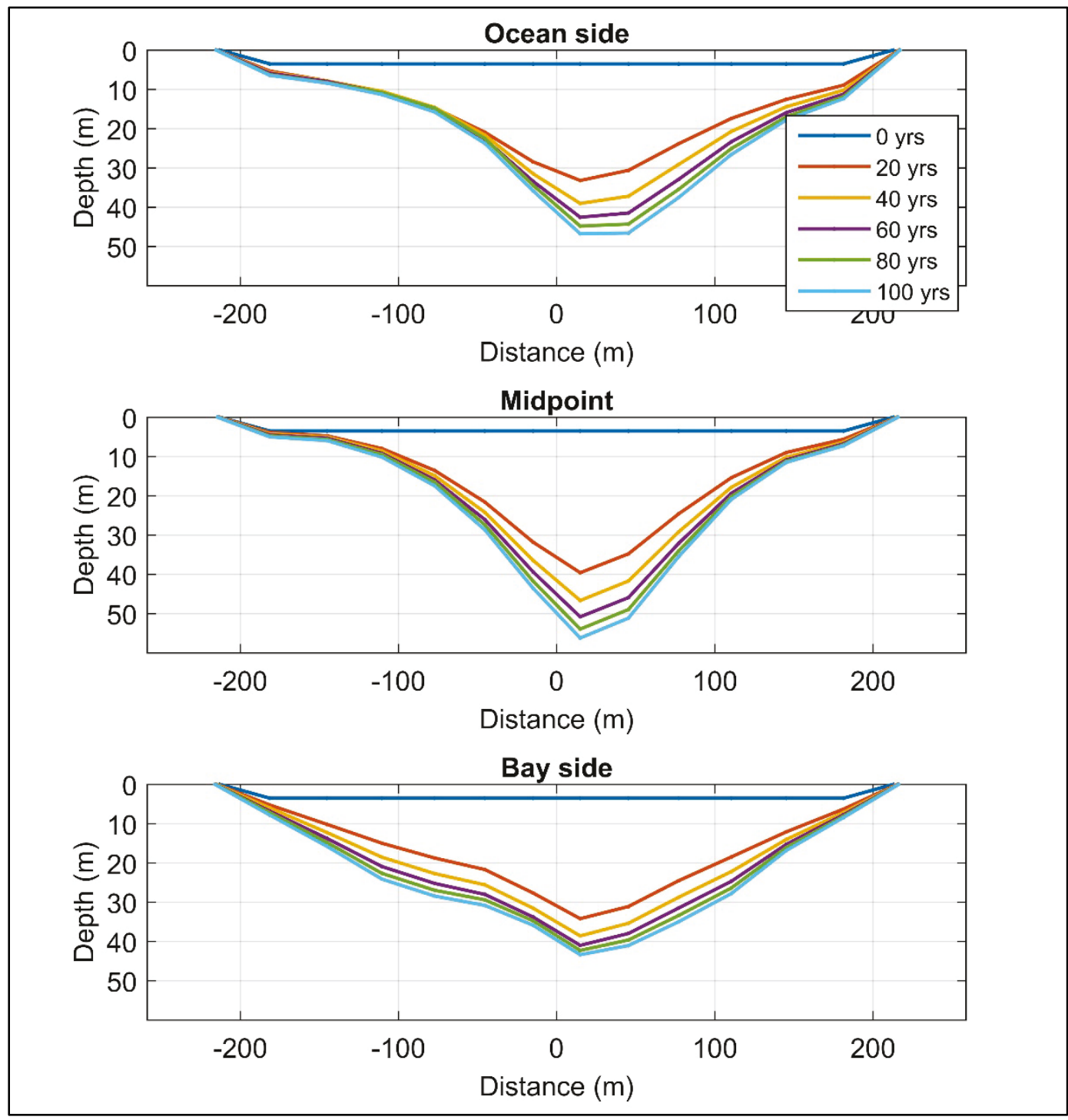

The bed volume change shows ebb shoal growth and inlet and bay loss (Figure 3.52). Ebb shoal volume increases throughout the simulation while the inlet erodes rapidly at first and slowly later in the simulation. The bay erodes continuously during the simulation at a greater rate than the inlet, owing to the inlet's ebb dominance. Net bay and inlet losses approximately balance net ebb shoal gains. 
Figure 3.52. Calculated bed volume change for East Pass.

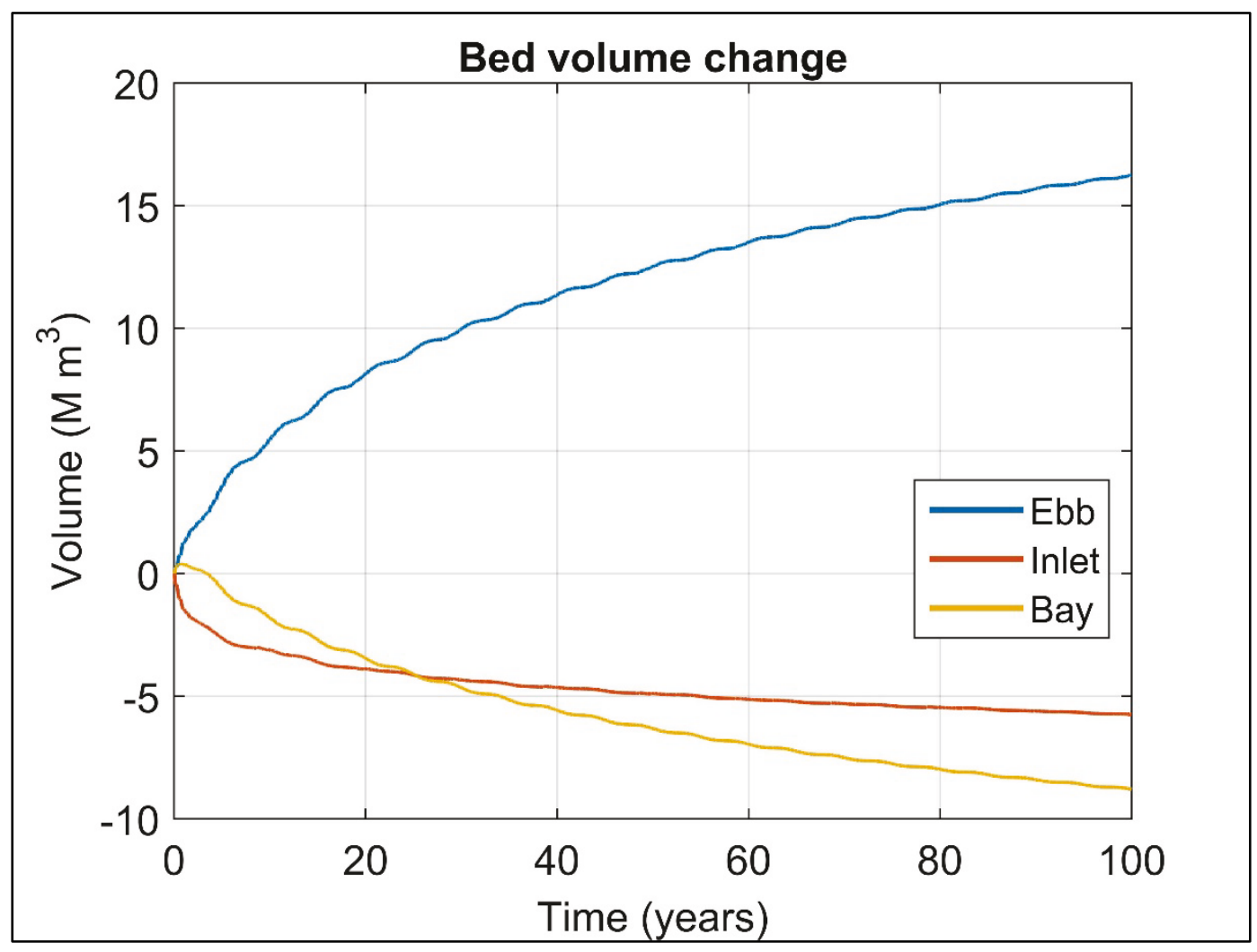

\subsubsection{Hydrodynamics}

Spatial current magnitude distribution near the end of the simulation during maximum flood and maximum ebb is depicted in Figure 3.53 and Figure 3.54, respectively. Flood currents enter the inlet, accelerate, and then exit the inlet and disperse laterally into the bay. The absence of a channel network within the bay leads to the observed pattern of wide flood flow dispersion near the inlet exit into the bay. Maximum ebb currents show a similar pattern in the bay, yet with some confluence and velocity increase near the edges of the inlet. Upon exiting the main ebb channel, the ebb flow forms a jet that extends offshore slightly rotated towards the positive $y$-axis. Maximum ebb currents are stronger within the inlet and are significantly stronger than maximum flood currents. 
Figure 3.53. Current magnitude during maximum flood at the end of the 100-year simulation for East Pass. Closer view of the inlet in zoomed figure on the right.

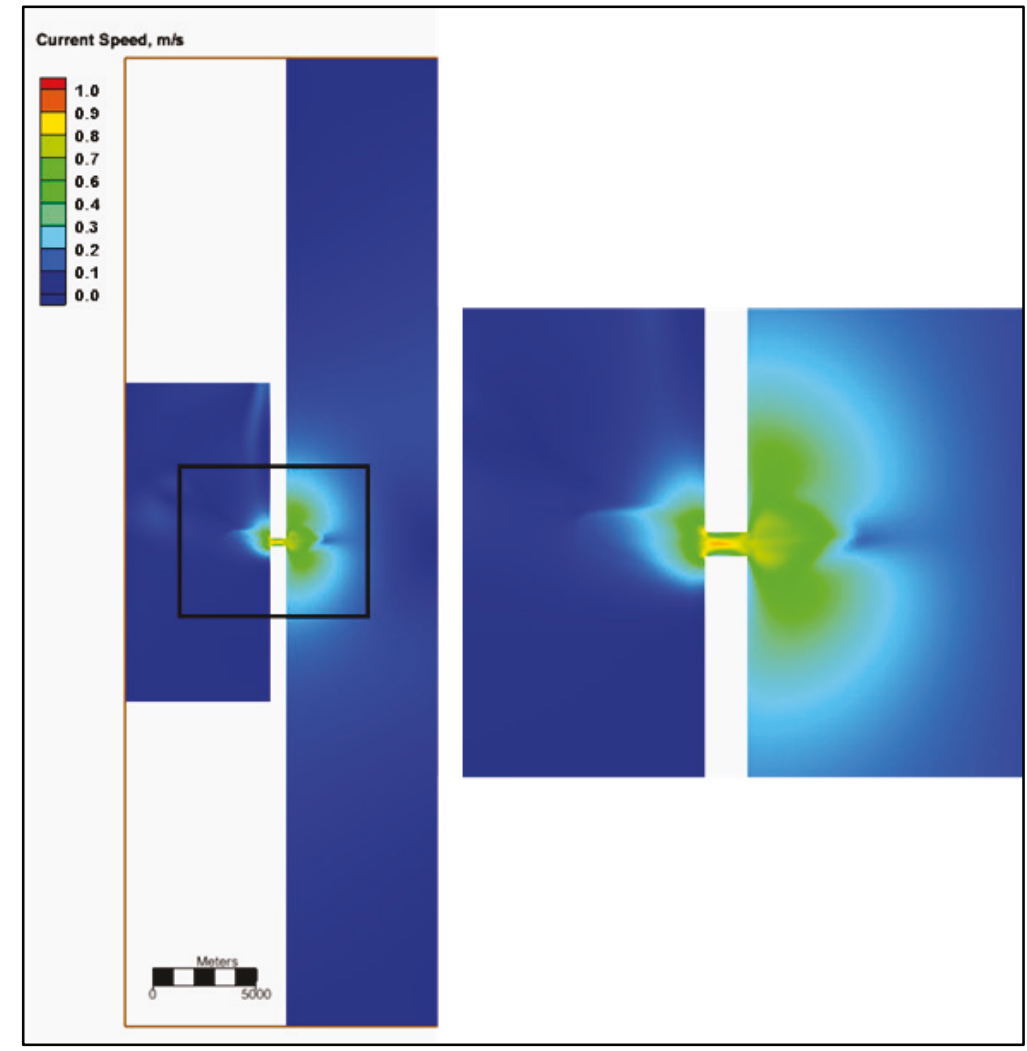

Figure 3.54. Current magnitude during maximum ebb at the end of the 100-year simulation for East Pass. Closer view of the inlet in zoomed figure on the right.

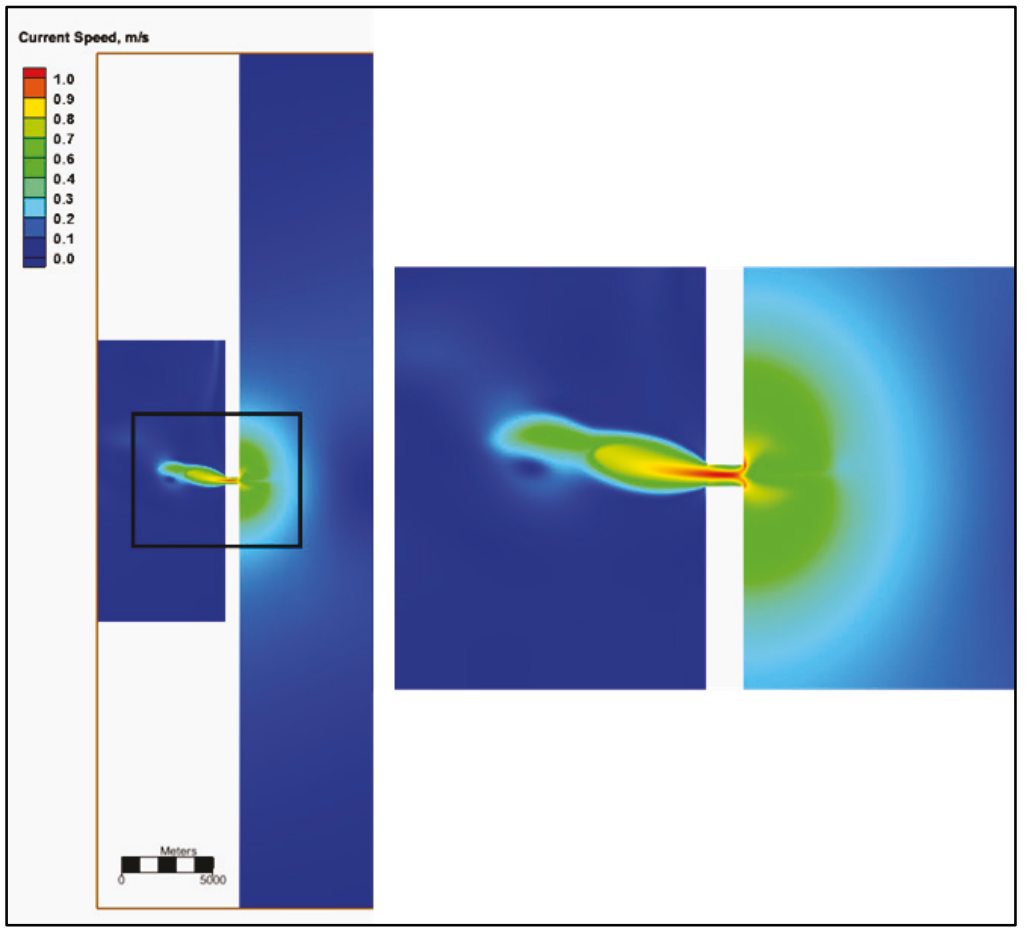


The tidal current envelope in the inlet throat decreases over the course of the simulation (Figure 3.55). Even though the current amplitude is decreasing through time, volume flux and tidal prism (Figure 3.56) initially increase as the cross-sectional area increases. Volume flux is ebb dominated during spring tide, and the long-term moving average tidal prism shows little variation from the mean after approximately 50 years.

Figure 3.55. Average and peak average tidal currents at the midpoint of the inlet (top left and top right inset, respectively). The two smaller panels (right inset) illustrate current patterns for the last year of the simulation.

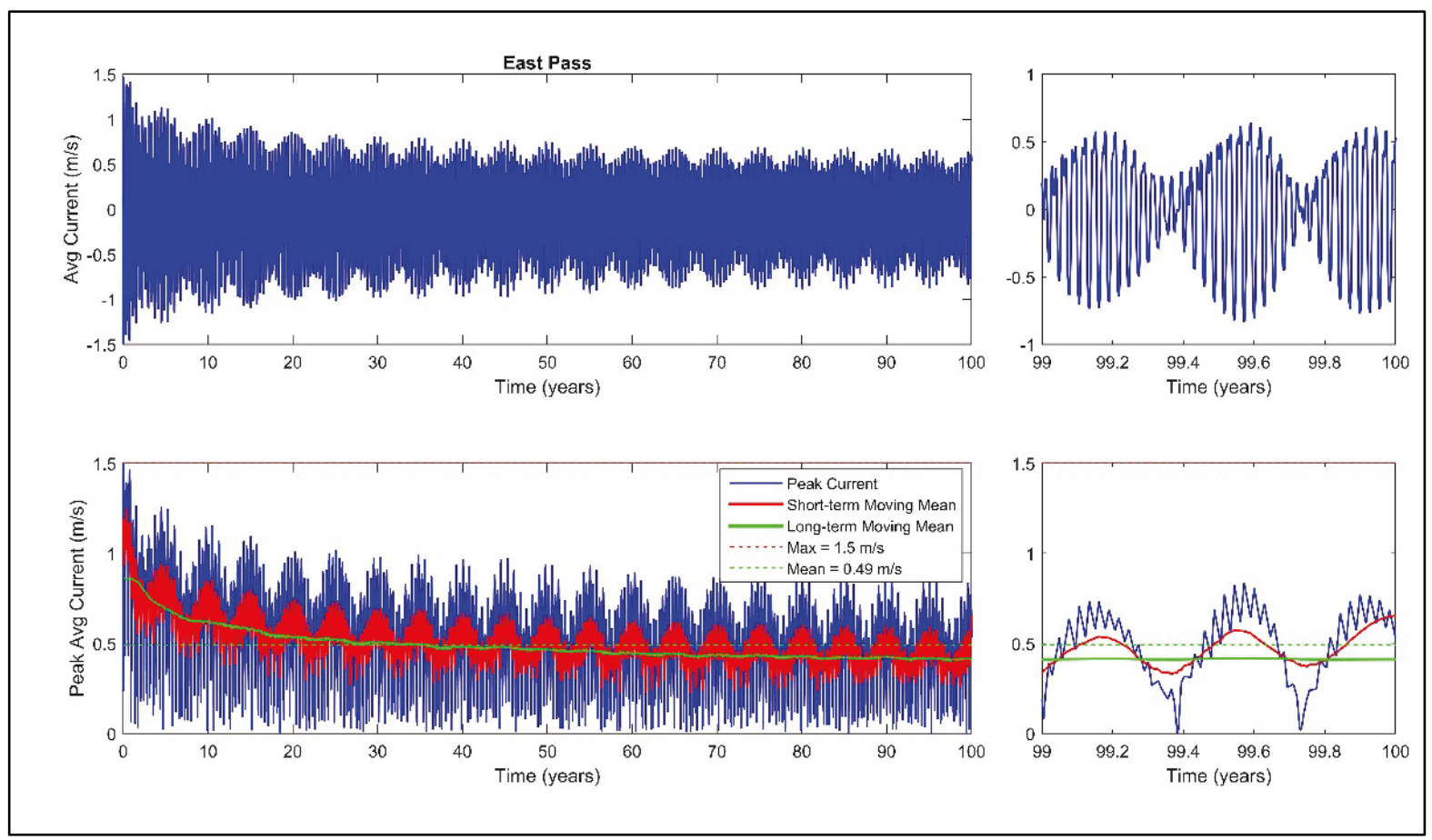


Figure 3.56. Volume flux and tidal prism (top left and top right inset, respectively) at the inlet midpoint. The two smaller panels (right inset) denote the last year of the simulation to illustrate tidal variability.

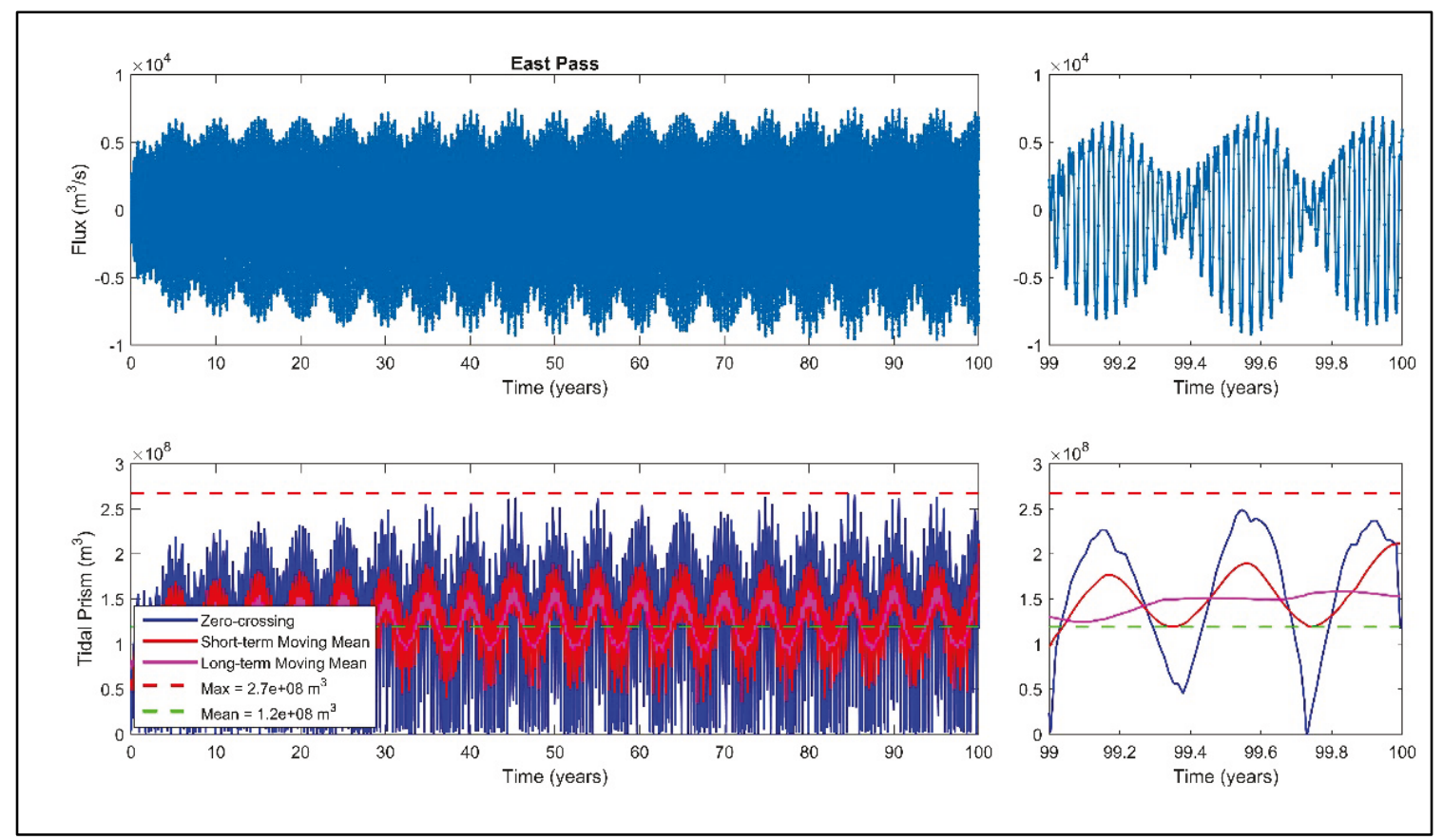

Maximum water-surface elevation difference between the ocean and bay decreases rapidly during the first 5 years then more gradually for the rest of the study period (Figure 3.57). Initially, the extremes are asymmetric with regard to the zero-crossing indicating steeper gradients during flood especially during tidal extremes. As the simulation progresses, this difference diminishes, yet the spring tidal gradients remain slightly skewed towards ebb dominance.

Figure 3.57. Calculated water surface elevation difference between the ocean and bay. Positive values denote sea surface slope from the ocean to the bay.

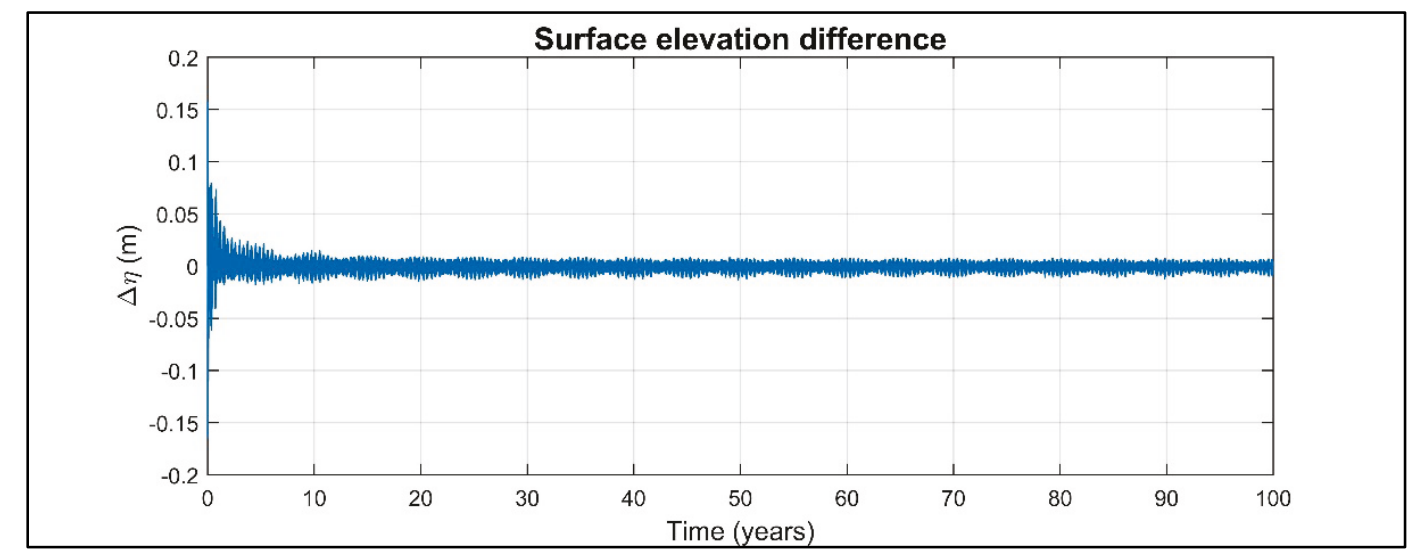




\subsubsection{Comparisons with empirical formulas}

The cross-sectional area calculated by the CMS increases uniformly with the maximum predicted by the tidal prism relationship (Figure 3.58). Cross-sectional area predicted by CMS increases throughout the simulation while the estimate derived from the tidal prism relationship is more uniform. The cross-sectional areas at all three locations converge to the lower limit predicted by the tidal prism relationship.

Figure 3.58. Inlet cross-sectional area calculated by the CMS (lines) at three inlet channel locations and the computed cross-sectional area from the tidal prism relationship (points).

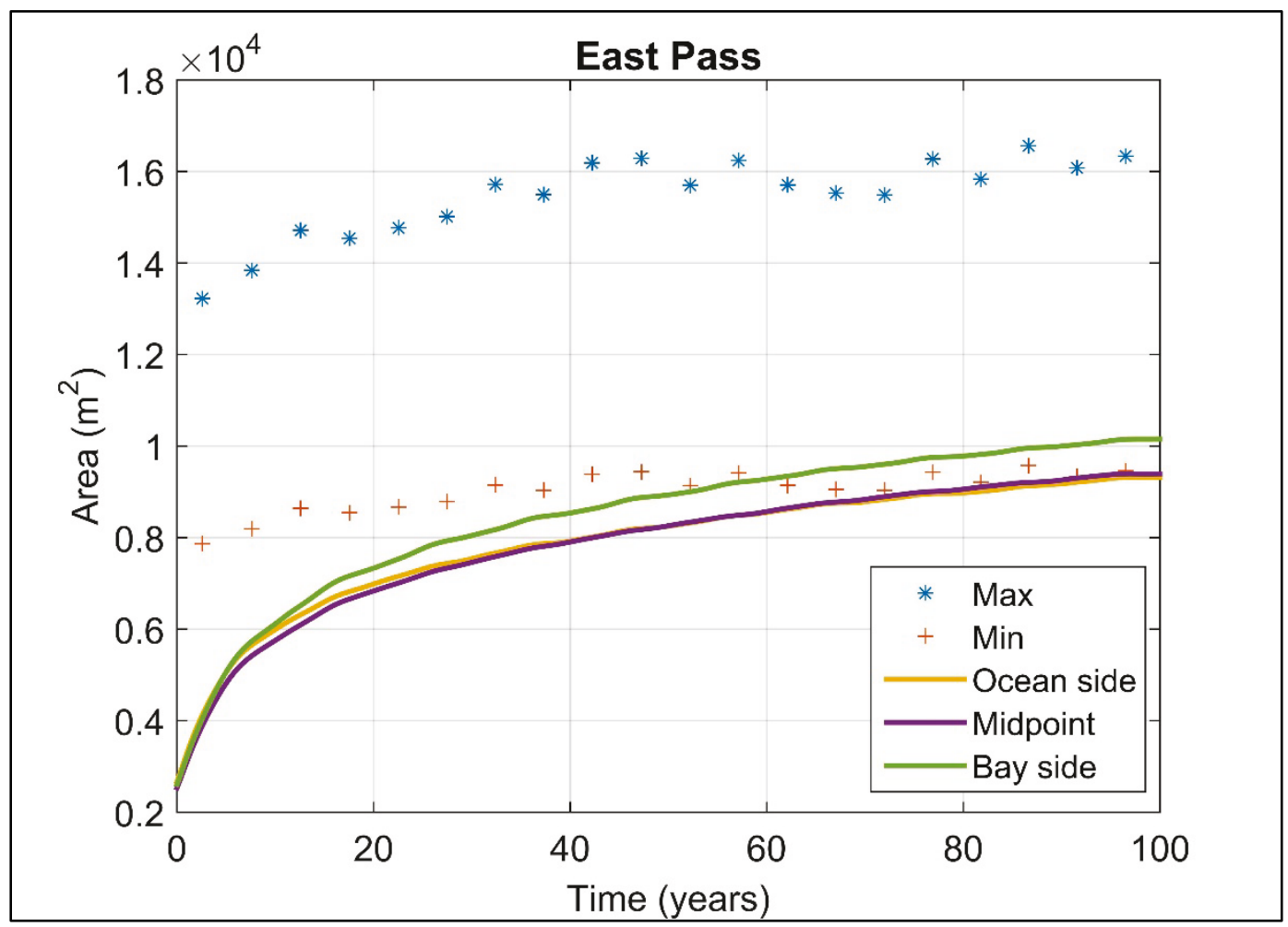

The CMS-calculated ebb shoal volume is significantly smaller than the empirical predictions based on computed tidal prism (Figure 3.59). Deriving shoal volume from spring tide conditions predicts a significantly higher ebb shoal volume than that which the CMS-computed volume is converging on. Both methods show a similar trend in that shoal volume is more uniform during the last half of the simulation. The underprediction of the CMS-calculated ebb shoal volume is not surprising because the measured tidal prism and shoal volumes for East Pass were off by an order of magnitude from the Walton and Adams (1976)-predicted values for moderately exposed coasts. 
Figure 3.59. Time series of ebb shoal volume calculated by the CMS (yellow line) and the computed empirical formulas that relate tidal prism to ebb shoal volume (points).

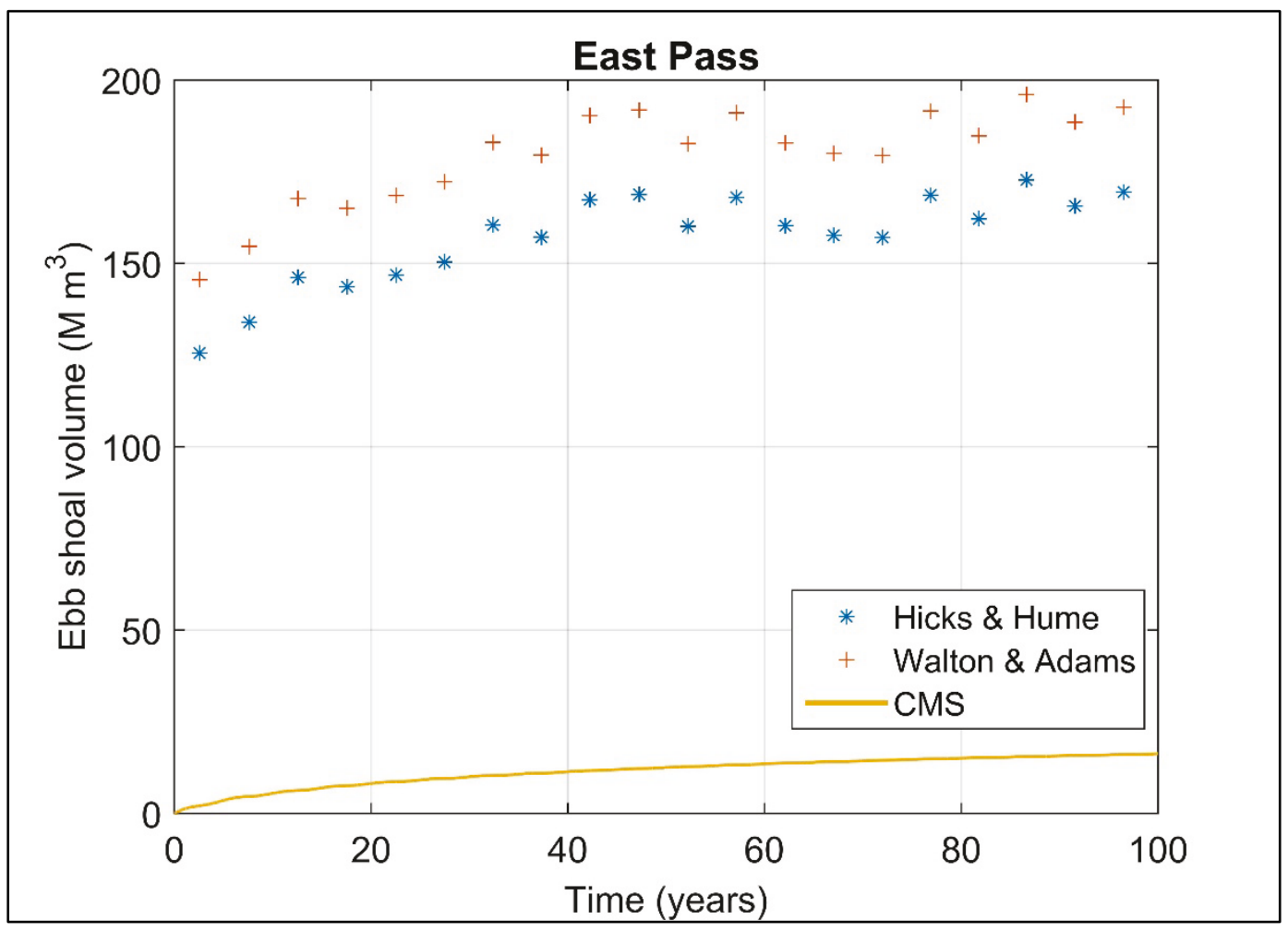

The Escoffier equilibrium theory applied to East Pass is depicted in Figure 3.6o. The input parameters (e.g., bay area, inlet dimensions, and watersurface elevation) are derived from the CMS-idealized East Pass simulation, and the plus signs denote the measured East Pass minimal cross-sectional area. Data filtering and averaging parameters are the same as those applied to Grays Harbor. The CMS results reveal inlet deepening and an overall decrease in the maximum current that exceeds the quadratic and Escoffier theoretical predictions yet trends well with the Escoffier prediction. 
Figure 3.60. An Escoffier analysis comparing the theoretically predicted (green and yellow lines) and CMS-computed (blue points) current. Plus signs denote the minimal cross-sectional area and the theoretical maximum velocity required for this inlet to remain stable. A 30-day low-pass filter delineates the overall trend of CMS-computed peak velocities for modeled cross-sectional areas (orange line).

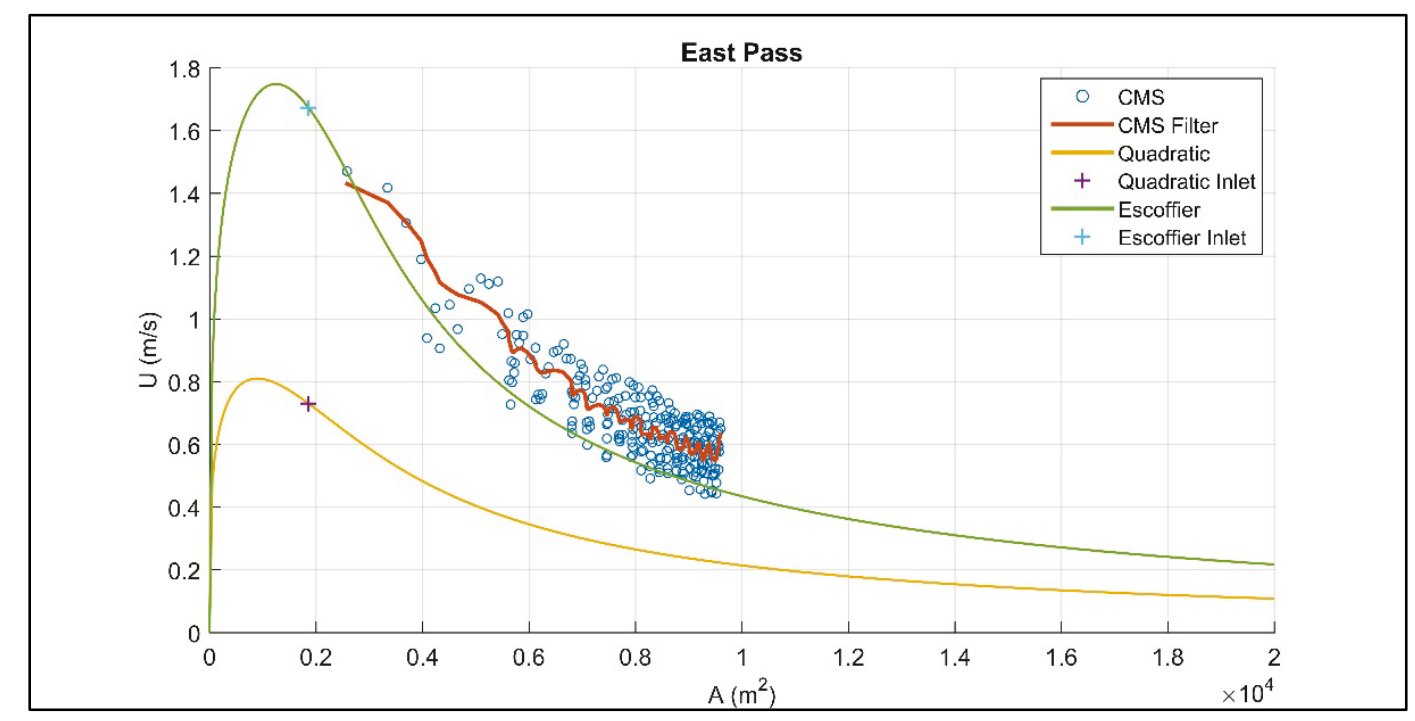

\subsection{Johns Pass}

Johns Pass is located on the Gulf Coast near Tampa, FL, and is part of a multi-inlet barrier inlet system. The model grid for the Johns Pass idealized inlet/bay system is depicted in Figure 3.61. The dimensions and initial depth are listed in Table A1. The modeled bay width and length, 5 and $3 \mathrm{~km}$, respectively, produce a rectangular area equal to the area of the back barrier lagoon, which is elongated in the alongshore direction typical of bar built estuaries. The depth contours offshore are straight and parallel and follow an equilibrium beach profile near the shoreline. Water depth is constant at $1.8 \mathrm{~m}$ within the throat and bay and tapered at the ocean side to match the offshore depths. The bay depth is based upon average conditions for Johns Pass. 
Figure 3.61. CMS grid and bathymetry for idealized Johns Pass simulation.

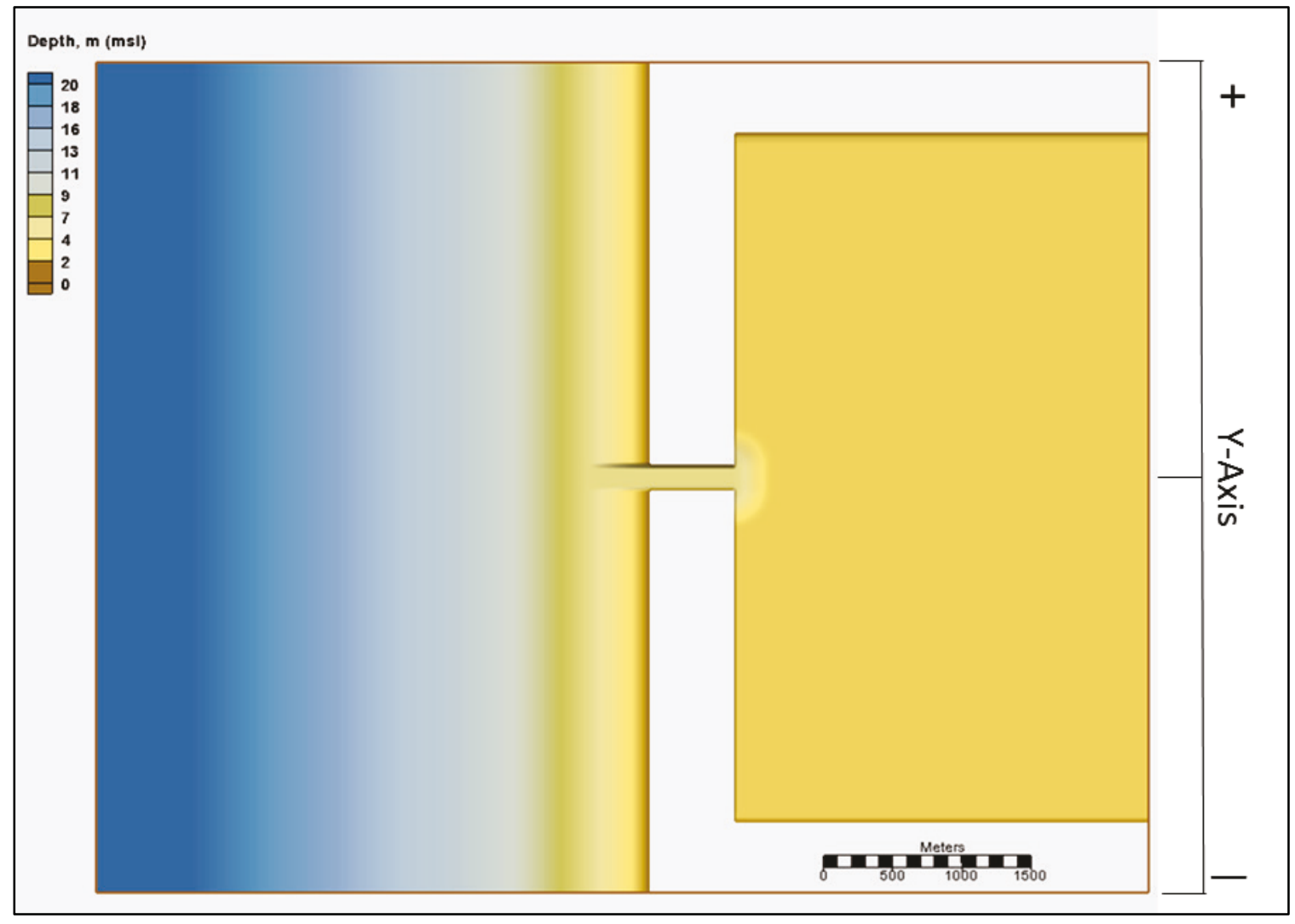

\subsubsection{Morphology}

The final morphology is depicted in Figure 3.62. The ebb shoal is highly skewed towards the negative $y$-direction (south) extending approximately $0.5 \mathrm{~km}$ up and $1.5 \mathrm{~km}$ down the coast and $1 \mathrm{~km}$ offshore. The main lobe extends from offshore of the inlet towards the negative $y$-direction, and the ebb channel is deep and extends approximately $1.5 \mathrm{~km}$ down the coast before veering offshore and incising the ebb shoal.

The main channel within the inlet throat is oriented along the centerline except adjacent to the entrance where it is rotated towards the negative $y$ direction. The inlet channel is deepest and narrowest on the bay side of the inlet throat where it is flanked by two shoals along the bank. Channel networks do not form in the large bay, but rather the dominant morphological feature is a broad shallow flood shoal approximately $1.5 \mathrm{~km}$ from the inlet. 
Figure 3.62. Calculated final depth for Johns Pass after 100-year simulation.

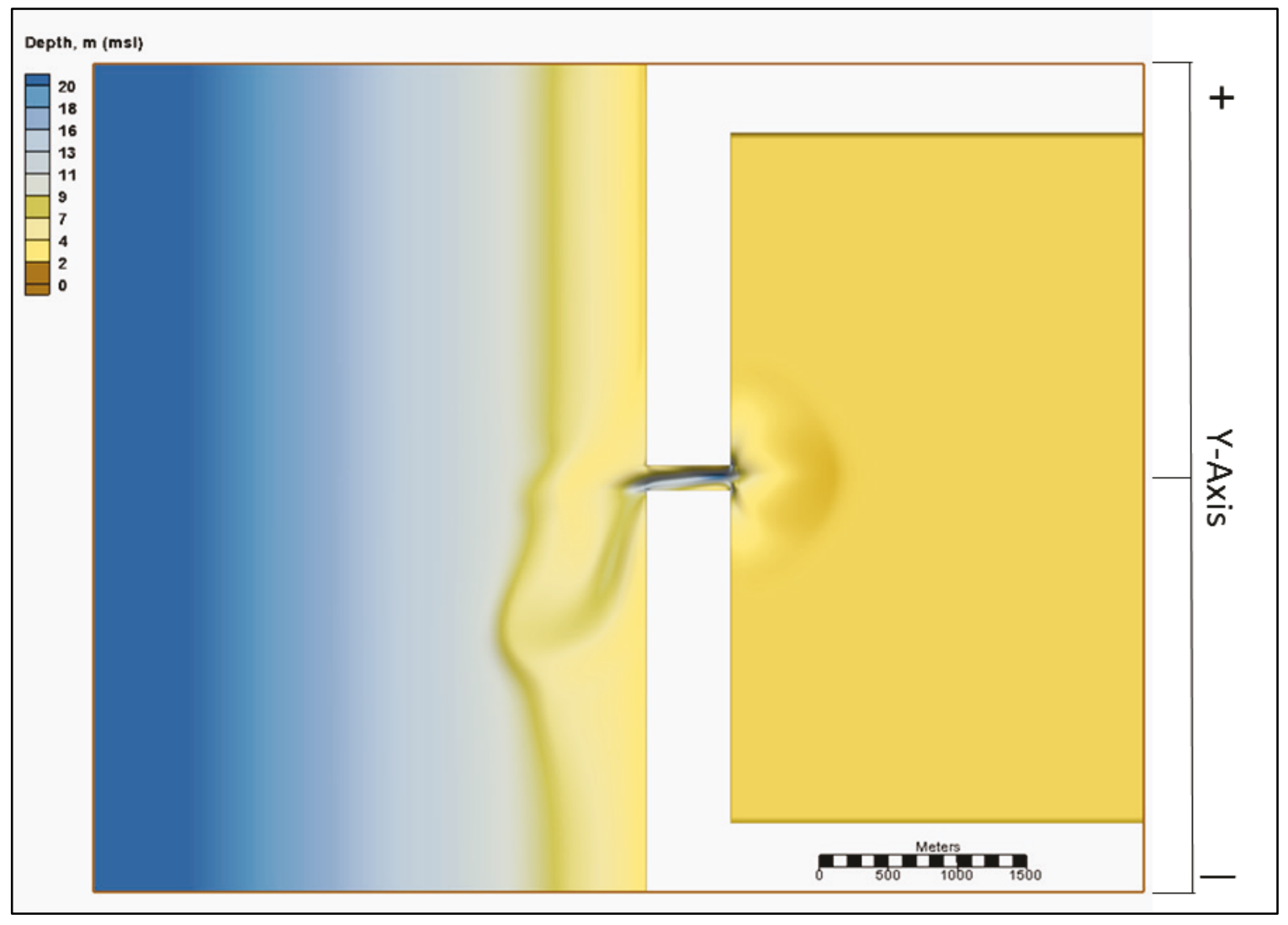

Figure 3.63 depicts the temporal evolution of the cross-sectional area at the ocean, midpoint, and bay side of the inlet. Bed deepening at the ocean side is indicative of bed scouring in a confined channel, in which the erosion is greatest near the center forming a cross section skewed in the negative $y$-direction. Deepening at the midpoint tends to be similar to the ocean side, but the deepest section is less skewed with respect to the centerline of the channel. On the bay side, the channel deepens and is skewed in the positive $y$-direction forming a relatively stable cross section. Towards the end of the simulation (last 20-40 years), there is very little change at all three locations in channel position or maximum depth. Maximum channel erosion occurs during the first 20 years of the simulation. 
Figure 3.63. CMS-predicted temporal evolution of inlet cross-sectional area for Johns Pass. Distances are alongshore from channel centerline with positive towards the right looking oceanward and negative towards the left.

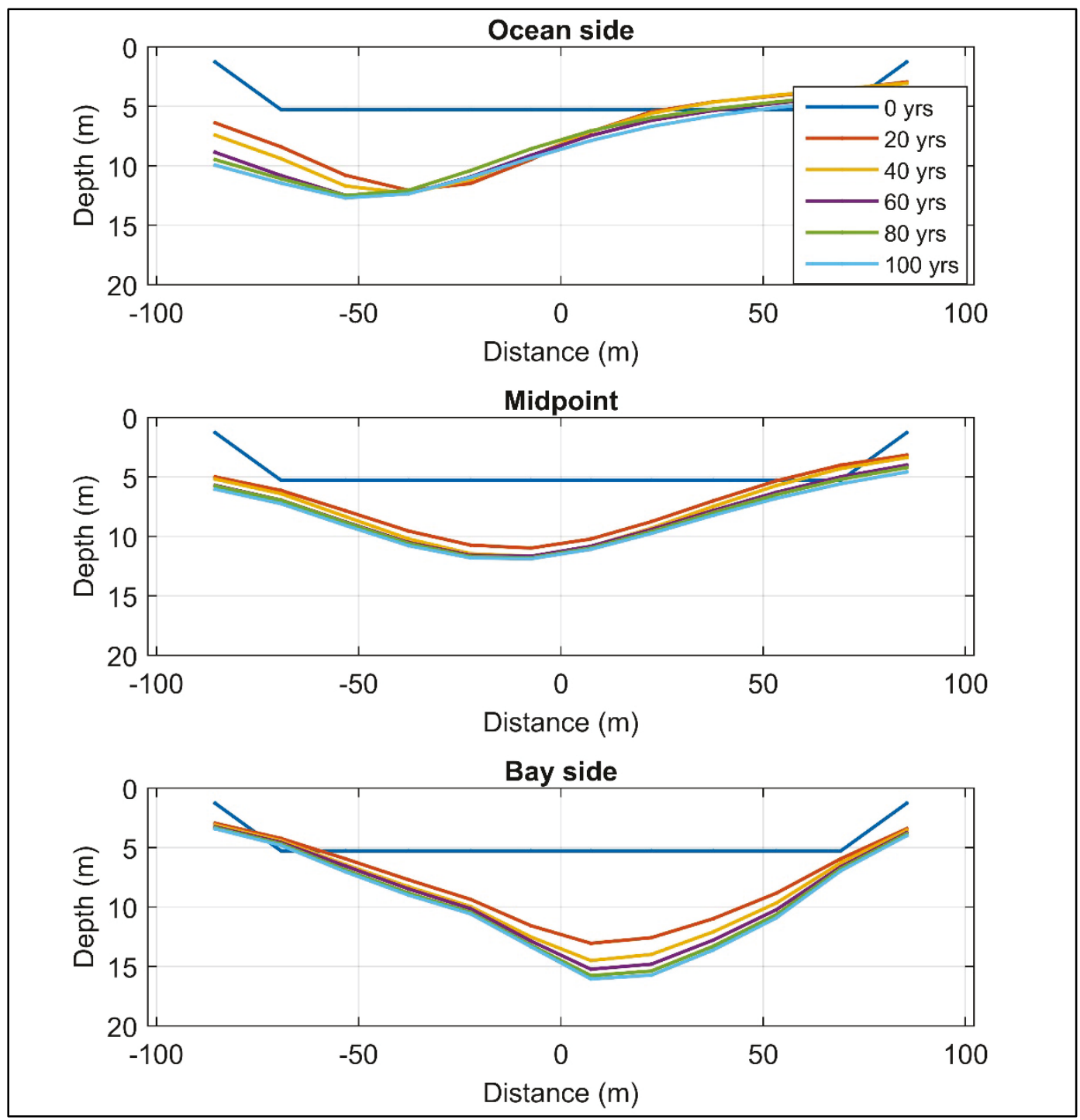

The net bed change in the bay, inlet, and ebb shoal volume is depicted in Figure 3.64. Ebb shoal volume initially increases rapidly but then at a reduced rate for the remainder of the simulation. The inlet deepens rapidly at the beginning of the simulation but then more gradually. The bay shows net losses but at a reduced magnitude compared to the inlet. The results for bed change for Johns Pass indicate that it is ebb dominant. Net gains on the ebb shoal exceed bay and inlet losses suggesting sediment supply from adjacent beaches and longshore sediment transport. The cycle of 10 years of wave data is evident in the cyclic behavior of minor volumetric change in both the ebb shoal and inlet channel; however, this is not captured in bay shoal volumetric change. 
Figure 3.64. Calculated bed volume change for Johns Pass.

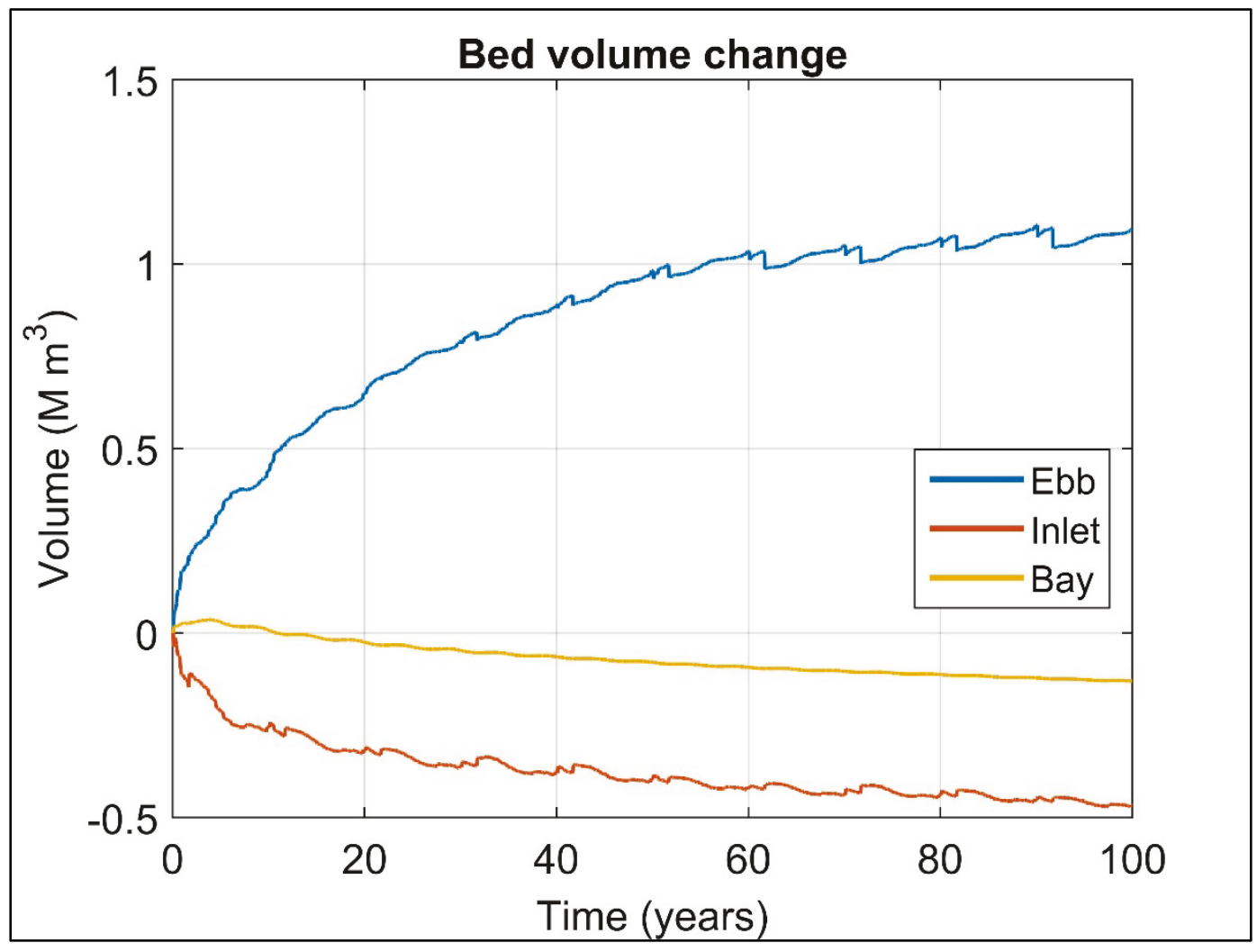

\subsubsection{Hydrodynamics}

Spatial current magnitude distribution near the end of the simulation during maximum flood and maximum ebb is depicted in Figure 3.65 and Figure 3.66, respectively. Flood currents enter the inlet then accelerate along the inlet channel. The high-flow region narrows, and then the flood current spreads into a large radial pattern upon exiting into the bay. Maximum ebb currents enter the inlet channel in a radial pattern across the bay with two regions of strong inflow on both sides of the inlet channel. The current accelerates through the inlet throat and forms a strong jet upon exiting into the ocean. The maximum ebb current is stronger within the inlet and exceeds the maximum flood current. 
Figure 3.65. Current magnitude during maximum flood at the end of the 100-year simulation for Johns Pass.

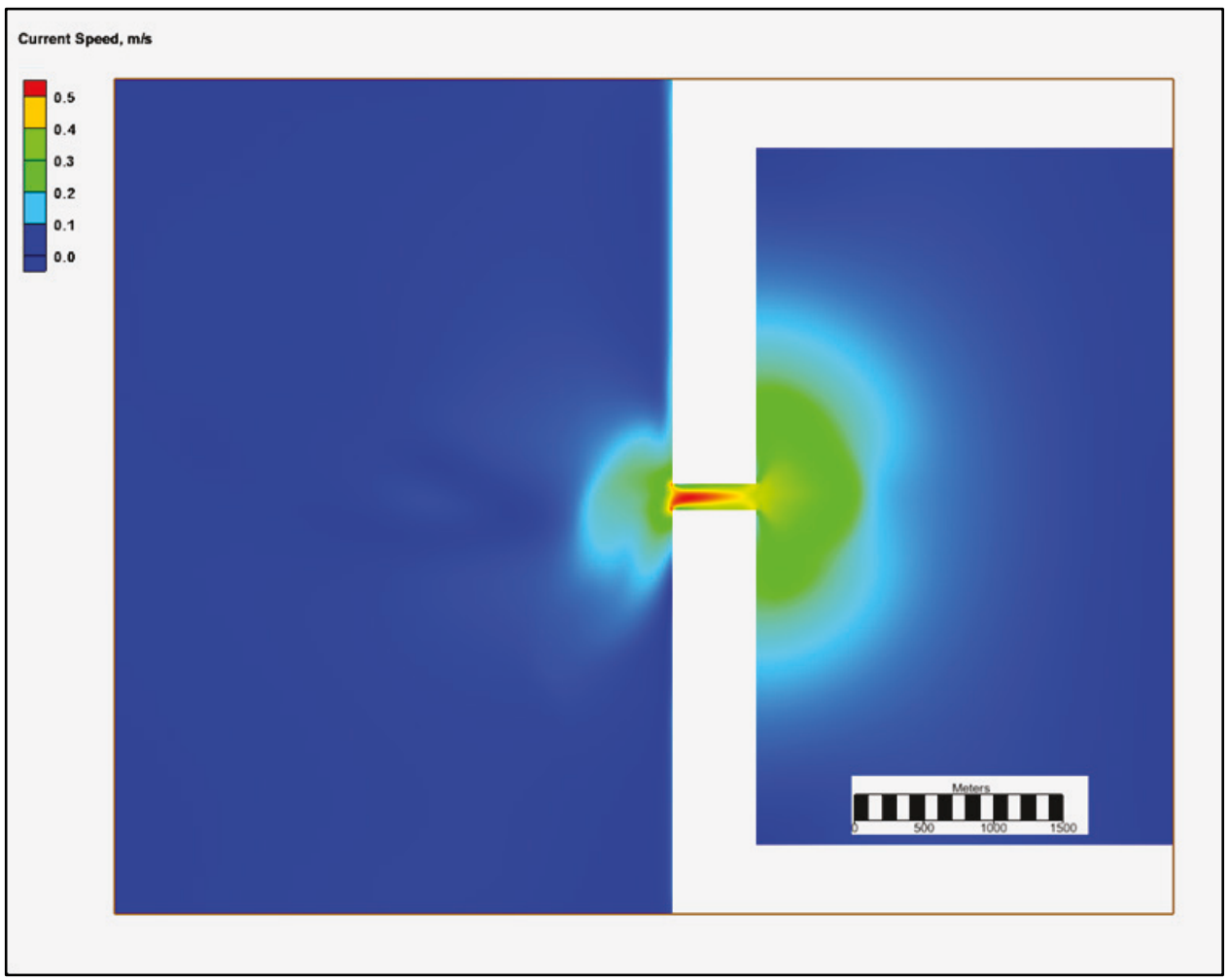

Figure 3.66. Current magnitude during maximum ebb at the end of the 100-year simulation for Johns Pass.

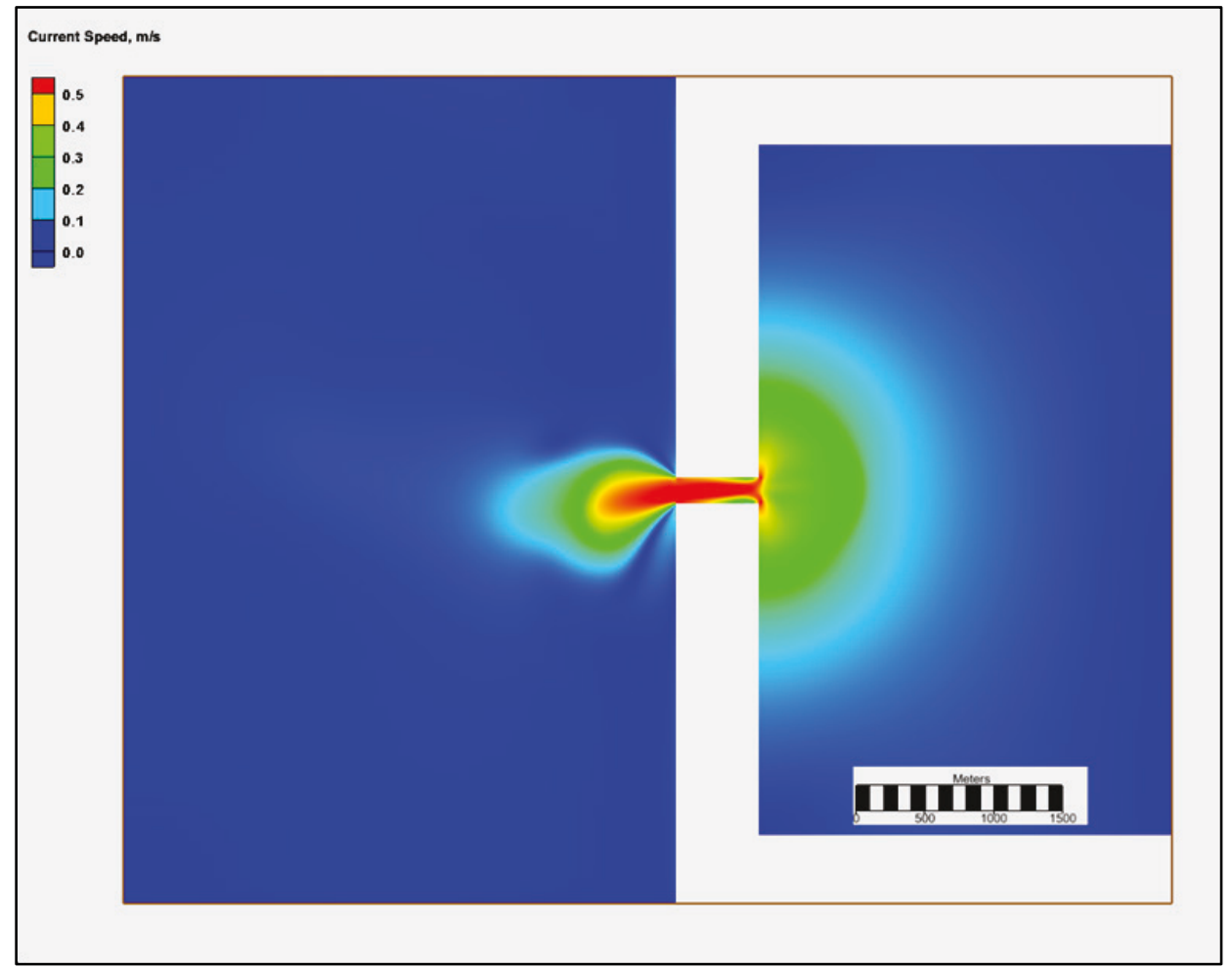


The tidal current envelope in the inlet throat decreases over the course of the simulation (Figure 3.67). Even though the current amplitude is decreasing, volume flux and tidal prism (Figure 3.68) initially increase as the cross-sectional area increases. Volume flux is moderately ebb dominated during spring tide, and the long-term moving average tidal prism shows little variation from the mean after about 20 years.

Figure 3.67. Average and peak average tidal currents at the midpoint of the inlet (top left and top right inset, respectively). The two smaller panels (right inset) illustrate current patterns for the last year of the simulation.

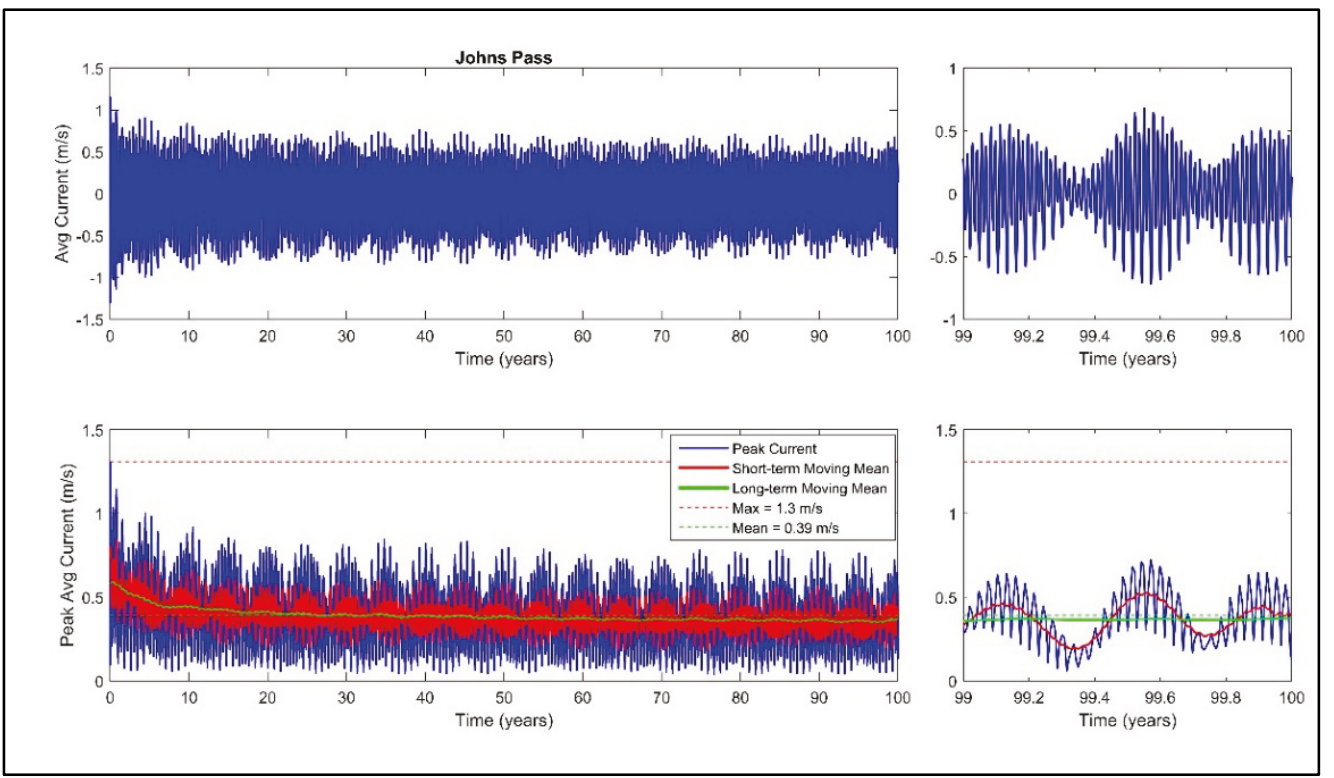

Figure 3.68. Volume flux and tidal prism (top left and top right inset, respectively) at the inlet midpoint. The two smaller panels (right inset) denote the last year of the simulation to illustrate tidal variability.

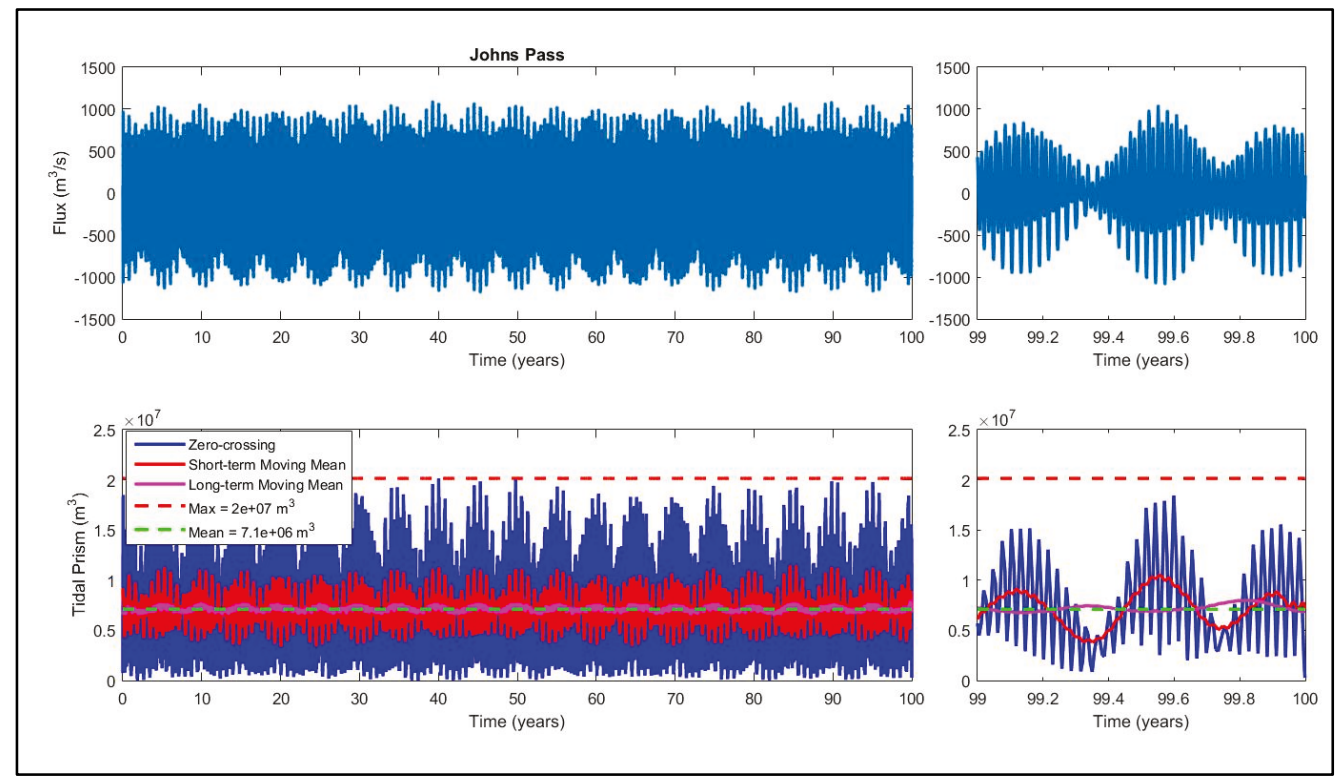


Maximum water surface elevation difference between the ocean and bay decreases rapidly during the first 5 years then more gradually (Figure 3.69). Initially, the extremes are asymmetric with regard to the zerocrossing indicating steeper gradients during ebb especially during tidal extremes. As the simulation progresses, this difference diminishes, but the slope is still greatest during ebb at spring tide.

Figure 3.69. Calculated water surface elevation difference between the ocean and bay. Positive values denote sea surface slope from the ocean to the bay.

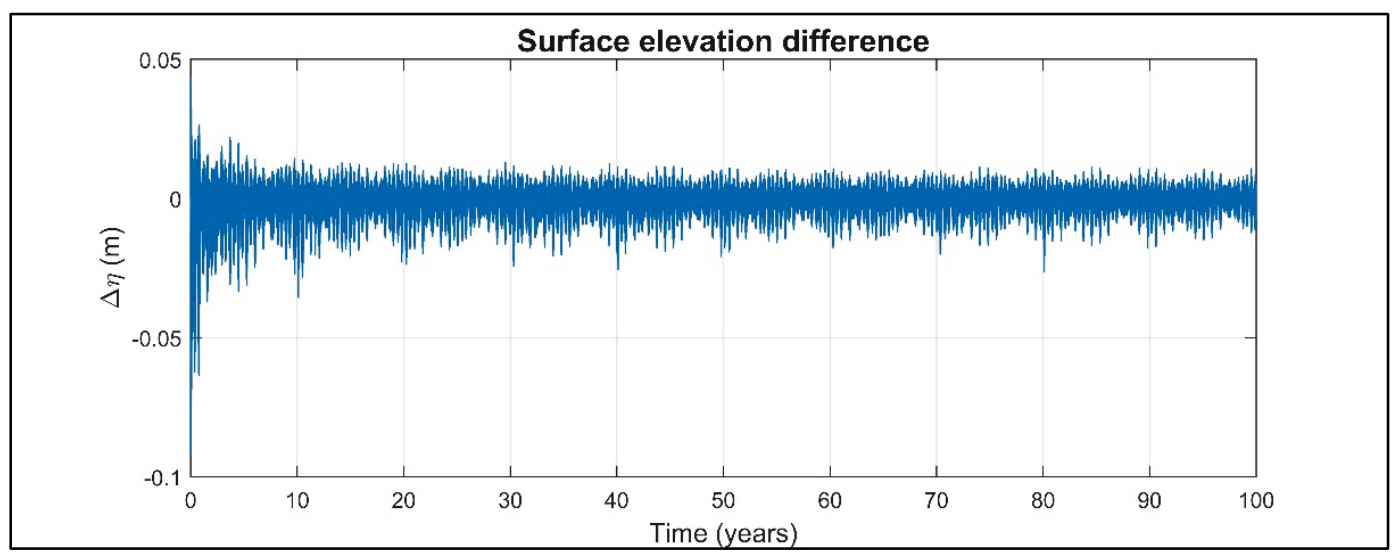

\subsubsection{Comparisons with empirical formulas}

The cross-sectional area predicted by the CMS increases at a higher rate than the maximum cross-sectional area predicted using the tidal prism relationship (Figure 3.70). The cross-sectional area at all three locations exceeds the maximum predicted by the tidal prism relationship. Crosssectional area predicted by the CMS increases throughout the simulation while the estimate derived from the tidal prism relationship remains relatively uniform predicting a stable inlet area based on tidal prism alone. 
Figure 3.70. Inlet cross-sectional area calculated by the CMS (lines) at three inlet channel locations and the computed cross-sectional area from the tidal prism relationship (points).

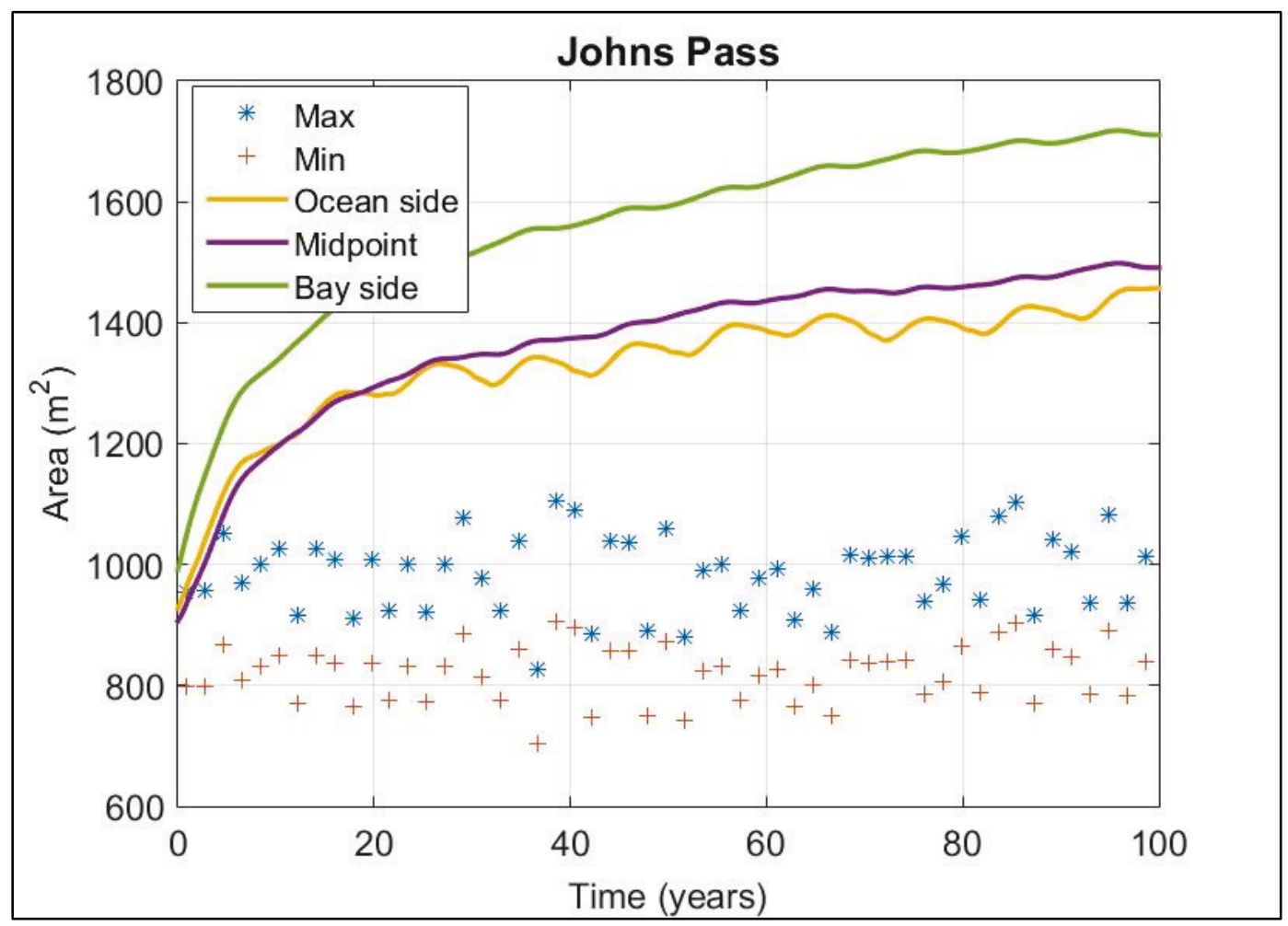

The CMS ebb shoal volume is smaller than the maximum predicted by the empirical formulas (Figure 3.71). Deriving shoal volume from spring tide conditions computed in CMS overpredicts the size of the ebb shoal with respect to the ebb shoal volume calculated (as well as the real world volume). However, both methods show a similar trend in that shoal volume is uniform during the last half of the simulation. 
Figure 3.71. Time series of ebb shoal volume calculated by the CMS (yellow line) and the computed empirical formulas that relate tidal prism to ebb shoal volume (points).

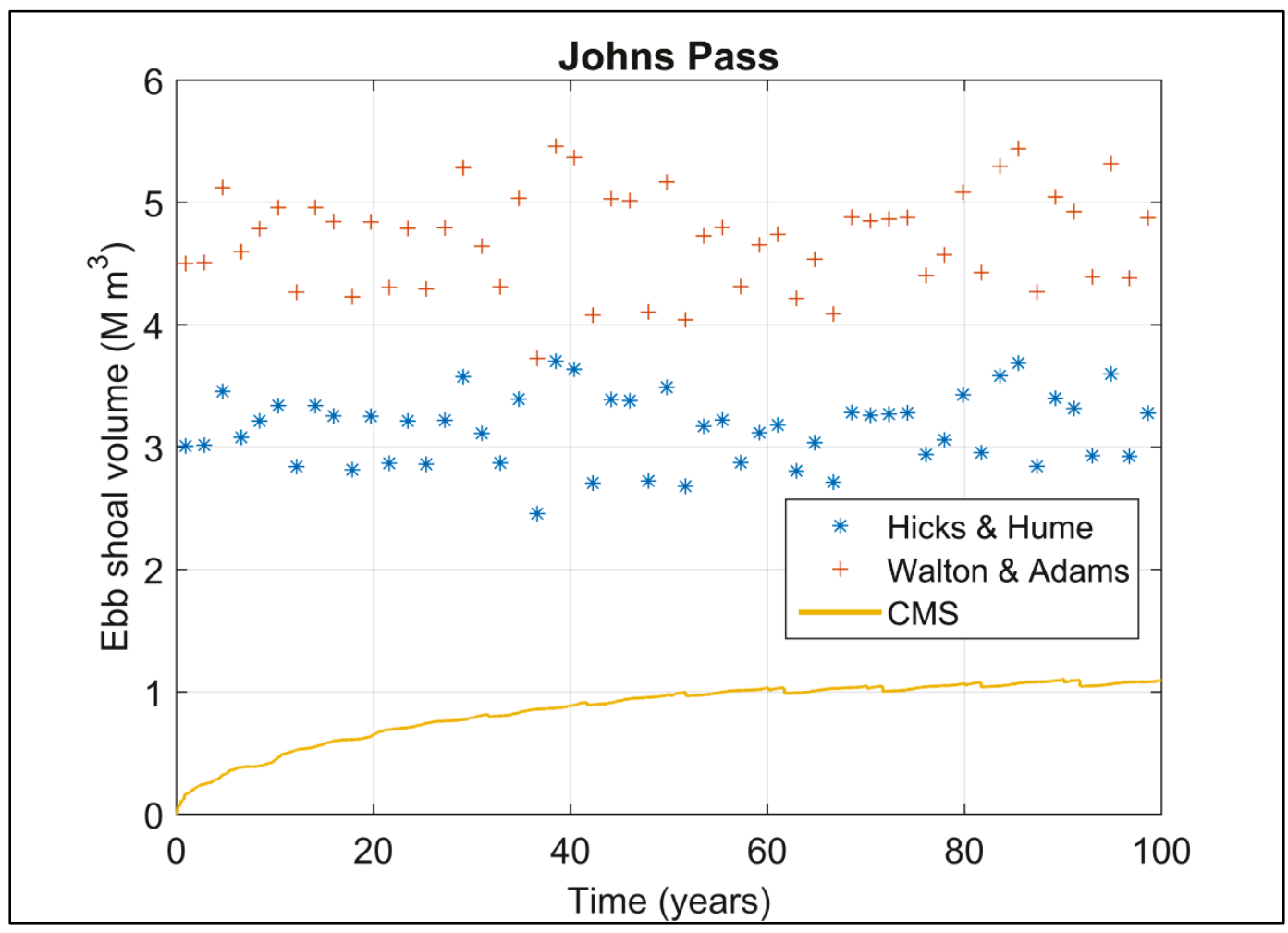

The Escoffier equilibrium theory applied to Johns Pass is depicted in Figure 3.72. The input parameters (e.g., bay area, inlet dimensions, and water surface elevation) are derived from the CMS-idealized Johns Pass simulation, and the plus signs denote the measured Johns Pass minimal cross-sectional area. Data filtering and averaging parameters are the same as those applied to Grays Harbor. The CMS results reveal inlet deepening and an overall decrease in the maximum current that exceeds the quadratic and Escoffier theoretical predictions. However, the CMS trends with the theoretical predictions, albeit CMS predicts higher equilibrium current speeds. 
Figure 3.72. An Escoffier analysis comparing the theoretically predicted (green and yellow lines) and CMS-computed (blue points) current. Plus signs denote the minimal cross-sectional area and the theoretical maximum velocity required for this inlet to remain stable. A 30-day low-pass filter delineates the overall trend of CMS-computed peak velocities for modeled cross-sectional areas (orange line).

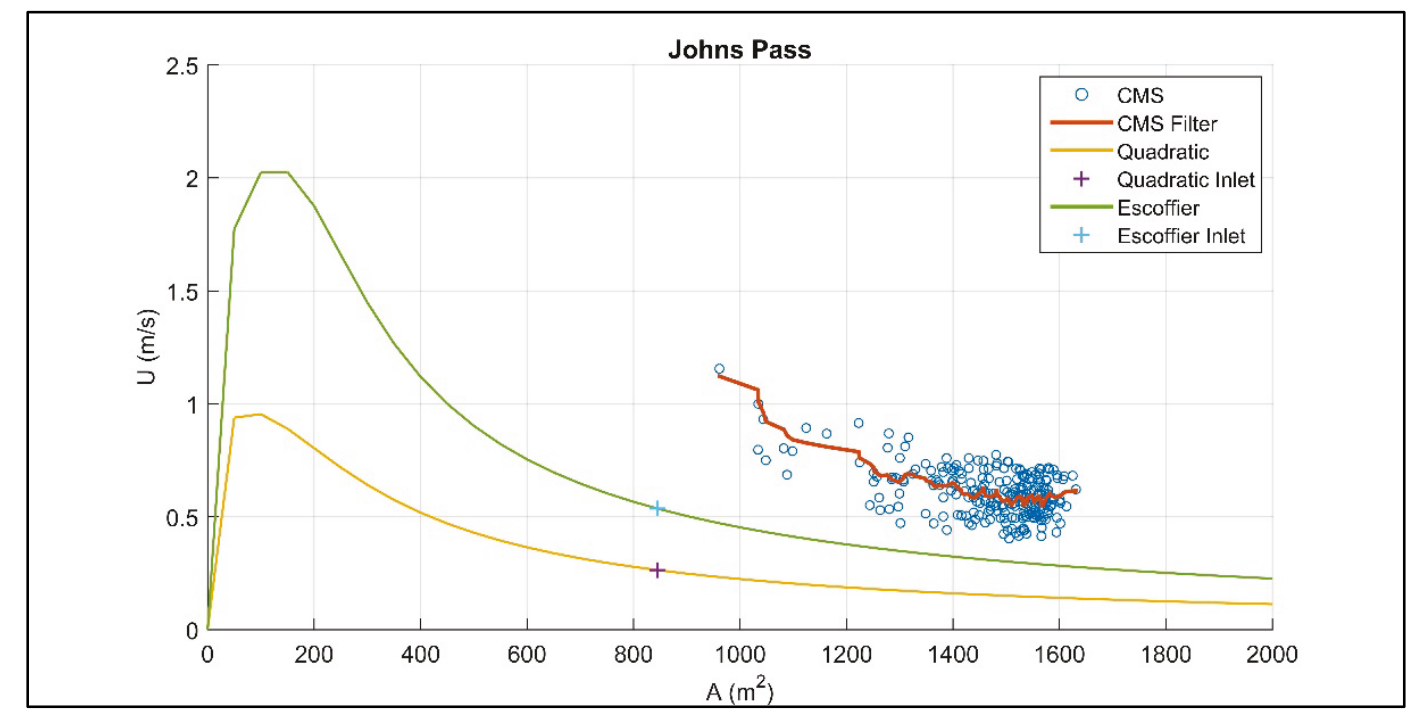

\subsection{Oregon Inlet}

Oregon Inlet is located on the Atlantic Coast near Hatteras, NC, and is part of the Cape Hatteras National Seashore. The model grid for the Oregon Inlet idealized inlet/bay system is depicted in Figure 3.73. The dimensions and initial depth are listed in Table A1. The modeled bay width and length, 38 and $80 \mathrm{~km}$, respectively, produce a rectangular area representing Pamlico Sound, which is the largest bay system simulated in this study. The depth contours offshore are straight and parallel and follow an equilibrium beach profile near the shoreline. Water depth is constant at $2.5 \mathrm{~m}$ within the throat and bay and tapered at the ocean side to match the offshore depths. The bay depth is based upon average conditions for Pamlico Sound. 
Figure 3.73. CMS grid and bathymetry for idealized Oregon Inlet simulation. Closer view of the inlet in zoomed figure on the right.

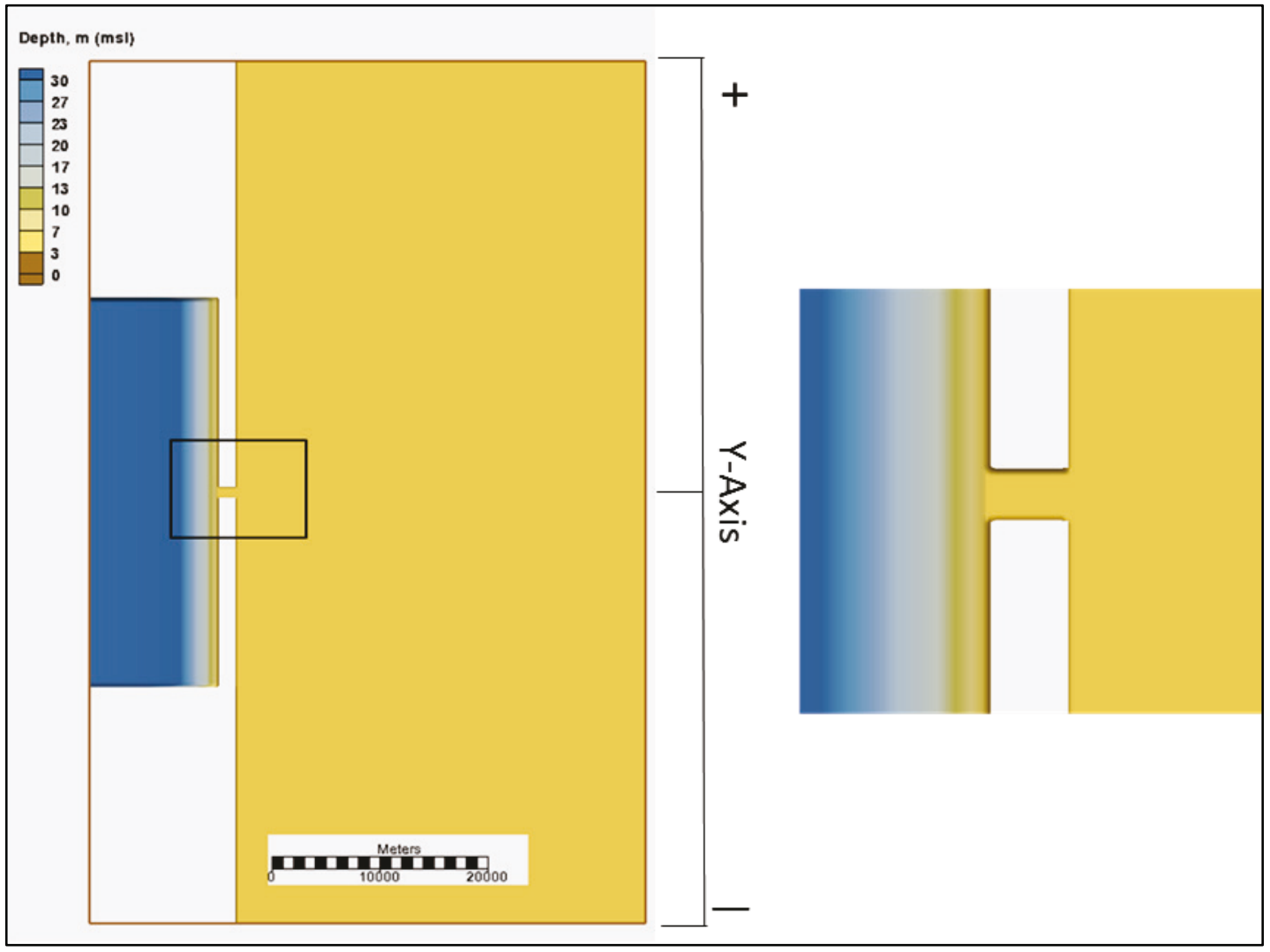

\subsubsection{Morphology}

The final morphology is depicted in Figure 3.74. The ebb shoal is skewed towards the negative $y$-direction (left) extending approximately $0.5 \mathrm{~km}$ up (right) and $1.5 \mathrm{~km}$ down (left) the coast and $2 \mathrm{~km}$ offshore. The main lobe extends from offshore of the inlet towards the negative $y$-direction, and there is no well-defined ebb channel.

The main channel within the inlet throat is wide and oriented along the centerline except where adjacent to the bay where it is slightly skewed towards the negative $y$-direction. The inlet channel is deepest on the ocean side. Channel networks do not form in the large bay but rather are confined near the inlet and abruptly terminate upon entering the bay. 
Figure 3.74. Final depth for Oregon Inlet after 100-year simulation. Closer view of the inlet in zoomed figure on the right. White areas shown inside the bays denote computational areas that were dry (above the water level) at the end of the simulation.

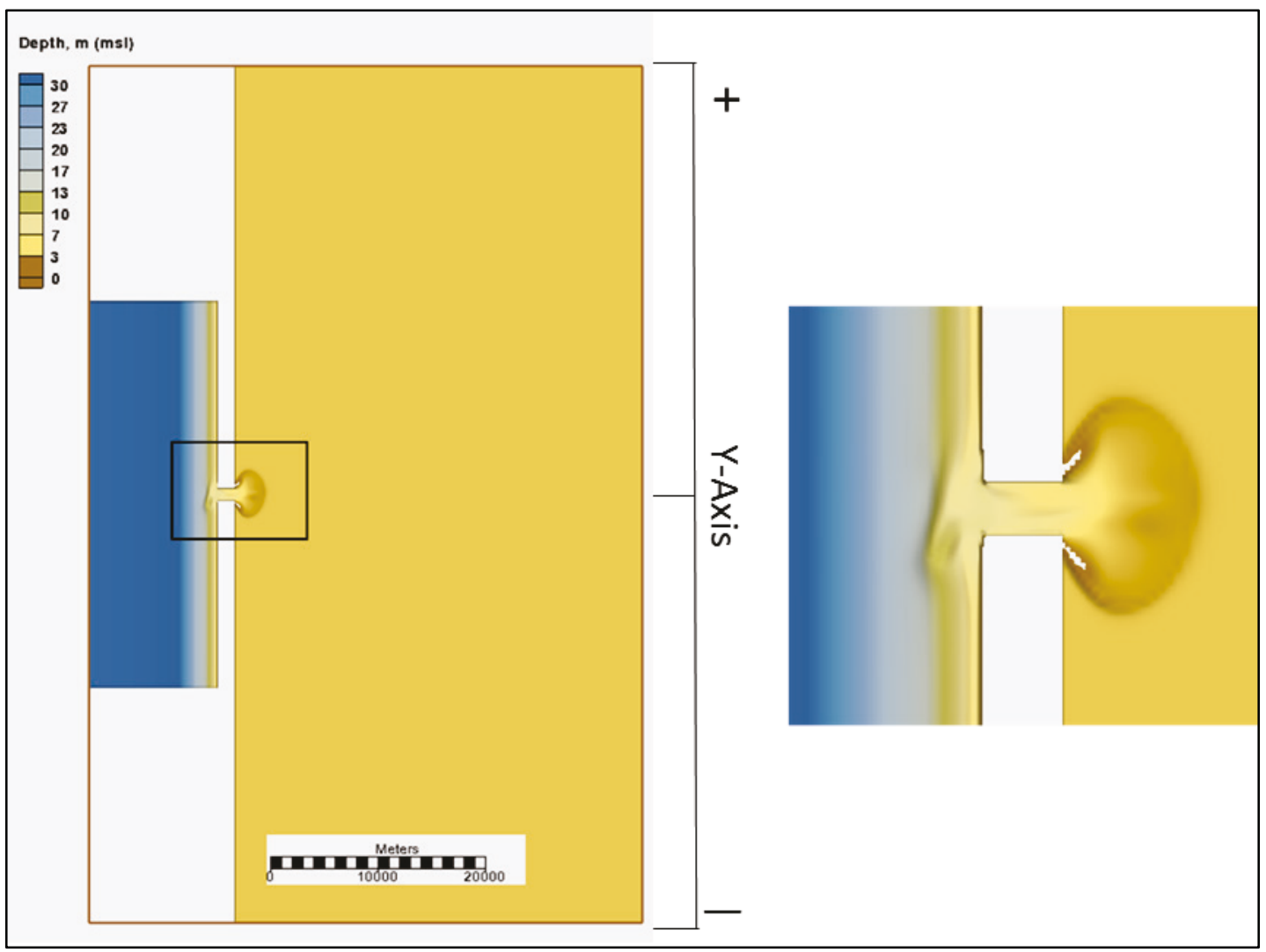

Figure 3.75 depicts the temporal evolution of the cross-sectional area at the ocean, midpoint, and bay side of the inlet. Bed deepening at the ocean side is fairly uniform across the inlet width and proceeds rapidly for the first 20 years and then more gradually. The deepest point is skewed in the negative $y$-direction. Deepening at the midpoint tends to be similar to the ocean side, but the deepest section is slightly more negatively skewed with respect to the centerline of the channel. On the bay side, the channel deepening progresses in a manner similar to the midpoint location. By the end of the simulation, there is very little change at all three locations in channel position or maximum depth. The depth is fairly uniform across the channel. 
Figure 3.75. CMS-predicted temporal evolution of inlet cross-sectional area for Oregon Inlet. Distances are alongshore from channel centerline with positive towards the right looking oceanward and negative towards the left.

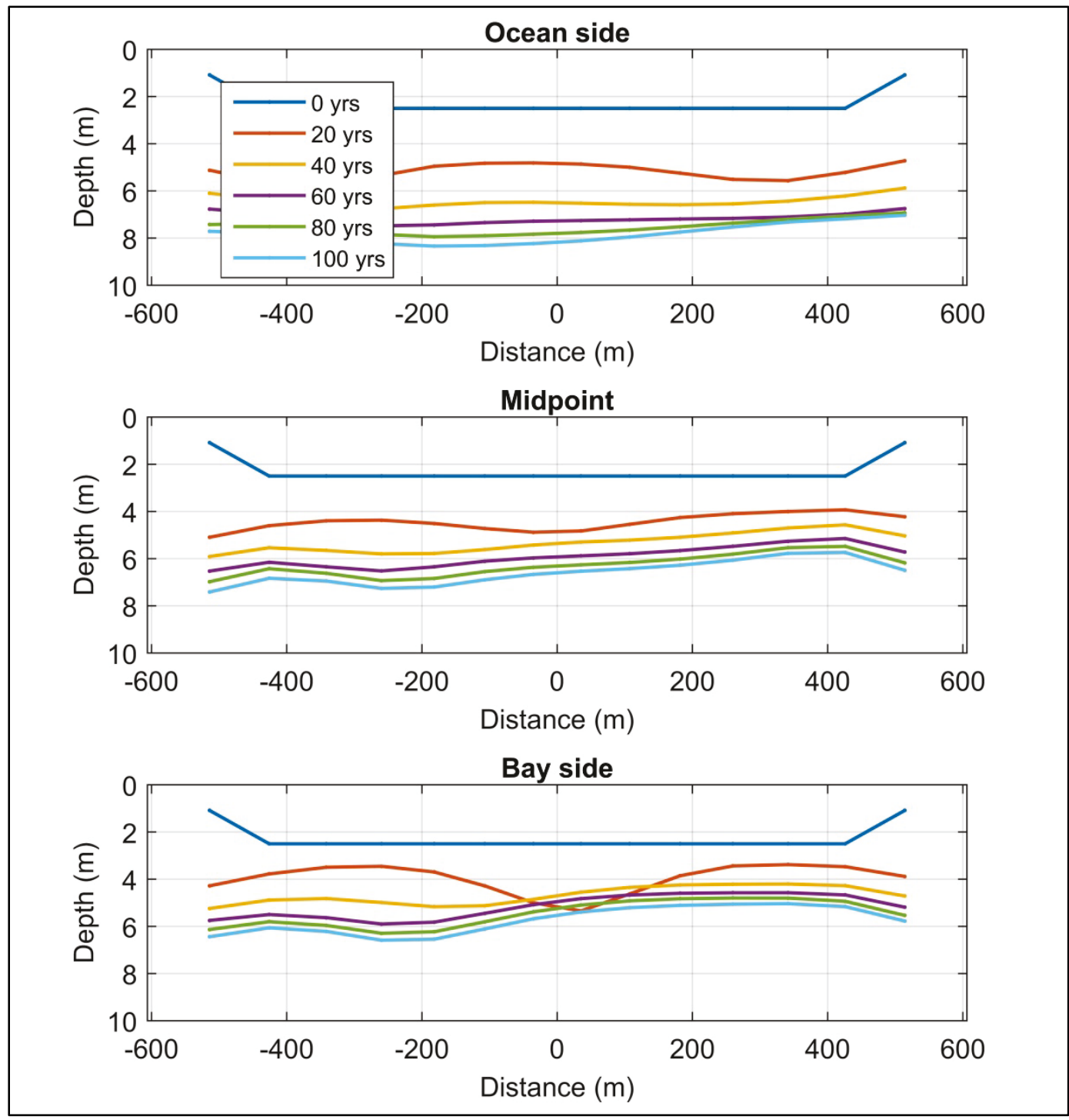

The net bed change in the bay, inlet, and ebb shoal volume is depicted in Figure 3.76. Ebb shoal volume increases uniformly throughout the simulation. The inlet deepens rapidly at the beginning of the simulation but then loses volume more gradually. The bay shows net gains that exceeds inlet losses. Net inlet losses exceed ebb shoal gains suggesting that sediment from the inlet also supplies some material to the bay. The bay also receives littoral sediment from longshore transport along adjacent beaches. The results for bed change for Oregon Inlet indicate that it is flood dominant. 
Figure 3.76. Calculated bed volume change for Oregon Inlet.

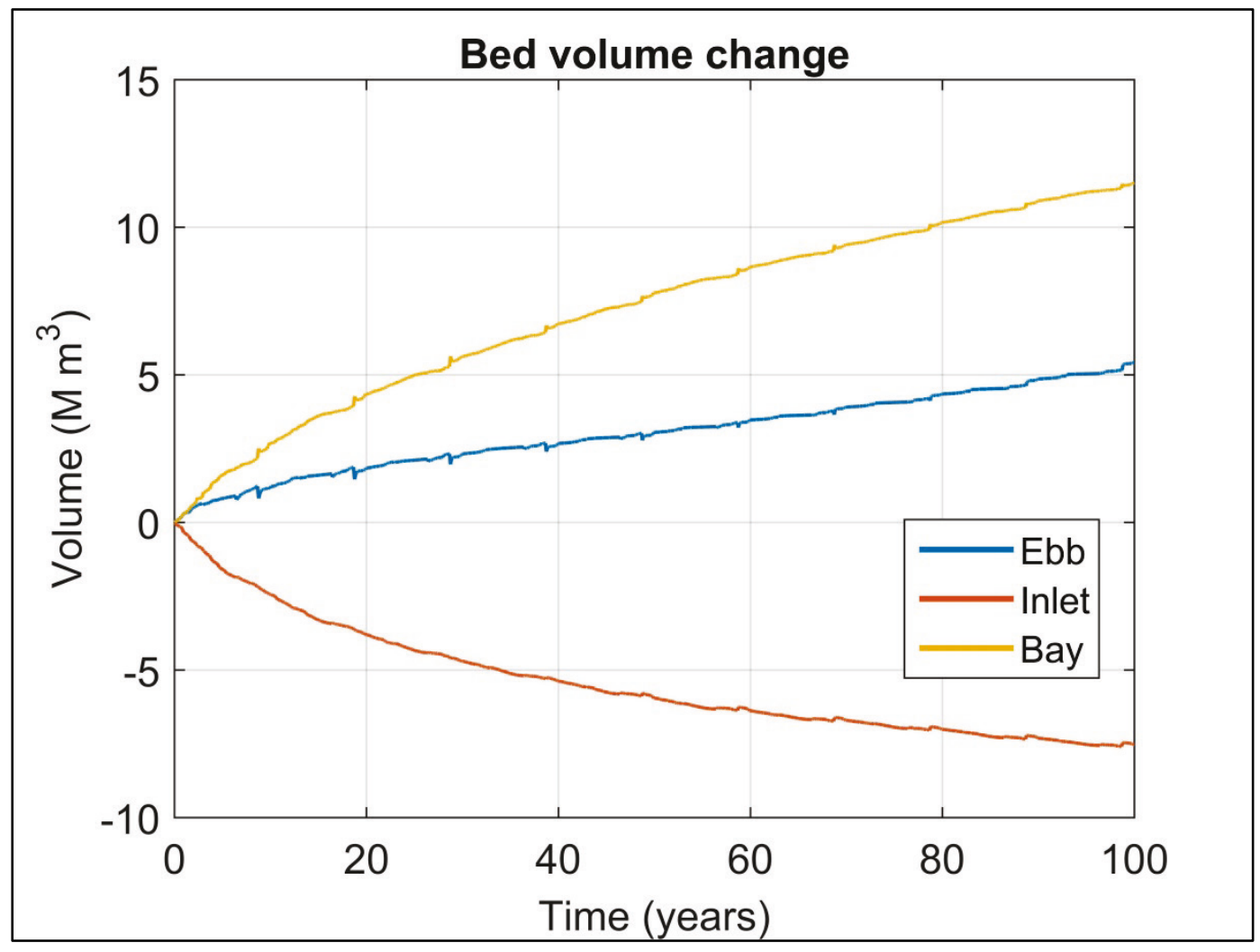

\subsubsection{Hydrodynamics}

Spatial current magnitude distribution near the end of the simulation during maximum flood and maximum ebb is depicted in Figure 3.77 and Figure 3.78, respectively. Flood currents enter the inlet then accelerate along the inlet channel. The high-flow region expands and then spreads into three branches upon exiting into the bay, which reduce in strength to form a radial outflow. Maximum ebb currents enter the inlet from the three branches within the bay and then spread and decelerate in the inlet to form a narrow outflow region that is slightly negatively skewed (to the left). The maximum flood current exceeds the maximum ebb current, as is typical for flood dominant inlets, and is strongest within the inlet throat. 
Figure 3.77. Current magnitude during maximum flood at the end of the 100-year simulation for Oregon Inlet. Closer view of the inlet in zoomed figure on the right. White areas shown inside the bays denote computational areas that were dry (above the water level) at the end of the simulation.

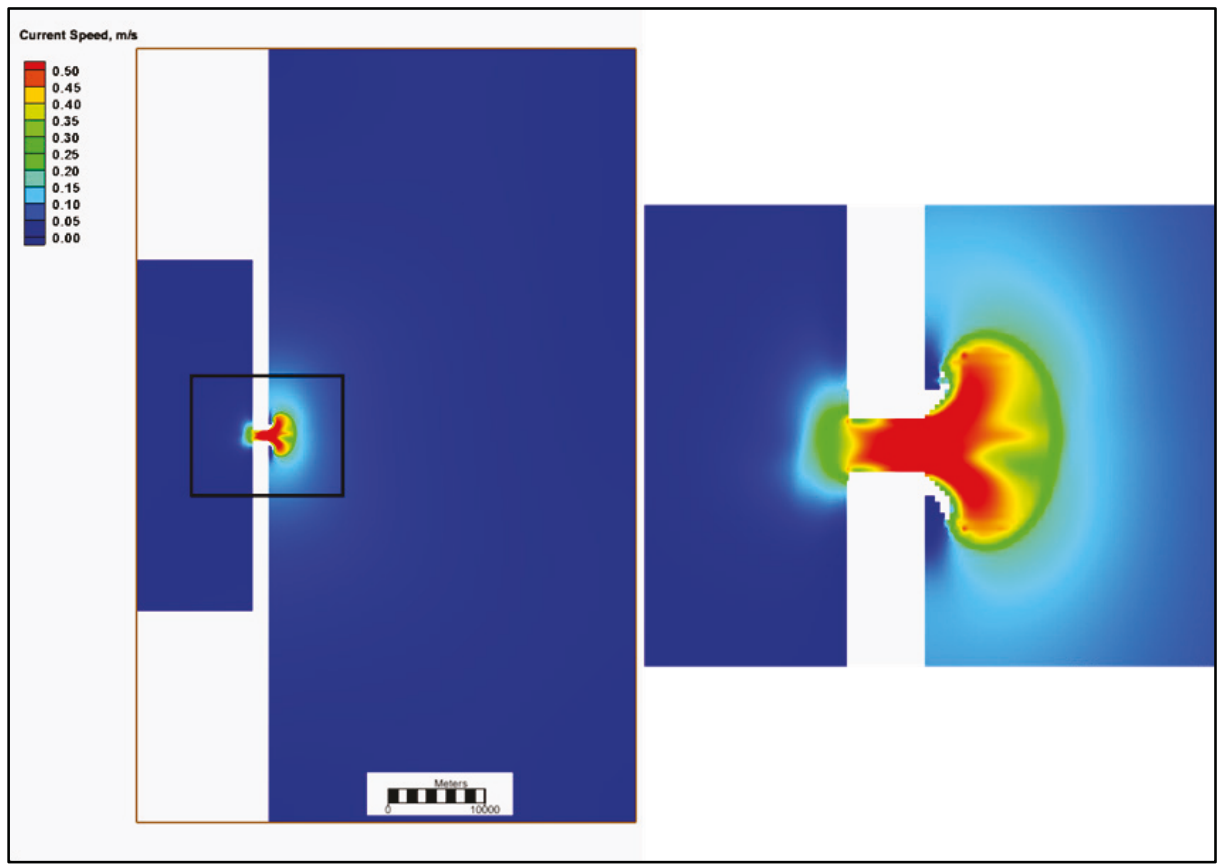

Figure 3.78. Current magnitude during maximum ebb at the end of the 100-year simulation for Oregon Inlet. Closer view of the inlet in zoomed figure on the right. White areas shown inside the bays denote computational areas that were dry (above the water level) at the end of the simulation.

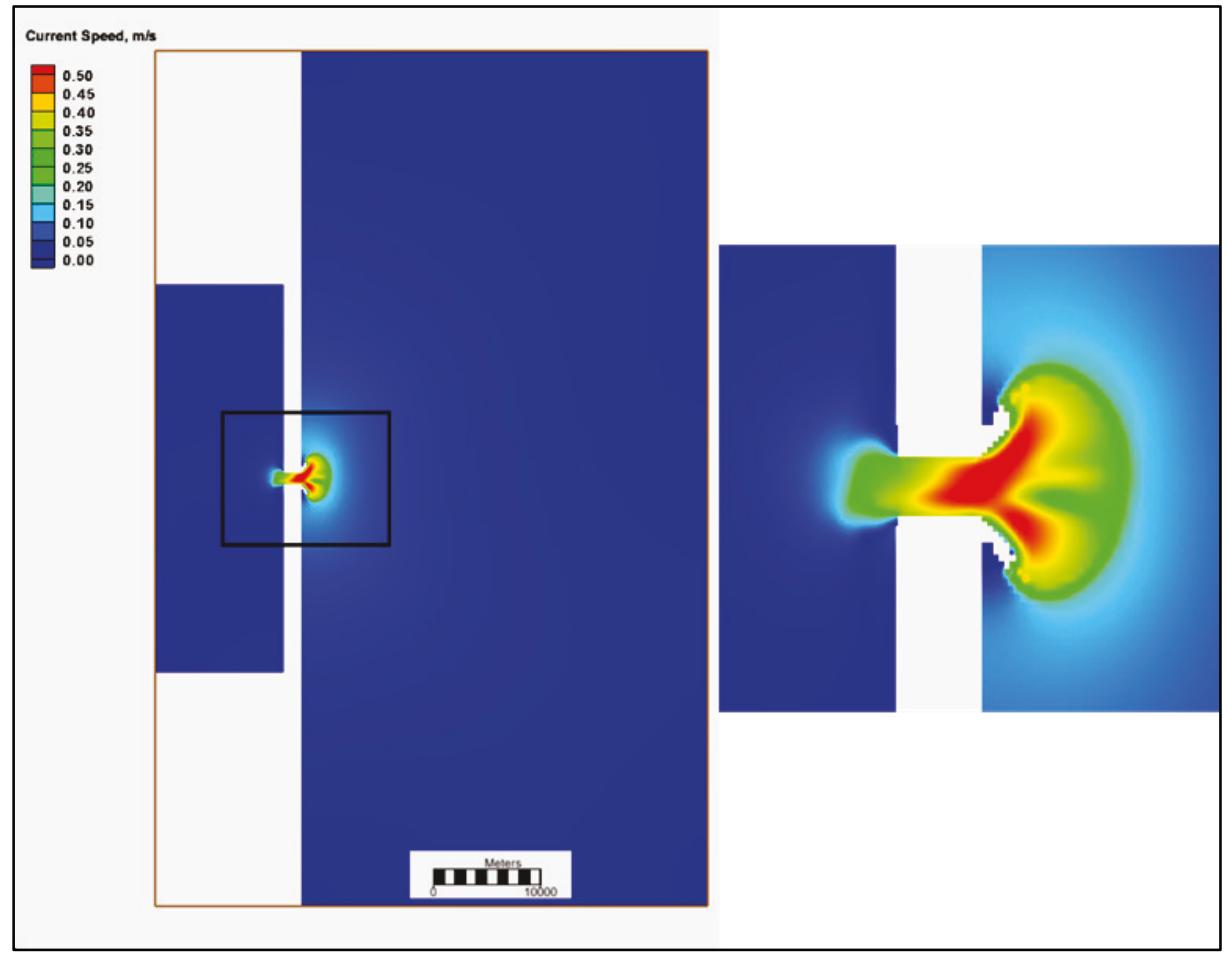


The tidal current envelope in the inlet throat decreases slowly over the course of the simulation (Figure 3.79). Volume flux and tidal prism envelope increase at first in the simulation but then grow more gradually for the remainder of the simulation (Figure 3.80).

Figure 3.79. Average and peak average tidal currents at the midpoint of the inlet (top left and top right inset, respectively). The two smaller panels (right inset) illustrate current patterns for the last year of the simulation.

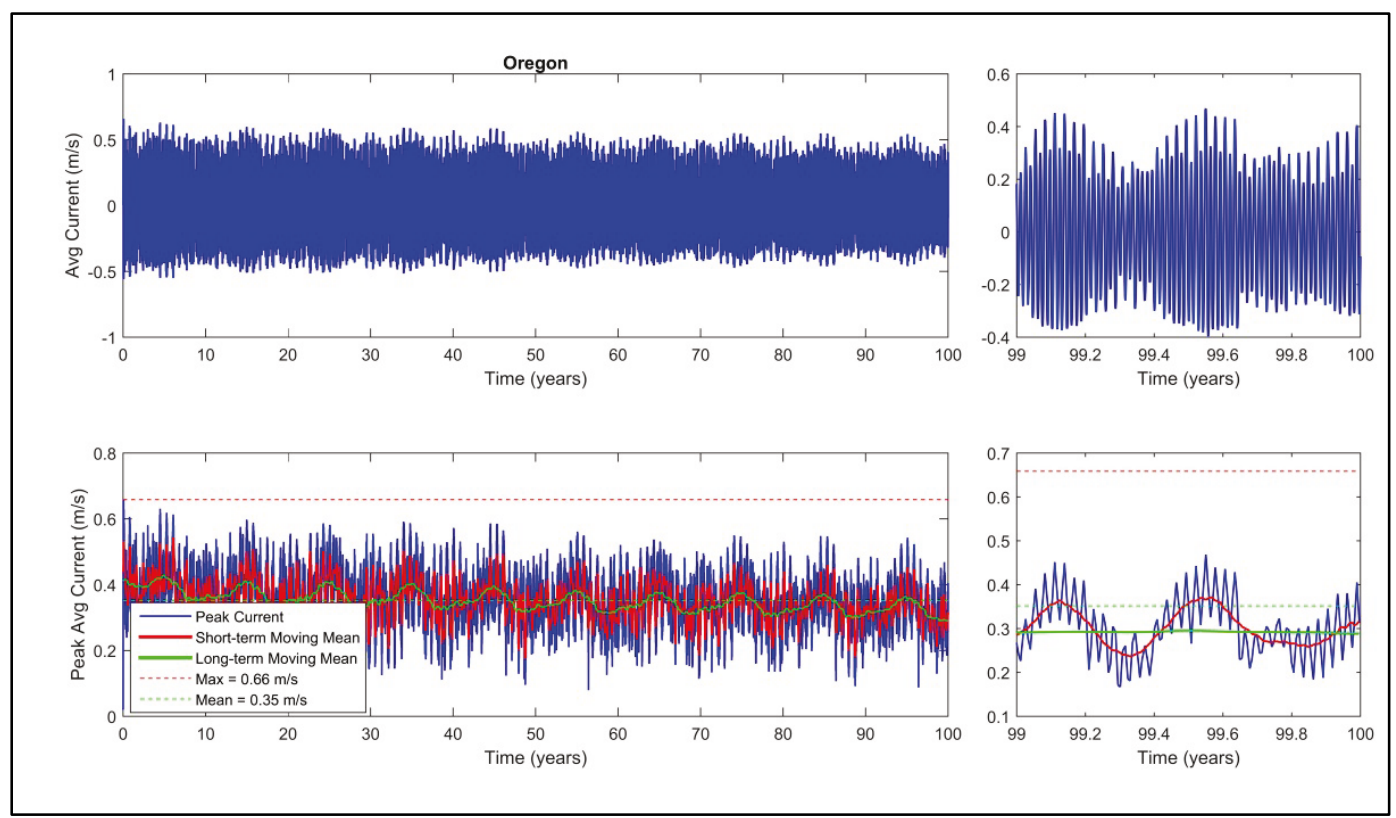

Figure 3.80 Volume flux and tidal prism (top left and top right inset, respectively) at the inlet midpoint. The two smaller panels (right inset) denote the last year of the simulation to illustrate tidal variability.

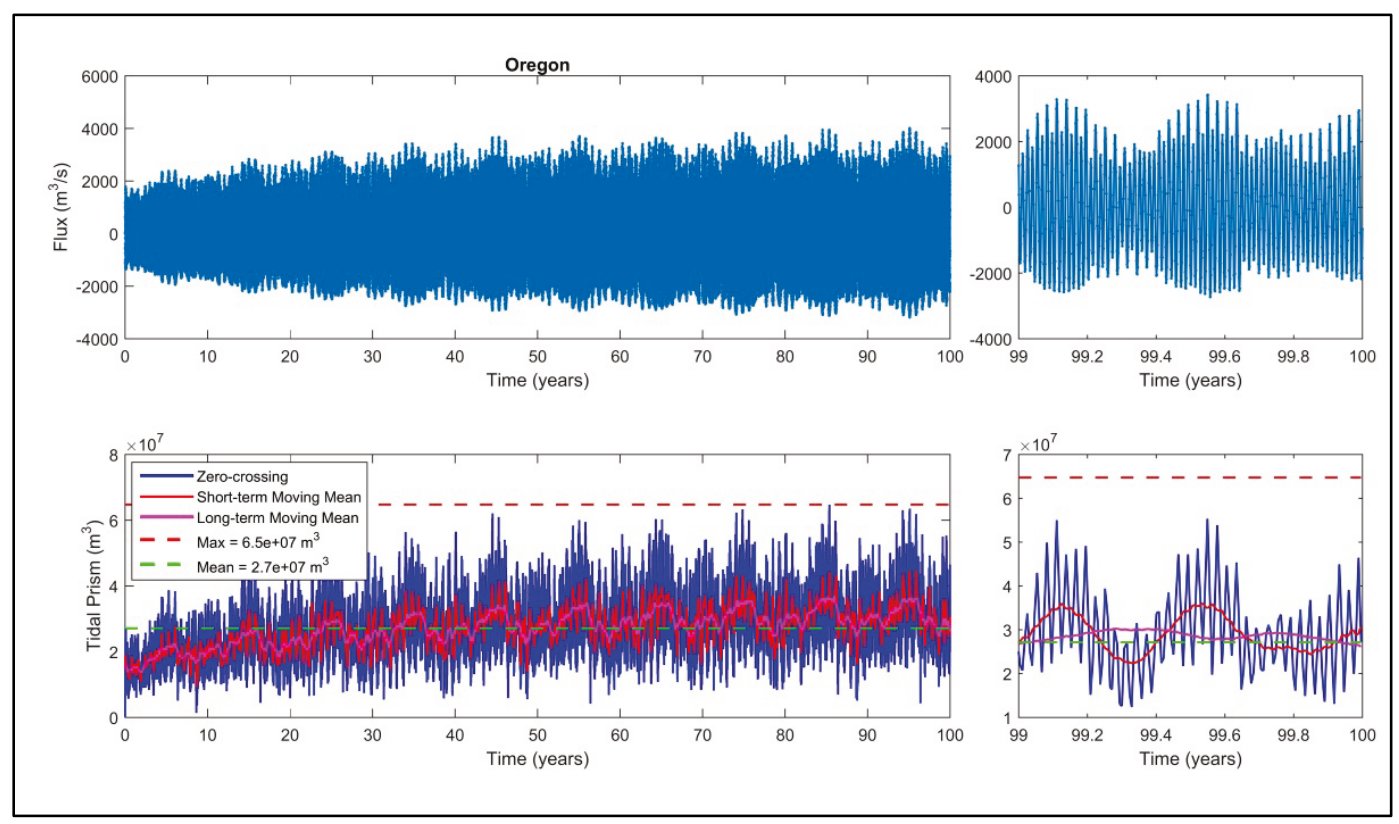


Maximum water surface elevation difference between the ocean and bay decreases rapidly during the first 15 years then more gradually (Figure 3.81). The extremes are asymmetric with regard to the zero-crossing indicating steeper gradients during flood especially during spring tide. These are interrupted by intermittent anomalous spikes throughout the simulation in which the slope is towards the ocean. The overall pattern is indicative of flood-dominated conditions in agreement with sediment deposition patterns.

Figure 3.81. Calculated water surface elevation difference between the ocean and bay. Positive values denote sea surface slope from the ocean to the bay.

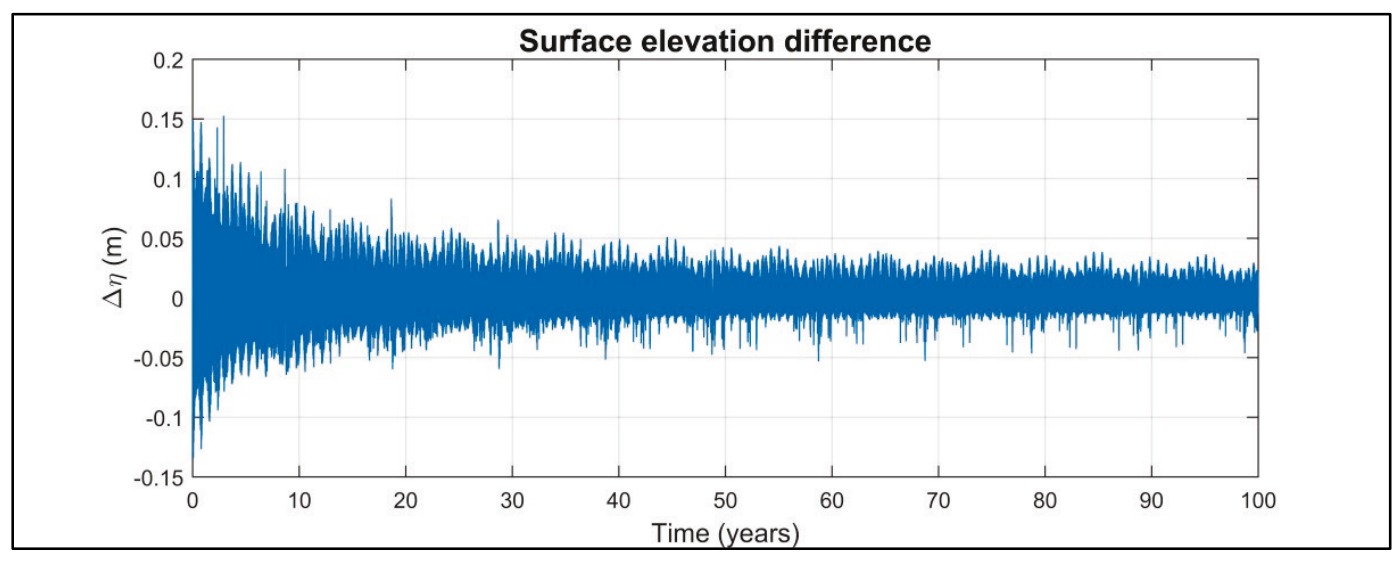

\subsubsection{Comparisons with empirical formulas}

The cross-sectional area predicted by the CMS increases uniformly with the maximum predicted by the tidal prism relationship (Figure 3.82). By the end of the simulation, the cross-sectional area at all three locations exceeds the maximum predicted by the tidal prism relationship. Crosssectional area predicted by the CMS and the tidal prism relationship increase throughout the simulation indicating the inlet has not reached equilibrium. However, given more time it appears that the minimum cross-sectional area predicted by the CMS would be consistent with the empirical results for the maximum cross-sectional area. 
Figure 3.82. Inlet cross-sectional area calculated by the CMS (lines) at three inlet channel locations and the computed cross-sectional area from the tidal prism relationship (points).

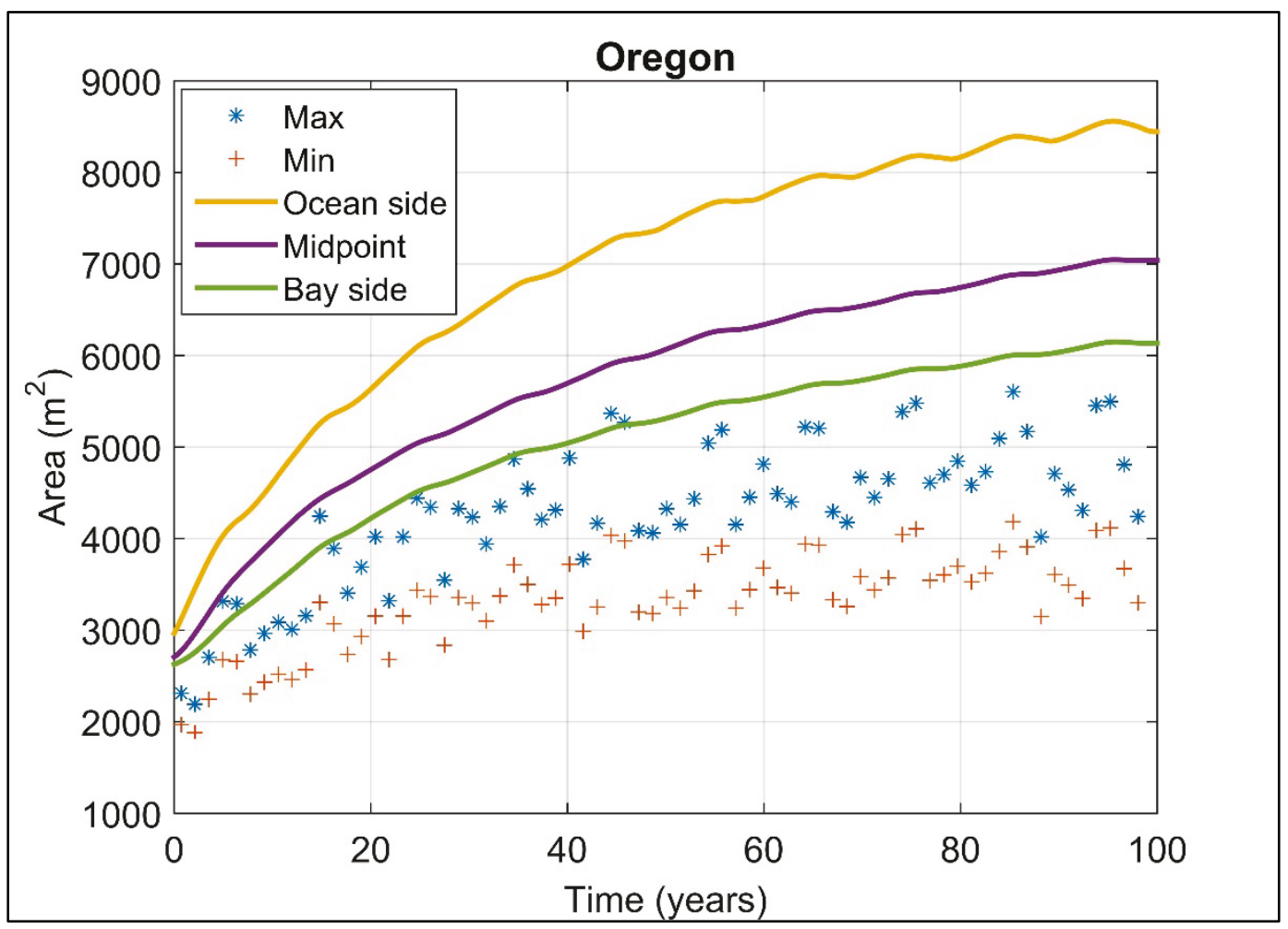

Time series of ebb shoal volume predicted by the CMS and the empirical formulas for ebb shoal volume from tidal prism are depicted in Figure 3.83. The CMS ebb shoal volume is significantly smaller than the maximum predicted by the empirical relationships. However, the CMS prediction is still increasing at the end of the simulation signifying that the system has not reached equilibrium. As the empirical formula shows a slower growth rate at the end of the simulation, it is possible that the CMS prediction will continue to increase and converge to the empirical solution. 
Figure 3.83. Time series of ebb shoal volume calculated by the CMS (yellow line) and the computed empirical formulas that relate tidal prism to ebb shoal volume (points).

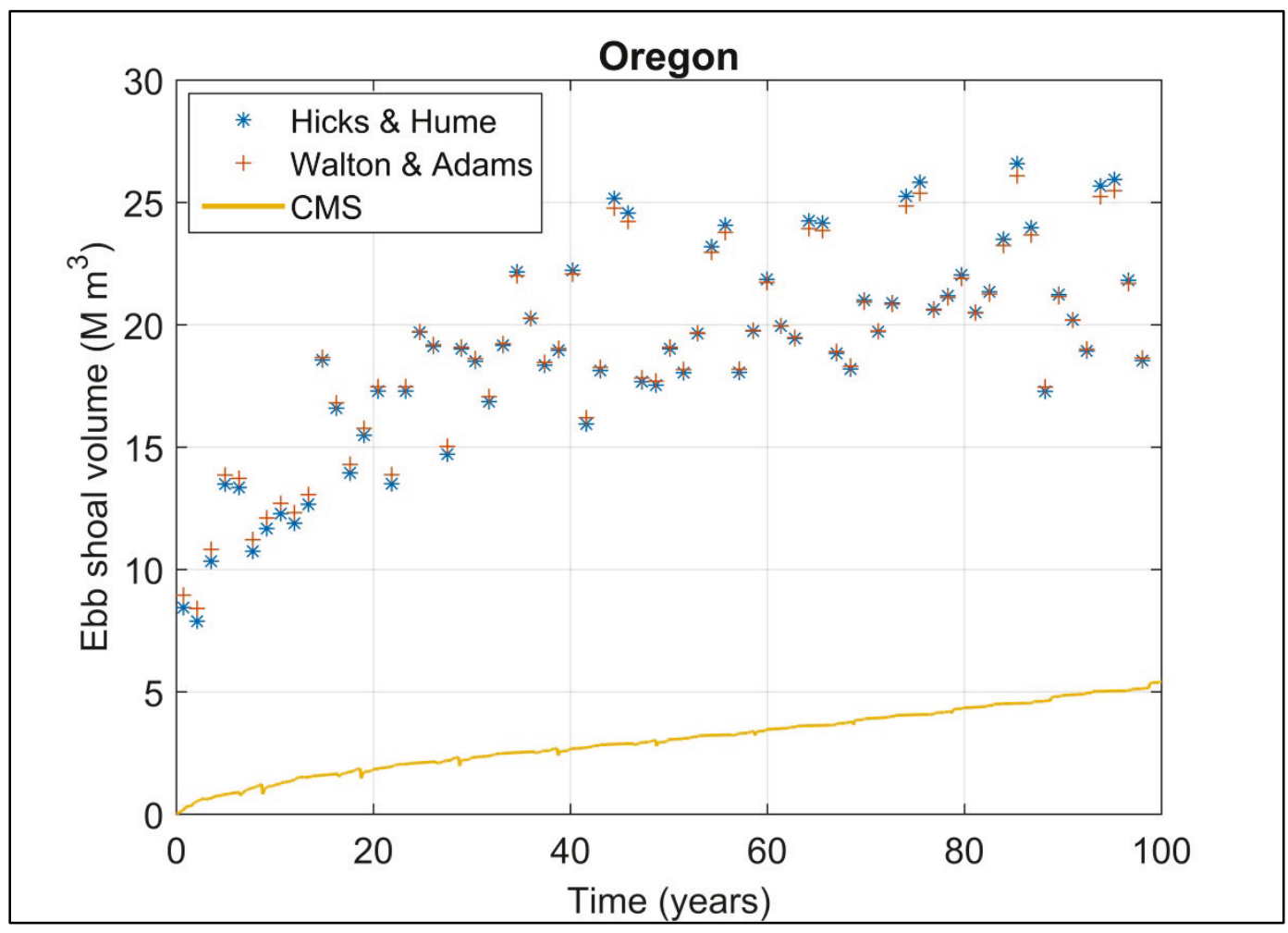

The Escoffier equilibrium theory applied to Oregon Inlet is depicted in Figure 3.84. The input parameters (e.g., bay area, inlet dimensions, and water-surface elevation) are derived from the CMS-idealized Oregon Inlet simulation, and the plus signs denote the measured Oregon Inlet minimal cross-sectional area. Data filtering and averaging parameters are the same as that applied to Grays Harbor. The CMS results reveal inlet deepening and an overall decrease in the maximum current that lies between the quadratic and Escoffier theoretical predictions. The theoretical predictions indicate that the system is potentially unstable. This is likely due to the extreme size of the bay in comparison to the inlet dimensions. In this case, the bay does not respond uniformly to changes in water level at the inlet, which is a requirement for the Escoffier theory. However, the inlet crosssectional area continues to increase near the end of the simulation so that the CMS result is advancing towards the equilibrium range of the Escoffier curve. Longer simulation may reveal that the CMS produces a stable system. 
Figure 3.84. An Escoffier analysis comparing the theoretically predicted (green and yellow lines) and CMS-computed (blue points) current. Plus signs denote the minimal cross-sectional area and the theoretical maximum velocity required for this inlet to remain stable. A 30-day low-pass filter delineates the overall trend of CMS-computed peak velocities for modeled cross-sectional areas (orange line).

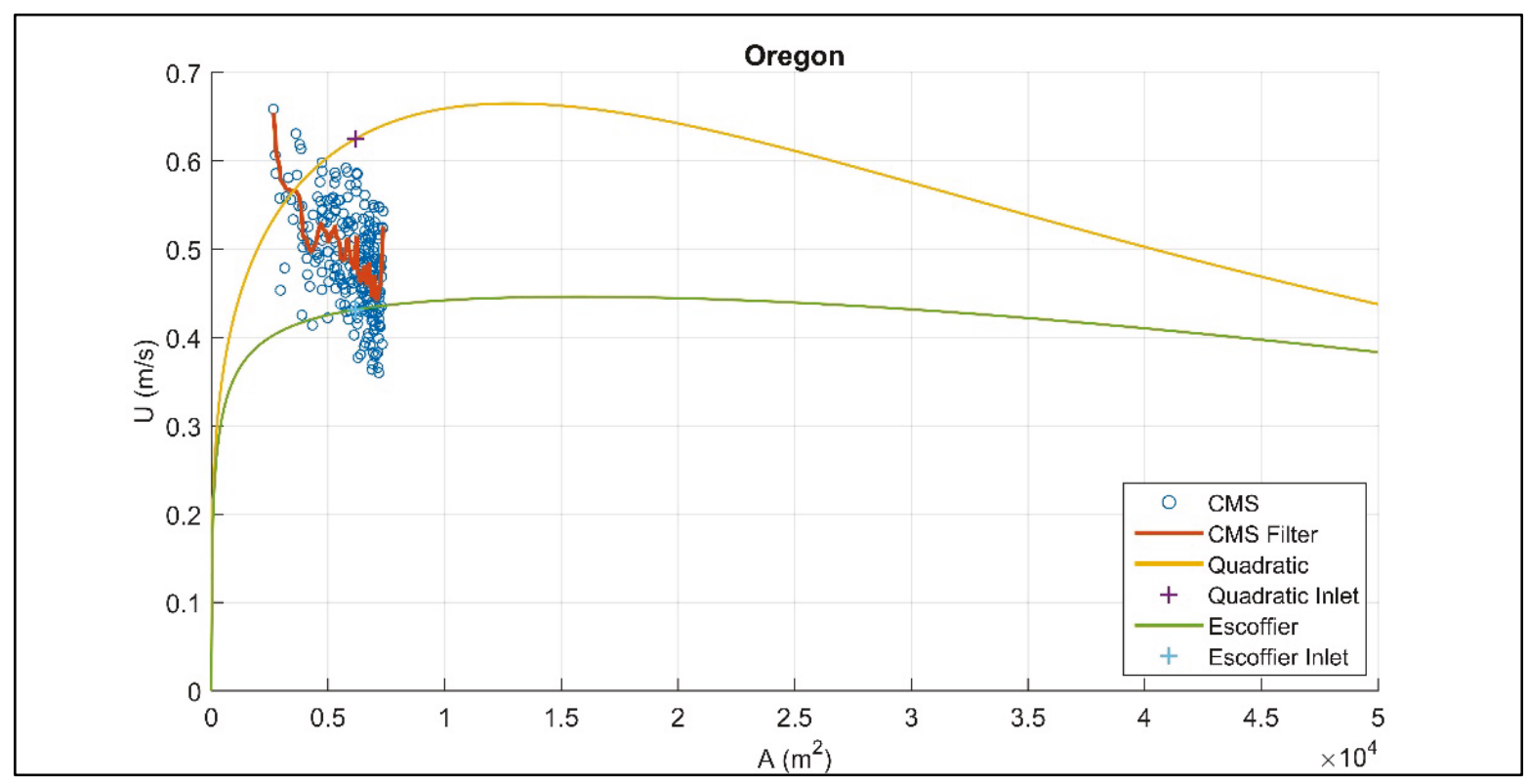

\subsection{Shinnecock Inlet}

Shinnecock Inlet is located on the south shore of Long Island, NY. The model grid for Shinnecock idealized inlet/bay system is depicted in Figure 3.85. The dimensions and initial depth are listed in Table A1. The simulated bay width and length, 3.2 and $12.5 \mathrm{~km}$, respectively, produce a rectangular area equal to the area of the back barrier lagoon, which is elongated in the alongshore direction typical of bar-built estuaries. The depth contours offshore are straight and parallel and follow an equilibrium beach profile near the shoreline. Water depth is constant at $2.2 \mathrm{~m}$ within the throat and bay and tapered at the ocean side to match the offshore depths. The bay depth is based upon average conditions for Shinnecock Inlet. 
Figure 3.85. CMS grid and bathymetry for idealized Shinnecock simulation.

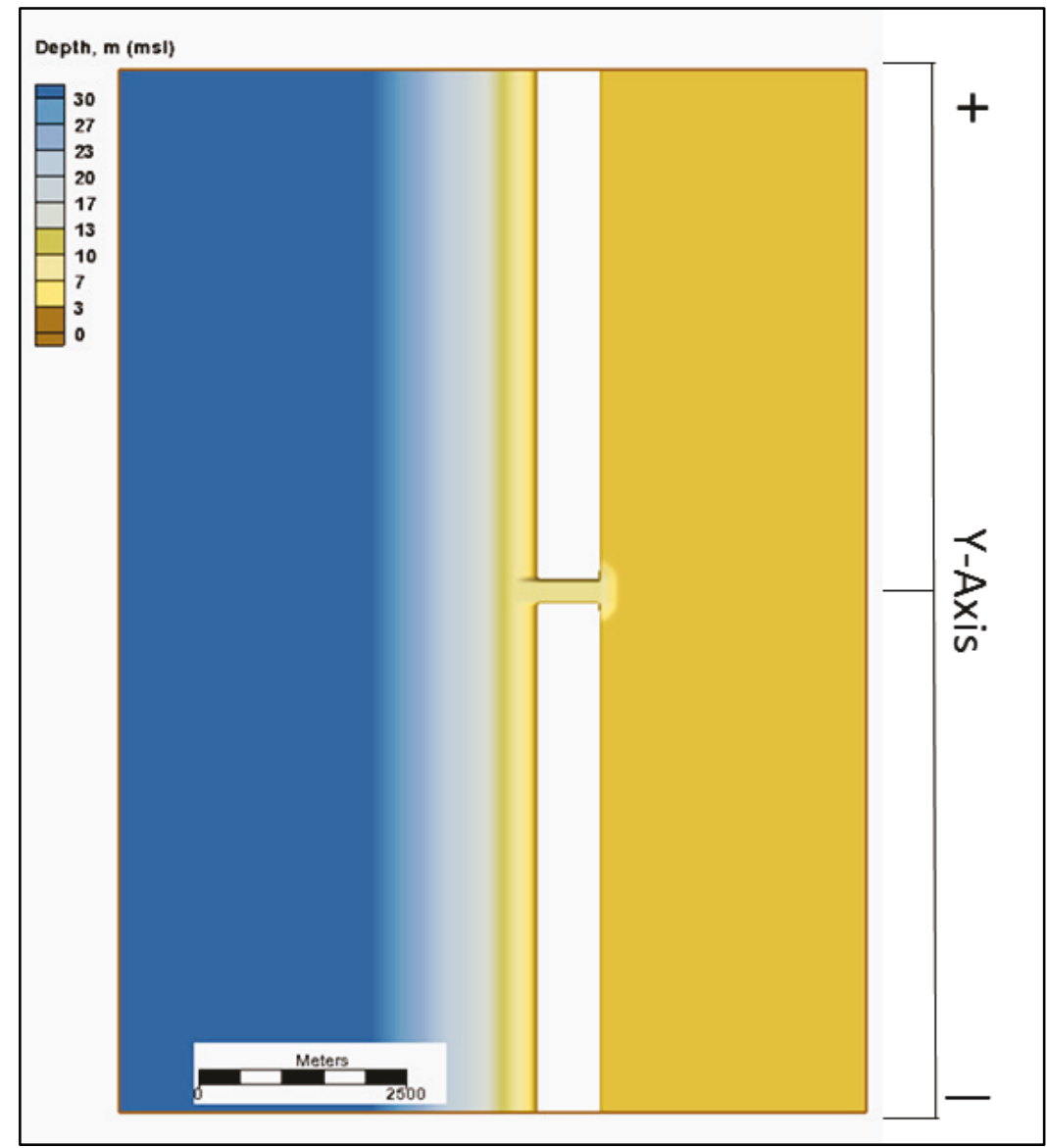

\subsubsection{Morphology}

The ebb shoal extends symmetrically approximately $1 \mathrm{~km}$ up and down the coast and $2 \mathrm{~km}$ offshore (Figure 3.86). The outer fringe of the main lobe is symmetric with respect to the inlet axis, but the shoal is wider on the $y$-positive (right) side of the inlet. The ebb channel is deep and slightly angled towards the negative $y$-direction (left). Marginal flood channels have formed on either side of the main terminal lobe.

The main channel within the inlet throat is oriented along the centerline and extends over most of the width of the inlet. Marginal bars flank both sides of the channel and grow in thickness towards the bay, especially on the positive ( $y$-axis) side. The bars result from flow separation at the entrance/exit during flood/ebb. The bay has developed into a network of incised channels that branch into several smaller channels towards the back bay. 
Figure 3.86. Calculated final depth for Shinnecock. White areas shown inside the bays denote computational areas that were dry (above the water level) at the end of the simulation.

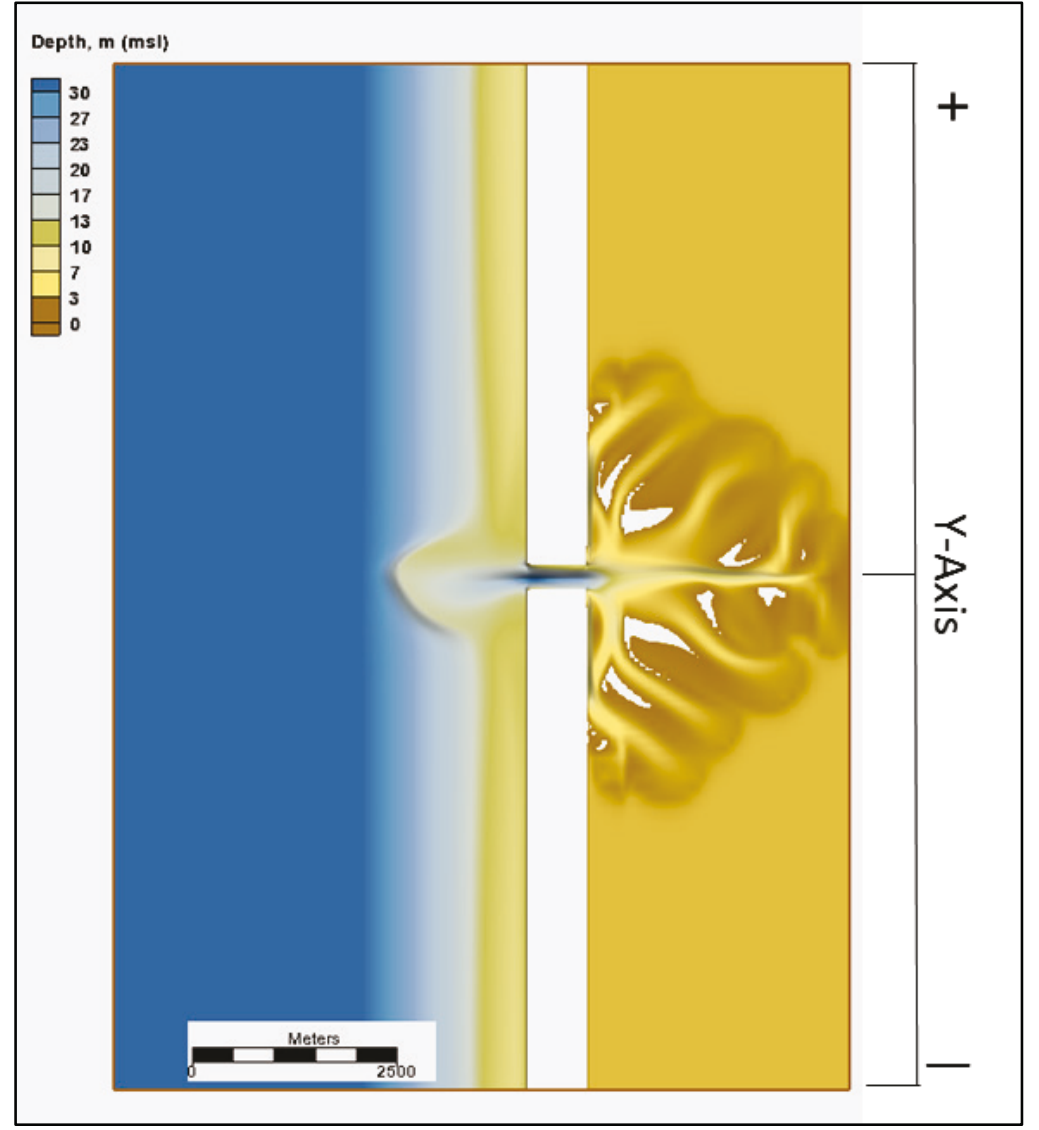

Figure 3.87 depicts the temporal evolution of the cross-sectional area at the ocean, midpoint, and bay side of the inlet. Bed deepening at the ocean side is indicative of bed scouring in a confined channel, in which the erosion is greatest in the center forming a bed profile that is slightly skewed in the negative $y$-direction. Deepening at the midpoint and bay side of the inlet trend in a similar manner. All three cross sections exhibit rapid deepening in the first 20 years that becomes more gradual during the remainder of the simulation. The profiles maintain similar shapes in that the deepest portion is in the middle of the inlet. 
Figure 3.87. CMS-predicted temporal evolution of inlet cross-sectional area for Shinnecock. Distances are alongshore from channel centerline with positive towards the right looking oceanward and negative towards the left.

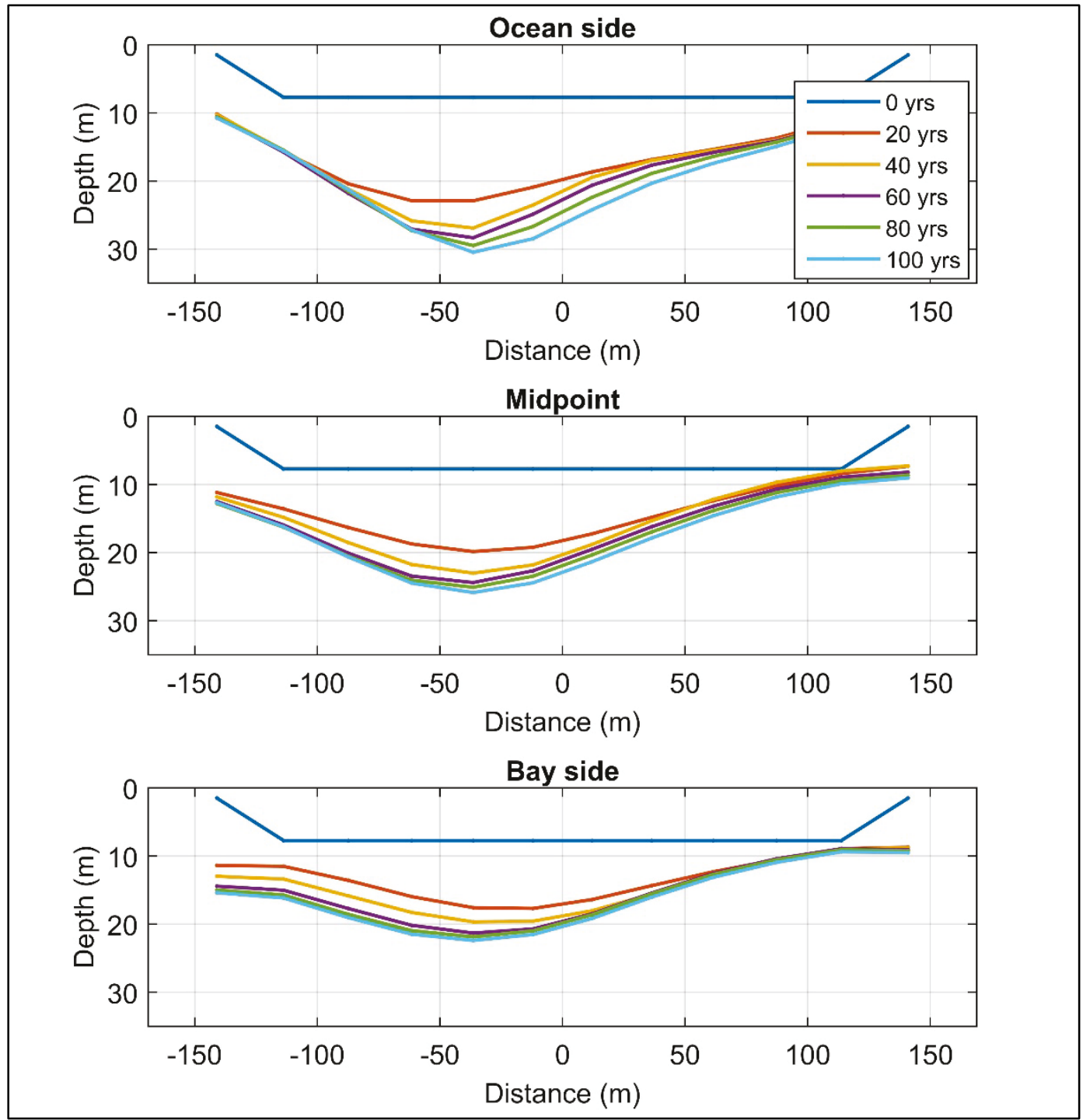

The net bed volume change in the bay, inlet, and ebb shoal is depicted in Figure 3.88. The primary sediment transport pathway removes material from the inlet and deposits it in the ebb and flood shoals. The ebb shoal volume increase, and initially the inlet volume decrease, demonstrates a stepwise pattern that is driven by storms in the simulation. Note that the accretion within the bay is smoother as it is not impacted directly by storm waves. By the end of the simulation, the bay and ebb shoal are still gaining sediment, but the inlet is approaching an equilibrium with no net gain or loss. Net gains in the ebb shoal and bay exceed inlet losses suggesting a sediment supply from longshore sediment transport along adjacent 
beaches. The results for bed change for Shinnecock Inlet indicate that it is flood dominant.

Figure 3.88. Calculated bed volume change for Shinnecock Inlet.

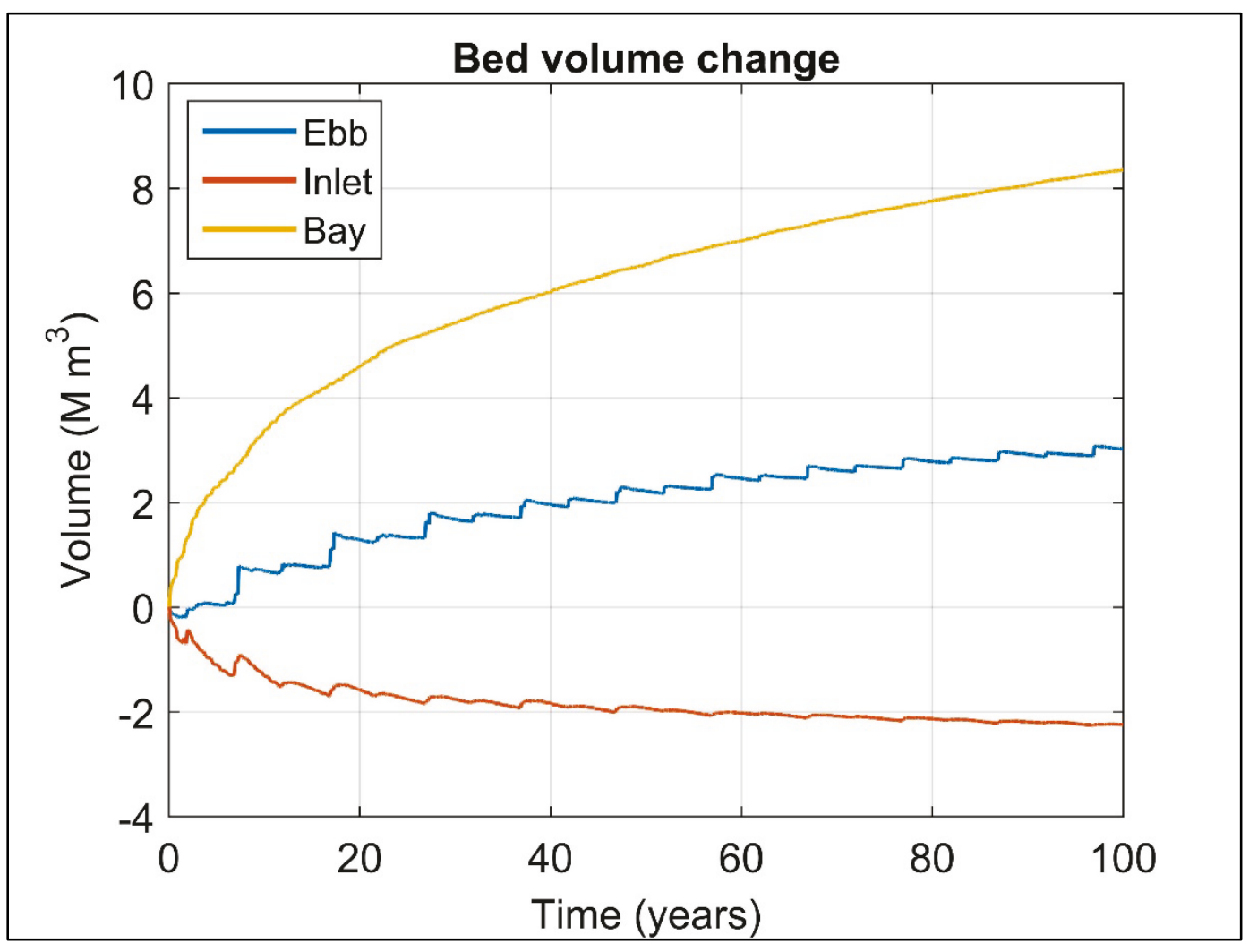

\subsubsection{Hydrodynamics}

Spatial current magnitude distribution near the end of the simulation during maximum flood and maximum ebb is depicted in Figure 3.89 and Figure 3.90, respectively. Flood currents enter the inlet and then accelerate along the channel. Currents diverge at the bay side end of the inlet forming multiple broad pathways that adhere to the bay channels. Shoals that have formed in the bay are intertidal, or exposed during low tide. Maximum ebb currents exit the bay channel network and converge and strengthen in the inlet throat. Upon exiting the inlet, a strong ebb jet forms extending from the main ebb channel beyond the outer terminal lobe. Maximum flood currents are significantly stronger than ebb currents, as is typical of flood dominant inlets, and are strongest within the inlet throat and bay channels. 
Figure 3.89. Current magnitude during maximum flood at the end of the 100-year simulation for Shinnecock Inlet. White areas shown inside the bays denote computational areas that were dry (above the water level) at the end of the simulation.

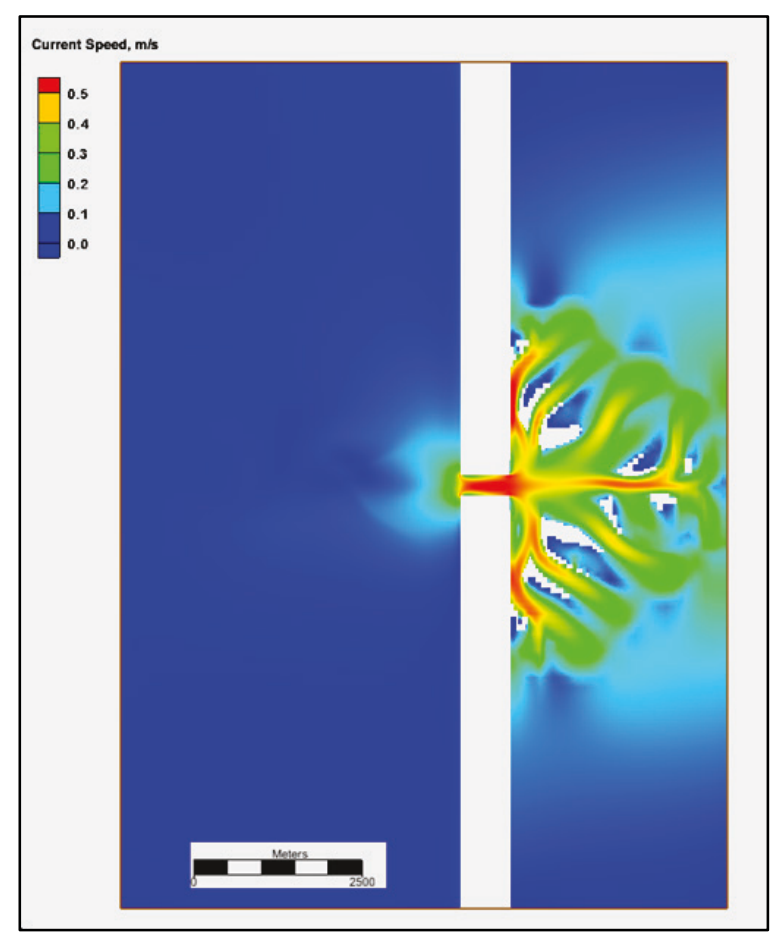

Figure 3.90. Current magnitude during maximum ebb at the end of the 100-year simulation for Shinnecock Inlet. White areas shown inside the bays denote computational areas that were dry (above the water level) at the end of the simulation.

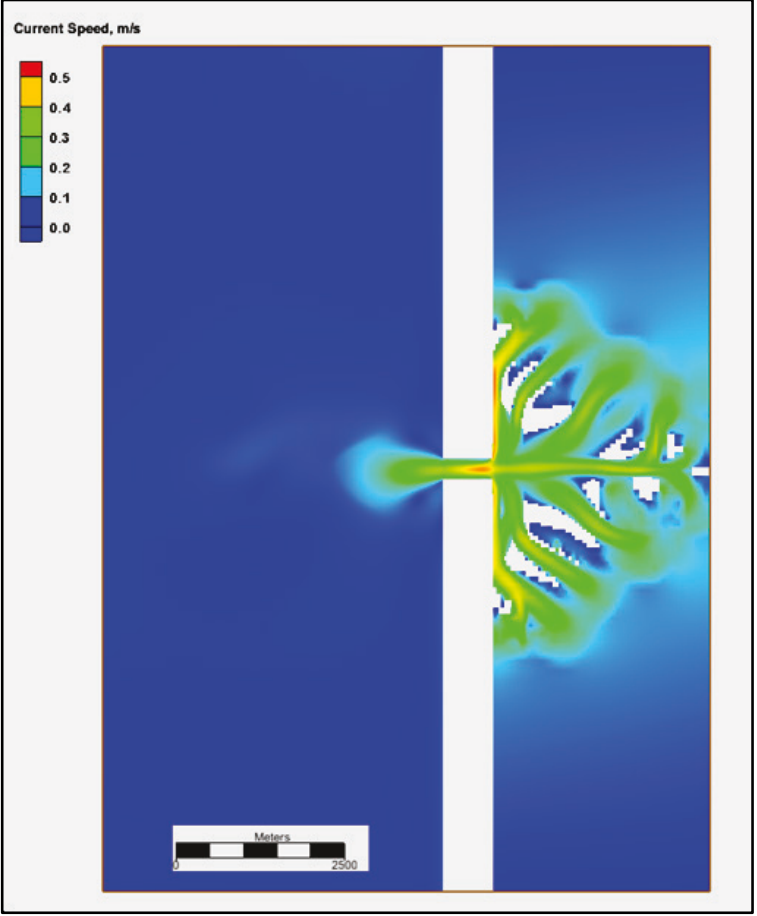


The tidal current envelope in the inlet throat decreases over the first 40 years and then diminishes more slowly over the course of the simulation (Figure 3.91). Volume flux and tidal prism envelope increase at first but then become more uniform for the remainder of the simulation (Figure 3.92).

Figure 3.91. Average and peak average tidal currents at the midpoint of the inlet (top left and top right inset, respectively). The two smaller panels (right inset) illustrate current patterns for the last year of the simulation.

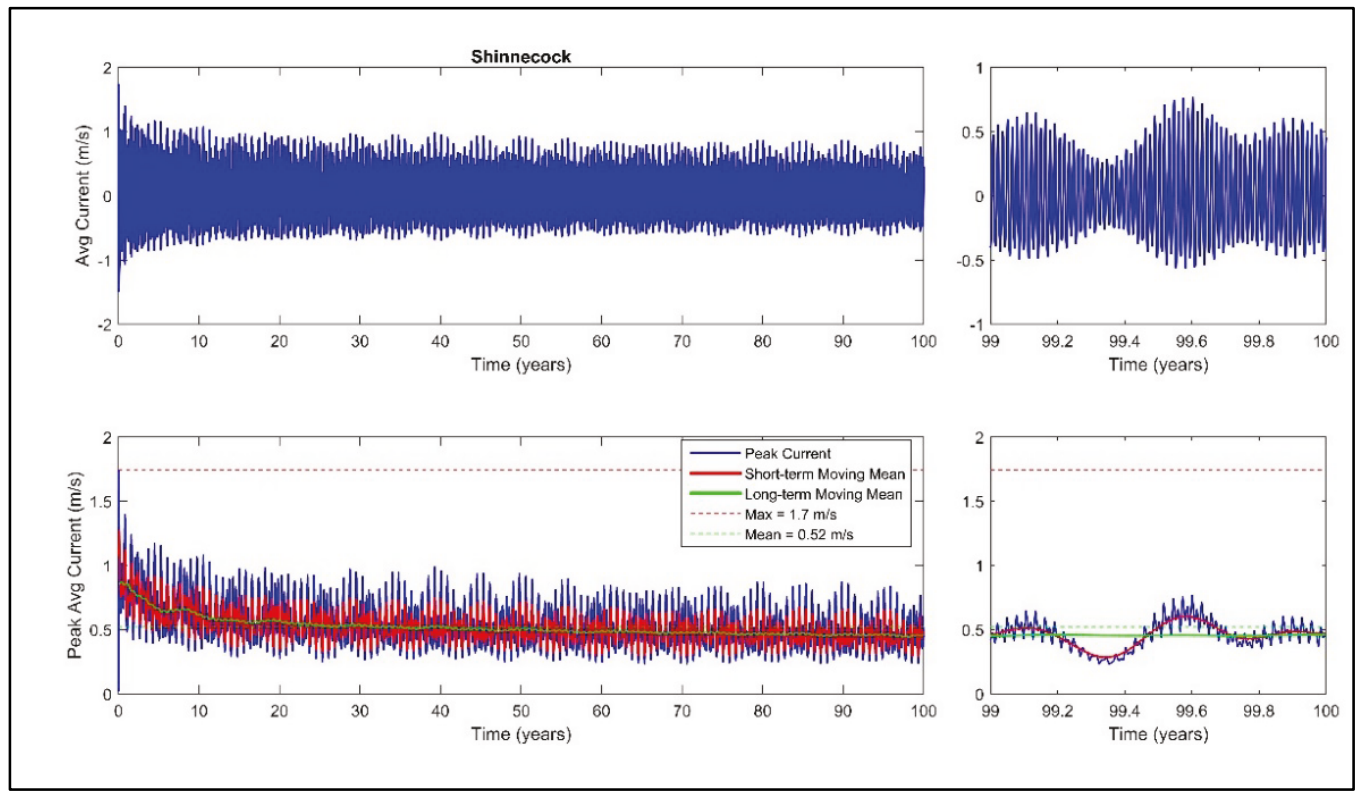

Figure 3.92. Volume flux and tidal prism (top left and top right inset, respectively) at the inlet midpoint. The two smaller panels (right inset) denote the last year of the simulation to illustrate tidal variability.

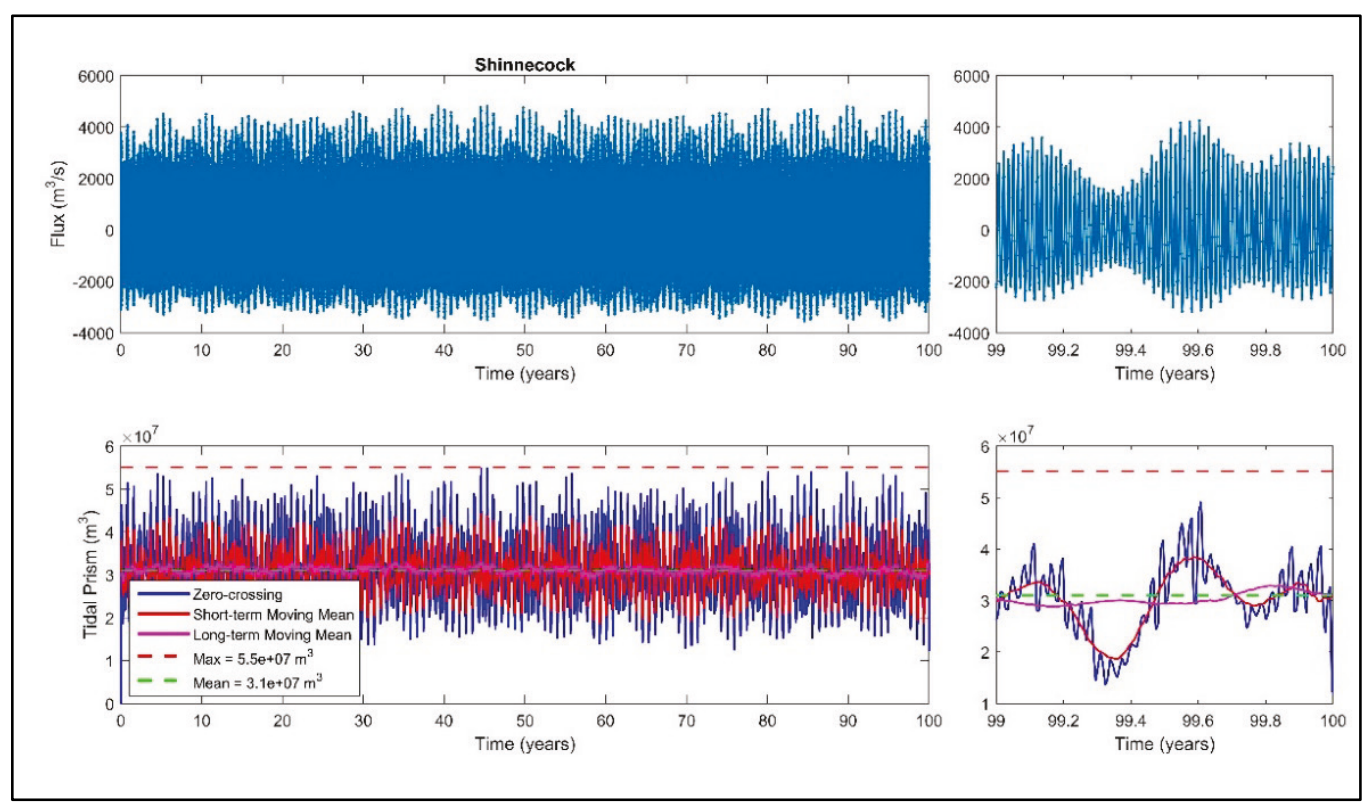


The maximum water surface elevation difference between the ocean and bay decreases rapidly during the first 15 years then more gradually (Figure 3.93). The extremes are asymmetric with regard to the zero-crossing indicating steeper gradients during flood especially during spring tide. This is indicative of flood dominated conditions in agreement with sediment deposition patterns.

Figure 3.93. Calculated water surface elevation difference between the ocean and bay. Positive values denote sea surface slope from the ocean to the bay.

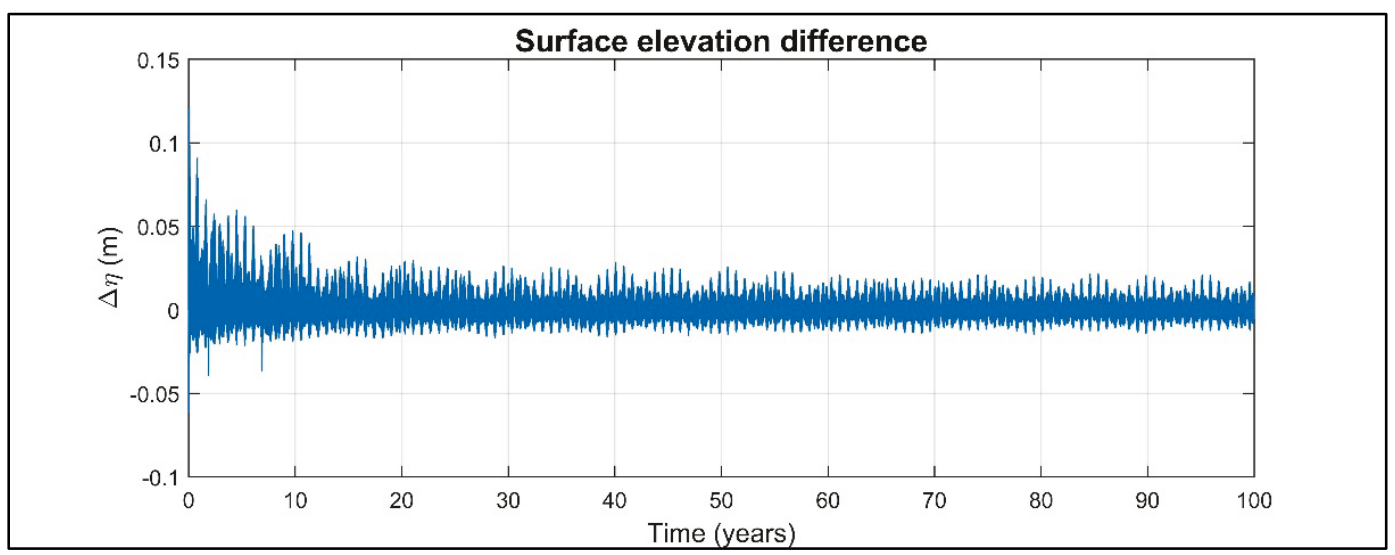

\subsubsection{Comparisons with empirical formulas}

The cross-sectional area predicted by the CMS increases at a faster rate than the maximum predicted by the tidal prism relationship (Figure 3.94). By the end of the simulation, the cross-sectional area at all three locations exceeds the maximum predicted by the tidal prism relationship. Crosssectional area predicted by the CMS increases throughout the simulation while the estimate derived from the tidal prism relationship is essentially uniform after approximately 50 years. 
Figure 3.94. Inlet cross-sectional area calculated by the CMS (lines) at three inlet channel locations and the computed cross-sectional area from the tidal prism relationship (points).

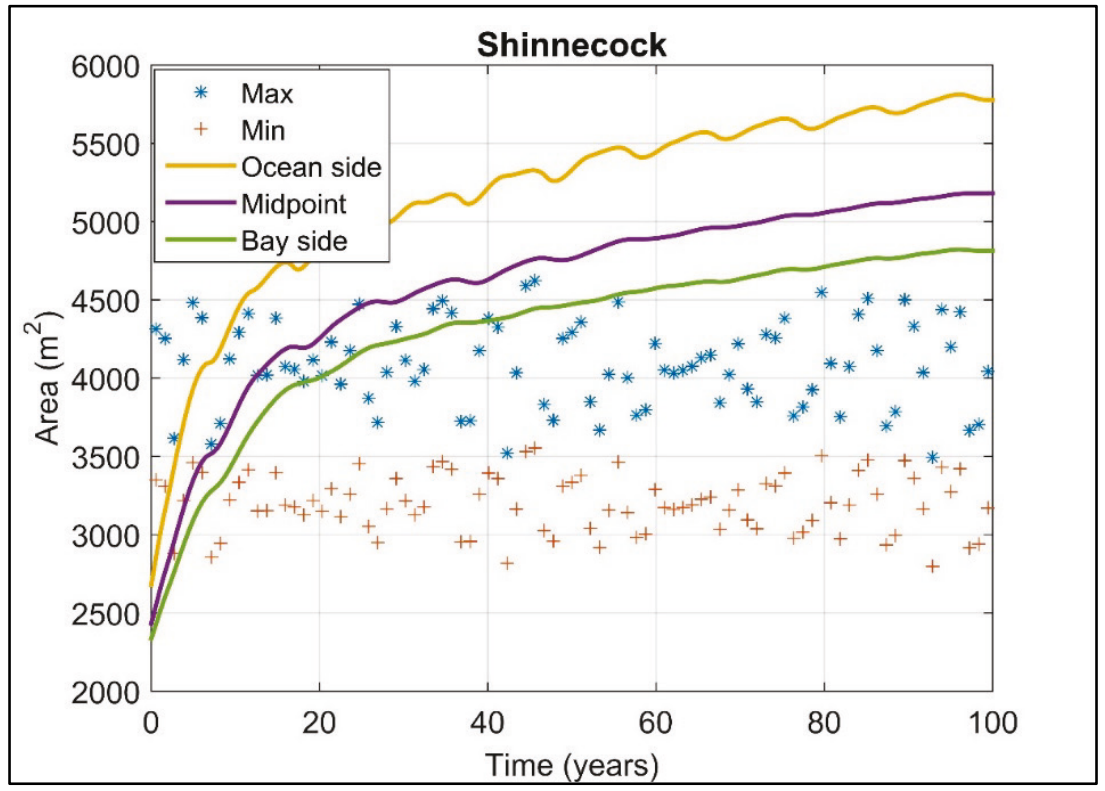

Time series of ebb shoal volume predicted by the CMS and the empirical formulas is depicted in Figure 3.95. The CMS ebb shoal volume is significantly smaller than the maximum predicted by the empirical relationships. However, the CMS prediction is still increasing at the end of the simulation signifying that the system has not reached equilibrium. With more time, it is possible that the CMS prediction will continue to grow and converge to the empirical solution. 
Figure 3.95. Time series of ebb shoal volume calculated by the CMS (yellow line) and the computed empirical formulas that relate tidal prism to ebb shoal volume (points).

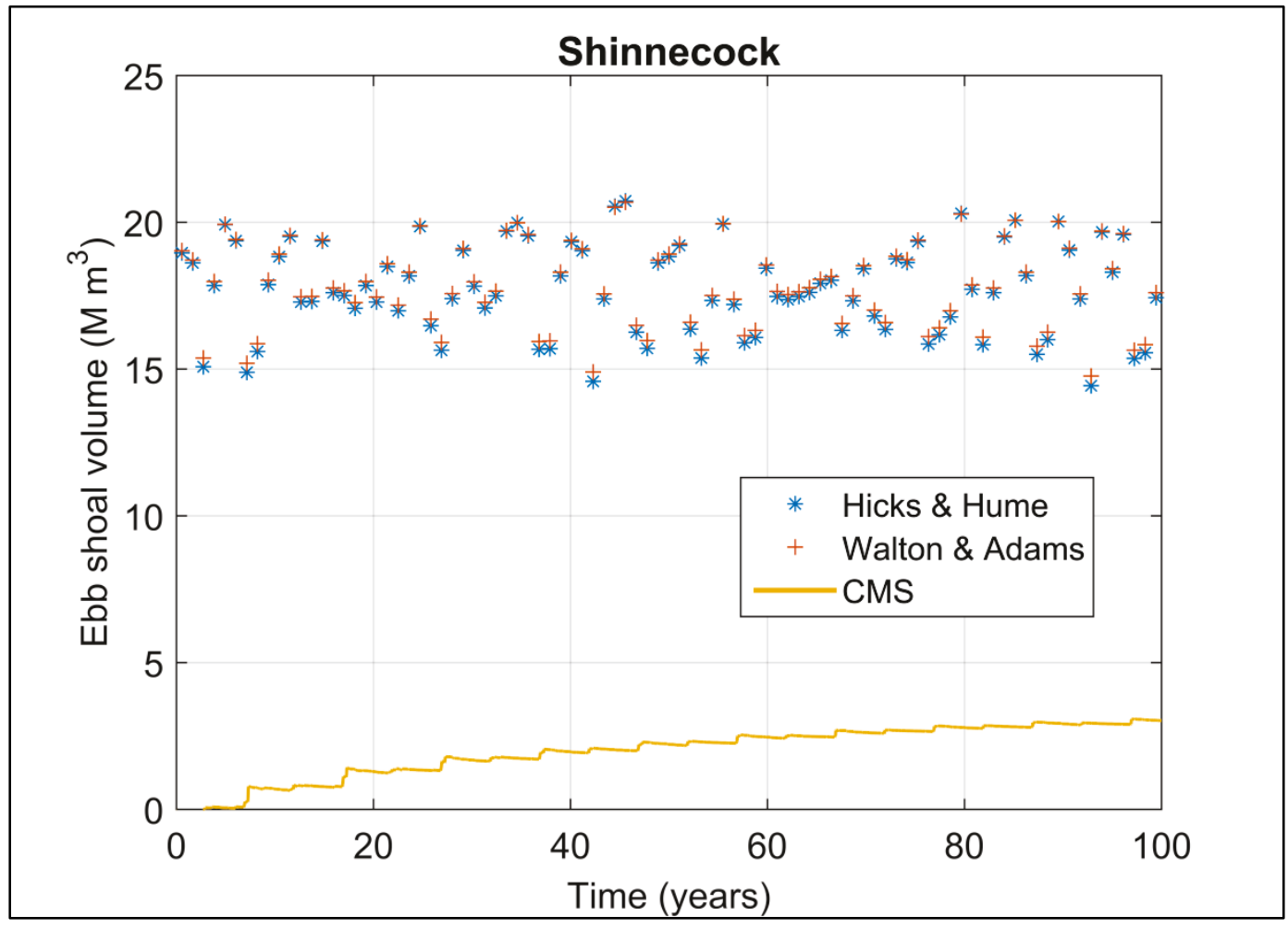

The Escoffier equilibrium theory applied to Shinnecock is depicted in Figure 3.96. The input parameters (e.g., bay area, inlet dimensions, and water-surface elevation) are derived from the CMS-idealized Shinnecock simulation, and the plus signs denote the measured Shinnecock minimal cross-sectional area. Data filtering and averaging parameters are the same as that applied to Grays Harbor. The CMS results reveal inlet deepening and an overall decrease in the maximum current that exceeds the quadratic and Escoffier theoretical predictions. However, the CMS results trend with the theoretical predictions, albeit the CMS predicts higher equilibrium current speeds, and the final predicted cross-sectional area is greater than that observed at Shinnecock Inlet. 
Figure 3.96. An Escoffier analysis comparing the theoretically predicted (green and yellow lines) and CMS-computed (blue points) current. Plus signs denote the minimal cross-sectional area and the theoretical maximum velocity required for this inlet to remain stable. A 30-day low-pass filter delineates the overall trend of CMS-computed peak velocities for modeled cross-sectional areas (orange line).

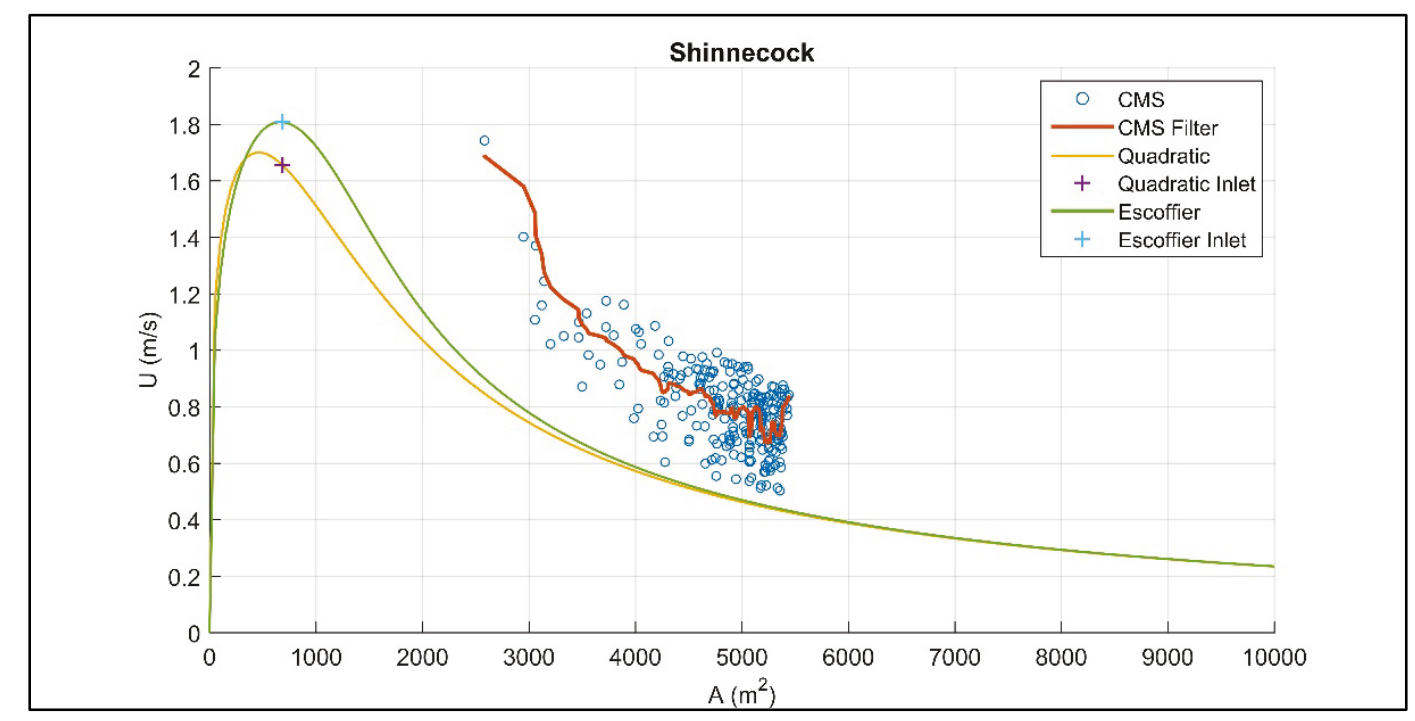

\subsection{Newburyport Inlet}

Newburyport Inlet is located near the town of Newburyport, MA, and is the terminus of the Merrimack River. The model grid for the Newburyport idealized inlet/bay system is depicted in Figure 3.97. The dimensions and initial depth are listed in Table A1. The simulated bay width and length, 3.0 and $5.9 \mathrm{~km}$, respectively, produce a rectangular area equal to the area of the bay, which is elongated in the alongshore direction typical of bar built estuaries. The depth contours offshore are straight and parallel and follow an equilibrium beach profile near the shoreline. The water depth is constant at $1.8 \mathrm{~m}$ within the throat and bay and tapered at the ocean side to match the offshore depths. The bay depth is based upon average conditions for Newburyport Inlet. 
Figure 3.97. CMS grid and bathymetry for idealized Newburyport simulation.

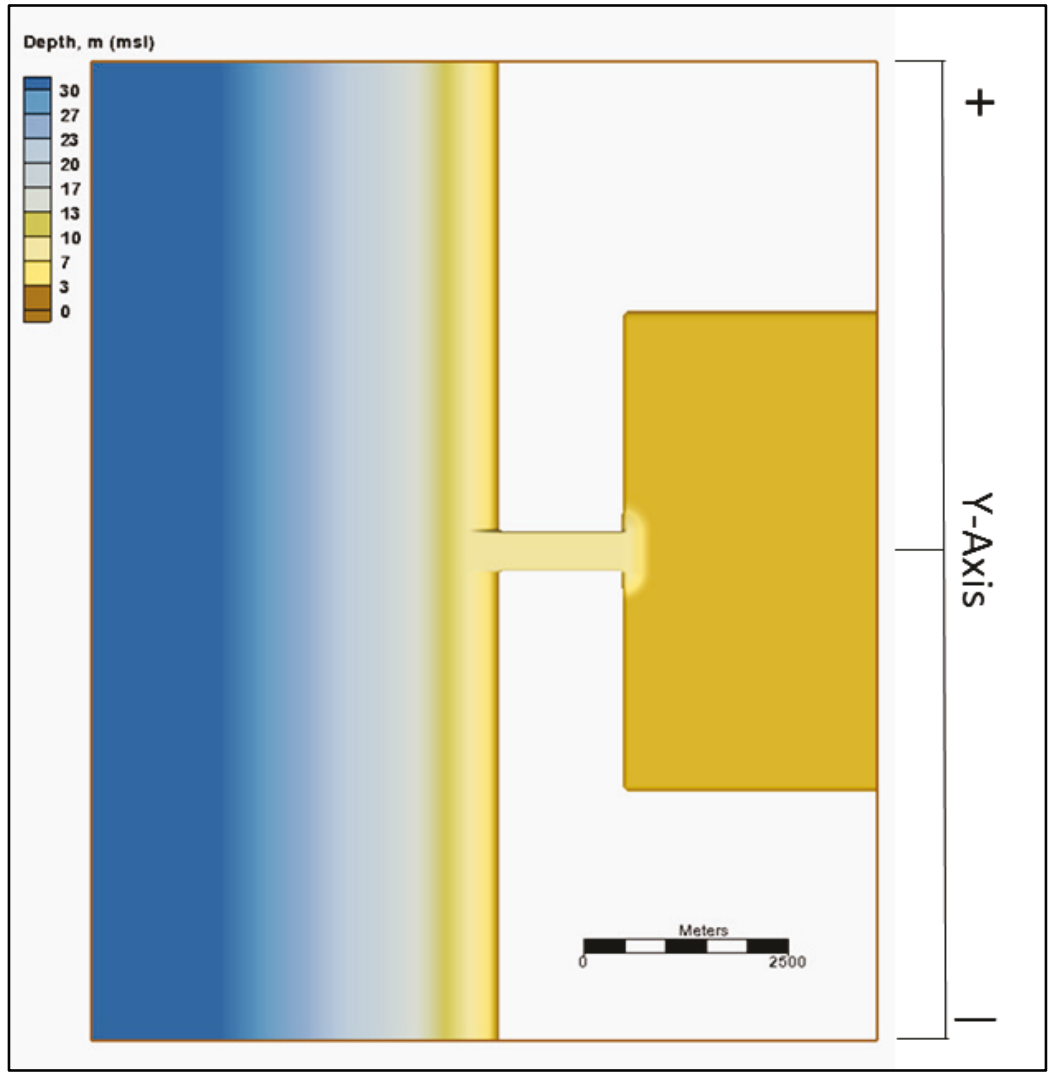

\subsubsection{Morphology}

The final morphological evolution is depicted in Figure 3.98. The ebb shoal is asymmetric and extends approximately $0.5 \mathrm{~km}$ up the coast (right), $2 \mathrm{~km}$ down the coast (left), and $2 \mathrm{~km}$ offshore. The outer fringe of the main lobe is rotated towards the negative $y$-axis, and the shoal is wider on the positive ( $y$-axis) side of the inlet. The ebb channel is deep and angled towards the negative $y$-direction.

The main channel within the inlet throat is oriented along the $y$-negative side of the inlet and extends over a small portion of the width. Shallow deposits have formed on the $y$-positive side of the inlet throat and grown in width towards the bay. The bay has developed into a network of incised channels that extend parallel to the barrier island and then branch into several channels towards the back bay. 
Figure 3.98. Calculated final depth for Newburyport after 100-year simulation. White areas shown inside the bays denote computational areas that were dry (above the water level) at the end of the simulation.

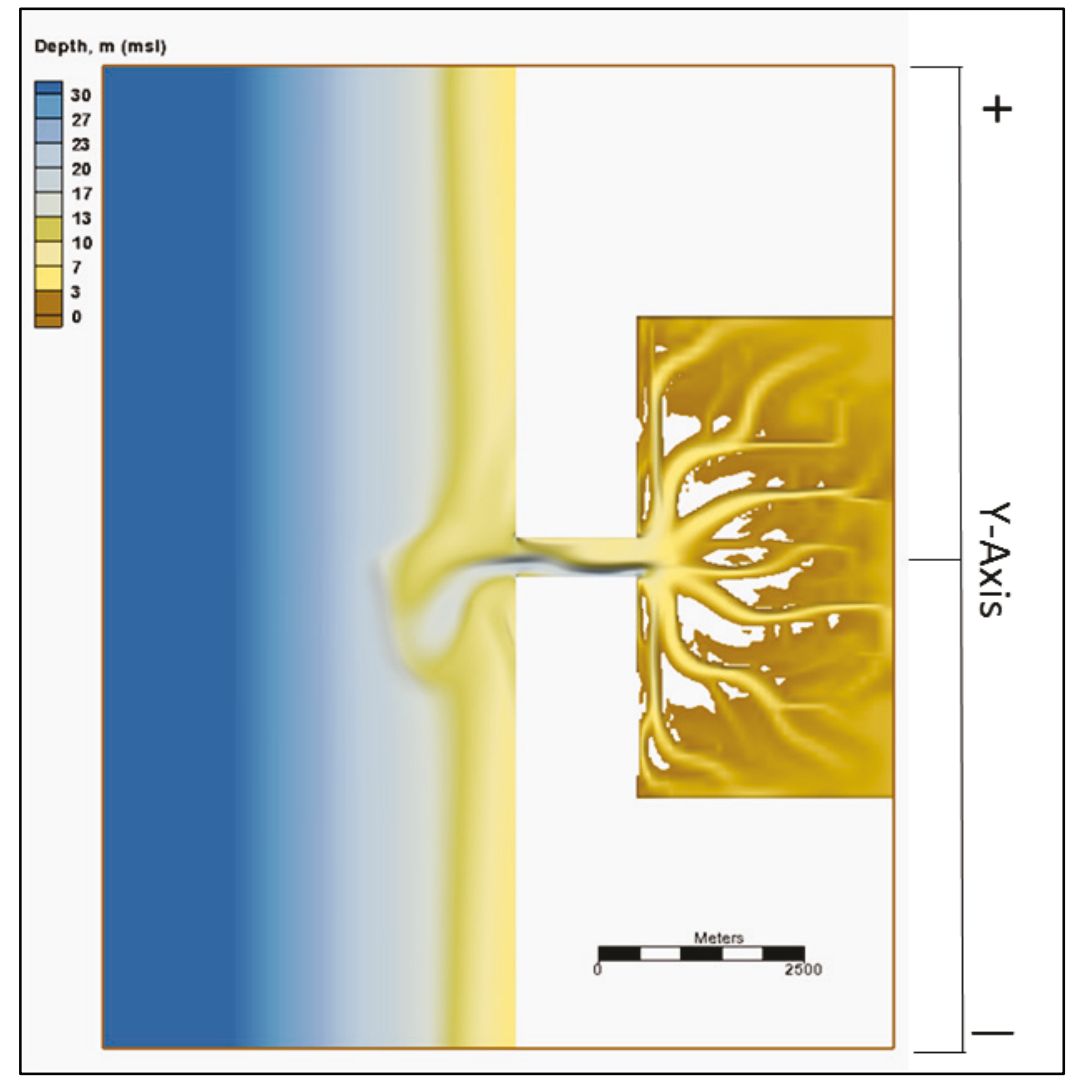

Figure 3.99 depicts the temporal evolution of the cross-sectional area at the ocean, midpoint. and bay side of the inlet. Bed deepening at the ocean side is indicative of bed scouring in a confined channel, in which the erosion is greatest in the center, forming a bed profile that is skewed in the negative $y$-direction. Deepening at the midpoint trends in a similar manner, but the deeper section migrates over time towards the $y$-negative direction. On the bay side, the bed profile likewise migrates towards the $y$-negative side of the channel. All three cross sections exhibit rapid deepening in the first 20 years that becomes more gradual during the rest of the simulation. The profiles maintain similar shapes and similar maximum depths. 
Figure 3.99. CMS-predicted temporal evolution of inlet cross-sectional area for Newburyport. Distances are alongshore from channel centerline with positive towards the right looking oceanward and negative towards the left.

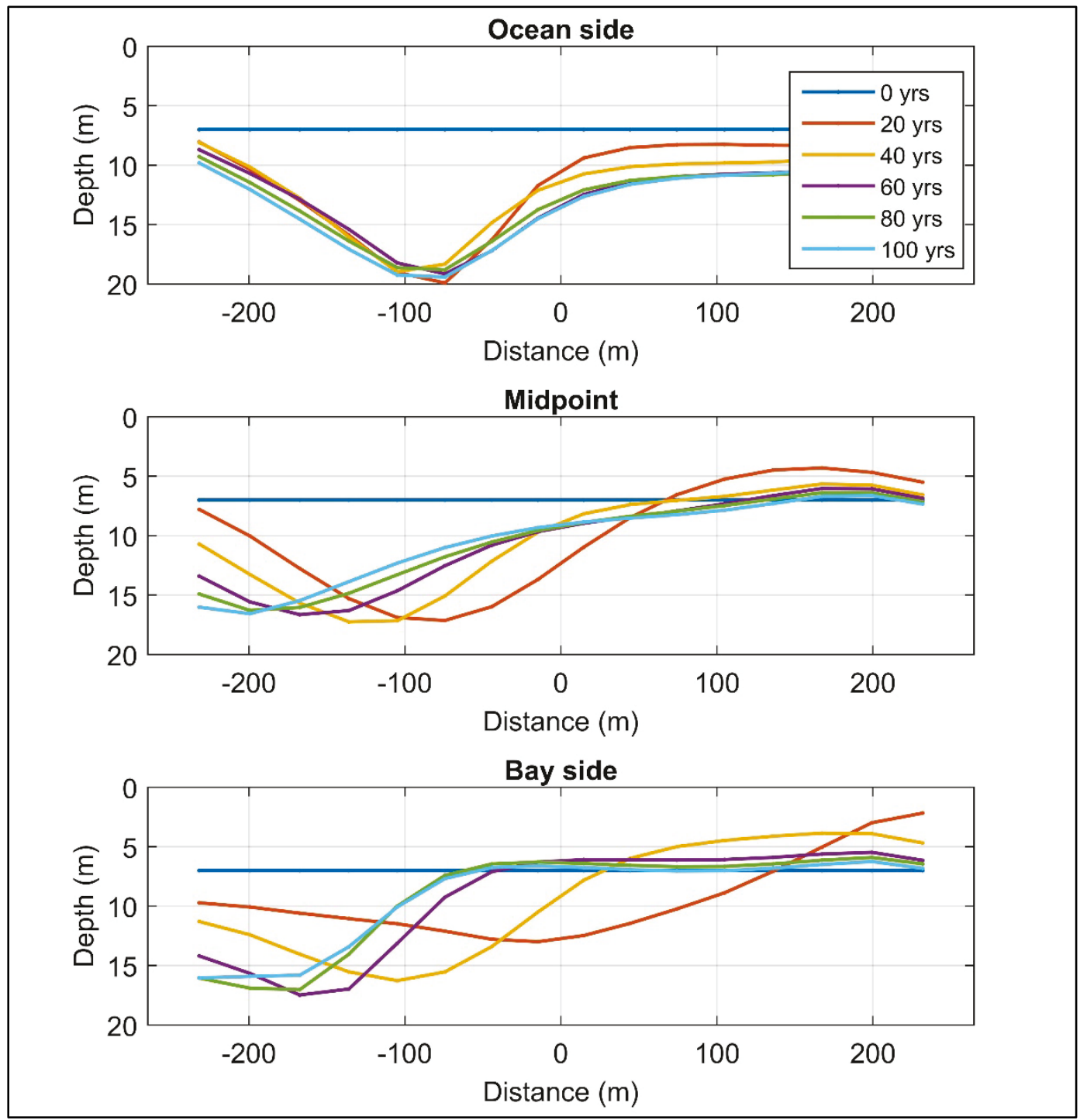

The net volume change in the bay, inlet, and ebb shoal are depicted in Figure 3.100. The primary sediment transport pathway removes material from the inlet and deposits it on the ebb and flood shoals. By the end of the simulation, the bay and ebb shoal are still gaining sediment, but the inlet is approaching equilibrium with no net gain or loss. Net ebb shoal and bay gains exceed inlet losses suggesting a sediment supply from longshore sediment transport along adjacent beaches. The results for bed change for Newburyport Inlet indicate that it is flood dominant. 
Figure 3.100. Calculated bed volume change for Newburyport.

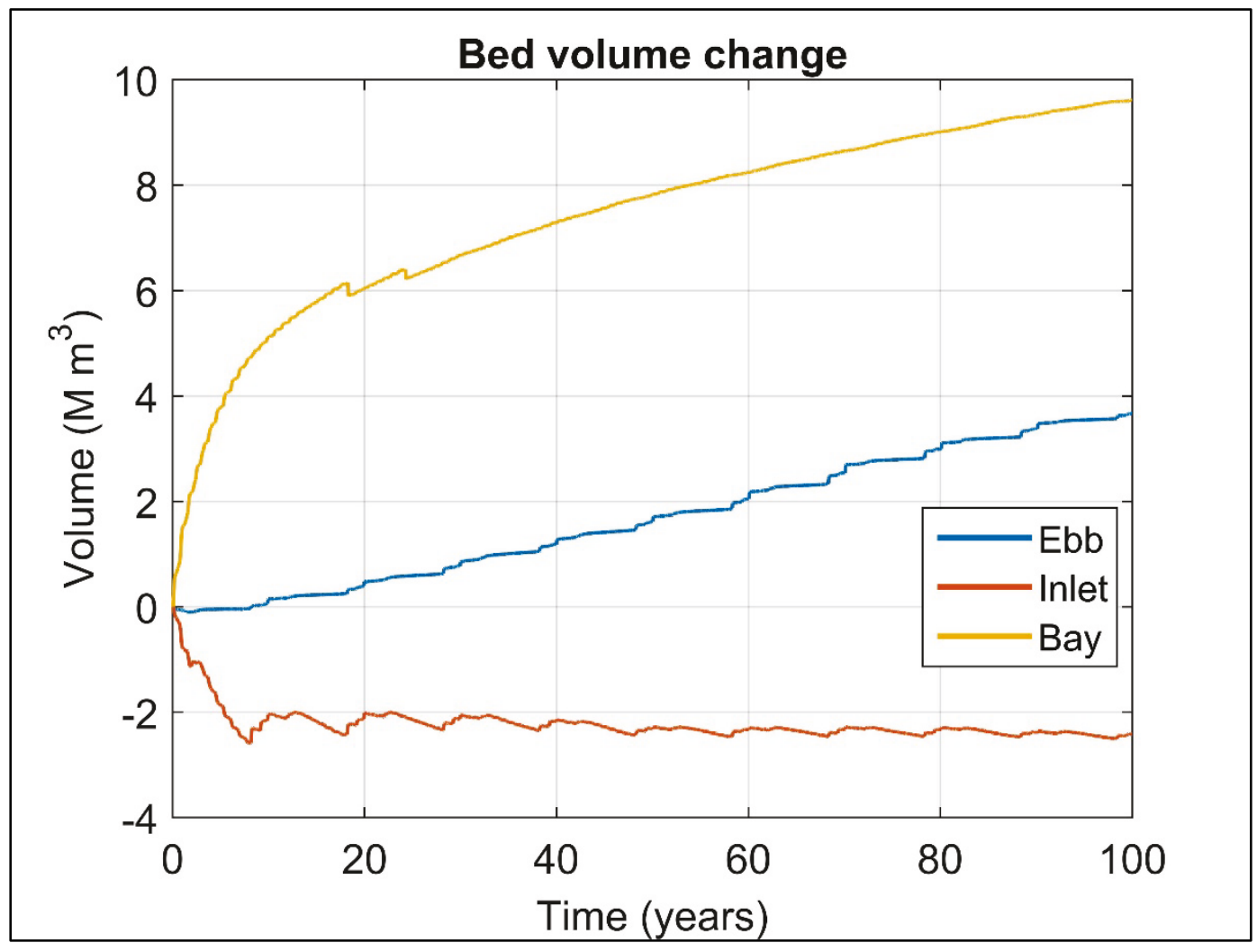

\subsubsection{Hydrodynamics}

Spatial current magnitude distribution near the end of the simulation during maximum flood and maximum ebb is depicted in Figure 3.101 and Figure 3.102, respectively. Flood currents enter the inlet then accelerate along the channel. Currents diverge at the end of the inlet forming multiple broad pathways that adhere to the bay channels. Shoals formed in the bay are partially exposed during maximum flood. Maximum ebb currents exit the bay channel network and converge and strengthen in the inlet throat. Maximum flows are slightly skewed towards the $y$-negative side of the inlet. Upon exiting, a jet forms extending from the main ebb channel beyond the outer terminal lobe. The maximum flood current is strongest within the inlet throat and exceeds the peak ebb currents as is typical of a flood dominant inlet. 
Figure 3.101. Current magnitude during maximum flood at the end of the 100-year simulation for Newburyport Inlet. White areas shown inside the bays denote computational areas that were dry (above the water level) at the end of the simulation.

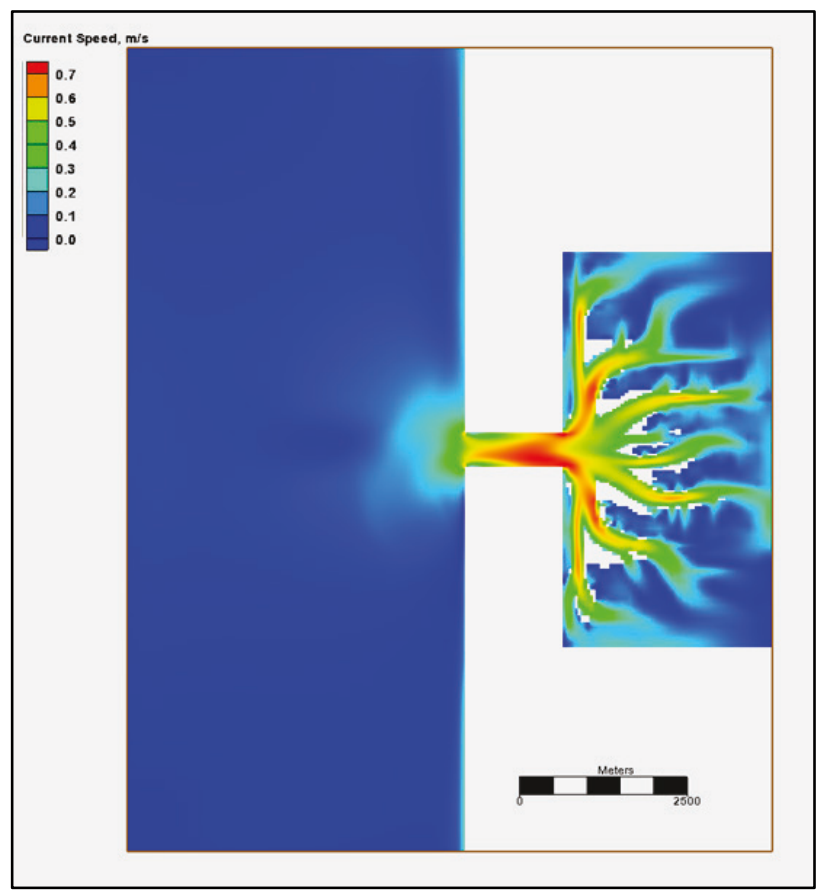

Figure 3.102. Current magnitude during maximum ebb at the end of the 100-year simulation for Newburyport Inlet. White areas shown inside the bays denote computational areas that were dry (above the water level) at the end of the simulation.

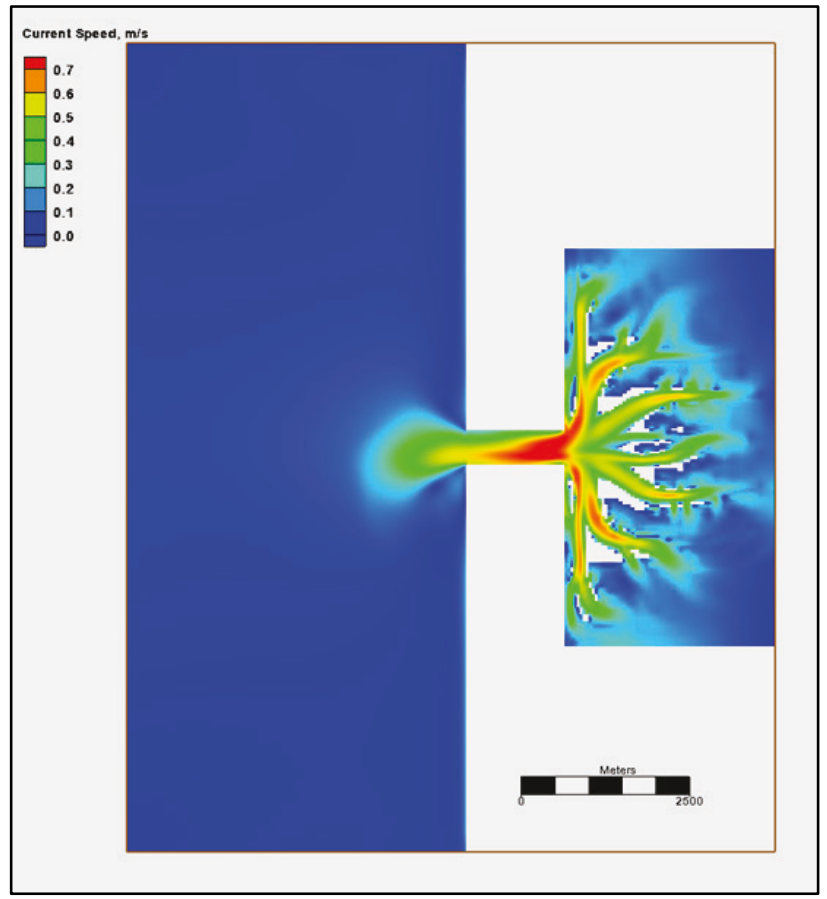


The tidal current envelope in the inlet throat decreases over the first 20 years of the simulation (Figure 3.103). Volume flux and tidal prism envelope are slightly higher during the beginning but then are generally uniform for the remainder of the simulation (Figure 3.104).

Figure 3.103. Average and peak average tidal currents at the midpoint of the inlet (top left and top right inset, respectively). The two smaller panels (right inset) illustrate current patterns for the last year of the simulation.
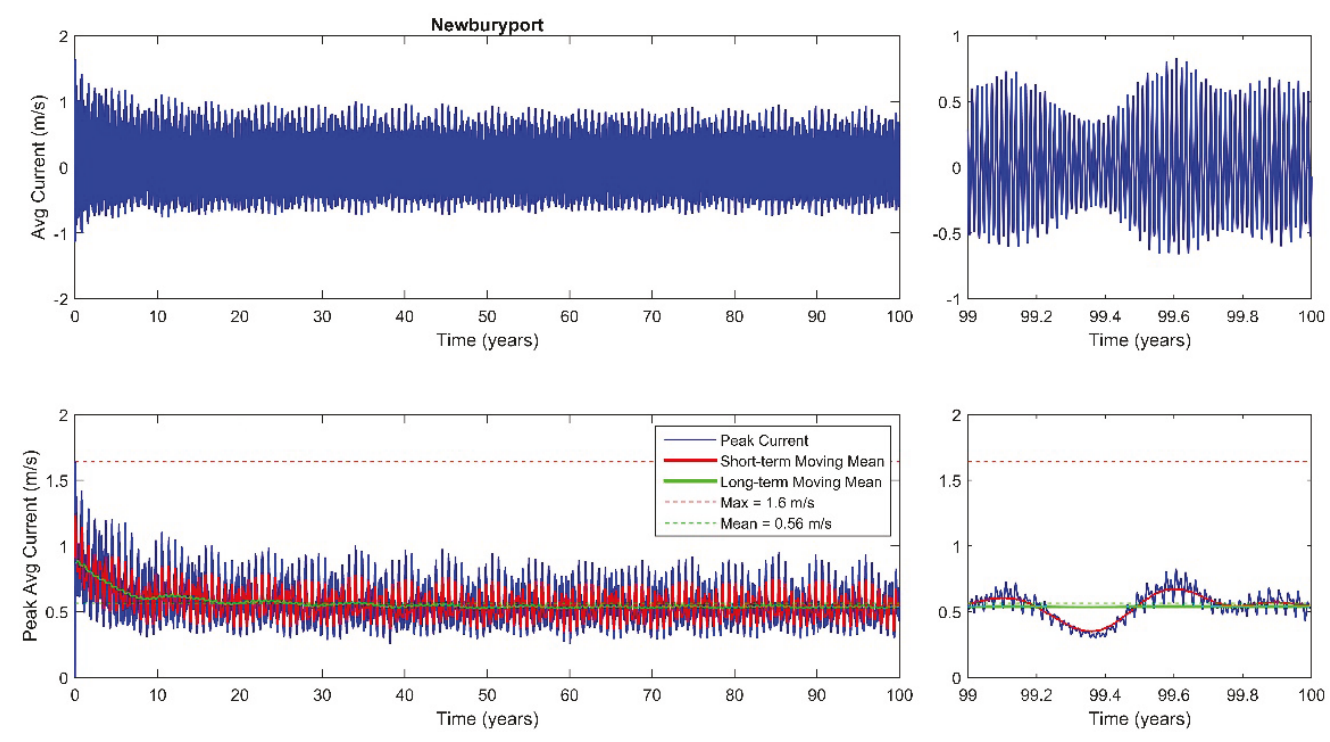

Figure 3.104. Volume flux and tidal prism (top left and top right inset, respectively) at the inlet midpoint. The two smaller panels (right inset) denote the last year of the simulation to illustrate tidal variability.
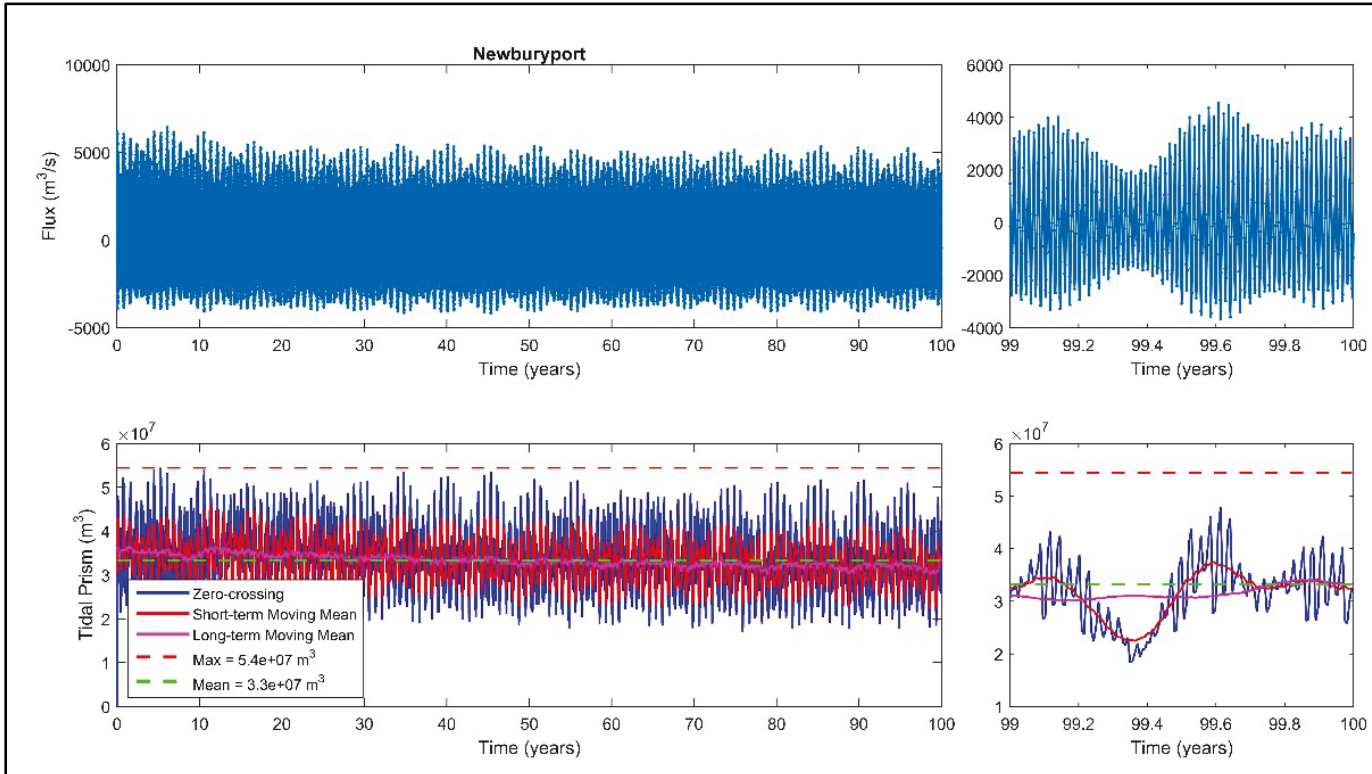
The maximum water surface elevation difference between the ocean and bay decreases rapidly during the first ten years then remains steady throughout the rest of the simulation (Figure 3.105). The extremes are asymmetric with regard to the zero-crossing indicating steeper gradients during flood. As the simulation progresses, this asymmetry persists, indicating flood dominant conditions during spring and neap tide.

Figure 3.105. Calculated water surface elevation difference between the ocean and bay. Positive values denote sea surface slope from the ocean to the bay.

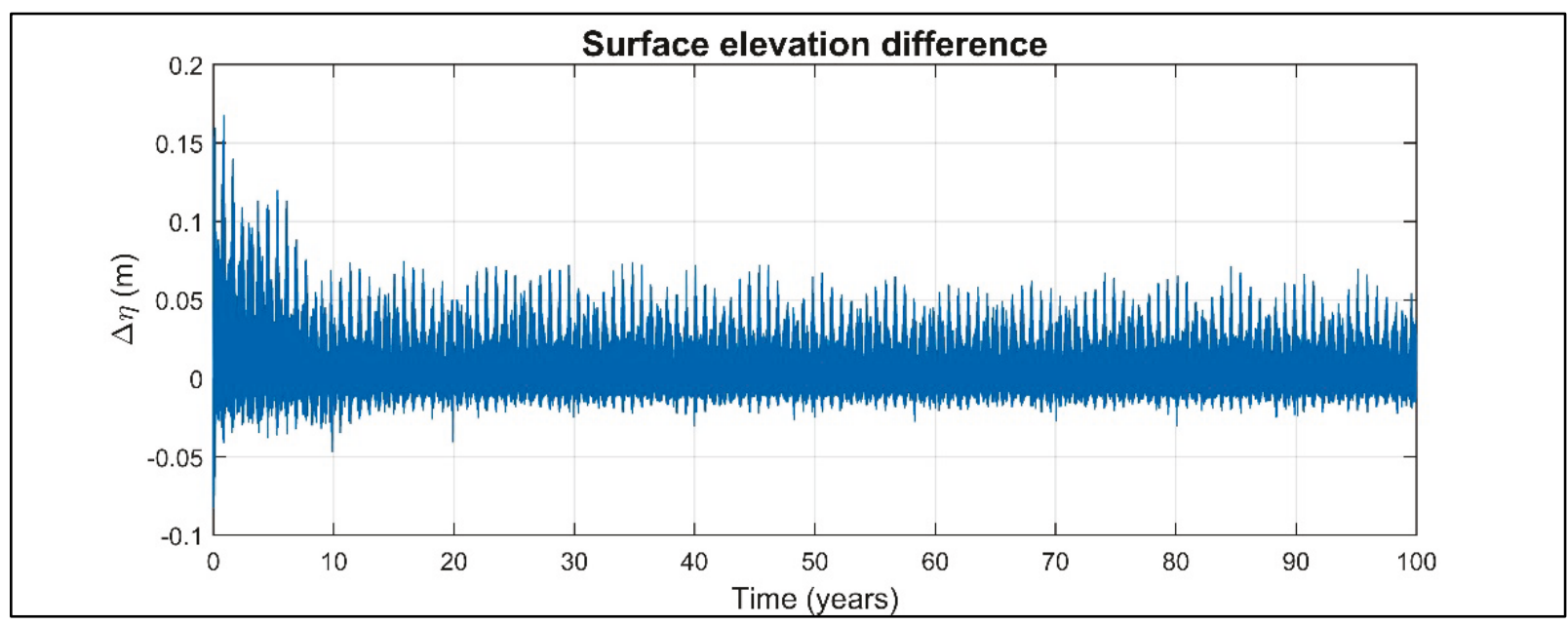

\subsubsection{Comparisons with empirical formulas}

The cross-sectional area predicted by CMS increases rapidly during the first 5-10 years in comparison to the maximum predicted by the tidal prism relationship (Figure 3.106). By the end of the simulation, the crosssectional area at all three locations exceeds the maximum predicted by the tidal prism relationship. The minimal cross-sectional area predicted by CMS increases over the first 15 years then becomes steady similar to the empirical (O'Brien) result, yet it remains above the empirical range. 
Figure 3.106. Inlet cross-sectional area calculated by the CMS (lines) at three inlet channel locations and the computed crosssectional area from the tidal prism relationship (points).

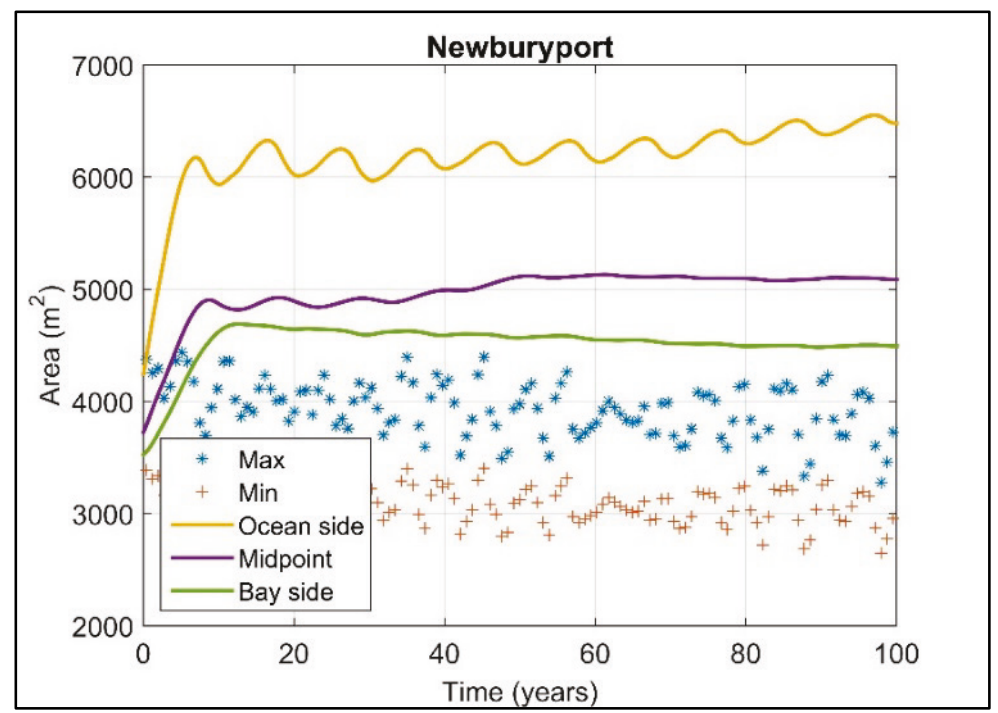

Time series of ebb shoal volume predicted by CMS and the empirical formulas are depicted in Figure 3.107. The CMS ebb shoal volume is smaller than the maximum predicted by the empirical formulas. However, the CMS prediction is still increasing at the end of the simulation signifying that the system has not reached equilibrium. With more time, it is possible that the CMS prediction will continue to grow and converge to the empirical solution.

Figure 3.107. Time series of ebb shoal volume calculated by the CMS (yellow line) and the computed empirical formulas that relate tidal prism to ebb shoal volume (points). Scale is adjusted to illustrate a slight decrease in ebb shoal volume at the beginning of the simulation ( $0-10$ years).

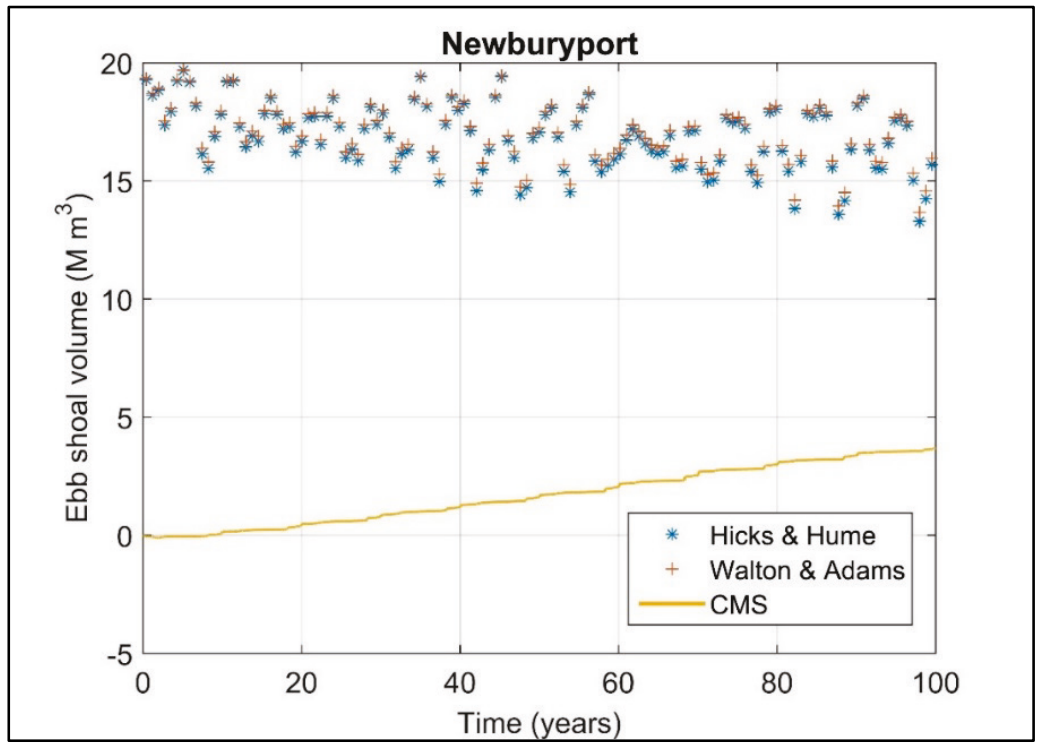


The Escoffier equilibrium theory applied to Newburyport is depicted in Figure 3.108. The input parameters (e.g., bay area, inlet dimensions, and water surface elevation) are derived from the CMS-idealized Newburyport simulation, and the plus signs denote the measured Newburyport minimal cross-sectional area. Data filtering and averaging parameters are the same as that applied to Grays Harbor. The CMS results reveal inlet deepening and an overall decrease in the maximum current that exceeds the quadratic and Escoffier theoretical predictions. However, CMS trends with the theoretical predictions, albeit CMS predicts higher equilibrium current speeds and the final predicted cross-sectional area is greater than that observed at Newburyport. Peak currents near the end of the simulation are converging on $\sim 0.8 \mathrm{~m} / \mathrm{sec}$, indicating that the model is theoretically producing a stable inlet system.

Figure 3.108. An Escoffier analysis comparing the theoretically predicted (green and yellow lines) and CMS-computed (blue points) current. Plus signs denote the minimal cross-sectional area and the theoretical maximum velocity required for this inlet to remain stable. A 30-day low-pass filter delineates the overall trend of CMS-computed peak velocities for modeled cross-sectional areas (orange line).

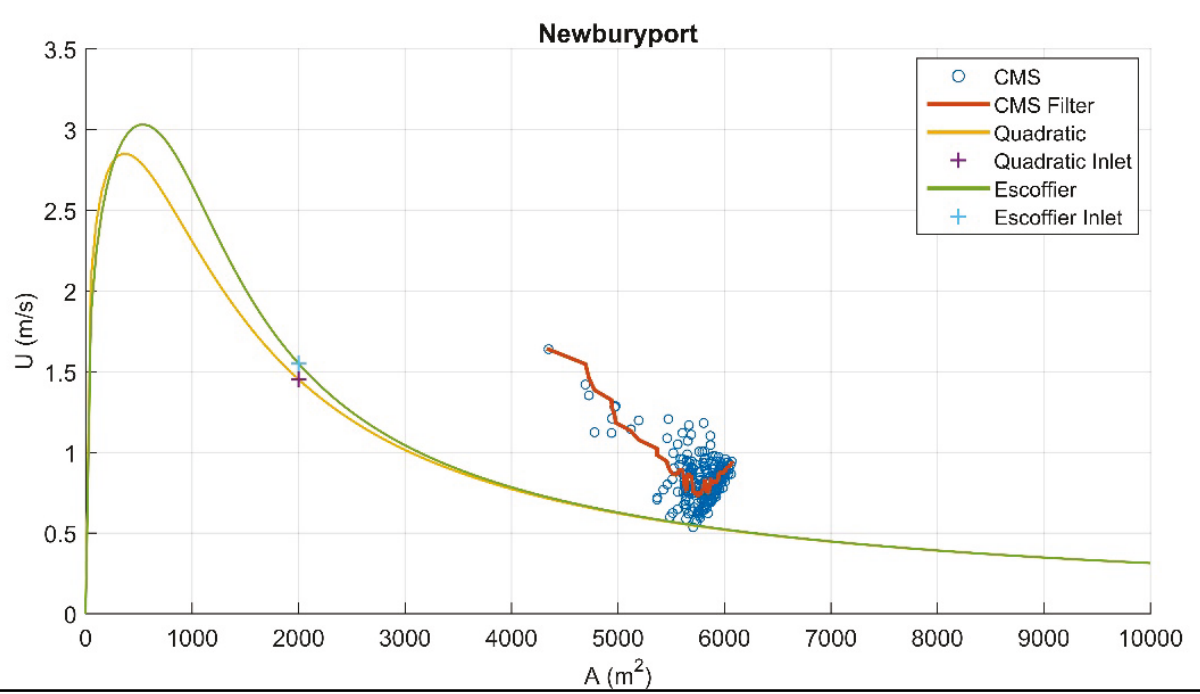




\section{Discussion}

\subsection{Morphology}

In all cases, morphological evolution of an initially featureless system included channel formation in the inlet and ebb shoal formation offshore of the inlet entrance. Well-defined channel networks formed in bays with stronger tidal flows, in particular the flood-dominant and high-wave energy systems (e.g., Pacific and Atlantic Coast cases). In more ebbdominant systems with weaker tidal flow in the bays, the bays did not develop channel networks but rather formed flood deltas limited in size with truncated depressions adjacent to the inlet. Wave-induced longshore sediment transport, in some cases, shifted the terminal lobe and ebb channel in the direction of net transport.

\subsubsection{Inlet morphological evolution}

Morphological evolution in the inlet consists of two primary trends. The first type is characterized by rapid channel growth in the first 20 years followed by much slower deepening for the remainder of the simulation and in some cases slight migration of the thalweg from the centerline. Shoal formation along the sides of the inlet near the entrance and exit is common. This inlet type is associated with the smaller bays and smaller inlet cross sections. The narrower width constricts the flow allowing the inlet to develop a deep channel in which the cross section is more prismatic.

The second type includes the formation of multiple channels in the inlet with widely varying morphological patterns. The morphology consists of deeper channels forming on the sides of the inlet near the ocean and bay ends separated by a shallower section in the middle. The deepest sections form on opposite sides of the inlet, such that the thalweg crosses from one side near the entrance of the inlet to the other side near the bay. The middle section includes shoals with deeper sections on either side. This inlet type is associated with the wider inlets and larger bays. The pattern is indicative of an immature channel network typical of tidal flats and lowlying coastal wetlands. The wider inlet permits the development of instabilities in the flow field and sediment transport conditions that lead to bifurcated networks. Confinement due to the finite inlet width prohibits channel network lateral expansion. Instead, the channel forms incised 
sections along the sides to compensate for the restrictive lateral boundary. Previous work has shown that a single grain size class can lead to overdeepening due to misrepresentation of bed composition by excluding larger particles that require greater bed stress for mobilization (Cayocca 2001). Natural tidal inlets consist of varying degrees of cross-bedding and mixed sediments that contribute to armoring, which are not captured in the model leading to greater erosion of the simulated channel (Dastgheib et al. 2008).

\subsubsection{Bay morphological evolution}

Bay morphological evolution includes dendritic channel network formation for systems with strong tidal flow. Bay channels form in random bifurcated networks that decrease in depth and width as a function of distance from the inlet. For systems in which the alongshore bay length is greater than the cross-shore length, channels tend to align perpendicular to the inlet channel upon exiting the inlet and then branch into smaller and shallower secondary channels that extend across the bay. The channels are separated by shoals that in some instances are exposed during low tide indicating that the model is capable of bar formation. The pattern is very typical of coastal plain salt marshes and other tidal flat areas with an abundant sediment supply.

Systems characterized by weak tidal flow do not form channel networks, and the majority of channel deepening is confined to the portion of the bay nearest to the inlet. In these cases, the bay may accumulate sediment over the course of the simulation resulting in sedimentation (e.g., the flood shoal development in the form of a crescent bar in the case of Johns Pass). The absence of channel network development is tied to the weak forcing, which is further reduced through the inlet and in the expansion zone as the flow enters the bay. Channels formed in the inlet end abruptly at the edge of the bay further signifying the reduction in current speed and associated weak sediment mobilization capacity.

\subsubsection{Ebb shoal morphological evolution}

Ebb shoals likewise develop into different patterns as a function of tide and wave forcing. In regions with strong wave forcing relative to tidal forcing, the ebb shoal is asymmetric with respect to the inlet axis and is skewed in the direction of wave-driven longshore transport. The ebb shoal is bisected by the ebb channel, which carries the majority of tidal-induced 
suspended sediments farther onto the shelf thereby extending the shoal offshore. The ebb channel orientation varies depending upon the sediment transport due to wave-induced longshore current and tidal circulation patterns. For some cases, such as East Pass, the channel is fairly symmetric and extends normal to the shoreline. For cases with relatively greater wave-induced longshore transport, the channel forms at an angle rotated in the downdrift direction. Marginal flood channels form on either side of the ebb channel adjacent to the shore and are more pronounced when the ebb channel extends normal to the shoreline.

\subsubsection{Sediment budget}

Table 4.1 lists the final ebb, inlet, and bay volumes for each modeled case, along with the net and the net change as a percentage of the total volume. In all cases that were simulated for this study, the ebb shoal and inlet initially increase and decrease in volume, respectively. The bay either increases or decreases depending on hydrodynamic conditions (flood/ebb dominance). In cases with flood dominance (Humboldt, Oregon, Shinnecock, Newburyport), the bay accumulates sediment forming flood shoals with varying degrees of channel development. For the other inlets (excluding Johns Pass), the net change was $<10 \%$ suggesting that ebb shoal accumulation approximately balances inlet and bay losses suggesting that sediment is redistributed locally and longshore transport was not significant in the system. For the cases in which the bay accumulates sediment (Humboldt, Oregon, Shinnecock, Newburyport), bay and ebb shoal accretion far exceed inlet losses implying that the majority of sediment supply is derived from wave-driven longshore transport. The rate of sediment volume change in the ebb shoal, inlet, and bay for Gulf Coast inlets is less than Atlantic/Pacific coast inlets, owing to the lower wave energy. 
Table 4.1. Final sediment volume in millions of cubic meters $\left(10^{6} \mathrm{~m}^{3}\right)$

\begin{tabular}{|r|r|r|r|r|c|}
\hline & \multicolumn{1}{c}{ Ebb Shoal } & \multicolumn{1}{c}{ Inlet } & \multicolumn{1}{c|}{ Bay } & \multicolumn{1}{c|}{ Net } & \multicolumn{1}{c|}{ Change } \\
\cline { 2 - 6 } Grays & 307.62 & -209.58 & -51.18 & 46.87 & $8.2 \%$ \\
\cline { 2 - 6 } MCR & 558.78 & -168.25 & -295.78 & 94.74 & $9.3 \%$ \\
\cline { 2 - 6 } Humboldt & 29.89 & -7.45 & 21.64 & 44.08 & $74.7 \%$ \\
\cline { 2 - 6 } Galveston & 50.12 & -42.53 & -5.62 & 1.97 & $2.0 \%$ \\
\cline { 2 - 6 } East Pass & 16.27 & -5.74 & -8.79 & 1.73 & $5.6 \%$ \\
\cline { 2 - 6 } Johns Pass & 1.10 & -0.47 & -0.13 & 0.50 & $29.4 \%$ \\
\cline { 2 - 6 } Oregon & 5.43 & -7.53 & 11.51 & 9.41 & $38.4 \%$ \\
\cline { 2 - 6 } Shinnecock & 3.03 & -2.24 & 8.35 & 9.14 & $67.1 \%$ \\
\cline { 2 - 6 } Newburyport & 6.34 & -2.44 & 10.15 & 14.05 & $74.2 \%$ \\
\cline { 2 - 6 } & & & & & \\
\hline
\end{tabular}

\subsection{Hydrodynamics}

The dominant flow patterns are driven by tides and include spectral bands of semi-diurnal, diurnal, and fortnightly components as representative of tidal conditions at the nine inlets. Secondary harmonics include M4 and other over-tides that are responsible for tidal asymmetry leading to flood or ebb dominance. Tidal current magnitudes at the beginning of the simulations are greatest and then diminish as the inlet cross section expands. Usually after approximately 20 years, the tidal current envelope becomes more uniform with the exception of spring/neap and seasonal variations. As such, maximum tidal currents during spring tide, which are responsible for the greatest sediment transport, are uniform through the remainder of the simulation. The average spring tidal current speed is approximately $1 \mathrm{~m} / \mathrm{sec}$ near the end of the simulation for all but the Gulf Coast inlets, which have smaller maximum currents, ranging from 0.6 to $0.75 \mathrm{~m} / \mathrm{sec}$.

The tidal prism computed by integrating the volume flux through the inlet between slack low and slack high tide generally increases or remains steady during the simulations. The majority of the increase occurs in the first 20 years and then becomes uniform within the spring/neap and seasonal envelopes. The increase is due to greater flux through the deeper inlet and greater storage capacity of the bay due to sediment erosion. For bays that accrete sediment, the volume flux and tidal prism remain more uniform throughout the simulation without an initial increase.

Humboldt, Newburyport, Shinnecock, and Oregon Inlets were determined to initialize as flood dominated while the other inlets initialized as ebb 
dominated. The degree of ebb/flood dominance tends to decrease during the simulation, but it does not switch such that an initial flood (ebb) dominated system becomes ebb (flood) dominated. Initially, tidal harmonics and bay geometry and hypsometry will drive the tidal dominance of the system. It is possible, that as deposition continues in flood dominant systems, that the bay hypsometry would change such that the inlet bay would not have enough accommodation space for deposition, potentially forcing the inlet towards ebb dominance (Walton 2002).

However, this transition was not modeled within the 100-year timeframe.

The long-term evolution of the bay, inlet, and ebb shoal sediment budget shows periodic variations in total volume. The periodic fluctuations correlate with the input wave time series and correspond to large wave events. Table 4.2 shows hydrodynamic conditions corresponding to wave variation at Shinnecock Inlet. Under regular waves (significant wave height: $\sim 1 \mathrm{~m}$ ), the tidal range is approximately $0.9 \mathrm{~m}$, and the maximum tidal current is approximately $1.4 \mathrm{~m} / \mathrm{sec}$. Under storm waves (significant wave height: $3-4 \mathrm{~m}$ ), both the water level and the tidal current increase due to nearshore wave-current interaction. The higher waves resuspend more sediment, and the stronger currents increase bed shear stress and carrying capacity. The result for Shinnecock Inlet is rapid accretion of the ebb shoal over short time periods accompanied by slight reduction in inlet erosion. These changes occur during extreme events disrupting the local equilibrium so that after the event has passed, the erosion/deposition patterns switch or are reduced until the next event. Over time, the amplitude of the sediment volume change diminishes as the system approaches equilibrium conditions reducing the effect of the extreme events.

Table 4.2. Hydrodynamic and wave conditions as large sediment movement occurs at Shinnecock Inlet.

\begin{tabular}{|l|l|c|c|}
\hline \multirow{2}{*}{ Hydrodynamic Parameter } & \multicolumn{2}{c|}{ Wave Height (m) } \\
\cline { 3 - 4 } & $\begin{array}{l}\text { High } \\
\text { water }\end{array}$ & 0.5 & $3 \sim 4$ \\
\cline { 2 - 4 } $\begin{array}{l}\text { Water surface elevation } \\
(\mathrm{m}, \mathrm{MSL})\end{array}$ & $\begin{array}{l}\text { Low } \\
\text { water }\end{array}$ & -0.4 & 0.6 \\
\hline \multirow{2}{*}{ Tidal current $(\mathrm{m} / \mathrm{sec})$} & Flood & 1.1 & -0.5 \\
\cline { 2 - 4 } & Ebb & 1.4 & 1.4 \\
\hline
\end{tabular}




\subsection{Long-term model predictions}

Model results are compared to the tidal prism relationship and the empirical formulas for ebb shoal volume. Grays Harbor, MCR, Galveston, and East Pass inlets fall within the empirical range of the tidal prism relationship from previous studies. In contrast, Humboldt, Newburyport, Johns Pass, Oregon and Shinnecock Inlets over predict the cross-sectional area. Note that Newburyport and Shinnecock Inlets are within 10\% of the tidal prism relationship at the end of the simulation. Furthermore, the inlets have not reached equilibrium and are still deepening after simulating 100 years of inlet evolution. Humboldt, Newburyport, Shinnecock, and Oregon Inlets are also the only four systems that accumulate sediment in the bay.

The results of 100 years of CMS simulations did not capture all of the predicted ebb shoal volumes as compared to the Walton and Adams (1976) or Hicks and Hume (1996) empirical formulas. In most cases, the ebb shoal volume is still growing at the end of the simulation, so the comparison would likely improve if the simulation is run longer. Most of the predictions however are within a factor of two of the empirical formulas. Although this comparison does not indicate the potential modeling factors that influence this variable, it does offer some insight on whether or not the CMS is capable of capturing the more relevant factors in predicting long-term evolution of ebb shoal growth.

It is possible that the shoal is underpredicted because the modeled offshore slope is steeper in the vicinity of the inlet. In this case, shoal growth may be incomplete as sediment is carried farther offshore into deeper regions where it cannot be recovered by tide and wave-driven transport to supply the ebb shoal. The strong ebb jet seen at some inlets has the capacity to transport sediment farther from shore into deeper water where it cannot be recovered by wave and tide forces. Walton and Adams (1976) noted smaller ebb shoals with increasing onshore waves. The increased wave power prohibits the maintenance of shoals that otherwise would be in equilibrium with the tidal forcing. The waves used in the study show high angles to the shoreline for most cases. The high angle may increase erosion leading to smaller ebb shoals than would be expected based on empirical models that are formulated using only the tidal prism. Alternatively, the depth and slope of the bay, or bay hypsometry, can influence the potential for sediment transport and 
erosion of the bay or the accommodation space for deposition within the bay, thus affecting the overall sediment budget of the inlet system.

Because of the non-linear dependence on tidal prism to predict ebb shoal volume, the empirical solutions are very sensitive to changes in the exponent. The coefficients applied in this study were derived from datasets that did not separate inlets based on anthropogenic modifications (i.e., jetties or seawalls), quantified energy factors (e.g., relative wave energy versus tidal energy), or maturity of inlet system (i.e., inlet age or multiple inlets). More field data could be used to refine the exponent and coefficient values for specific coastal regions and improve shoal volume predictions.

In addition to the tidal prism relationship and the empirical formulas for ebb shoal volume, the CMS is gauged in terms of Escoffier's inlet stability analysis. The Escoffier formula predicts the maximum current speed and determines inlet stability. The Escoffier analysis applied to the CMS time series predictions provides a measure of the model's ability to develop into a long-term stable inlet. In all cases, the average of the maximum inlet velocity decays over time in agreement with the Escoffier solution in which $U$ is proportional to $1 / A$ for inlets with large cross-sectional areas and stable conditions. The CMS maximum velocity is less than the peak velocity predicted by the Escoffier formula. With the exception of Oregon and Galveston, the CMS cross-sectional areas are in the equilibrium range of the Escoffier curve signifying that further simulation will reduce the maximum current to the threshold for the initiation of sediment motion and prohibit further cross-sectional area growth.

One of the underlying assumptions in Escoffier's theory is that the water surface elevation in the bay remains horizontally uniform as the bay fills or drains. The phase lag between the entrance and farthest reaches of long shallow bays combined with friction can lead to nonlinearities that modulate volume flux and water surface elevations through the system. In these cases, the Escoffier theory is less applicable because co-oscillations and other factors generate a greater phase lag between ocean and bay. The water surface is not uniform throughout the bay in violation of the Escoffier theory. While all inlets show some degree of variable surface elevation, the assumptions imposed by Escoffier for the two largest bays, Oregon and Galveston, are the most strained owing to their much greater volume. Straining the limits of the Escoffier assumptions is likely a 
contributing factor to the lack of agreement between model predictions and the Escoffier theory for these larger shallow bays.

In most cases, the CMS-predicted cross-sectional area is greater than the corresponding inlet, indicating the CMS is overpredicting inlet size. However, the idealized inlets have fixed boundaries that constrict the flow so that the tendency is to generate faster currents that deepen the inlet as opposed to wider inlets with slower currents. Additionally, the CMS was run with a single grain size, which is not representative of channel thalweg bottoms. Without multiple grain sizes, the CMS will not winnow finer sediments and allow the channel thalweg to become armored with coarser sediments, which reduces overall channel deepening in the inlet throat. 


\section{Summary}

This study investigated the use of CMS as an engineering tool to predict the long-term morphological evolution of idealized barrier inlet systems and verify the results against established theoretical and empirical formulations that describe the stability and equilibrium conditions of tidal inlets. The study was motivated by the need to develop an effective way to model the long-term impacts of relative sea level rise on navigation projects in support of the USACE Civil Works mission. The study had three major goals: (1) demonstrate the numerical stability of the CMS for simulation periods up to 100 years, (2) demonstrate the feasibility of carrying out long-term simulations in the context of engineering applications, and (3) verify that CMS's hydrodynamic, wave, and morphological algorithms reproduce the known generic characteristics of inlets on climatological time scales.

The following summarizes the main conclusions drawn from this report:

- The CMS is able to quantify the basic hydrodynamic and geomorphic long-term tenets of barrier island systems based on the three theoretical and empirical formulations dictating inlet size and stability. Starting from a highly idealized, featureless barrier-inlet geomorphology, the model generates the major morphological characteristics including inlet channels, ebb shoals, marginal flood channels, flood shoals, bars, and bay channel networks. The predicted morphology is analogous to actual barrier inlet systems and with some exceptions generally follows empirical scaling laws for equilibrium cross-sectional area and inlet shoal growth. Understanding shoal, inlet, and bay morphological processes is a key component in many applied coastal studies. This report demonstrates the CMS's skill, with some noted limitations, as an engineering tool capable of investigating longterm morphological change.

- Modeled inlet cross-sectional area was in general agreement with the tidal prism relationship. Shoal volume did not show as good agreement and was underpredicted. Other factors such as incident wave angle, local beach slope, fixed lateral boundaries, and sensitivity to the fitting parameters for the empirical shoal volume formula were not as well constrained and may contribute to the bias towards smaller shoals predicted by the model. 
- The model is run on a PC and includes wave, flow, and sediment transport calculations. The numerical code is stable, and the simulation times for most inlets is less than a week, with the exception of Oregon Inlet which takes approximately 2 weeks owing to its much larger model domain. Given that the idealized inlets are drawn from a range of actual systems, the model is suitable for long-term studies of similar U.S. coastal barrier islands. Furthermore, runtime efficiency demonstrated in this study establishes CMS as a robust tool that can be used for civil works projects with constrained time limits.

- The results of this study were based on idealized-inlet systems to determine if the CMS can reproduce essential theoretical and empirical relationships known to drive the long-term morphodynamics in barrier-inlet systems. The study demonstrated that CMS did produce the major features of barrier island inlets (e.g., channel formation, ebbdelta growth, and channel network development in the back bay). Future work should involve a hindcast modeling study of real inlets over decadal or longer time periods to validate the CMS sediment transport and morphological change predictions. The combination of idealized simulations to demonstrate the development of barrier island geometric features combined with validation of real inlets forms the basis for applying the CMS to investigate long-term morphological processes in a regime of global sea-level change. Therefore it is recommended to conduct a real-inlet validation test before applying the CMS for use in USACE Civil Works projects that involve forecasting inlet behavior on decadal or longer time-scales. 


\section{References}

Cayocca, F. 2001. "Long-Term Morphological Modeling of a Tidal Inlet: The Arcachon Basin, France." Coastal Engineering, vol. 42: 115-142.

Conner, C., T. Kendall, K. Berresford, P. Mull, S. Ming, and J. Cole. 2006. "California Harbors: Where Does the Sand Go?” In Proc. 3oth Int. Conf. Coastal Engineering, 3810-3822.

Dastgheib, A., J. Roelvink, and Z. Wang. 2008. "Long-Term Process-Based Morphological Modeling of the Marsdiep Tidal Basin." Marine Geology, vol. 256: 90-100.

Dean, R. G. 1991. "Equilibrium Beach Profiles: Characteristics and Applications.” Journal of Coastal Research, 7(1): 53-84.

Demirbilek, Z., and J. Rosati. 2011. Verification and Validation of the Coastal Modeling System: Report I. Executive Summary. ERDC/CHL-TR-11-10. Vicksburg, MS: U.S. Army Engineer Research and Development Center.

Dissanayake, D., J. Roelvink, and M. Van der Wegen. 2009. "Modelled Channel Patterns in a Schematized Tidal Inlet,” vol. 56: 1069-1083.

Escoffier, F. F. 1940. “The Stability of Tidal Inlets.” Shore and Beach, vol. 8: 114-115.

Escoffier, F. F. 1977. Hydraulics and Stability of Tidal Inlets. Washington, DC: Department of Defense, Department of the Army, Corps of Engineers, Coastal Engineering Research Center.

Florida Department of Environmental Protection (FDEP). 2013. East Pass Inlet Managment Implementation Plan. Division of Water Resources Management, Florida Department of Environmental Protection.

Frey, A. E., A. Morang, and D. B. King. 2015. Galveston Island, Texas, Sand Management Strategies. ERDC/CHL TR-16-13. Vicksburg, MS: U.S. Army Engineer Research and Development Center.

Gelfenbaum, G., C. R. Sherwood, C. D. Peterson, G. M. Kaminsky, M. Buijsman, D. C. Twichell, P. Ruggiero, A. E. Gibbs, and C. Reed. 1999. "The Columbia River Littoral Cell: A Sediment Budget Overview.” In Proceedings of Coastal Sediments, 1660-1675.

Hayes, M. O. 1980. "General Morphology and Sediment Patterns in Tidal Inlets." Sedimentary Geology, vol. 26: 139-156.

Hench, J. L., and R. A. Luettich Jr. 2003. "Transient Tidal Circulation and Momentum Balances at a Shallow Inlet.” Journal of Physical Oceanography, vol. 33: 913932.

Hicks, D. M., and T. M. Hume. 1996. "Morphology and Size of Ebb Tidal Deltas at Natural Inlets on Open-Sea and Pocket-Bay Coasts, North Island, New Zealand. Journal of Coastal Research, vol. 12: 47-63. 
Hughes, S. A. 2002. "Equilibrium Cross Sectional Area at Tidal Inlets.” Journal of Coastal Research, vol. 18: 160-174.

Inman, D. L., and R. Dolan. 1989. "The Outer Banks of North Carolina: Budget of Sediment and Inlet Dynamics along a Migrating Barrier System." Journal of Coastal Research, vol. 5: 193-237.

Jarrett, J. T. 1976. Tidal Prism-Inlet Area Relationships. Vicksburg Mississippi: U.S. Army Engineer Waterways Experiment Station.

Kana, T. W. 1995. "A Mesoscale Sediment Budget for Long Island, New York." Marine Geology, vol. 126: 87-110.

Komar, P. D. 1996. "Tidal-Inlet Processes and Morphology Related to the Transport of Sediments." Journal of Coastal Research, vol. 23: 23-45.

Kraus, N. C. 1998. "Inlet Cross-Sectional Area Calculated by Process-Based Model." Coastal Engineering Proceedings, vol. 1: 3265-3278.

Lesser, G., J. Roelvink, J. Van Kester, and G. Stelling. 2004. “Development and Validation of a Three-Dimensional Morphological Model.” Coastal Engineering, vol. 51: 883-915.

Lin, L., Z. Demirbilek, and H. Mase. 2011. "Recent Capabilities of CMS-Wave: A Coastal Wave Model for Inlets and Navigation Projects.” Journal of Coastal Research, Special Issue 59: 7-14.

Lin, L., Z. Demirbilek, H. Mase, J. Zheng, and F. Yamada. 2008. CMS-Wave: A Nearshore Spectral Wave Processes Model for Coastal Inlets and Navigation Projects. ERDC/CHL TR-08-13. Vicksburg, MS: U.S. Army Engineer Research and Development Center.

Nahon, A., X. Bertin, A. B. Fortunato, and A. Oliveira. 2012. "Process-Based 2DH Morphodynamic Modeling of Tidal Inlets: A Comparison with Empirical Classifications and Theories." Marine Geology, vol. 291: 1-11.

O'Brien, M. P. 1939. "Estuary Tidal Prism Related to Entrance Areas." Civil Engineering, vol. 1: 738-739.

O'Brien, M. P. 1969. "Equilibrium Flow Areas of Inlets on Sandy Coasts.” Journal of Waterways and Harbors Division, vol. 95: 43-52.

Oertel, G. F. 1988. "Processes of Sediment Exchange between Tidal Inlets, Ebb Deltas and Barrier Islands.” In Hydrodynamics and Sediment Dynamics of Tidal Inlets, Lecture Notes on Coastal and Estuarine Studies, edited by D.G. Aubrey and L. Weishar, 297-318. New York: Springer-Verlag Inc.

Rosati, J., D., T. L. Walton, and K. Bodge. 2002. Longshore Sediment Transport. Coastal Engineering Manual, Part III, Coastal Sediment Processes, III-2-2, EM 1110-21100. Washington, DC: U.S. Army Corps of Engineers.

Sánchez, A., and W. Wu. 2011a. "A Non-Equilibrium Sediment Transport Model for Coastal Inlets and Navigation Channels.” Journal of Coastal Research, Special Issue No. 59: 39-48. 
Sánchez, A., W. Wu, T. Beck, H. Li, J. Rosati III, R. Thomas, J. Rosati, Z. Demirbilek, M. Brown, and C. Reed. 2011b. Verification and Validation of the Coastal Modeling System, Report 3: Hydrodynamics. ERDC/CHL-TR-11-10. Vicksburg, MS: U.S. Army Engineer Research and Development Center.

Sánchez, A., W. Wu, H. Li, M. Brown, C. Reed, J. D. Rosati, and Z. Demirbilek. 2014. Coastal Modeling System: Mathematical Formulations and Numerical Methods. ERDC/CHL TR-14-2. Vicksburg, MS: U.S. Army Engineer Research and Development Center.

Smith, J. B., and D. M. FitzGerald. 1994. "Sediment Transport Patterns at the Essex River Inlet Ebb-Tidal Delta, Massachusetts, U.S.A.” Journal of Coastal Research 10(3): 752-774.

Stive, M. J., and R. Rakhorst. 2008. "Review of Empirical Relationships between Inlet Cross-Section and Tidal Prism." Journal of Water Resources and Environmental Engineering, vol. 23: 89-95.

Styles, R. 2006. "Application of a Bottom Boundary Layer Model in Contrasting Wave and Current Environments: Grays Harbor, Washington." Journal of Waterway, Port, Coastal and Ocean Engineering, vol. 132: 379-387.

Van der Vegt, M., H. Schuttelaars, and H. De Swart. 2006. "Modeling the Equilibrium of Tide-Dominated Ebb-Tidal Deltas." Journal of Geophysical Research: Earth Surface, vol. 111(2003-2012).

Van Leeuwen, S., M. Van der Vegt, and H. De Swart. 2003. "Morphodynamics of EbbTidal Deltas: A Model Approach.” Estuarine, Coastal and Shelf Science, vol. 57: 899-907.

Walton, T. L. 2002. Tidal Velocity Asymmetry at Inlets. ERDC/CHETN-IV-47. Vicksburg, MS: U.S. Army Engineer Research and Development Center.

Walton, T. L., and W. D. Adams. 1976. "Capacity of Inlet Outer Bars to Store Sand." Coastal Engineering Proceedings, vol. 1: 1919-1937.

Walton, T. L., and F. F. Escoffier. 1981. "Linearized Solution to Inlet Equation with Inertia.” Journal of the Waterway Port Coastal and Ocean Division, vol. 107: 191-194.

Wamsley, T., and H. Hanson. 2002. "Evaluation of Proposed Submerged Jetty Spur on Shoreline Evolution, Grays Harbor, WA.” Int Coastal Eng Conf. ASCE, 26252637.

Wang, P., N. C. Kraus, and R. A. Davis Jr. 1998. "Total Longshore Sediment Transport Rate in the Surf Zone: Field Measurements and Empirical Predictions." Journal of Coastal Research 14(1): 269-282.

Wang, Z., and I. Townend. 2012. "Influence of the Nodal Tide on the Morphological Response of Estuaries.” Marine Geology, vol. 291: 73-82.

Yalin, M. S. 1992. River Mechanics. Oxford: Pergammon. 
Yu, Q., Y. Wang, B. Flemming, and S. Gao. 2014. "Scale-Dependent Characteristics of Equilibrium Morphology of Tidal Basins along the Dutch-German North Sea Coast." Marine Geology, vol. 348: 63-72. 


\section{Appendix A: Wave Climatology}

The three west coast inlets, Grays Harbor, MCR, and Humboldt, have the highest average wave conditions. The integrated half-plane spectra subdivided into 10-degree bins (shown on the top row of Figure A1) indicates the largest waves approach from the west and northwest with maximum heights exceeding $8 \mathrm{~m}$ at MCR and Grays Harbor. The three east coast inlets, Oregon, Shinnecock, and Newburyport, have medium wave conditions (shown on the bottom row of Figure A1). Waves are primarily from the southeast at all stations with maximum wave heights of approximately $6 \mathrm{~m}$ at Oregon Inlet. The Gulf coast has the lowest average wave heights (shown on the middle row of Figure A1). Wave direction is variable between sites owing to the difference in shoreline orientation and other regional and local climatological factors. At Galveston and East Pass waves are generally from the southeast and south, respectively. Wave direction at John Pass is, however, heavily skewed to the shore-parallel direction and average wave height is much lower. This is due to the fact that the passage of extra-tropical storms is typically preceded by relatively strong southerly pre-frontal wind and followed by stronger winds and waves from the north-northeast post-front.

Figure A1. Wave climatology for all modeled Inlets. The dashed line indicates the shoreline orientation at each of the inlets.

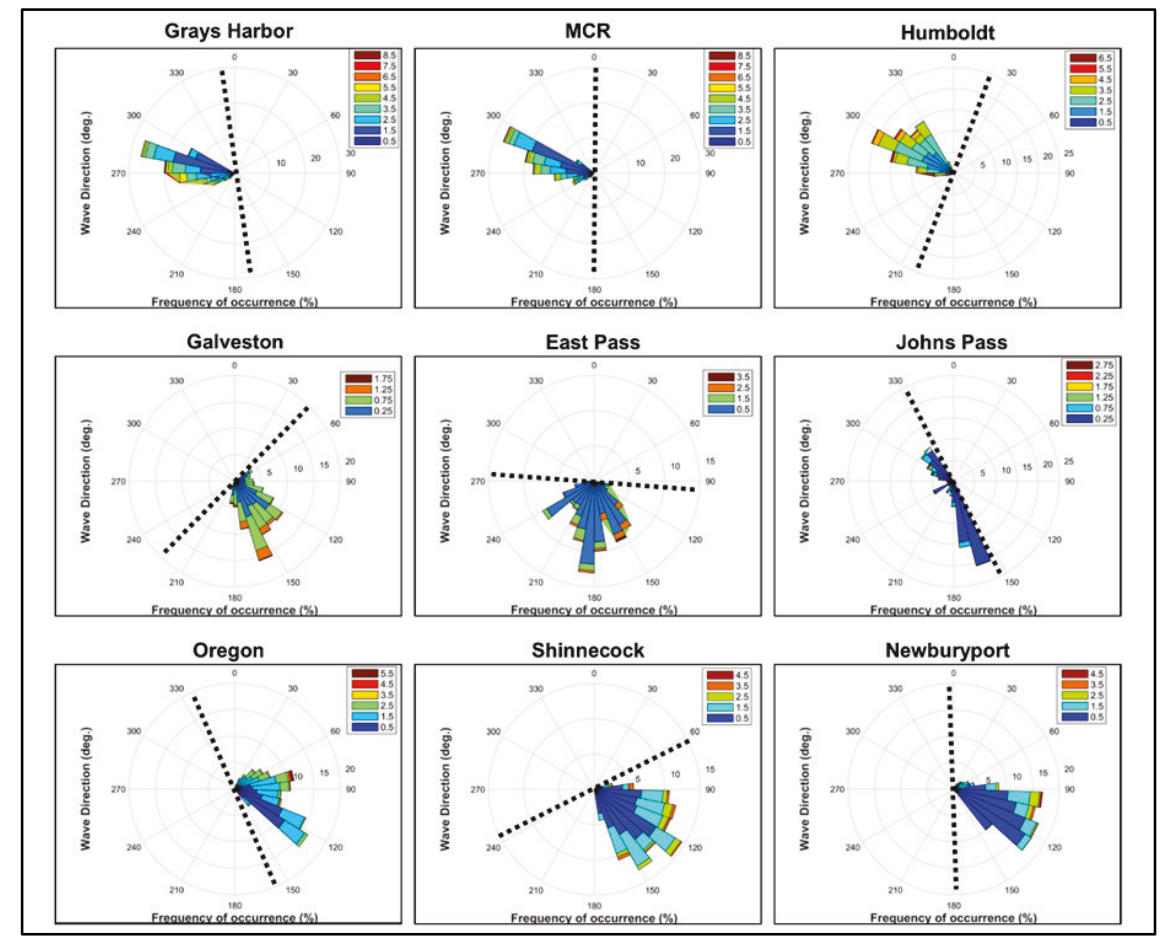


The longshore sediment transport rate estimated from previous studies and the CERC formula applied to the wave climatology in this study indicate the degree of correspondence between the field and model estimates (Table A1). Previously published field estimates are derived from various sources including other models.

Table A1. Sediment transport rates for the 9 inlets. References denote the source of the field estimates.

\begin{tabular}{|l|c|c|l|}
\hline Inlet & CERC $\left(\mathrm{m}^{3} /\right.$ year $)$ & $\begin{array}{c}\text { Published Field } \\
\text { Estimates }\left(\mathrm{m}^{3} / \text { year }\right)\end{array}$ & Data Source \\
\hline Grays Harbor & $-4.1 \times 10^{6}$ & $-2.45 \times 10^{5}$ & Wamsley and Hanson (2002) \\
\hline Columbia River & $-2.1 \times 10^{6}$ & $-4.3 \times 10^{6}$ & Gelfenbaum et al. (1999) \\
\hline Humboldt & $-3.1 \times 10^{6}$ & $-1.1 \times 10^{6}$ & Conner et al. (2006) \\
\hline Galveston & $-1.47 \times 10^{5}$ & $-1.71 \times 10^{5}$ & Frey et al. (2015) \\
\hline East Pass & $8.53 \times 10^{4}$ & $6.96 \times 10^{4}$ & FDEP $(2013)$ \\
\hline Johns Pass & $-1.34 \times 10^{5}$ & $-2.7 \times 10^{4}$ & Wang et al. (1998) \\
\hline Oregon Inlet & $-9.19 \times 10^{5}$ & $-5.0-10 \times 10^{5}$ & Inman and Dolan (1989) \\
\hline Shinnecock & $5.0 \times 10^{5}$ & $4.0 \times 10^{5}$ & Kana (1995) \\
\hline Newburyport & $8.1 \times 10^{5}$ & $1.5 \times 10^{5}$ & Smith and Fitzgerald (1994) \\
\hline
\end{tabular}




\section{Appendix B: Representative Wave Parameter Time Series}

Figure B1. Wave height, period, and direction plot for Grays Harbor, WA (taken from WIS station 83011).

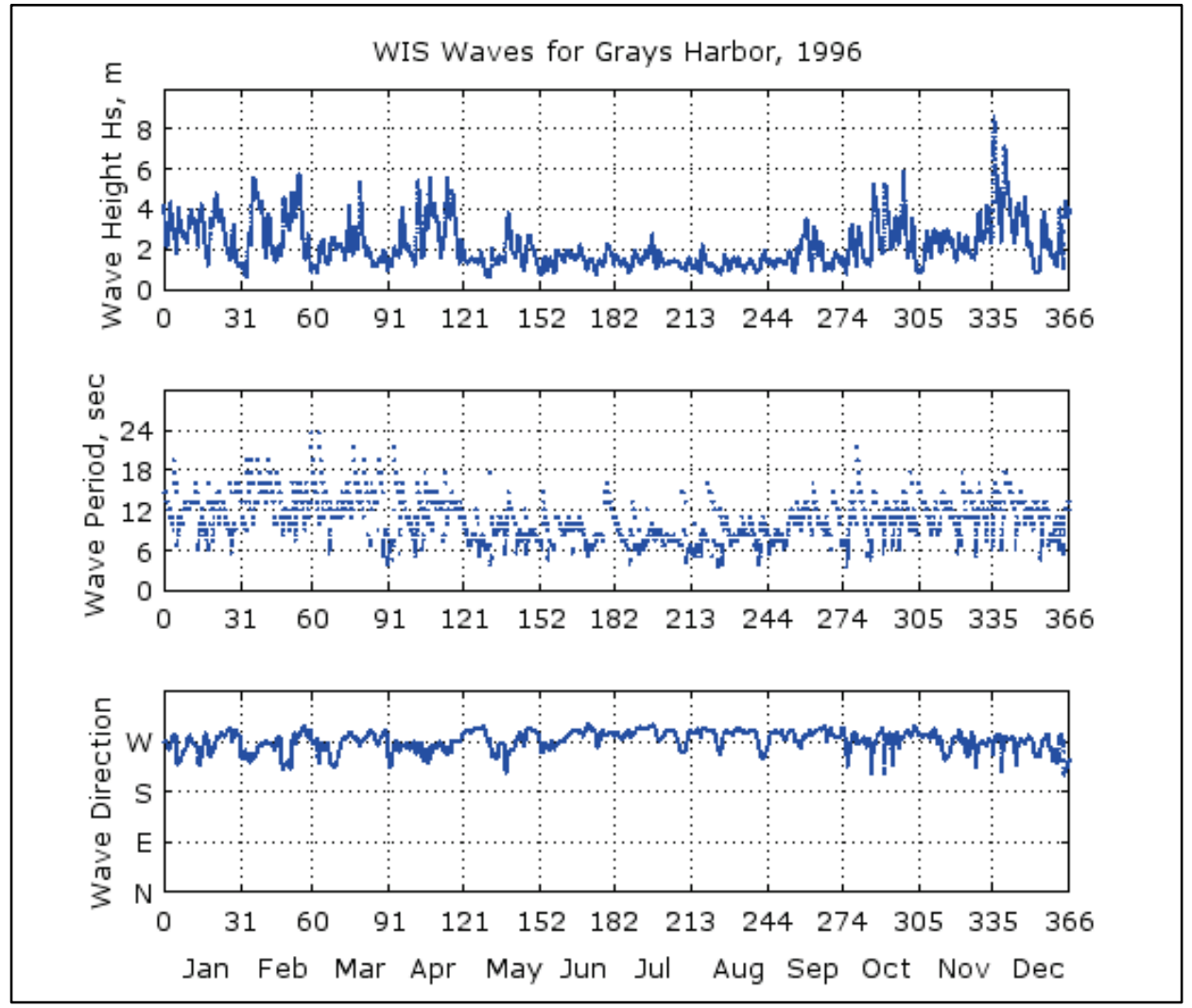


Figure B2. Wave height, period, and direction plot for MCR, TX (taken from WIS station 83015).

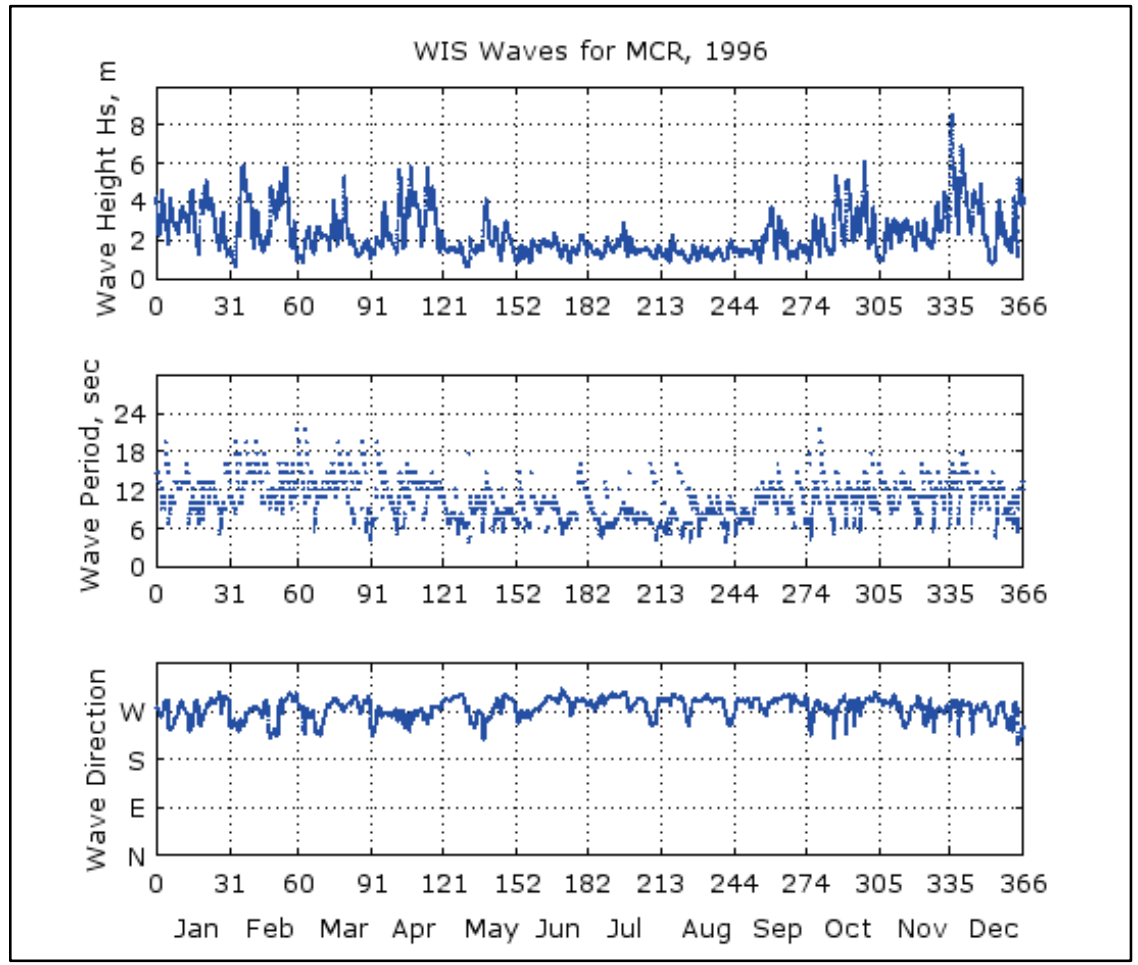

Figure B3. Wave height, period, and direction plot for Humboldt Inlet, CA (taken from WIS station 83047).

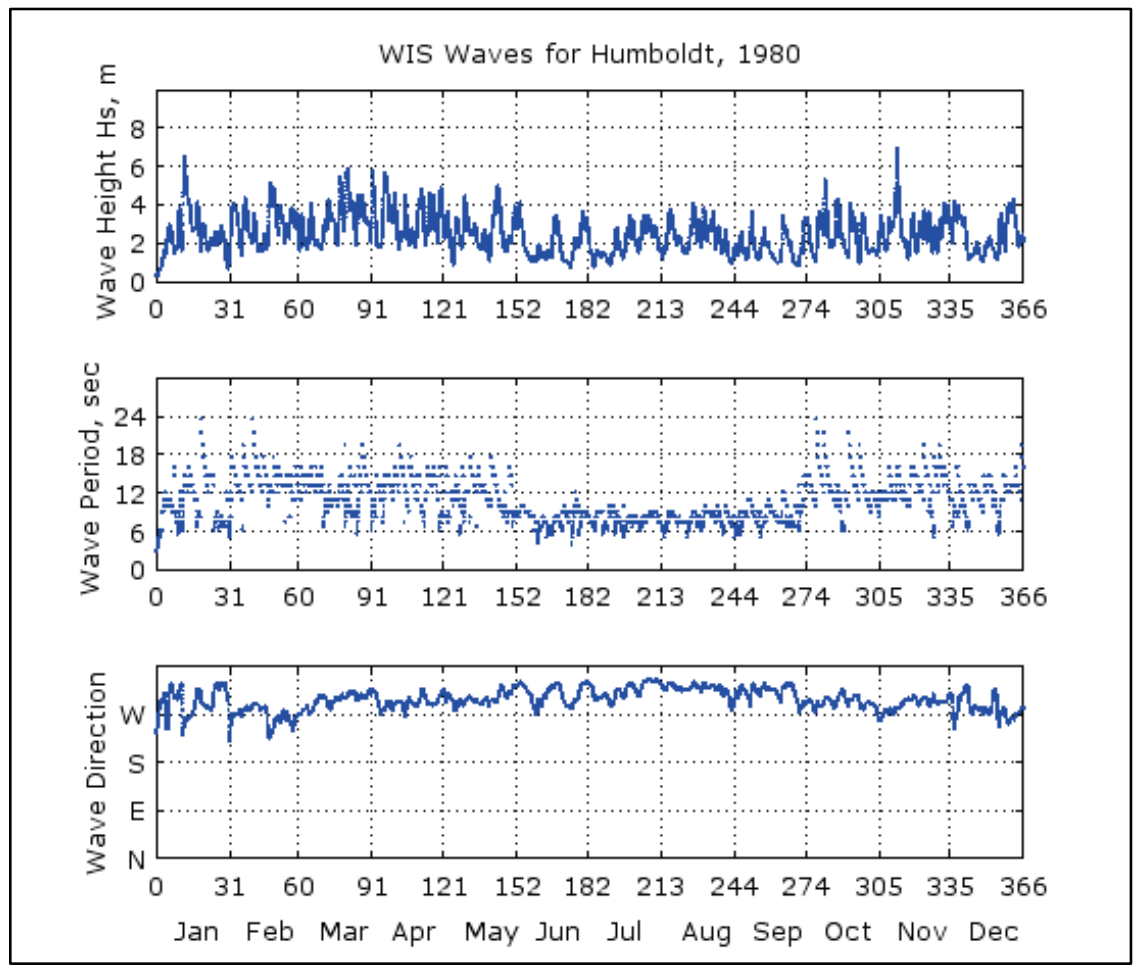


Figure B4. Wave height, period, and direction plot for Galveston Entrance, TX (taken from WIS station 73074).

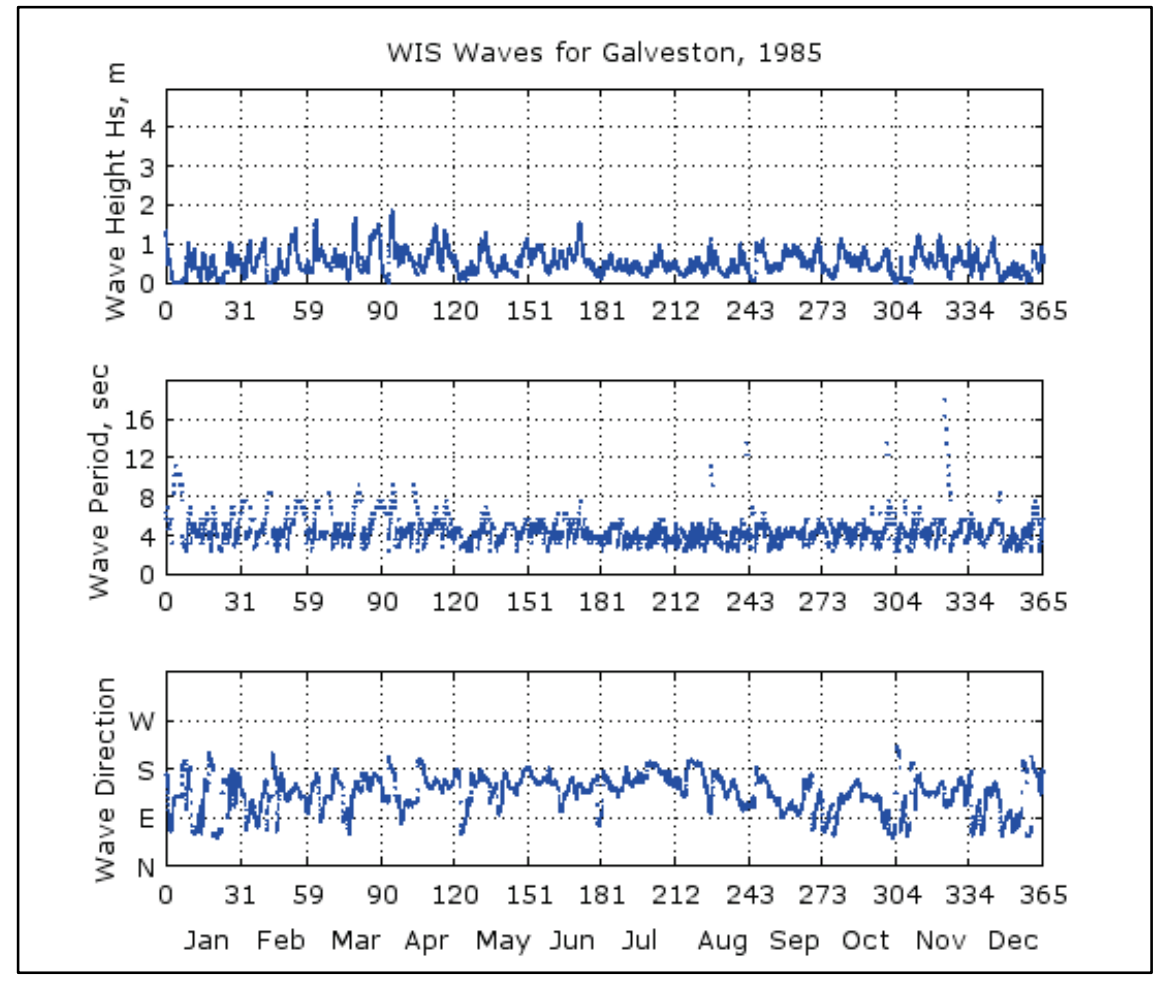

Figure B5. Wave height, period, and direction plot for East Pass, FL (taken from WIS station 73176).
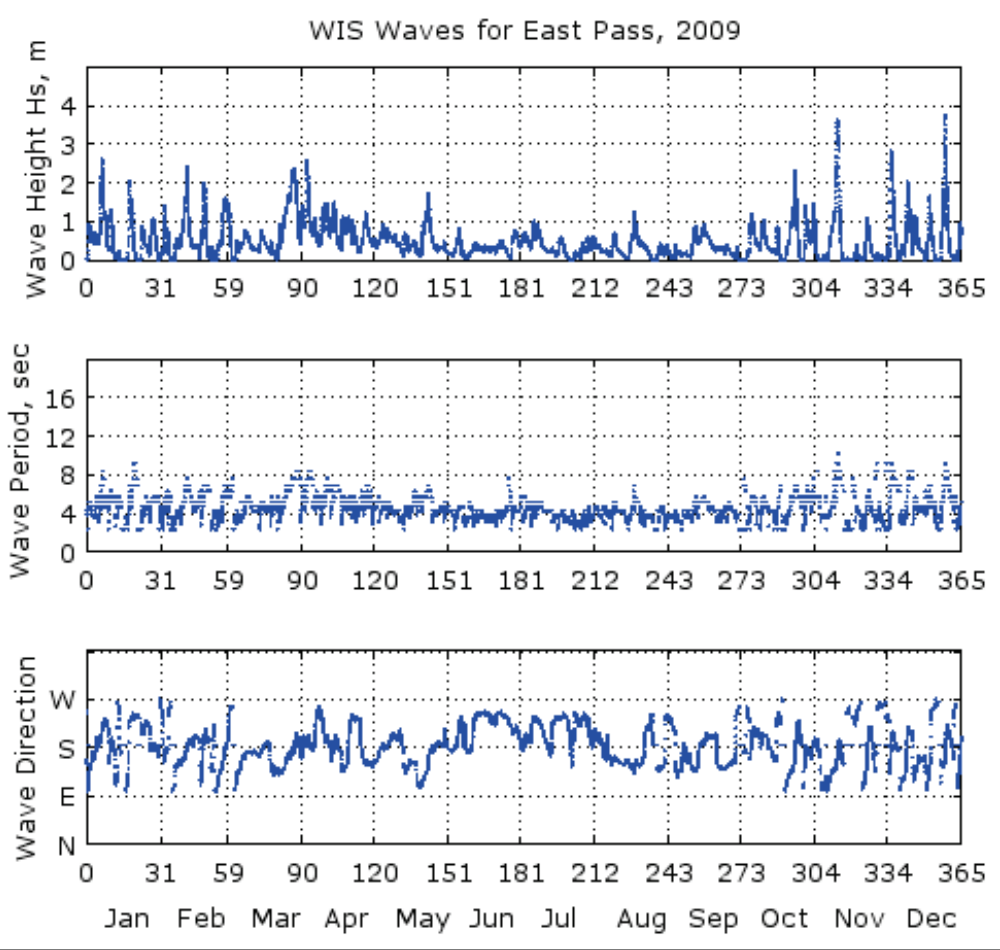
Figure B6. Wave height, period, and direction plot for Johns Pass, FL (taken from WIS station 73293).

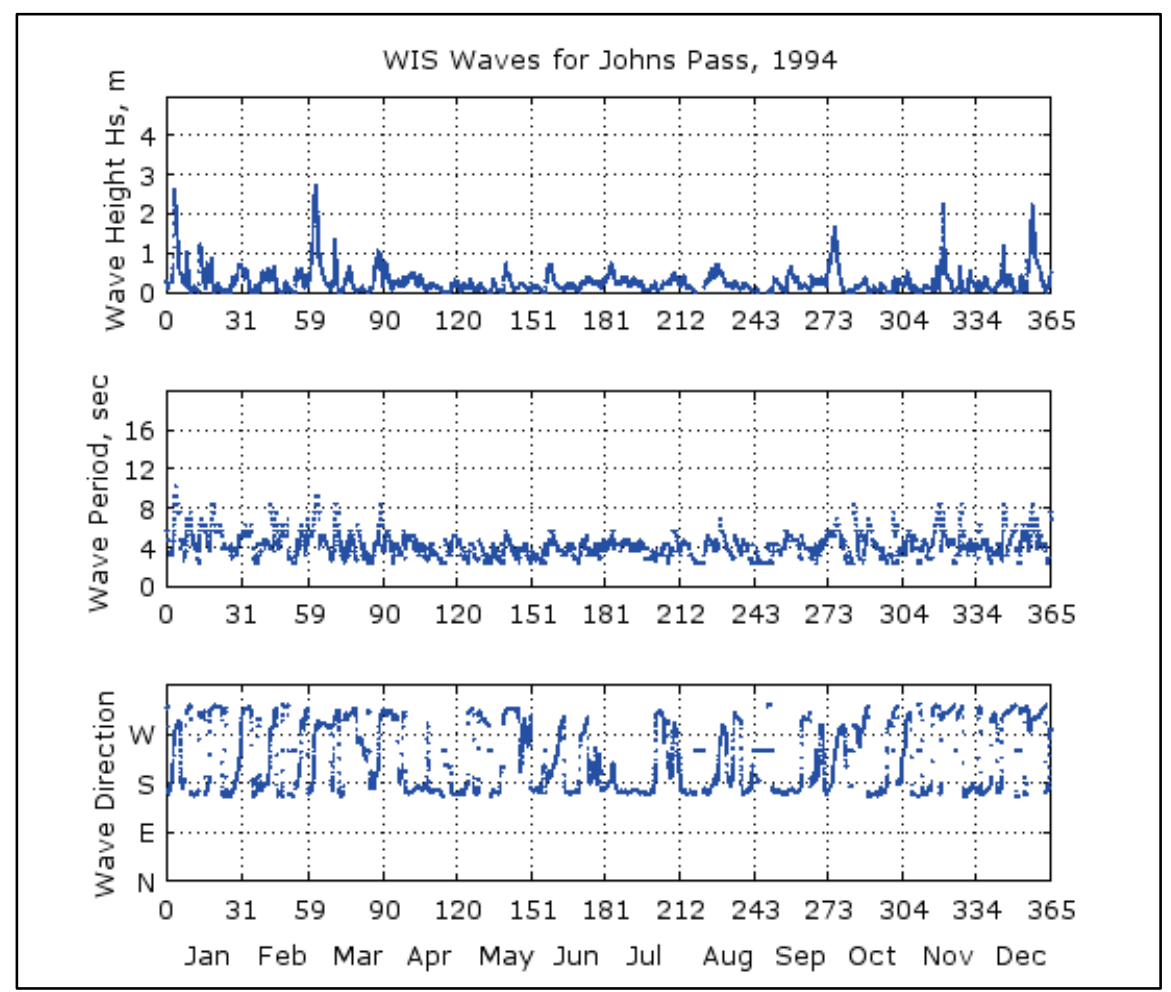

Figure B7. Wave height, period, and direction plot for Oregon Inlet, NC (taken from WIS station 63223).
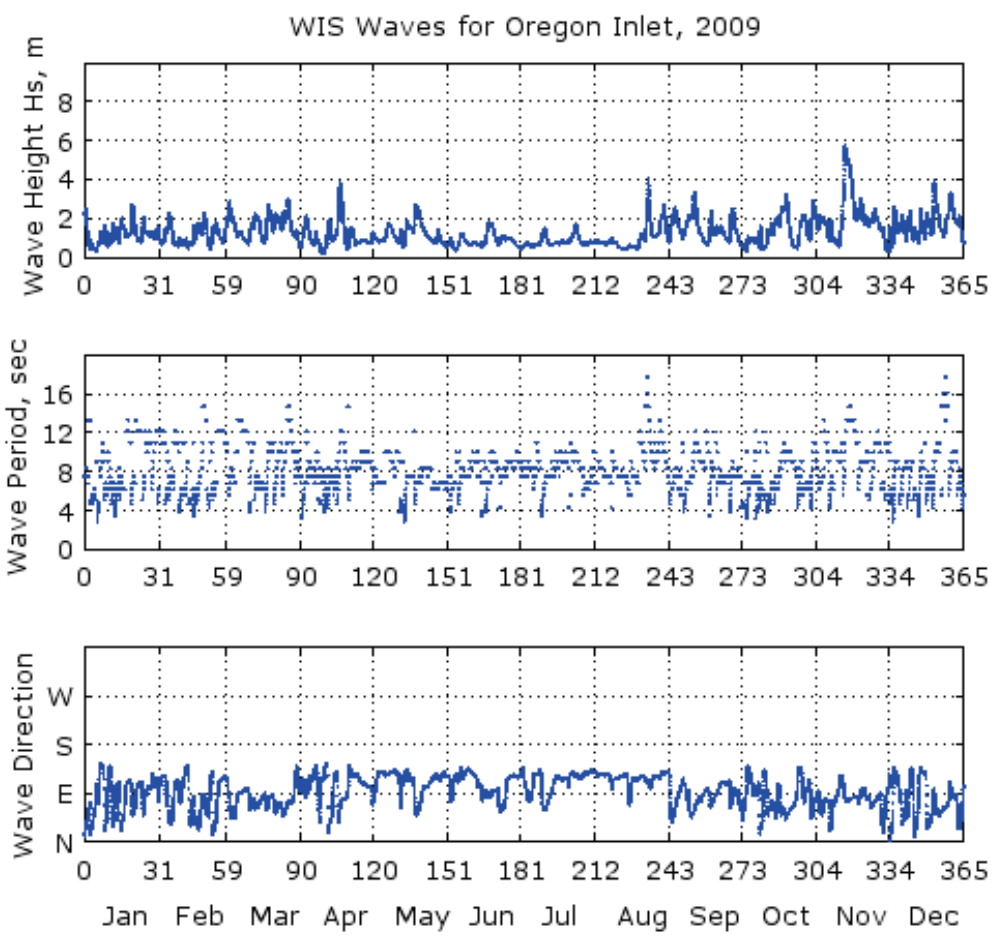
Figure B8. Wave height, period, and direction plot for Shinnecock Inlet, NY (taken from WIS station 63135).

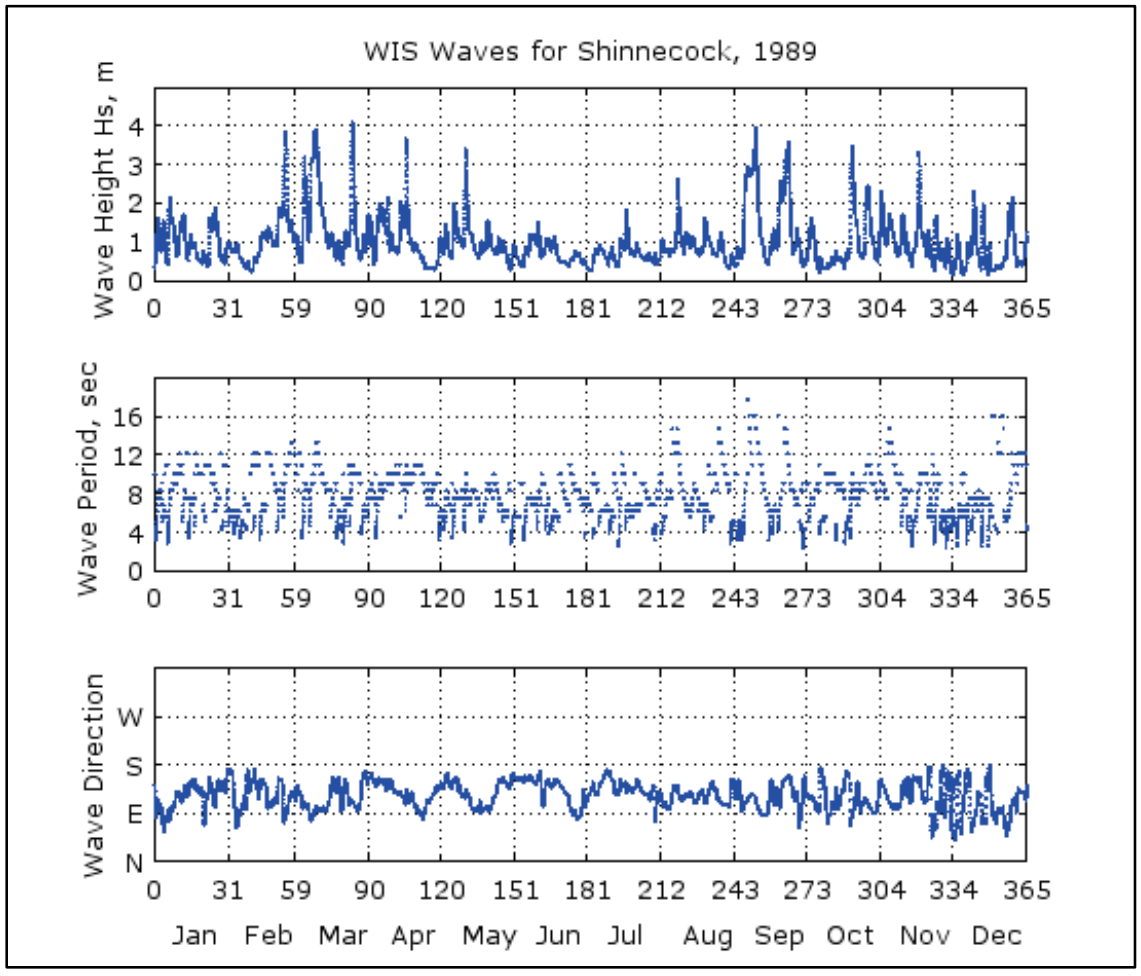

Figure B9. Wave height, period, and direction plot for Newburyport Inlet, MA (taken from WIS station 63045).

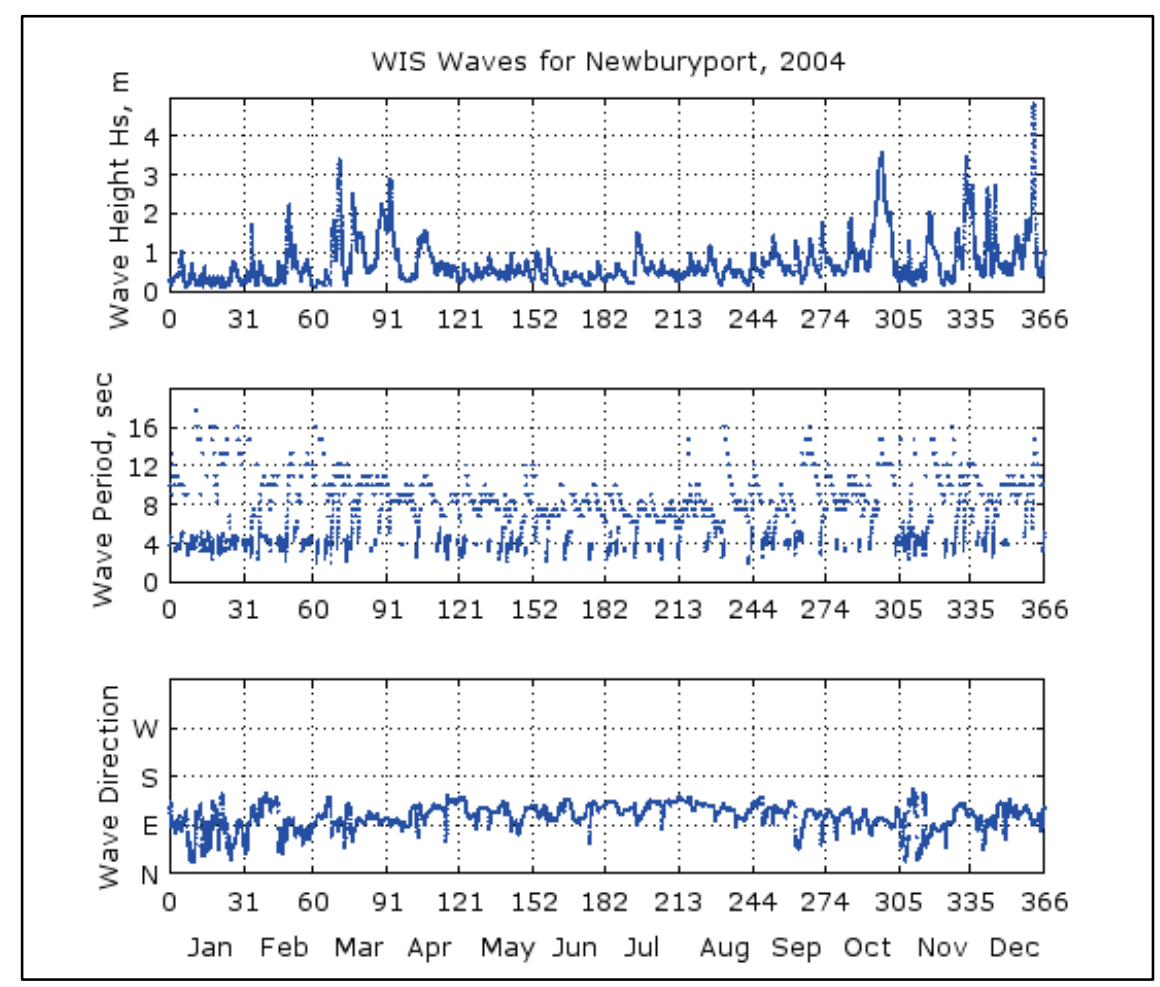




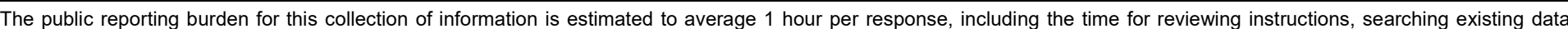

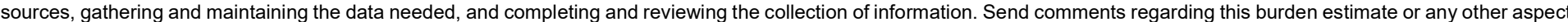

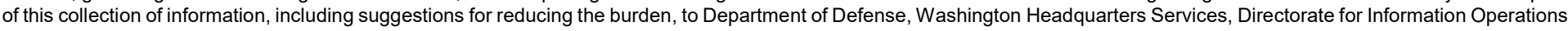

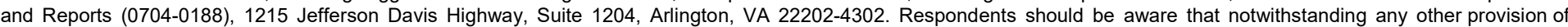
law, no person shall be subject to any penalty for failing to comply with a collection of information if it does not display a currently valid OMB control number. PLEASE DO NOT RETURN YOUR FORM TO THE ABOVE ADDRESS.

\begin{tabular}{l|l|l}
$\begin{array}{l}\text { 1. REPORT DATE } \\
\text { July } 2018\end{array}$ & $\begin{array}{l}\text { 2. REPORT TYPE } \\
\text { Final Report }\end{array}$ & 3. DATES COVERED (FrOm - To)
\end{tabular}

\section{TITLE AND SUBTITLE}

Long-Term Morphology Modeling for Barrier Island Tidal Inlets

\section{5a. CONTRACT NUMBER}

5b. GRANT NUMBER

5c. PROGRAM ELEMENT NUMBER

5d. PROJECT NUMBER

\section{6. $\operatorname{AUTHOR}(S)$}

Richard Styles, Mitchell E. Brown, Katherine E. Brutsché, Honghai Li, Tanya M. Beck, and Alejandro Sánchez 5e. TASK NUMBER

5f. WORK UNIT NUMBER

CG66LB

8. PERFORMING ORGANIZATION REPORT NUMBER

ERDC/CHL TR-18-12

10. SPONSOR/MONITOR'S ACRONYM(S) HQUSACE

11. SPONSOR/MONITOR'S REPORT NUMBER(S)

12. DISTRIBUTION/AVAILABILITY STATEMENT

Approved for public release; distribution is unlimited.

\section{SUPPLEMENTARY NOTES}

\section{ABSTRACT}

The U.S. Army Corps of Engineers, Coastal Inlets Research Program, conducted at the U.S. Army Engineer Research and Development Center, Coastal and Hydraulics Laboratory, has developed the Coastal Modeling System (CMS) as a coupled wave, hydrodynamic, and sediment transport numerical modeling system. The primary focus of this study is to validate CMS for long-term applications through simulations of tidal inlet evolution and verify the results against established theoretical and empirical formulations that describe the stability and equilibrium conditions of tidal inlets. A wide range of conditions are chosen to test the breadth of model applicability including varying waves, tide and inlet geomorphic characteristics. The model is run for 100 years and the resulting morphological state is gauged in terms of inlet stability theory. Overall, CMS compares well to theoretically and empirically predicted inlet cross-sectional areas with some noted deviations due in part to the artificial nature of the idealized inlet geometry. The sharp spatial transition at either end of the inlet throat leads to artificially large gradients that may increase erosion and associated cross-sectional area. The results suggest that CMS can efficiently and accurately, to the degree of available empirical information, quantify long-term evolution of barrier island tidal inlet systems.

\section{SUBJECT TERMS}

Barrier islands, Computer simulation, Geomorphology, Hydrodynamics, Inlets, Numerical analysis

\section{SECURITY CLASSIFICATION OF:}

\begin{tabular}{|l|l|l|l|}
\hline a. REPORT & b. ABSTRACT & c. THIS PAGE & ABSTRACT \\
Unclassified & Unclassified & Unclassified & SAR
\end{tabular}

18. NUMBER OF 19a. NAME OF RESPONSIBLE PERSON PAGES Richard Styles

156 19b. TELEPHONE NUMBER (Include area code) 601-634-4065 
7. PERFORMING ORGANIZATION NAME(S) AND ADDRESS(ES) (continued)

Coastal and Hydraulics Laboratory

U.S. Army Engineer Research and Development Center 3909 Halls Ferry Road

Vicksburg, MS 39180-6199

Institute for Water Resources

Hydrologic Engineering Center

609 Second Street

Davis, CA 95616-4687 